\title{
Canadian National Security Culture: Explaining Post 9/11Canadian National Security Policy Outcomes
}

by

\author{
Alan J. Stephenson
}

A thesis submitted to the Faculty of Graduate and Postdoctoral Affairs in partial fulfillment of the requirements for the degree of

Doctor of Philosophy

in

Political Science

Carleton University

Ottawa, Ontario

(C) 2016, Alan J. Stephenson 


\section{Abstract}

This dissertation examines how Canada views national security in the post 9/11 world. The hypothesis asserts that Canadian national security policy decisions post 9/11 resulted from policy choices that were limited and constrained by domestic institutional structures and a contemporary Canadian National Security Culture that perceives security broadly and endogenously as a value to be weighed against other competing values. Although initial policy decisions were shaped by domestic security norms, variation in final security policy outcomes were determined by the interrelated contestation of three intervening variables, identity, cultural-institutional structure, and interests.

Drawing on constructivist theory, this dissertation develops a novel concept of national security culture by adopting Wolfers' notion of national security as the preservation of acquired values to explain preference formation and applies it to the Canadian society-polity nexus as the referent object. Within this framework, a distinct Canadian National Security Culture is established and shown to have evolved through the historical and sociological construction of Canadian society and polity around the one omnipresent existential threat to Canada's sovereignty and independence, the United States. This process resulted in unique national security concerns over the protection of acquired values, the articulation of dangers, and behaviour of actors.

To test how social factors shaped and determined post 9/11 Canadian national security policy outcomes, three separate, but interrelated cases were examined from 2001 to 2015: the 2004 National Security Policy statement; the establishment of Marine Security Operations Centres; and the role of NORAD. This research found that the national security policies that Canada instituted following 9/11 exposed a contemporary 
Canadian National Security Culture that viewed $9 / 11$ as a criminal act. Risk managing the Canada-US relationship meant quickly ameliorating legitimate US insecurities, while using time and space to determine the optimal means for the preservation of Canadian acquired values, thus privileging social factors in determining final outcomes.

This dissertation concludes that Canada views national security as a domesticcentric continuum with its focus on the protection of Canadian society and its acquired values. Understanding the social underpinnings of national security in Canada is crucial to insightful analysis and policy prescription by national security practitioners. 


\section{Acknowledgements}

The road to completion of a $\mathrm{PhD}$ is a personal journey that requires the support and confidence of many. I wish to thank my thesis supervisor, Dr. Elinor Sloan, for her insightfulness and enduring patience over many years; Dr. Mira Sucharov for her theoretical course corrections; and Dr. Norman Hillmer, who was always available to provide advice, guidance, and encouragement. I would not have been able to complete this work without the continued support of family and friends. I specifically wish to thank my wife, Katarina, for her trust and conviction that this dissertation would be successfully completed while patiently putting up with rooms full of books and my countless hours spent at the computer. Sasha, our daughter, who was born shortly after beginning my doctoral studies, has brightened each day as she has helped daddy write. Lastly, my parents, Doris and Jim, who believed in me enough to share the burden of daily responsibilities at times when the commitments of two working parents proved overly daunting. 


\section{Table of Contents}

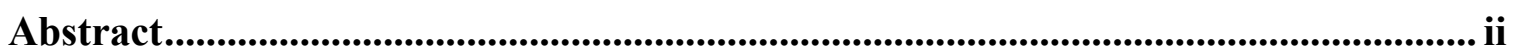

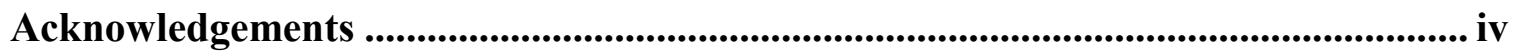

Table of Contents ............................................................................................................ $\mathrm{V}$

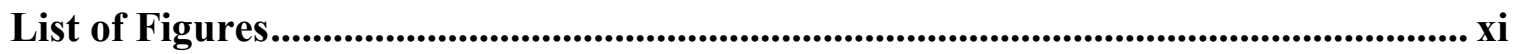

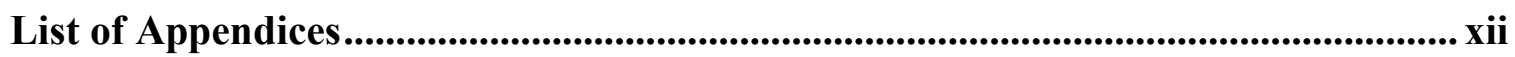

1 Chapter: Introduction ...................................................................................... 1

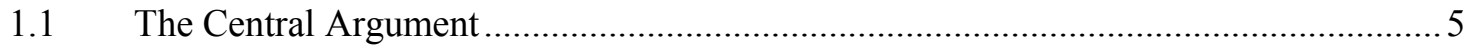

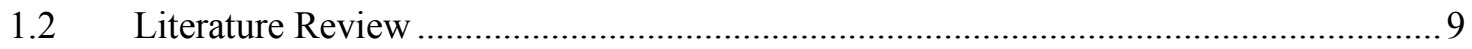

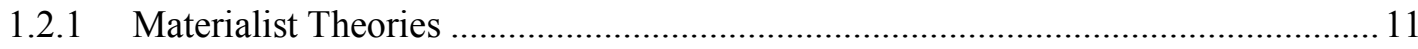

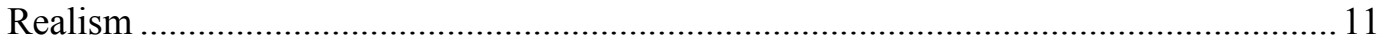

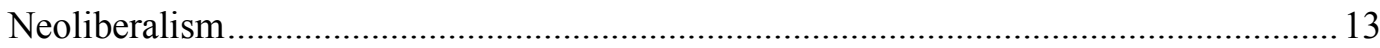

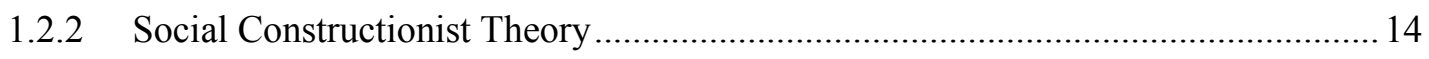

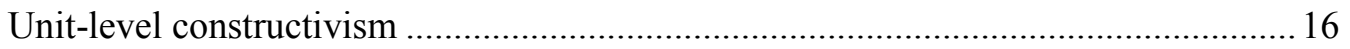

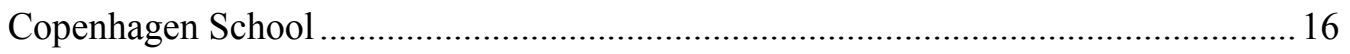

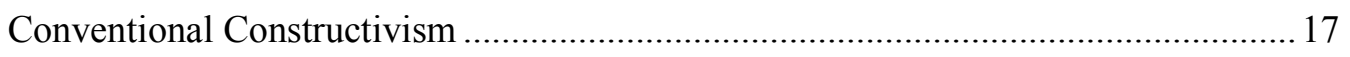

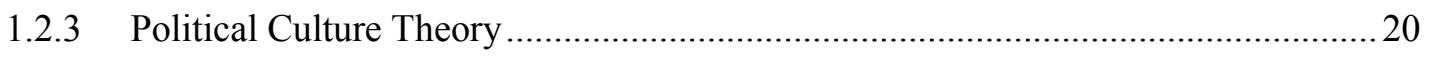

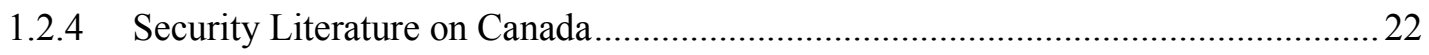

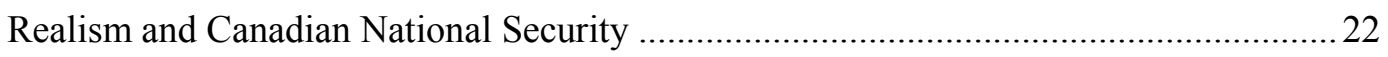

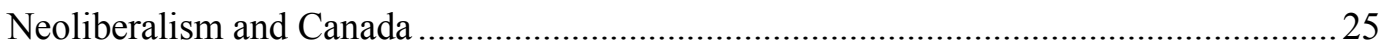

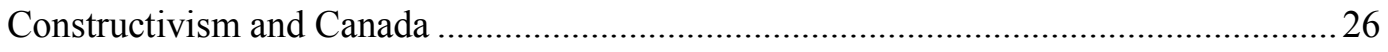

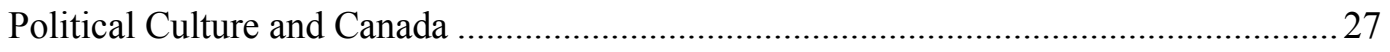

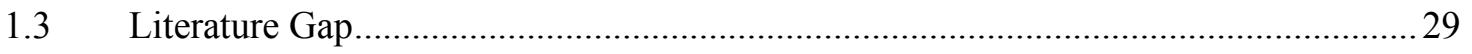

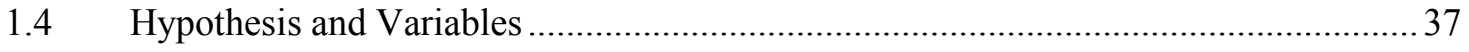




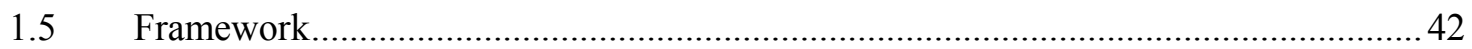

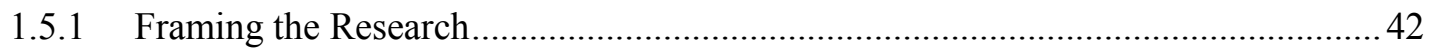

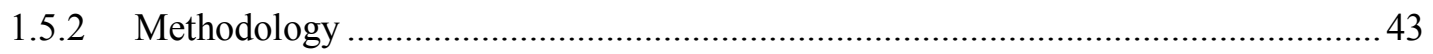

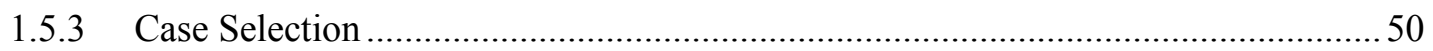

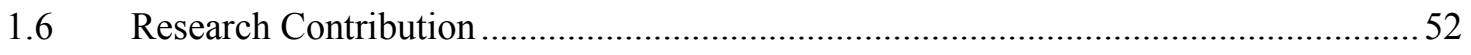

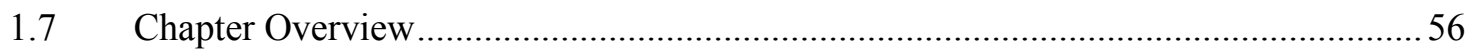

2 Chapter: National Security Culture: Bridging The Theoretical Gaps ................. 60

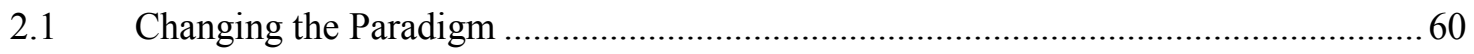

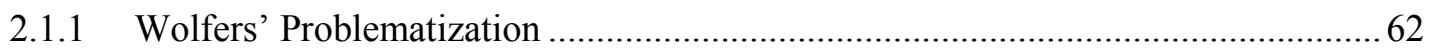

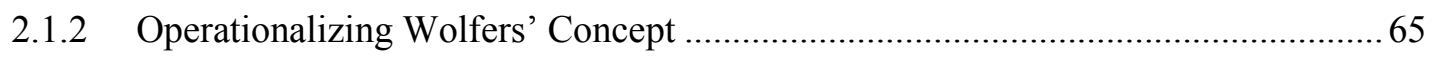

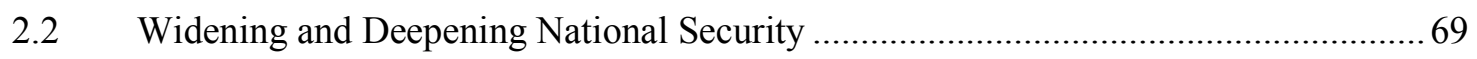

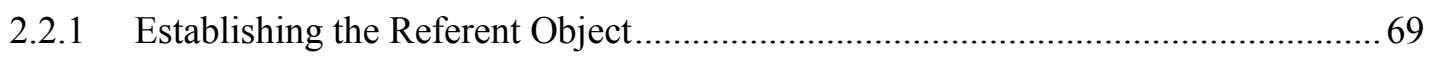

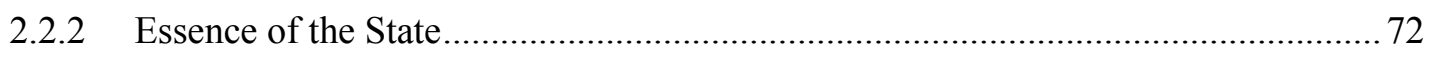

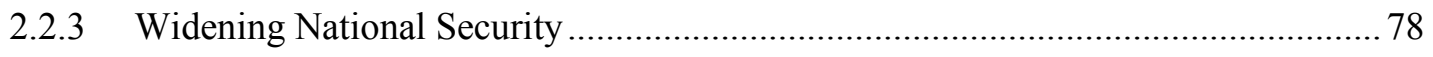

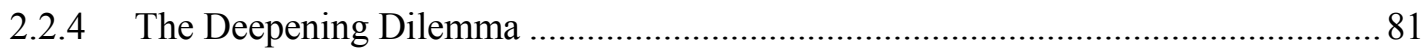

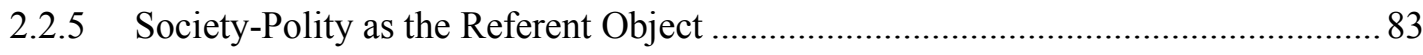

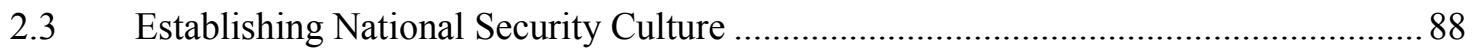

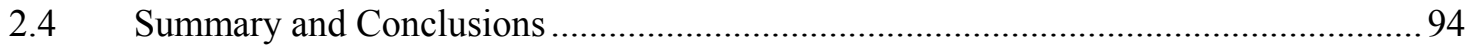

3 Chapter: Establishing Canadian National Security Culture ................................ 97

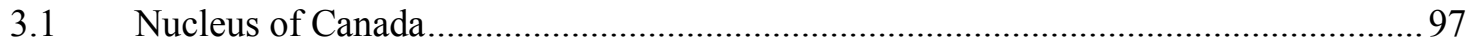

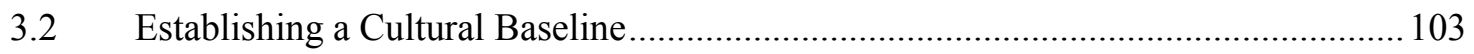

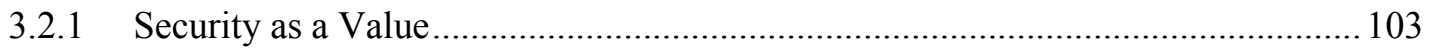

3.2.2 Foundations of Canadian Society and Polity .................................................... 107

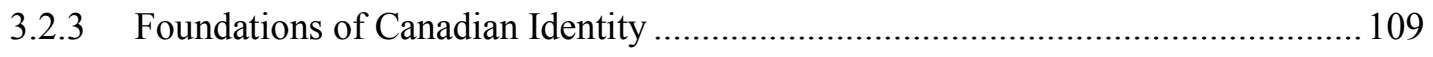

3.3 Canadian Culture, Institutions and Security Norms ............................................. 117

3.3.1 Foundations of the Canadian Security Culture …............................................... 117 


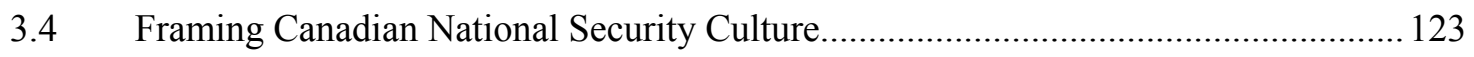

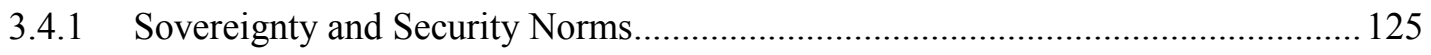

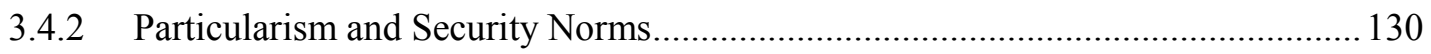

3.4.3 Collectivism/Communitarianism and Security Norms........................................ 135

3.4.4 Respect for Authority and Security Norms ..................................................... 143

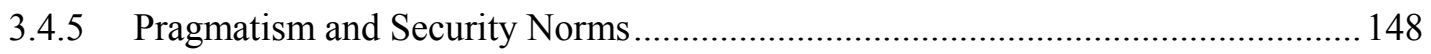

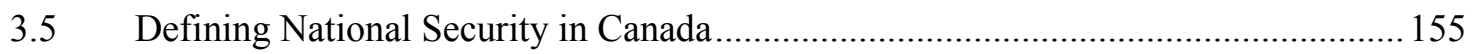

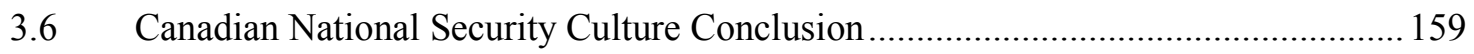

4 Chapter: Case Study - The NATIONAL SECURITY POLICY Statement: An Expression of Canadian National Security Culture .................................................... 164

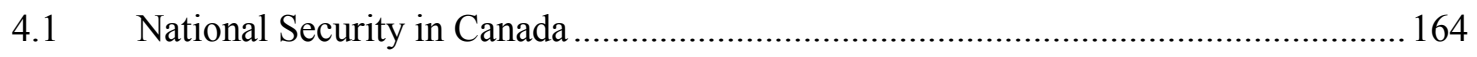

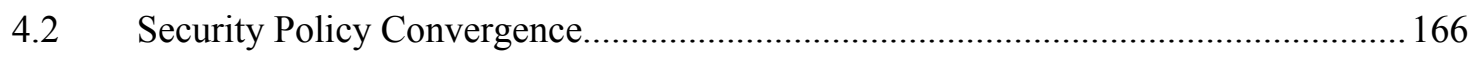

4.2.1 The Changing International Defence Policy Environment .................................. 166

4.2.2 The Changing Domestic Security Policy Environment ...................................... 170

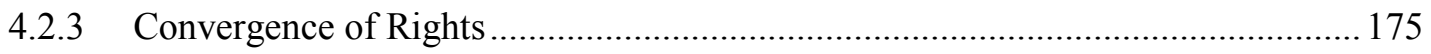

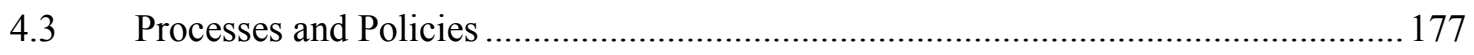

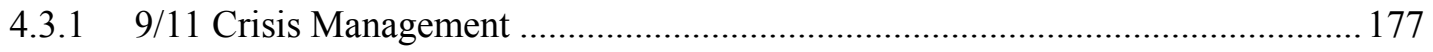

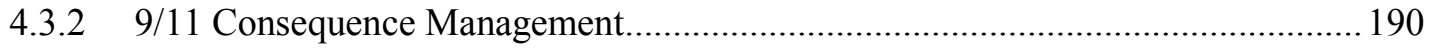

4.3.3 Development of the International Policy Statement .......................................... 194

4.3.4 Development of the National Security Policy Statement..................................... 198

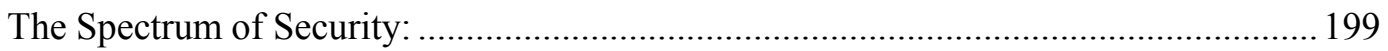

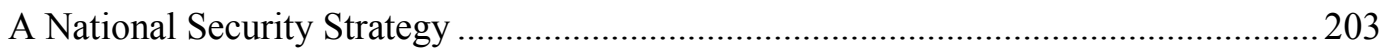

Reshaping the Canadian National Security Structure …...........................................205

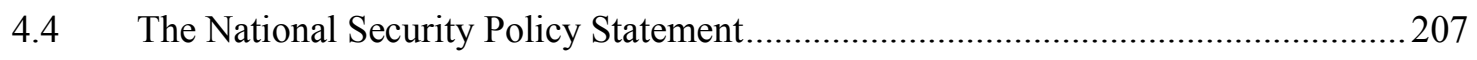

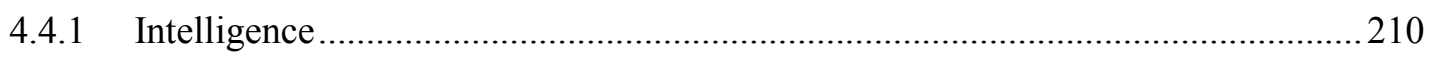

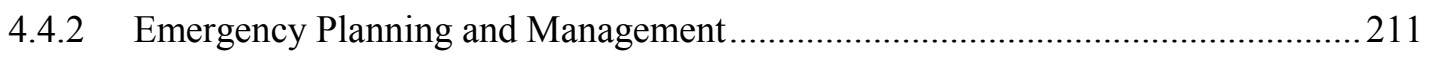




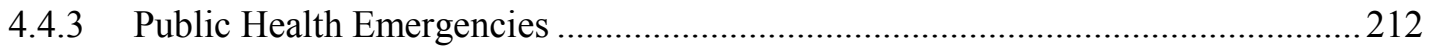

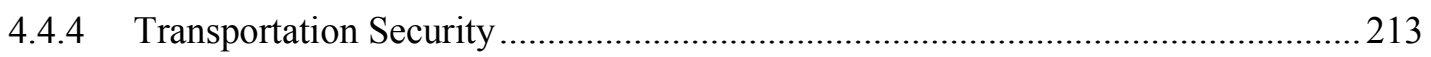

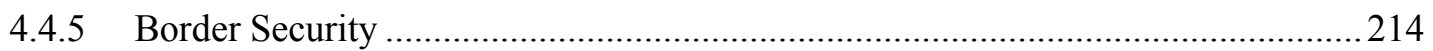

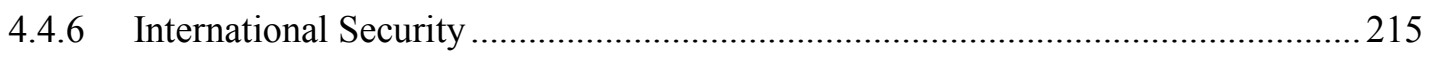

4.4.7 National Security Policy Statement Summary ..................................................... 216

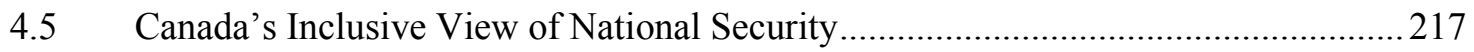

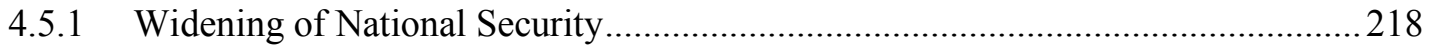

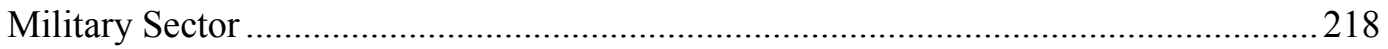

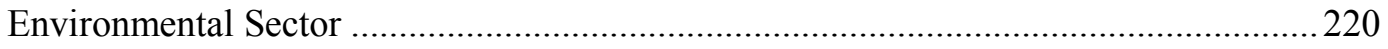

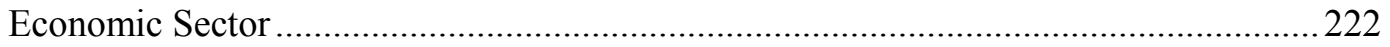

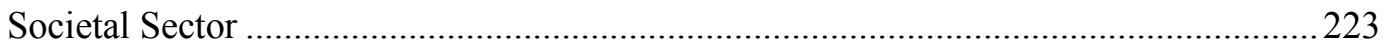

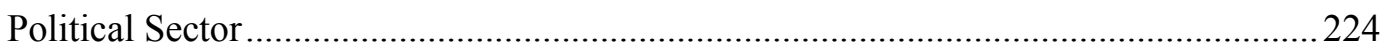

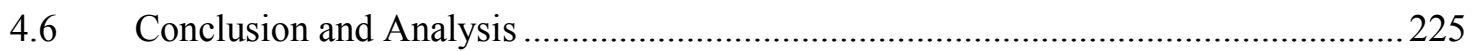

5 Chapter: Case 2 - Marine Security Operations Centres ................................. 233

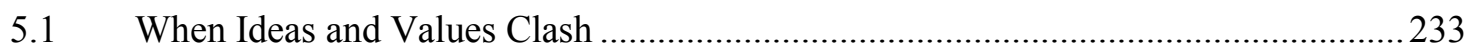

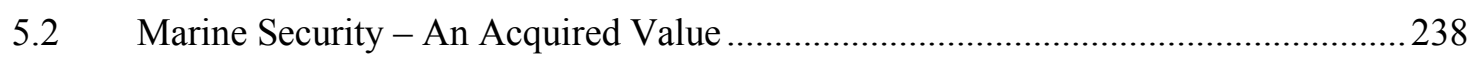

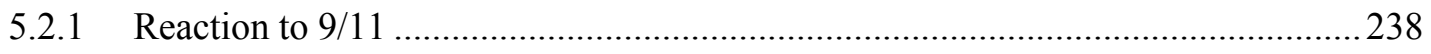

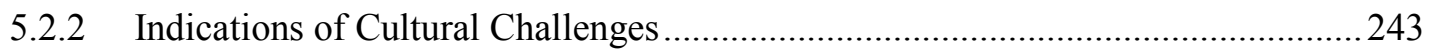

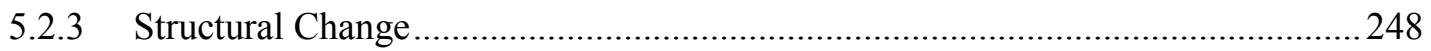

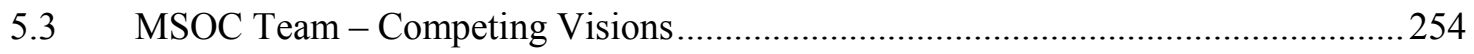

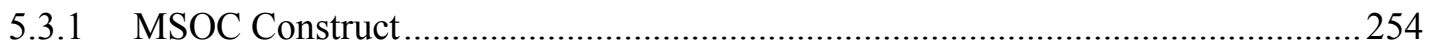

5.3.2 Department of National Defence / Canadian Armed Forces..................................25

5.3.3 Canadian Coast Guard / Department of Fisheries and Oceans ..............................2257

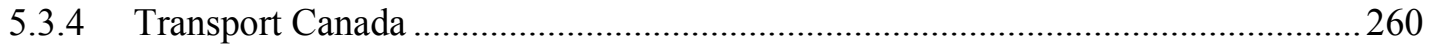

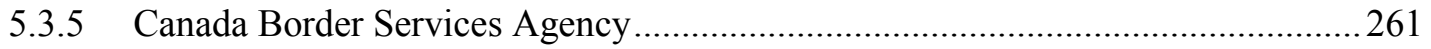

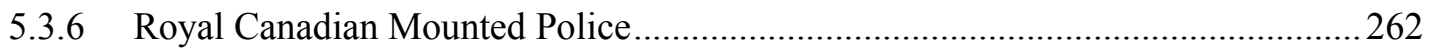




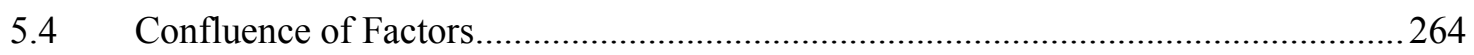

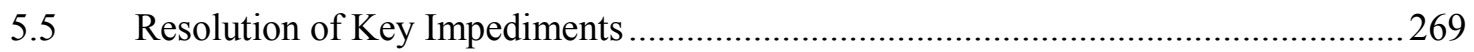

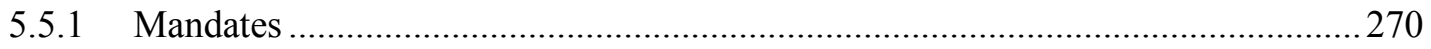

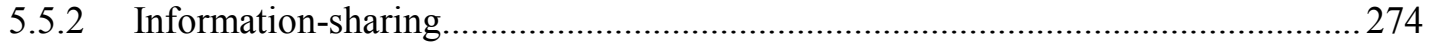

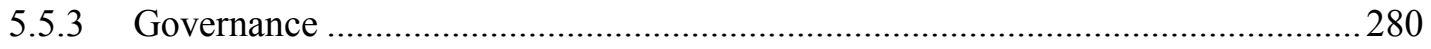

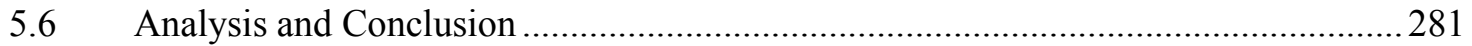

6 Chapter: Case 3 - Not Too Close But Not Too Far: The Role of NORAD ....... 288

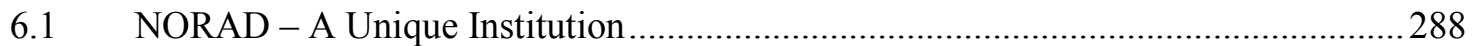

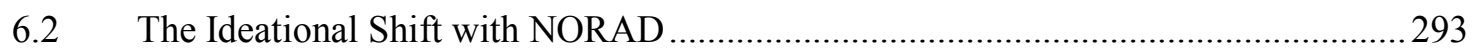

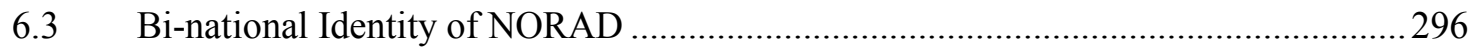

6.4 September 11, 2001 - A Critical Juncture..........................................................299

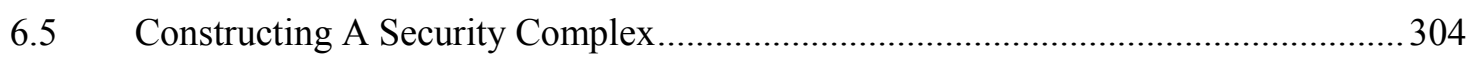

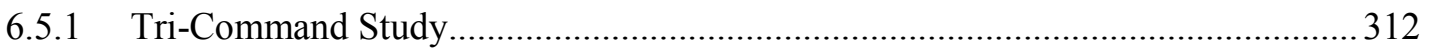

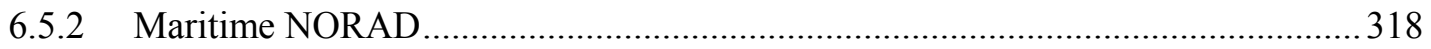

6.5.3 Evolution of NORAD’s Maritime Warning Mission ............................................. 324

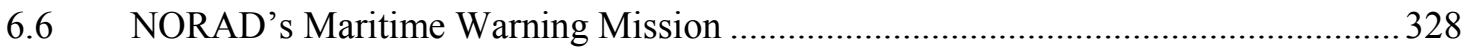

6.6.1 A Square Peg in a Round Hole? ................................................................... 328

6.6.2 Acquired Value of NORAD’s Maritime Warning Mission ...................................336

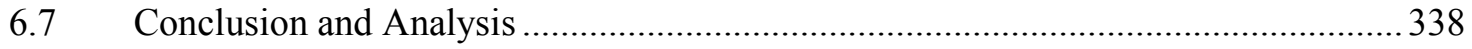

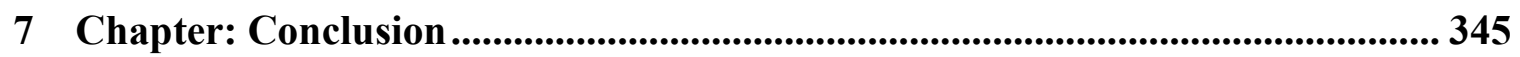

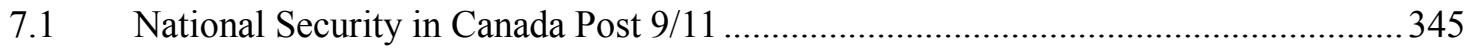

7.2 Changing the Paradigm - The Theoretical Framework............................................. 346

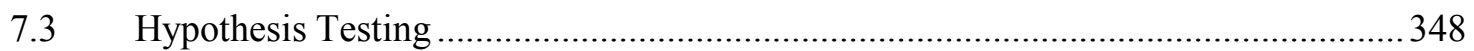

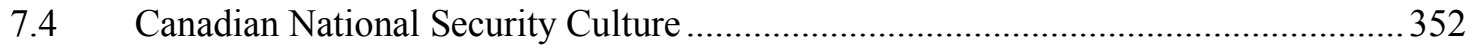

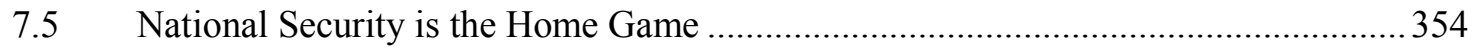

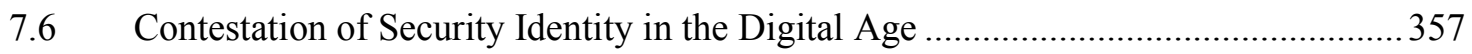




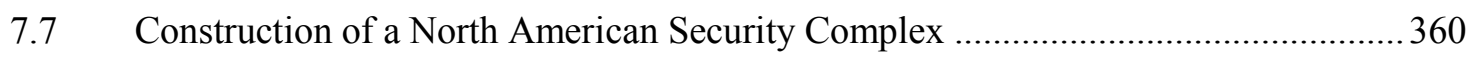

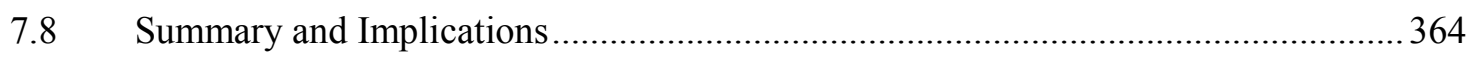

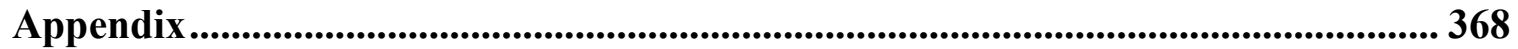

Bibliography ......................................................................................................................369 


\section{List of Figures}

Figure $1 \quad$ Lines of Argument..........................................48

Figure 2 The Spectrum of National Security.............................202 


\section{List of Appendices}

Appendix The Scope of the National Security Policy............................368 


\section{Chapter: Introduction}

While states were still adjusting to the unipolar world following the collapse of the Soviet Union, the cataclysmic events on the $11^{\text {th }}$ of September $2001(9 / 11)$ announced that a clear and present, asymmetric danger had arrived in North America, changing the continental security landscape. The 9/11 terrorist attack on New York City demonstrated that a small group of purposive actors could inflict considerable damage on a powerful nation by attacking at the seams of a liberal democracy, using modern technology to advantage. The focus of United States (US) national security policy shifted immediately from primary concentration on the 'away game' to one of equally supporting the emerging challenges at home. ${ }^{1}$ Although greater emphasis on protecting the US homeland was included, the 2002 National Security Strategy of the United States was clear in articulating that National Security was separate and distinct from Homeland Security. ${ }^{2}$ This critical juncture in North American security had a significant impact on Canadian 'national security' and the resultant policy choices highlighted the distinct security norms and values that constitute national security in Canada.

Canada has never produced a National Security Strategy like the US, the United Kingdom, or Australia and has no established process for the development of a formal national strategy. However, in 2004, Prime Minister Paul Martin chose to publish the National Security Policy statement, a publication that is unique: the wide ranging nature of security concerns identified in the National Security Policy statement stand in sharp

\footnotetext{
${ }^{1}$ Elinor C. Sloan, Security and Defence in the Terrorist Era: Canada and the United States Homeland, 2nd ed. Montréal: McGill-Queen's University Press, 2010.

${ }^{2}$ Chapter IX of the 2002 National Security Strategy of the United States separates "national and homeland security" into external and internal institutional realms of security responsibility. This assessment is corroborated in "America's 2002 National Security Strategy [that] remained rooted in the overseas dimension of guaranteeing security for the US Homeland" - Sloan, 2010, p. 61.
} 
contrast to the international conception of national security articulated in the National Security Strategy of the United States. Whereas the US National Security Strategy development process is designed to create consensus on foreign and defense policies ${ }^{3}$ under the auspices of 'national security', the Martin Government chose to articulate national security in terms of domestic security initiatives and later announced its international defence and foreign policy under the rubric, Canada's International Policy Statement, in 2005. This departure from traditional conceptions of national security ${ }^{4}$, which does not focus on external, material threats to the state and privileging military capabilities found in the National Security Strategies ${ }^{5}$ of like-minded states, is puzzling. The Martin Government's use of 'national security' to articulate internal security

\footnotetext{
${ }^{3}$ Don M Snider, "The National Security Strategy: Documenting Strategic Vision”, Strategic Studies Institute, US Army War College, March 1995, as well as Alan G. Whittaker, Shannon A. Brown, Frederick C. Smith, \& Elizabeth McKune, The National Security Policy Process: The National Security Council and Interagency System, Washington, D.C.: National Defense University, U.S. Department of Defense, August, 2011.

${ }^{4}$ Traditional concepts of security studies cover a wide spectrum of thought but are narrow in definition. Peter Katzenstein distinguishes between the traditional "narrow definition of security [that] tends to focus on material capabilities and the use and control of military force by states .... Those interested in the state and in traditional issues of national security tend to favour established realist and liberal approaches." His book, The Culture of National Security, consciously adopts the traditional, narrow definition of security studies in presenting the social determinates of national security policy. - Chapter 1 in Peter J. Katzenstein, ed, The Culture of National Security: Norms and Identity in World Politics, New York: Colombia University Press, 1996b; "The traditionalist mindset equates national security with national (military) defence." - Kenneth Booth and Nicholas Wheeler, Security Dilemma: Fear, Cooperation, and Trust In World Politics, New York: Palgrave MacMillan, 2008, p.137; Also see Mark Neocleous, "From Social to National Security: On the Fabrication of Economic Order," Security Dialogue, Vol 37, No.3, 2006, pp. 363-84; Robert Mandel, The Changing Face of National Security: A Conceptual Analysis, London: Greenwood Press, 1989; Stephen M. Walt, "The Renaissance of Security Studies," International Studies Quarterly 35, no. 2, June 1991, pp. 211-239; Barry Buzan and Lene Hansen, The Evolution of International Security Studies, Cambridge, UK: Cambridge University Press, 2009; Barry Buzan, People, States \& Fear: An Agenda for International Security Studies in the Post-Cold War Era, Second Edition, Colchester, UK: ECPR Press, 2009; M. Kent Bolton, U.S. Foreign Policy and International Politics: George W. Bush, 9/11, and the Global-Terrorist Hydra, New Jersey: Pearson Prentice Hall, 2005; Sloan, 2010, p. 66.

${ }^{5}$ See White House, National Security Strategy 2010, May 2010; HM Government, A Strong Britain in an Age of Uncertainty: The National Security Strategy, October 2010; Australian Government, Strong and Secure: A Strategy for Australia's National Security, 2013; This approach is also reflected by WD Macnamara and Ann Fitz-Gerald, "A National Security Framework for Canada”, Policy Matters, Vol.3, No. 10, October 2002.
} 
measures in a policy statement was not a linguistic anomaly, but is indicative of a domestic-centric ideational concept of 'national security' held by Canada.

Given that three major Canadian cities were less than 300 nautical miles from 9/11 Ground Zero, Canada and the US reacted differently in the aftermath of the attack. This has been acknowledged and assessed in the literature ${ }^{6}$, but the underlying causes have not been sufficiently explored. The existing explanations for variation in Canada's national security policies post 9/11 offer little in understanding the causal mechanisms. Too often Canadian security policies are measured against American securitization rhetoric and realist national security paradigms with little recognition that Canada possesses a distinct security culture. As Arnold Wolfers stated in 1952, 'national security' is an ambiguous symbol ${ }^{7}$, and as such needs to be problematized in terms of the society for which state sponsored security is intended to protect.

This topic warrants further study for several reasons. Understanding the fundamental nature of the national security debate constitutes a critical academic pursuit, given that a basic element of the social contract between the individual and the state are the limits imposed on individual freedoms in exchange for government sponsored security. ${ }^{8}$ Notionally accepting that the $9 / 11$ attack was perpetrated by a common threat to both states, there is a distinct lack of analysis of the Canadian national security response to the event and the consequences to Canada of the emergence of this new

\footnotetext{
${ }^{6}$ Sloan, 2010; Douglas A Ross and Hira Anil, "Canada, a Land of Deep Ambivalence: Understanding the Divergent Response to US Primacy After 9/11", Canadian-American Public Policy, no. 68, December, 2006; J. L Granatstein, Whose War is it?: How Canada can Survive in the Post 9/11 World, 1st Canadian ed., Toronto: HarperCollins, 2007; Sara McGuire, "'Securing' the Homeland? A Comparison of Canadian and American Homeland Security Policy in the Post-9/11 Period”, McMaster University, 2013.

${ }^{7}$ Arnold Wolfers, “National Security' as an Ambiguous Symbol”, Political Science Quarterly, Vol 67, No. 4, December 1952, p 481.

${ }^{8}$ Bryan Mabee, The Globalization of Security: State Power, Security Provision and Legitimacy, New York: Palgrave MacMillan, 2009.
} 
existential threat. Addressing this deficiency will aid in accounting for the variations in the identification of threats to 'national security' between two 'like' peoples and how they choose to deal with such threats. Obtaining a better understanding of how threats are perceived and what measures are preferred in dealing with insecurities are therefore critical to understanding variations in Canadian security and defence policies.

Similarly, better understanding of the causal mechanisms that shape and determine policy options is important for national security practitioners who wish to influence policy decision-makers. The complexity of national security issues and the fact that the largest discretionary item in the Canadian federal budget is for defence ${ }^{9}$ inevitably leads to contestation of values, interests, and identity regarding security policy choices at all three levels of analysis (individual, state, and international). ${ }^{10}$ Understanding the meaning of 'national security' to Canadians as well as the limitations and constraints placed on decision-makers by society and the polity is important for longterm policy development and meaningful discussion.

While many academics problematize Canadian national security in terms of power and material structures that take state identity and interests as exogenously given ${ }^{11}$, Canadian national security policy decisions post $9 / 11$ were not consistent with realist

\footnotetext{
${ }^{9}$ See David Perry, “The Growing Gap Between Defence Ends and Means: The Disconnect between the Canada First Defence Strategy and the Current Defence Budget”, Vimy Paper 19, Conference of Defence Associations Institute, June 2014.

${ }^{10}$ For example, regarding the issue of balancing the federal budget, "defence is one of the few parts of government that the [Harper] Conservatives can cut that won't result in substantial backlash from both opposition parties and the public. Moreover, among conservatives, there is an ideological divide between so called "budget hawks" and "defence hawks". The former prioritize small government over a strong national defence, whereas the latter favour the reverse." - Eric de Roos, "The Politics of Canadian Defence Spending", Vanguard, 19 August 2015, found online on 20 November 2015 at http://www.vanguardcanada.com/2015/08/19/the-politics-of-canadian-defence-spending/ .

${ }^{11}$ Jean-Christophe Boucher, "The Cost of Bandwagoning: Canada-US Defence and Security Relations after 9/11”, International Journal, Vol 67, No. 4, 2012, pp. 895-914; Stéfanie von Hlatky, The Great Asymmetry: American Allies in Times of War, Oxford: Oxford University Press, 2013; Frank P Harvey,
} 
or neoliberal paradigms, but demonstrated how deeply these decisions were invested in Canadian identity and national security culture. However, even constructivist / sociological accounts ${ }^{12}$ insufficiently explain the deeply held ideational factors imbedded in Canadian society that were instrumental in the construction of national interests and security policy options. Strategic culture is the primary method of analysis within this constructivist literature, but the state level explanans fail to identify what really matters, how identities and norms influence the ways in which Canadian actors define national security in the first place.

\subsection{The Central Argument}

The insufficiently explained variations in Canada's post 9/11 national security policies prompted the research question "how does Canada view national security in the post 9/11 world?". This dissertation advances the theory that the social construction of Canada over time has produced a distinct Canadian National Security Culture (independent variable) that affects the perception of threats, the manner in which matters of national security are addressed, and the resultant security policy outcomes (dependent variable). Although initial policy decisions were shaped by domestic security norms found in contemporary Canadian National Security Culture, variation in final security

\footnotetext{
"Canada's Addiction to American Security: The Illusion of Choice in the War on Terrorism", The American Review of Canadian Studies, Vol 35, No.2, Summer 2005, pp 265-294; Bill Dymond and Michael Hart, "Canada and the global challenge: Finding a place to stand," Commentary 180, CD Howe Institute, Toronto, 2003; Philippe Lagassé, "A Common "Bilateral” Vision: North American Defence Cooperation, 2001-2012", in Jonathan Paquin et al, Game Changer: The Impact of 9/11 on North American Security, Vancouver: UBC Press, 2014.

12 Justin Massie, "Making Sense of Canada's "Irrational" International Security Policy: A Tale of Three Strategic Cultures", International Journal, Vol. 64, No. 3, 2009, pp. 625-645; Stéphane Roussel et Chantal Robichaud, "L'État postmoderne par excellence ? Internationalisme et promotion de l'identité internationale du Canada", Études internationales, Vol. 35, No. 1, 2004, pp. 149-170; Osvaldo Croci, "Facing up to regional security challenges", in Emil Kirchner and James Sperling, eds, National Security Cultures: Patterns of Global Governance, New York: Routledge, 2010; Éric Tremblay and Bill Bentley, "Canada's Strategic Culture: Grand Strategy and the Utility of Force", Canadian Military Journal, Vol. 15, No.3 Summer 2015.
} 
policy outcomes were determined in large measure by the interrelated contestation of three intervening social variables (identity, cultural-institutional structure, and interests). Based on a constructivist/ sociological institutionalist framework, the aim of this research is to explain the security norms and values that limit and constrain the policy options of Canadian decisions-makers. In other words, it will provide evidence of how social factors shape different aspects of national security policies.

Existing accounts do not fully explain Canadian national security behavior as they are largely deterministic, emphasizing how relatively fixed national threat definitions constrain policy options in realist accounts, how 'complex interdependence' compels the alignment of choices towards established institutions with limited options in neoliberal approaches, and how internal policy formulation is a power-maximizing, adversarial process in bureaucratic politics analyses. Although material factors may situate the problem, ideational factors will have causal influence in shaping policy outcomes in matters of choice. The fundamental error made when applying these models to Canadian national security is the failure to recognize that the sole existential threat to Canada is not directed at the state itself but indirectly to the society for which the state exists. The only continuous, direct, existential threat to Canadian sovereignty and independence has been and continues to be assimilation of its society and polity into the United States.

This reality has had significant impact on the Canadian perception of national security, as Canadian society does not perceive the US in terms of 'a threat' per se. Instead, Canadian society conceives national security in terms of state protection of acquired values that are in need of safeguarding primarily from a hegemonic neighbour and only secondarily from an inconsistent, dynamic international environment. Given 
Canada's secure geostrategic location, traditional international threats as defined by most analysts only indirectly endanger Canada by undermining international order and stability. ${ }^{13}$ Since the Second World War, Canada's international policies have exhibited a Grotian approach to the international environment rather than reflecting Hobbesian materialist assumptions. ${ }^{14}$ On the one hand, Canada recognizes that it has a bilateral obligation to contribute to the security of its powerful neighbor while, on the other hand, it has generally emphasized a multilateral approach to international peace and stability through international institutions.

At the domestic level, the guiding and constraining effects of international security institutions are seen as a reflection of Canadian values and are reinforced by a distinct Canadian National Security Culture ${ }^{15}$. Canadian society as a whole and elites ${ }^{16}$ within the polity share a well-established set of fundamental beliefs and values that are

\footnotetext{
${ }^{13}$ Even at the height of the Cold War, there was little fear that Canada would lose any of its physical base to invasion. However, recognition that Canada would be a central battlespace in any conflict between the US and the Soviet Union caused the governments to choose realist national security policies, although Canadian society held less stark views of the international environment. See Robert Bothwell, "The Canadian Isolationist Tradition," International Journal, Vol 54, No.1, 1999, pp.76-87; Steven Kendall Holloway, Canadian Foreign Policy: Defining the National Interest, Peterborough: Broadview Press, 2006. ${ }^{14}$ See Maureen Appel Molot, "Where Do We, or Should We, or Can we Sit? A review of Canadian Foreign Policy Literature," in Duane Bratt and Christopher John Kukucha, Readings in Canadian Foreign Policy: Classic Debates and New Ideas, Toronto: Oxford University Press, 2007; Tom Keating, Canada and World Order: The Multilateralist Tradition in Canadian Foreign Policy, Toronto: McClelland and Stewart Inc., 1993; Brian W Tomlin, Fen Osler Hampson, and Norman Hillmer. Canada's International Policies: Agendas, Alternatives and Politics. Toronto: Oxford University Press, 2008; A. Claire Cutler, "The 'Grotian Tradition' in International Relations", Review of International Studies, Vol. 17, No. 1, January, 1991, pp. 41-65.

${ }^{15}$ I develop the concept of Canadian National Security Culture through constructivist and political culture sociological constructs in Chapters 2 and 3.

16 "Political elites consist of persons who are able, by virtue of their strategic position in powerful organizations and movements, to affect political outcomes and workings of political institutions regularly and seriously." - John Higley and Heinrich Best. Democratic Elitism: New Theoretical and Comparative Perspectives, 1st ed., Vol 111, Boston: Brill, 2010, p. 6; This dissertation will make a distinction between elites in general that are leaders and representatives of diverse norms, values, and beliefs in a pluralistic society and the elite decision-makers who are responsible and accountable for the decision-making powers they have been granted. All elites are a product of their society and the social factors that limit and constrain behavior.
} 
instrumental in shaping ${ }^{17}$ national security institutions and policies. These include a deepseated belief regarding the appropriateness and utility of the use of force as an act of last resort, a fundamental belief in ameliorating insecurities by establishing rules based order through multilateral institutions, a particularistic ${ }^{18}$ approach to conflict resolution that seeks common ground, and a desire to be a reliable, team player (ally) while maintaining the sovereign right for protection of Canadian acquired values. Canada intentionally separates endogenous national security from exogenous international security, as the latter is a matter of choice for a 'middle power' ${ }^{19}$, while the former is a matter of survival as an independent state.

In essence, Canadians see the solution to international security problems through the prism of their historical experiences in the territorial confines of a relatively peaceful, secure environment. Canadian National Security Culture is an overlapping component of Canadian political culture that has varied over time and evolved through amicable resolution of wide ranging issues with its powerful neighbour requiring state protection of Canadian values. The security norms that have emerged have become part of Canadian identity and have been embedded in domestic institutions. These in turn serve as the foundation from which the political contestation over value trade-offs occur when

\footnotetext{
${ }^{17}$ I choose the term 'shaping' to indicate the ideational boundaries that are implicit in state identity and culture and that establish the 'arena' for political contestation.

${ }^{18}$ I will make use of the definitions of universalism and particularism as defined by Parsons, Talcott \& Edward A. Shils, eds., Towards a General Theory of Action, Cambridge: Harvard University Press, 1951, p.82. In essence, universalism is a concept where situations are judged and applied universally according to uniform criteria and not according to actor or individuals' relation with the given subject which is considered particularism. Political particularism considers that each political community has a right to promote its own interests and independence without reference to the whole; For a more precise description of the behavioral approach observed in Canada see Charles Taylor, 'Conditions of an Unforced Consensus on Human Rights', in J. R. Bauer and D. Bell eds., The East Asian Challenge for Human Rights, New York: Cambridge University Press, 1999, p. 124; Particularism will be explicated in Chapter 2.

${ }^{19}$ This neo-realist paradigm may be an appropriate description of Canada's relative power, but Canada is not a 'billiard ball' reacting to international pressures. As will be argued later, given Canada's geopolitical circumstances, ideation has significant causal force in resource extraction in the creation of national power.
} 
defining and conceiving national interests and security policies. Contemporary Canadian National Security Culture shapes the policy options available to decisions makers and bounds a decision-makers rational choice.

\subsection{Literature Review}

National security remains a contested concept and literature on the subject spans the wide theoretical spectrum from rationalism to reflectivism. ${ }^{20}$ Insights generated from this epistemologically diverse field provide greater understanding and appreciation of the intersubjective nature of national security. Over the past twenty years, there has been a progressive widening of security discourse to include domestic and transnational threats as well as a deepening of the referent object beyond the state to include institutions, civil society, and elites. ${ }^{21}$ Although materialist perspectives continue to dominate analysis, ideational approaches have progressively established themselves where human agency rather than concern over 'balance of power' is having a significant effect on understanding security, particularly in matters of choice. It is the greater inclusion of

\footnotetext{
${ }^{20}$ For a good overview of the current state of debate, see Barry Buzan and Lene Hansen, The Evolution of International Security Studies, Cambridge, UK: Cambridge University Press, 2009; Specific examples: Peter J Katzenstein, ed, The Culture of National Security: Norms and Identity in World Politics, New York: Colombia University Press; David Baldwin, "The Concept of Security", Review of International Studies, Vol 23, No.1, 1997; J. Ann Tickner, 'Re-visioning Security', in Ken Booth and Steve Smith, eds., International Relations Theory Today, University Park: Pennsylvania State University Press, 1995; John Peterson and Hugh Ward, "Coalitional Instability and the New Multidimensional Politics of Security: A Rational Choice Argument for US-EU Cooperation", European Journal of International Relations, Vol.1, 1995; Joseph J. Romm, Defining National Security: The Nonmilitary Aspects, New York: Council on Foreign Relations Press, 1993; Martin Shaw, "There Is No Such Thing as Society: Beyond Individualism and Statism in International Security Studies', Review of International Studies, Vol 19, 1993; Graham Allison and Gregory F. Treverton, eds., Rethinking America's Security: Beyond Cold War to New World Order, New York: Norton, 1992; Ken Booth, "Security and Emancipation", Review of International Studies, Vol 17, 1991, pp. 313-26; Richard Ullman, "Redefining Security", International Security, Vol 8, 1983; Jessica Tuchman Matthews, "Redefining Security", Foreign Affairs, Vol 68, 1989; Barry Buzan, People, States \& Fear: The National Security Problem in International Relations, London: Harvester Wheatsheaf, 1983; Lester Brown, Redefining National Security, Worldwatch Paper No. 14, Washington, DC, 1977; and Arnold Wolfers, "“National Security' as an Ambiguous Symbol," Political Science Quarterly, Vol 67, No. 4, December 1952, pp. 481-502.

${ }^{21}$ Buzan and Hansen, 2009; Mandel, Robert, The Changing Face of National Security: A Conceptual Analysis, London: Greenwood Press, 1989.
} 
domestic agency that is changing the flow of security discourse and where this research makes a theoretical contribution through identification and analysis of the domestic sociological variables inherent in Canadian national security policy formulation.

Power is a ubiquitous concept in political science; however, power does not just appear. National power is first created / constructed through society's ability and desire to transform material wealth into useable state power and then defined through ideational application. Realism, in its various forms, has dominated security studies in its 'distribution of power' approach, generally defined in terms of material capabilities ${ }^{22}$ that treat norms as inconsequential. Although neoclassical realism has reintroduced domestic level variables, with identity being one, its focal point remains analysis of material power capabilities. Power is also at the heart of neoliberal explanations of global interdependence ${ }^{23}$ as the political aspects of multilateral dependency are described in materialist terms. Power is certainly a critical factor in analysis; however, studies on Canadian security policy using this approach never achieve satisfactory explanans for variances, due to superficial attention to domestic factors. ${ }^{24}$ Realism and neoliberalism often leave explanations to important issues under-specified and insufficient when they ignore the normative influences on actors' interests and choices.

Constructivism, however, asks different questions and deviates from the static material assumptions of previous International Relations (IR) theories through the belief

\footnotetext{
${ }^{22}$ Kennth N. Waltz, Theory of International Politics, New York: Random House, 1979; David A. Baldwin, "Power and International Relation", in Walter Carlsnaes et al, ed. Handbook of International Relations, London: Sage Publications, 2002.

${ }^{23}$ Robert Keohane and Joseph Nye Jr., Power and Interdependence, $4^{\text {th }}$ ed, Toronto: Longman, 2012.

${ }^{24}$ Jean-Christophe Boucher, "The Cost of Bandwagoning: Canada-US Defence and Security Relations after 9/11”, International Journal, Vol 67, No. 4, 2012, pp. 895-914; Sean M Maloney, “Are We Really Just: Peacekeepers? The Perception Versus the Reality of Canadian Military Involvement in the Iraq War", IRPP Working Paper Series no. 2003-02.
} 
that the core assumptions of world politics are socially constructed (not exogenously given, hence capable of being transformed by human practice). Ideas, culture, identity and norms matter in the construction of national power and in many cases, are causal in the determination of the 'elements of national power' 25 as the form and substance that state power takes is dependent in large measure to the society in which it accumulates. "Material power and coercion often derive their causal power from culture." ${ }^{26}$ Although some academics point out that power analysis is in fact a point of convergence ${ }^{27}$, neoclassical realism's materialistic, structural foundation does not fully recognize the importance of agency inherent in the formulation of national security policy.

\subsubsection{Materialist Theories}

Realism: Realism is the theory of power politics ${ }^{28}$; however, there is significant variation within the realist theoretical framework. Although all realists trace their lineage through Thucydides, Machiavelli, and Hobbes, some theorists consider power to be a means to an end, while others believe it to be an end unto itself. This leads realism to be

\footnotetext{
${ }^{25}$ David Baldwin identifies two principal approaches to power analysis, 'elements of national power', and 'relational power'. He attributes Han's Morgenthau's influential textbook, Politics Among Nations, as the foundational work for 'elements of national power' advocates, which depicts 'power as a resource' where power is a possession or property of states. The aggregate power of a state is essentially the sum of all the elements that proponents believe can be measured and combined. Robert Dahl developed a 'relational power' approach in which power is an actual or potential causal relationship to two or more actors leading to behaviour modification, rather than power simply being a possession. This approach circumvents both the problems of aggregate measurement and fungibility by defining power in a multidimensional, causal manner. By breaking down power into its dimensional, constituent parts, analysts can investigate how they 'influence and control' the behaviour of others in a variety of settings. This relational approach provided avenues to power analysis that could be incorporated into other theories since it equates power with outcomes. - David Baldwin, "Power and International Relations", in Carlsnaes, Risse and Simmons eds., Handbook of International Relations, London: Sage, 2002.

${ }^{26}$ Peter J Katzenstein, ed, The Culture of National Security: Norms and Identity in World Politics, New York: Colombia University Press, 1996b, p.40.

${ }^{27}$ Baldwin, 2002; John Glenn, "Realism versus Strategic Culture: Competition and Collaboration?", International Studies Review, Vol 11, 2009, pp. 523-551.

${ }^{28}$ See Brian C Schmidt, "Competing Realist Conceptions of Power," Millennium: Journal of International Studies, Vol. 33, No 3, 2005 for a succinct summary.
} 
divided generally into classical ${ }^{29}$, structural $^{30}$, and neo-classical ${ }^{31}$ realist theories.

\section{Classical realists believe that it is a fundamental aspect of human behavior to amass}

power and dominate others. Structural realists, also referred to as neo-realists, argue that anarchy within the structure of the international system compels states to seek power whereas neo-classical realists accept the importance of systemic forces, but account for the power-seeking behavior of states by incorporating variables at the unit level. In all forms of realism, national security is all about power relationships between states mired in a Hobbesian environment where interests and state identity are exogenously given.

\footnotetext{
${ }^{29}$ Morgenthau developed the classical concept of power based on the primordial nature of man and establishes 'power as a resource' approach where he equates power with the possession of identifiable and measurable resources. Classical realists like Morgenthau can actually be read much more profoundly than simply advocating 'power as a resource'. Morgenthau's complex definition of power can be associated with both the relational and elements of power approaches as evidenced in Morgenthau's all-encompassing explanation of power closely follows Max Weber's relational definition of power as 'the probability that one actor within a social relationship will be in a position to carry out his own will despite resistance, regardless of the basis on which this probability rests.' - See Brian C Schmidt, 2005, p. 532.

30 According to Kenneth Waltz's Theory of International Politics, competition and socialization in an anarchical environment force states towards selecting power-seeking ends and rational decision-making processes that seeks 'balance-of-power'. International politics can primarily be understood in reference to the number and relative power of states - the structure of the international system. Defensive realists, see power as a means to an end such that states are 'security-maximizers' that will either accrue more power (balancing) or join coalitions (bandwagoning) in order to counterbalance changes in the international system that affect them. As an offensive realist John Mearsheimer contends that states are compelled to maximize their relative power due to the structure of the international system. Thus he maintains that all great powers have revisionist aims in the balance of power and will pursue expansionist policies as a means of survival. This focus on the continuous struggle for power and inability of states to control their destiny as a result of the anarchy in the international system in both offensive and defensive realism is the distinctive feature of structural realism. Significantly, structural realists admit that neo-realist theory 'pays little attention to individuals or domestic political considerations' and 'tends to treat states like black boxes or billiard balls'.

${ }^{31}$ Neo-classical realists argue that unit-level factors such as state-society relationships and statesmanship are important and that domestic political processes act as 'transmission belts' or 'filters' between systemic pressures and state behaviour. Power is generated by the state as means to an outcome, not an end in itself, and as such has the behavioral characteristic of 'influence maximization'. Neo-classical realists side with classical realism in viewing anarchy as a permissive condition rather than a causal force, but accept structural realism's systemic distribution of power through material capabilities. 'The causal logic of neoclassical realists places domestic politics as an intervening variable between the distribution of power and foreign policy behaviour.' See S.M. Walt, 'The Enduring Relevance of the Realist Tradition', in I. Katznelson and H.V. Milner, eds, Political Science: the state of the Discipline, New York: Norton, 2002, p 211 and Brian Schmidt and Thomas Juneau, "Neo-classical realism and power" in A. Toje and B Kunz eds., Neoclassical Realism in European Politics: Bringing Power Back In, New York: Manchester University Press, 2012.
} 
By incorporating some of the domestic factors found in classical realism with structuralism's distribution of power, neo-classical realists argue what matters most in measuring relative power is not aggregate national power so much as decision-makers' perceptions of the distribution of power. This is an important intervening variable as actual political leaders and elites determine defence and foreign policy. This introduction of greater agency in International Relations (IR) theory makes measurements more dynamic and accounts for greater variation in behaviour and outcomes than the parsimony of structural realism. However, neo-classical realism never fully explicates how elite decision-makers translate 'perception of distribution of power' changes into 'perceived threats' that require state action.

Neoliberalism: Embracing three central tenants of neo-realism (states are central actors, anarchy shapes state behaviour, and states are self-interested), Robert Keohane, in After Hegemony, drew very different conclusions about the potential for sustained cooperation. Neoliberals believe states construct institutions to overcome obstacles to international cooperation where actors are utility-maximizers and not neo-realist defensive positionalists. Neoliberal institutionalists argue that states build international regimes in order to promote mutually beneficial cooperation through agreement on clusters of principles, norms, rules, and decision-making procedures that reduce transactional costs, alleviate problems of asymmetrical information and limit the uncertainty that members face in evaluating each others' policies. National security for 
neoliberals remains focused on material factors of exogenously given self-interest based in a Lockean ${ }^{32}$ environment of rivalry.

Daniel Deudney and John Ikenberry ${ }^{33}$ developed the concept of 'security cobinding' that they contrast to neo-realism's concept of 'balancing' to address the behavior of states in an anarchical system. They contend that western liberal democracies have developed a distinctive structure to address anarchy by tying one another to mutually constraining institutions. In this manner, co-binding with potential threats into predictable and restrained behaviour precludes the need for the associated costs of balancing. Although both realism and neo-liberalism acknowledge a human dimension, both view states as rational, self-help actors in an anarchic system, treating interests as given and leave little room for agency.

\subsubsection{Social Constructionist Theory}

Constructivism is not a theory per se, but an approach to social inquiry based on three ontological propositions: ideas rather than material forces primarily determine the structures of human association; these ideas condition identities which inform interests and in turn the actions of purposive actors; and structures and agents are mutually constituted. By emphasizing a social ontology and methodology, constructivists focus on the norms and shared understanding of legitimate behaviour that lead to the construction of shared identities and institutions. Norms provide context to interests and material factors. Relationships are a product of historical processes and interaction over time, leaving greater room for agency, and thus the possibility of change, than other IR

\footnotetext{
${ }^{32}$ Alexander Wendt, Social theory of International Politics, Cambridge: Cambridge University Press, 1999, p. 194.

${ }_{33}$ Daniel Deudney and John Ikenberry, "The Nature and Sources of Liberal International Order", Review of International Studies, April 1999, Vol 25, Issue 2, pp.179-196.
} 
theories. ${ }^{34}$ In positing an intersubjective ontology, constructivism provides a venue for the cross-pollination among theories and lends itself to an emphasis on causality, hypothesis testing, and objective truths through its focus on the mutual constitution of identity and the social agent/structure dialectic. ${ }^{35}$

Constructivist literature covers a wide spectrum as "there are many

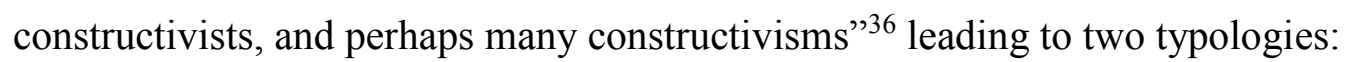
conventional and critical. ${ }^{37}$ Not only is the spectrum wide, but three different forms evolved that capture three levels of analysis: holistic, systemic, and unit-level. ${ }^{38}$ Holistic constructivism is concerned with the macro-level dynamics of a changing international system, particularly regarding the implications of the demise of state sovereignty, and the mutually constitutive relationship between the state and international order. ${ }^{39}$ The most influential work of systemic constructivism is Alexander Wendt's Social Theory of International Politics in which he builds an IR constructivist systemic theory based on the logic of appropriateness and the role of shared ideas and norms in shaping state

\footnotetext{
${ }^{34}$ Alexander Wendt, 1999; Katzenstein, 1996b; March, James G. and Olsen, Johan P., “The New Institutionalism: Organizational Factors in Political Life”, The American Political Science Review, 1984, Vol 78, p. 734-49.

35 Tim Dunne et al, International Relations Theories: Discipline and Diversity, Oxford: Oxford University Press, 2007; Walter Carlsnaes et al, ed., Handbook of International Relations, London: Sage Publications, 2002.

${ }^{36}$ Richard Price and Christian Reus-Smit, "Dangerous Liasons? Critical International Theory and Constructivism”, European Journal of International Relations, Vol. 4, No. 3, p. 288

${ }^{37}$ Richard Price and Christian Reus-Smit argue that constructivism has its intellectual roots in the third IR debate and is part of the broader family of critical theory. They propose that constructivism can be distinguished between 'modern' (minimal foundationalist) and 'postmodern' (anti-foundationalist) scholarship. Ted Hof, however, characterizes constructivism as 'conventional' and 'critical' where the former is closer to mainstream IR theory in terms of epistemology and methodology, whereas the latter adopts many of the positions found in critical theory. See Ted Hof, "The Promise of Constructivism in International Relations Theory", International Security, Vol 23, No. 1, 1998, pp. 171-200.

${ }^{38}$ See Chapter 8 Christian Reus-Smit, "Constructivism”, in Birchell et al, Theories of International Relations, $3^{\text {rd }}$ edition, New York: Palgrave MacMillan, 2005.

${ }^{39}$ Ibid, p. 201. John Ruggie and Friedrich Kratochwil are leaders in the area of holistic constructivism.
} 
behaviour. Wendt outlines three ideal-type cultures of anarchy (Hobbesian, Lockean, and Kantian) that are based on different role relationships, enmity, rival, or friend. ${ }^{40}$

Unit-level constructivism concentrates on the relationship of domestic norms and ideational processes that constitute state identity and interests rather than in the constitutive effects of the international domain. As part of the academics seeking to open the Waltzian state 'black box' in the 1980s, Barry Buzan argued for a wider and deeper understanding of the concept of security. Using a constructivist approach, he deconstructed the 'essence' of the state arguing that the constituent parts could be threatened in five different sectors. In doing so, he provided the avenue for the unit-level development of critical constructivist analysis that analyses discourses and linkages between security policies and historical / discursive identity construction. The approach, articulated by Buzan in People, States, and Fear (1983/1991) established the Copenhagen School of Security Studies which went on to redefine the concept of security 'as a move to frame an issue as above and beyond politics', thus providing a postmodern 'critical constructivist' framework for the examination of a wider and deeper understanding of national security.

Copenhagen School: In its foundational book, Security: A New Frameworkfor Analysis (1998), Ole Waever articulated the concept of 'securitization' which is a synthesis of classical political realism and constructivist approaches. ${ }^{41}$ Securitization is a process-oriented theory of security which focuses on how the speech act of a securitizing

\footnotetext{
${ }^{40}$ Wendt uses a typology of Hobbesian, Lockean, and Kantian cultures (enmity, rivalry, friendship) to describe the logic of international anarchy whereas Buzan interprets the English School's typology differently as Hobbesian, Grotian, and Kantian. Wendt, Social Theory of International Politics, pp.246312; Buzan, Barry, "The English School: An Underexploited Resource in IR." Review of International Studies, Vol 27, No.3, 2001, pp. 471-488.

${ }^{41}$ Michael C Williams, "Words, Images, Enemies: Securitization and International Politics", International Studies Quarterly, Vol 47, 2003, pp. 511-531.
} 
actor transforms a particular issue into an existential matter of state security. The process traces the discourse of the securitizing actor/agent who politicizes the need for security of a referent object to the target audience that must be persuaded to accept the need for security of the referent object and moves the issue outside the political 'rules of the game'. Securitization thus becomes an extreme version of politicization that can effectively be analysed by disaggregating the whole into the five major sectors through discourse analysis and political constellations. ${ }^{42}$ In effect, this theory dismisses 'given' geopolitical realities in favour of national securitization processes of intersubjectively shared discourses on security and their re-aggregation to make 'national' sense of geopolitical realities. $^{43}$

Conventional Constructivism: Focusing on the regulatory and constitutive social and legal norms that become institutionalized within a state, Peter Katzenstein demonstrated the internal domestic determinates of national security policies in the landmark conventional constructivist study, The Culture of National Security: Norms and Identity in World Politics. ${ }^{44}$ Under Katzenstein's lead, a group of scholars established an analytical approach at the unit-level that departed from the dominant assumptions in contemporary national security by arguing in The Culture of National Security that:

a) security environments are part cultural and institutional rather than simply material; b) cultural environments shape state identity which in turn affects state behaviour.

${ }^{42}$ Buzan, Wæver, and de Wilde, 1998, Chapter 2. There are three variants of securitization theory that have evolved in which scholarly works can be classified; philosophical, sociological and poststructural.

${ }^{43}$ See Stefano Guzzini, et al, "Securitization as a Causal Mechanism", Security Dialogue, Vol 42, No. 4-5, 2011, pp. 329-341.

44 Peter J. Katzenstein, ed, The Culture of National Security: Norms and Identity in World Politics, New York: Colombia University Press, 1996b. 
Unit-level conventional constructivism enables the explanation of variations in identity, interests and actions across states due to internal socialization processes that have the ability to transform the identity and interests of state actors independent of international factors which other constructivist forms disregard. Among the contributing scholars following Katzenstein's approach, Alistair Johnston reconceived 'strategic culture' into a theory that uses state level cultural analysis to explain grand strategy and approaches to war fighting. Concerned with improving the work of two prior 'generations' of strategic culture scholars regarding the relationship between culture and strategy, Johnston leaned on Clifford Geertz's view of the symbolic content of culture ${ }^{45}$ to define strategic culture as

an integrated "system of symbols (e.g., argumentation structures, languages, analogies, metaphors) which acts to establish pervasive and long-lasting strategic preferences by formulating concepts of the role and efficacy of military force in interstate political affairs, and by clothing these conceptions with such an aura of actuality that the strategic preferences seem uniquely realistic and efficacious." ${ }^{46}$

In doing so, Johnston continued in the tradition of the previous generations in linking strategic culture with the concept of political culture which he calls a 'mind set' that limits and constrains institutions, ideologies or behaviors from the body politic.

Two academic works have embodied Wendt's argument that "states are people too" ${ }^{\prime 7}$ and using unit-level analysis developed the concept of a state possessing a 'national security culture'. John Duffield identified a specific national security culture in post-World War Two Germany that has sought multilateral cooperation to answer its

\footnotetext{
${ }^{45}$ Clifford Geertz, The Interpretation of Cultures, New York: Basic Books, 1973, pp. 89-90. For Geertz, culture does not remain solely in the ideational realm as it can include ritual behaviour; however political scientists view culture is primarily ideational in order to differentiate it as the dependent variable from actual behavior.

${ }^{46}$ Alastair Iain Johnston, “Thinking about Strategic Culture”, International Security, Vol. 19, No. 4, 1995, p. 46.

${ }^{47}$ Wendt, Social Theory of International Politics, 1999, pp. 215-223.
} 
security concerns. Using four determinates found in the international (structure and institutions) and domestic (capacity and predispositions) environments, Duffield argued that Germany's desire to form collective alliances was ideational. ${ }^{48}$ Domestically, he identified the two principal sources of 'national disposition' as: 1) sets of ideas relevant to security policy that were widely shared within a society or by its political elites, and 2) from national institutions.

The second work by Emil Kirchner and James Sperling attempts to understand the impact of national security cultures on four categories of national security governance policies through empirical evidence found in eleven case studies of Westphalian and post-Westphalian state structures. ${ }^{49}$ Building on previous works on security culture, ${ }^{50}$ Kirchner/Sperling defines national security culture through four criteria: worldview, national identity, instrumental preferences, and interaction preferences. They argued that "National security cultures provide the lens through which national authorities refract the structural position of the state in the international system; it explains the subjective understanding of objective threats to national security, the instruments relied upon to meet those threats and the preference for unilateral or multilateral action." ${ }^{51}$

\footnotetext{
${ }^{48}$ John S. Duffield, World Power Forsaken: Political Culture, International Institutions, and German Security Policy After Unification, Stanford: Stanford University Press, 1998. For a similar but alternate approach, see Thomas U. Berger, "Norms, Identity, and National Security in Germany and Japan," in Peter J Katzenstein, Cultural Norms and National Security: Police and Military in Postwar Japan, Ithaca, N.Y: Cornell University Press, 1996a.

${ }^{49}$ Emil Kirchner and James Sperling eds, National Security Cultures, New York: Routledge, 2010.

${ }^{50} \mathrm{Ibid}, \mathrm{p} 11$ and $\mathrm{p} 15$, note 6 .

${ }^{51}$ Ibid, p. 11.
} 


\subsubsection{Political Culture Theory}

Political culture has been a staple of comparative politics since the 1960 's ${ }^{52}$, and has been used extensively in constructivist analysis as its basic theory that culture is intersubjective and has causal force fits into the core tenets of constructivism. Many scholars who subscribe to socially based, cultural explanations provide cross-fertilization of ideas moving seamlessly between comparative and international relations analysis. ${ }^{53}$ Political culture literature covers a wide spectrum of approaches that in essence is "the product of both the collective history of a political system and the life histories of the members of that system .... [which] encompasses both the political ideals and the operating norms of a polity." ${ }^{54}$ It is most useful in analysing preference formation and defining the range of possible options that set the agenda in which political contestation occurs.

Political culture contributes towards identifying and explaining values and value systems within a political community that direct choices among presented alternatives. The influence of culture on policy is dependent on many structural and environmental factors, particularly with respect to national security. Political culture research provides both descriptive and explicative analysis that can be used as evidence with respect to

${ }^{52}$ See two of the foundational works - Lucian W Pye and Sidney Verba, Political Culture and Political Development. Princeton: Princeton University Press, 1965; Gabriel A. Almond and Sidney Verba, The Civic Culture: Political Attitudes and Democracy in Five Nations, an Analytic Study, Boston: Little, Brown, 1965.

${ }^{53}$ Scholars such as Peter Katzenstein, Martha Finnemore, Kathryn Sikkink, John Duffield, Peter A. Gourevitch, Thomas Berger, Elizabeth Kier, James Sperling have contributed towards both fields and generally do not categorized themselves within one field of study.

${ }^{54}$ Lucian W. Pye, "Political Culture," in International Encyclopedia of the Social Sciences, Vol. 12, ed, David L. Sills, New York: Macmillan and Free Press, 1968, p. 218 quoted in Richard W. Wilson, "The Many Voices of Political Culture: Assessing Different Approaches," World Politics, Vol 52, No.2, 2000, p. 247; also see David J. Elkins, "A Cause in Search of its Effect, Or what does Political Culture Explain?" Comparative Politics, Vol 11, No.2, 1979, pp. 127-145. 
certain dependent variables and a study's referent collectivity. ${ }^{55}$ A major difficulty in making greater use in the field of this literature has been in the failure to achieve consensus regarding the variables that constitute the structure of political culture. For Ruth Lane, "the effective use of the political culture approach lies in operationalizing detailed models of political cultures and in integrating them with formal decision models. ${ }^{56 "}$ This belief is held by both comparativist and international relations scholars ${ }^{57}$.

Duffield turned to political culture to determine the 'ideational sources of national predispositions', citing three important components that make it particularly useful compared to alternative ideational concepts: "[1] the cognitive, which includes empirical and causal beliefs; [2] the evaluative, which consists of values, norms, and moral judgments; and [3] the expressive or affective, which encompasses emotional attachments, patterns of identity and loyalty, and feeling of affinity, aversion, or indifference." 58 Within political culture, he identifies five categories of widely shared attitudes that form the national security culture subset: 1) worldview; 2) matters of identity, loyalty, and emotional attachments; 3) evaluative standards of political culture that determine the principle goals and values of political life (national interests); 4) causal beliefs (intrinsic values); and 5) shared norms concerning appropriate political behavior. $^{59}$

\footnotetext{
55 See Elkins, 1979.

${ }^{56}$ Ruth Lane, "Political Culture: Residual Category Or General Theory?", Comparative Political Studies, Vol 25, No.3, 1992, p. 364,

${ }^{57}$ See Elkins, 1979; Martha Finnemore and Kathryn Sikkink, "International Norm Dynamics and Political Change," International Organization, Vol 52, No.4, 1998, pp: 887-917; Helen V Milner, "Rationalizing Politics: The Emerging Synthesis of International, American, and Comparative Politics," International Organization, Vol 52, No.4, 1998, pp. 759-786.

58 Duffield, 1998, p.23.

${ }^{59}$ Ibid, pp. 24-25.
} 


\subsubsection{Security Literature on Canada}

Realism and Canadian National Security: Realism as a theory is about the pursuit of power and its application to further a state's interests and goals. Although power is a ubiquitous concept, as a framework for analysis the application of realist theories have proven to have had inconsistent results when applied to Canada except under very specific, temporal circumstances. ${ }^{60}$ Canada has never demonstrated any desire to 'dominate' other states and, outside of raising large military forces during two World Wars, Canada has no history of building and maintaining substantial military power. Although Canada possesses all of the classical realist 'elements of national power', it lacks the desire to dominate and its national security interests are seldom expressed in terms of self-help within Hobbesian anarchy.

Although few Canadian academics view themselves as a 'realists' ${ }^{61}$, the majority of writing on Canadian national security policy has been dominated by one particular Waltzian issue - Canada's relative capability that determines its place in the world as a 'middle-power' ${ }^{62}$ This has led to the examination of a narrow range of issues centred on the concepts of 'balancing' and 'bandwagoning' due in large part to asymmetric power relationship ${ }^{63}$ between Canada and its only neighbour, the US. This leaves Canada with

\footnotetext{
${ }^{60}$ See David Haglund and Tudor Onea, "Sympathy for the Devil: Myths of neoclassical Realism in Canadian Foreign Policy," Canadian Foreign Policy, Vol 14, Issue 2, 2008, pp. 53-66.

61 Illustratively, a recent survey of IR practitioners in North American universities found only 15 percent of Canadian professors self-identified as working within the "realist" paradigm, as against 25 percent in the United States. See Michael Lipson, Daniel Maliniak, Amy Oakes, Susan Peterson, and Michael J. Tierney, "Divided Discipline? Comparing Views of US and Canadian IR Scholars," International Journal, Vol 62, pp. 327-343, Spring 2007, cited at p. 332 - found in Haglund and Onea, 2008.

${ }_{62}$ Maureen Appel Molot, "Where Do We, or Should We, or Can we Sit? A review of Canadian Foreign Policy Literature," in Duane Bratt and Christopher John Kukucha, Readings in Canadian Foreign Policy: Classic Debates and New Ideas, Toronto: Oxford University Press, 2007.

${ }^{63}$ For examples of asymmetric analysis see John Herd Thompson and Stephen J. Randall, Canada and the United States: Ambivalent Allies, 4th ed., Athens: University of Georgia Press, 2008; Sloan, 2010; Hillmer
} 
two options, one of opposition and one of accommodation with US security policies. ${ }^{64}$

Canadian balancing strategies have been categorized in a number of ways to explain

national security policies: 'soft-balancing' to ameliorate American power through

alliances ${ }^{65}$ and international institutions ${ }^{66}$; 'defence-against-help ${ }^{67}$ that creates sufficient

internal power to avoid US interference; and 'counter-weight' - often seen as

internationalism or multilateralism ${ }^{68}$ - to enable Canada a voice in counterbalancing the

power of the US. Many argue that Canada's national security interests are best met as a

'niche major power' employing 'soft power'.

However, bandwagoning is generally the preferred approach, particularly as a

defensive measure that seeks security over direct profiting from American power. 'Hard

bandwagoning' advocates in Canada argue for alignment with US security policies ${ }^{69}$ and

and Granatstein, 2008; Frank P Harvey, "Canada's Addiction to American Security: The Illusion of Choice in the War on Terrorism", The American Review of Canadian Studies, Vol 35, No. 2; Summer 2005.

${ }^{64}$ Stephen M. Walt, Taming American Power: The Global Response to US Primacy, New York: W. W. Norton, 2005.

${ }^{65}$ Stefanie von Hlatky, American Allies in Times of War: The Great Asymmetry, New York: Oxford University Press, 2013.

66 "Canada may exercise soft balancing against the United States within common institutions, such as the North Atlantic Treaty Organization (NATO) and the United Nations Security Council (UNSC), by binding the hegemon to institutionalized norms and rules, and by restraining its potential unilateralism." - Justin Massie, "Towards Greater Opportunism: Balancing and Bandwagoning in Canadian-American Relations," in Paquin, P. and James, P. et al, Game Changer: The Impact of 9/11 on North American Security, Vancouver: UBC Press, 2014, p. 50; Timothy A. Sayle, "Taking the Off-Ramp: Canadian Diplomacy, Intelligence, and Decision-making before the Iraq War", in Jack Cunningham and Ramesh Chandra Thakur, Australia, Canada, and Iraq: Perspectives on an Invasion, Toronto: Dundurn Press, 2015, pp. 210 227.

${ }^{67}$ Duane Bratt and Donald Barry, "Defense Against Help: Explaining Canada-U.S. Security Relations," American Review of Canadian Studies, Vol 38, No1, 2008, pp. 63-89.

68 "The strength of its American alliance gave Canada space to pursue a vigorous internationalism (Hillmer, 2002: 70; Hillmer, 2005b: 33)" in Tomlin, Brian W., Fen Osler Hampson, and Norman Hillmer, Canada's International Policies: Agendas, Alternatives and Politics, Toronto: Oxford University Press, 2008; Charles-Philippe David and Stéphane Roussel, “"Middle Power Blues”: Canadian Policy and International Security after the Cold War," American Review of Canadian Studies, Vol 28, No. 1, 1998, pp. 131- 156

${ }^{69}$ James G Fergusson, Canada and Ballistic Missile Defence, 1954-2009: Déjà Vu All Over Again, Vancouver: UBC Press, 2010. 
greater participation in American-led international security ventures ${ }^{70}$ as a matter of Canadian national security interests. Although historically Canada has preferred the soft varieties of balancing and bandwagoning, recent events have given rise to 'neocontinentalism"71 that sees Canada as a "foremost' rather than a "middle" power. 'Soft bandwagoning' is a continentalist approach ${ }^{72}$ that moderately or symbolically support US foreign policy preferences and can take many forms: 'deeper integration' 73 in economic and security institutions to leverage the bilateral relationship; 'defensive soft bandwagoning, 74 that supports bilateral security through protection of Canadian sovereignty; and 'multilateral institutionalism' ${ }^{\text {, }}$, bonding Washington's behavior to international norms through defence partnering with allies.

In both 'balancing and bandwagoning' strategies, Canadian realists are concerned with the alliance security dilemma ${ }^{76}$ of 'abandonment ${ }^{\text {'77 }}$ or 'entrapment' ${ }^{78}$ in analysis of Canadian national security policies. The introduction of greater domestic variables by neoclassical realists has not changed the analytical approach to the aforementioned

\footnotetext{
${ }^{70}$ Joel Sokolsky, "Realism Canadian Style: National Security Policy and the Chrétien Legacy", Policy Matters, Vol 5, No. 2; Montreal: Institute for Research on Public Policy, 2004.

${ }^{71}$ Massie, 2014.

${ }^{72}$ Ibid, p. 54; Jean-Christophe Boucher, "The Cost of Bandwagoning: Canada-US Defence and Security Relations after 9/11", International Journal Vol 67, No. 4, 2012, p. 899.

${ }^{73}$ Colin Robertson, Now for the Hard Part: A User's Guide to Renewing the Canadian-American Partnership, Calgary.: Canadian Defence and Foreign Affairs Institute, 2011.

${ }^{74}$ Steven Kendall Holloway, Canadian Foreign Policy: Defining the National Interest, Peterborough: Broadview Press, 2006.

${ }^{75}$ James Eayrs, In Defence of Canada: growing up Allied, Toronto: University of Toronto Press, 1980, p. 369, quoted in Massie, 2014, p.55, note 34, regarding Pearson's hope to contain the US through the NATO alliance.

76 "Alliance security dilemma" is a Jack Snyder term (1984), for a succinct explanation see Mike Bourne, Understanding Security, Hampshire: Palgrave Macmillan, 2014, p. 119.

${ }^{77}$ Joseph Jockel, "Saving NORAD: Should Ottawa Seize the Obama Moment?", The School of Public Policy: SPP Briefing Papers, Vol 2, Issue 3, September 2009.

${ }^{78}$ Hugh White, "Why Australia Invaded Iraq: A Study in Alliance Management", in Jack Cunningham and Ramesh Chandra Thakur, Australia, Canada, and Iraq: Perspectives on an Invasion, Toronto: Dundurn Press, 2015.
} 
relative capability paradigms. ${ }^{79}$ For example, although Patrick Lennox approaches post9/11 security changes from a "power plus ideas" perspective, he ultimately determines the root cause as "the structural hierarchy of power." ${ }^{" 00}$ In what could be classified as a pre-neoclassical approach, David Dewitt and John Kirton conceived Canada as a 'principle power' in their 'complex neo-realism' ${ }^{\prime 81}$ theory that included similar domestic determinants being advanced in this dissertation (worldview, societal, and governmental).

Neoliberalism and Canada: In the bilateral case of Canada and the US, it is logical for the US to bind itself with others to induce weaker states to conform to US policy. For Canada, self-interests can be pursued with a more powerful partner, like the US, as institutions provide greater confidence in calculating costs and benefits. ${ }^{82}$ Robert Keohane and Joseph Nye describe in great detail this "fascinating and complex set of systems and coalitions that crisscross [Canada-US] national boundaries" ${ }^{\prime 3}$ of government, agencies, and nongovernmental actors that directly affect decision-making in both nations making the interstate relationship distinct from others. However in the fourth edition of Power and Interdependence, they note that military power plays a minor role in the Canada-United States (CANUS) relationship and that this relationship 'does not purely rely on an outside threat' but 'more on the joint gain than the zero-sum aspects' ${ }^{84}$

\footnotetext{
${ }^{79}$ Haglund and Onea, 2008.

${ }^{80}$ Patrick Lennox, "From Golden Straitjacket to Kevlar Vest: Canada's Transformation to a Security State," Canadian Journal of Political Science, Vol 40, No.4, 2007, pp. 1017-38.

${ }^{81}$ David B. Dewitt and John Kirton, "Three Theoretical Perspectives", in Duane Bratt and Christopher John Kukucha, Readings in Canadian Foreign Policy: Classic Debates and New Ideas, Toronto: Oxford University Press, 2007; David B. Dewitt and John J. Kirton, Canada as a Principal Power: A Study in Foreign Policy and International Relations, Toronto: Wiley, 1983.

${ }^{82}$ Robert Keohane, After Hegemony, Princeton: Princeton University Press, 2005.

${ }^{83}$ Robert Keohane and Joseph Nye Jr., "Introduction: The Complex Politics of Canadian-American Interdependence," International Organization, Vol 28, No 4, Autumn 1974, p. 596.

${ }^{84}$ Robert Keohane and Joseph Nye Jr., Power and Interdependence, ${ }^{\text {th }}$ ed, Toronto: Longman, 2012.
} 
Other neo-liberal literature focuses in large part on shared values between Canada and the US to explain asymmetric security cooperation, which mitigate threats to liberal societies. ${ }^{85}$ Issues of continued economic prosperity ${ }^{86}$ and other mutual material interests on a global scale ${ }^{87}$ dominate utility-maximization through negotiation and institutionalization. Canada's global power is reliant on its continued economic prosperity which affects its ability to negotiate within international institutions to alleviate security uncertainties of others. ${ }^{88}$

Constructivism and Canada: A relatively new approach to security analysis of Canadian policies, this literature is relatively thin and diverse with respect to security analysis and covers the spectrum from individual, human to collective, global security. Specific constructivist analysis of national security has primarily focused on 'strategic culture' where state-level behavior is used to explain Canada's post 9/11 international policies $^{89}$ and grand strategy. ${ }^{90}$ Exploring the deeper cultural and political histories of identity construction in the 'anglosphere', recent comparativist research by political scientists Louis Pauly, Christian Reus-Smit, and Srdjan Vucetic, has provided insight into

\footnotetext{
${ }^{85}$ Stéfanie von Hlatky and Jessica N. Trisko, "Sharing the Burden of the Border: Layered Security CoOperation and the Canada-US Frontier," Canadian Journal of Political Science, Vol 45, No.1, 2012, pp. 63-88.

86 Thomas d'Aquino, "Security and Prosperity in the Canada-United States Relationship: Two Sides of the Same Coin," Canadian Defence \& Foreign Affairs Institute, March 2011.

${ }^{87}$ Charles Doran, "Was 9/11 a Watershed?", in Paquin, P. and James, P. et al, Game Changer: The Impact of 9/11 on North American Security, Vancouver: UBC Press, 2014.

${ }^{88}$ Daniel R. Madar, Canadian International Relations, Toronto: Prentice Hall Allyn and Bacon Canada, 2000, pp. 259-264.

${ }^{89}$ Justin Massie, "Making Sense of Canada's "Irrational" International Security Policy: A Tale of Three Strategic Cultures," International Journal, Vol. 64, No. 3, 2009, pp. 625-645; Alan Bloomfield and Kim R Nossal, "Towards an Explicative Understanding of Strategic Culture: The Cases of Australia and Canada," Contemporary Security Policy, Vol.28, No.2, August 2007, pp.286-307; Brendon O'Connor and Srdjan Vucetic, "Another Mars-Venus Divide? Why Australia Said 'Yes' and Canada Said 'Non' to Involvement in the 2003 Iraq War," Australian Journal of International Affairs, Vol 64, No.5, 2010, pp. 526-48.

90 Éric Tremblay and Bill Bentley, "Canada's Strategic Culture: Grand Strategy and the Utility of Force", Canadian Military Journal, Vol. 15, No.3, Summer 2015.
} 
the ideational foundations of Canadian security policy decisions. ${ }^{91}$ Critical

constructivism has also been used to study post-9/11 Canadian national security response through 'biopolitical analysis' 92 and the Copenhagen School's 'securitization theory'93.

Only one study has specifically addressed Canada's 'national security culture' and that was done within a larger, global comparative study of Westphalian states. ${ }^{94}$ Using a framework developed by John Duffield concerning the relationship between state-level security culture and security policy, Osvaldo Croci identifies the dialectic between political elites and the public by focusing on perception of threats in Canada's international policies and concludes that national security culture is defined by acceptance of elite policy choices by the public over time. ${ }^{95}$ Using a constructivist framework and democratic peace theory, Stéphane Roussel, argues that Canada and the US are predisposed to cooperation due to liberal-democratic norms and values. ${ }^{96}$

Political Culture and Canada: Canada and the US emerged from a shared British North America culture that has been extensively analysed by political scientists, historians and sociological comparativists. From this 'common' beginning, it has been shown that unique Canadian and American identities were socially constructed through shared historical experiences within a North American threat environment. The

\footnotetext{
${ }^{91}$ Louis Pauly and Christian Reus-Smit, "Negotiating Anglo-America: Australia, Canada, and the United States", in Peter Katzenstein, ed, Anglo-America and its Discontents: Civilizational identities beyond West and East, New York: Routledge, 2012, pp. 127-151; Srdjan Vucetic, The Anglosphere: A Genealogy of a Racialized Identity in International Relations, Stanford: Stanford University Press, 2011.

92 Colleen Bell, "Biopolitical Governance in Canada's National Security Policy," Security Dialogue, 2006, Vol 37, No.2, p. 147-165.

93 Sara McGuire, "Securing' the Homeland? A Comparison of Canadian and American Homeland Security Policy in the Post-9/11 Period", doctoral thesis McMaster University, 2013.

${ }^{94}$ Kirchner and Sperling, 2010.

95 Osvaldo Croci, "Facing up to regional security challenges," in Kirchner, Emil and Sperling, James, eds, National Security Cultures: Patterns of Global Governance, New York: Routledge, 2010.

${ }^{96}$ Stéphane Roussel, The North American Democratic Peace: Absence of War and Security InstitutionBuilding in Canada-US Relations, 1867-1958, Montreal: McGill-Queen's University Press, 2004.
} 
ideational schism created by the American Revolution led each state on separate trajectories with respect to their place in international society and the consequences of historical choices that ultimately affect the national security culture of each society. By cross-referencing political science ${ }^{97}$ and sociological ${ }^{98}$ literature with Canadian political culture works, this study will be able to determine the security norms and values embedded in Canadian society from these secondary sources.

Of the principal scholars who have authored political cultural analysis of Canada, there have been no significant references to or around the specificity of security. Historical and sociological accounts speak of the importance of the society-polity relationship and the domestic role that culture or regionality plays in shaping Canada's international policies but rarely analyse the underlying security norms and values that shape Canadian attitudes towards the formulation of such policies. ${ }^{99}$ The sole exception is perhaps the literature on Quebec that transcends the political culture / science divide. Often accused of 'hijacking' Canadian foreign policy ${ }^{100}$, the literature that analyses the regional impact of Quebec on national security ${ }^{101}$ represents the sub-state (society-polity) ideational analysis that this dissertation argues is central to understanding Canadian

\footnotetext{
${ }^{97}$ Philip Resnick, The European Roots of Canadian Identity, Peterborough, Ontario: Broadview Press, 2005; Will Kymlicka, "Being Canadian”, Government and Opposition, Vol 38, No. 3, 2003, p.357-385. ${ }^{98}$ Seymour Martin Lipset, Continental Divide: The Values and Institutions of the United States and Canada, New York: Routledge, 1990; Gad Horowitz, "Notes on 'Conservatism, Liberalism and Socialism in Canada"', Canadian Journal of Political Science, Vol. 11, No. 2, 1978, pp. 383-399; Edward Grabb, James Curtis, and Douglas Baer, "Defining moments and recurring myths: Comparing Canadians and Americans after the American Revolution" The Canadian Review of Sociology and Anthropology, Nov 2000, Vol 37, No.4, pp. 373-419.

${ }^{99}$ Charles F. Doran, "Thoughts on a Different Tomorrow," Annals of the American Academy of Political and Social Science, Vol 538, No.1, 1995, pp. 9-15; Ailsa Henderson, "Regional Political Cultures in Canada," Canadian Journal of Political Science, Vol 37, No.3, 2004, pp. 595-615.

100 J. L. Granatstein, Who Killed the Canadian Military?, 1st ed., Toronto: Harper Flamingo Canada, 2004.

${ }^{101}$ David Haglund and Stéphane Roussel, "It's a Long Road from Fort Greely to Chicoutimi: Quebec Sovereignty and the Issue of Missile Defense", Comparative Strategy, Vol 27, No. 4, July 2008, pp. 361 375 .
} 
national security. Again, this culturally based literature covers a range of approaches:

'strategic culture' ${ }^{102}$, 'small nation theory' ${ }^{\prime 03}$, as well as 'ideational' 104 and provides

evidence of the intersubjective nature of policy formulation in Canada.

\subsection{Literature Gap}

While both realism and neoliberalism have contributed to the understanding of Canadian national security they are limited in explanatory power as they treat state actors with exogenously attributed properties only interested in material factors. They tend to be highly descriptive and rarely posit questions about paradigm choice that leave important questions about Canada's place in the world unasked, therefore not debated. This leads to deterministic threat definitions that are often contradictory. ${ }^{105}$ Arguments that focus on Canada's relative ranking as a middle power often seek power accumulation as a means to an end but consistently fail to explain 'the end' other than as a nebulously defined interest. ${ }^{106}$ Canada uses its cumulative power in a judicious and calculated manner, as described by the principal realist Henry Kissinger ${ }^{107}$, through skilled statesmen for political ends impelled by domestic imperatives. Domestic politics matter significantly in

\footnotetext{
102 Justin Massie, "Regional Strategic Subcultures: Canadians and the use of Force in Afghanistan and Iraq," Canadian Foreign Policy Journal, Vol 14, No.2, 2008, pp. 19-48.

103 Paul C. Adams, "The September 11 attacks as viewed from Quebec: the small-nation code in geopolitical discourse," Political Geography, Vol 23, 2004, pp. 765-795.

104 Jean-Sébastien Rioux, “Two Solitudes: Quebecers' Attitudes Regarding Canadian Security and Defence Policy", Canadian Defence and Foreign Affairs Institute, Research Paper Series, 23 February 2005.

${ }^{105}$ Whereas many Canadian realists argued that it was in Canada's interest to go to war with Iraq in 2003, John Mearshiemer and Stephen Walt argued the opposite case for the United States. - John Mearshiemer and Stephen Walt, “An Unnecessary War”, Foreign Policy, January/February 2003, pp.51-59.

106 Joel Sokolsky, 2004.

107 "Canada's somewhat aloof position combined with the high quality of its leadership gave it an influence out of proportion to its military contribution...(It) was beset by ambivalences which, while different from those of Europe, created their own complexities. It required both close economic relations with the United States and an occasional gesture of strident independence. Concretely, this meant that its need for American markets was in constant tension with its temptation to impose discriminatory economic measures; its instinct in favor of common defense conflicted with the temptation to stay above the battle as a kind of international arbiter. Convinced of the necessity of cooperation, impelled by domestic imperatives toward confrontation, Canadian leaders had a narrow margin for maneuver that they utilized with extraordinary skill.” Found in Henry Kissinger, White House Years, Boston: Little Brown, 1979, p 383.
} 
determining Canadian national security policy with respect to international structural implications or ad hoc allied state imperatives.

In explaining Canada's decision not to participate in the 2003 invasion of Iraq, analysts focus on alliance theory and the lack of government cohesion and available military capabilities. ${ }^{108}$ This power-centric analysis fails to account for the deeply held ideational factors involved in this and other security policy choices. Principle over power considerations are fundamental cleavages in Canadian politics. The fact that Canada chose not to make even a token military contribution to the Iraq coalition to indicate alliance participation ${ }^{109}$ is indicative that realist assumptions were of less importance in this decision than domestic and international ideational factors. In assessing the impact of 9/11 on security cooperation between Canada and the US, Charles Doran illustrates the limitations of causal explanations in realism, "The difference of opinion regarding whether bandwagoning or balancing was the valid perspective reveals the importance of the psycho-cultural dimension of relations between Canada and the United States." ${ }^{\prime 10}$ Ideation matters.

Dewitt and Kirton understood the role society plays in the debate within Canada for the 'employment of power' ${ }^{111}$; however, contemporary neo-classical realism never

\footnotetext{
${ }^{108}$ See Stéfanie von Hlatky, The Great Asymmetry: American Allies in Times of War, Oxford: Oxford University Press, 2013; and Sokolsky, 2004.

${ }^{109}$ Token military contributions such as liaison teams or airlift support act as a 'soft-bandwagoning' strategy to indicate political support without committing substantial resources.

${ }^{110}$ Charles Doran, "Was 9/11 a Watershed?", in Paquin, P. and James, P. et al, Game Changer: The Impact of 9/11 on North American Security, Vancouver: UBC Press, 2014, p. 16.

${ }^{111}$ Dewitt and Kirton, 2007, p. 38 - "A complex neo-realist orientation perceives the domestic environment as being marked by the emergence of highly salient, ongoing disputes over foreign policy issues, grounded in the interest of autonomous major organizations throughout the national society. The high importance of domestic organizations rests in the first instance on the likelihood that the country's possession of a surplus margin of capability allows for and prompts an effective debate within society about the purposes for which that power should be employed."
} 
discusses the operationalization of society in influence maximization as part of the 'statesociety' intervening variable. Although neo-classical realism introduces ideation with power, they continue to conflate society with the state ${ }^{112}$, failing to take into account the implications of societal power in Fareed Zakaria's state strength formula ${ }^{113}$. In bypassing society in favour of decision-makers ${ }^{114}$ at the state level, neo-classical realism ignores an important domestic element of power, that of the electorate in liberal democracies.

Decision-makers and elites do not have the luxury of 'extracting resources' and 'carrying out its wishes' without consideration of the society for whom they must remain legitimate $^{115}$. In arguing for unit specificity in power analysis, neo-classical realism ignores the one variable that makes states unique, society, and the inherent power limitations that cultural values embed in state institutions.

The utility of the neo-liberal explanation is also limited for a number of reasons. First, like realism, the demarcation between the international and the domestic levels assumes exogenous domestic interests and nationalistic bargaining approaches towards materialist goals without providing context to the underlying societal concerns. The validity of materialist arguments hinges on demonstrating that a state's material base governs its cultural superstructure; however, many of the examples that Keohane and

\footnotetext{
112 Lennox, 2007; Dewitt and Kirton, 2007.

${ }^{113}$ Zakaria explains that state power is dependent on both traditional national power measurements and state strength, the government's ability to 'extract national power for its ends', as well as the 'capacity and cohesion to carry out its wishes'. Fareed Zakaria, From Wealth to Power: the Unusual Origins of America's World Role, Princeton: Princeton University Press, 1998, p. 38-39.

${ }^{114}$ Competition within the elite covers a wide spectrum of ideation and manifests itself in many forms that shape factors being considered by decision-makers. "Two fundamental processes underlie political activity within democratic polities: elite competition and public reactivity...these two processes are inherently and inextricably linked together. Competition within the elite stratum serves to regulate the behavior of actors; elite actions which violate norms of acceptability are brought before the public eye, with the intent of elicit a negative reaction from the public." - Timothy Kersey, Constrained Elitism and Contemporary Democratic Theory, Vol. 4, New York, NY: Routledge, 2016, p. 111.

115 See J. Talliaferro, "State Building for Future Wars: Neoclassical Realism and the Resource-Extractive State,” Security Studies, Vol 15, No 3, pp. 464-495; Haglund and Roussel, 2008.
} 
Nye cite in their Canadian case study ${ }^{116}$ analysis are indicative of ideational security concerns that are of equal or greater importance than simply material concerns. In their case study, national security was more about negotiation of other social and socioeconomic insecurities rather than concerns with military co-binding. ${ }^{117}$

Secondly, neo-liberalism compels the alignment of choices towards established institutions with limited attention to the underlying processes that shape interests. Whether co-operation between Canada and the United States is seen as arising from their strong trade relationship or a shared philosophical viewpoint, the liberal view neglects the fact that economics and security are often competing interests that affect the perception of threats. The complexity of interdependence is highlighted by the 'intermestic' ${ }^{118}$ nature of the relationship that causes a "blurring of traditional distinctions between foreign and domestic policies on numerous issues."119 Thus behavior does not follow established institutional constraints as politicians on both sides of the border depoliticize and delink most issues to ensure security and economic disputes remain sector-specific. ${ }^{120}$

Past debates focusing solely on states and military power are less applicable today as the imperative of global conflict has subsided and the tools available for states to exercise power have expanded. The final approach, constructivism, has shortcomings too. Although there is broad acceptance that national security studies needs to be deepened, there has been reluctance in the empirical literature on security culture to

\footnotetext{
${ }^{116}$ Robert Keohane and Joseph Nye Jr., Power and Interdependence, 2012, Chapter 7, pp. 143-186.

${ }^{117}$ Ibid, pp. 143-149. This aligns with the premise of this dissertation that contends one must look to cultural factors to properly understand national security in Canada.

${ }^{118}$ Intermestic is a term used in international relations for the interconnectedness between international and domestic politics.

${ }^{119}$ Geoffrey Hale, So Near Yet so Far: The Public and Hidden Worlds of Canada-US Relations, Vancouver: UBC Press, 2012, p 127.

${ }^{120}$ Ibid. Chapters 10 and 11 are case studies that exam the smart border accords in the wake of 9/11.
} 
expand the levels of analysis and disaggregate the unit known as the 'state'. Actors within the state, from individual decision-makers to stakeholders in the polity to society as a whole, determine what is in need of state sponsored protection and what constitutes a threat, not the state itself. Constructivist approaches to Canadian national security literature are primarily written from an IR perspective, using state culture to explain state foreign policy decisions ${ }^{121}$ and exogenously given, preconceived threats. ${ }^{122}$ Few scholars venture beyond a posteriori study of state security policies and analysis of elite decisionmakers to explain what constitutes a security threat to Canada and why it is perceived as such.

Strategic culture literature suffers from similar problems. The contestation whether strategic culture was causal or contextual ${ }^{123}$ was due to Johnston's premise of binding state culture to strategy. It leads to a priori interpretive explanans, such as "Canada's three concurrent and coexistent strategic cultures: continental softbandwagoning, defensive internationalism, and soft-balancing Atlanticism", rather than exploring the cultural causality. ${ }^{124}$ Deepening this investigation inward to analyse the social construction of the security debate in Canada (national security culture) will elicit a more comprehensive causal understanding of the resultant policies. Since strategic culture is really just security culture, as Haglund $\operatorname{argues}{ }^{125}$, then reorienting the referent

\footnotetext{
${ }^{121}$ Vucetic, 2011; Pauly and Reus-Smit, 2012.

122 Massie, 2009; Croci, 2010.

${ }^{123}$ Colin Gray argued that strategic culture could only be seen as contextual as it transcended both cause and effect. Johnston's position was that Gray's use of strategic culture was so muddled that it blurred the distinction between independent and dependent variable - Alastair Iain Johnston " Strategic cultures revisited: reply to Colin Gray”, Review of International Studies, Vol 25, 1999, pp. 519-523./

${ }^{124}$ Massie, 2009.

125 "Once the definition [of strategic culture] has been sufficiently 'precised', why not envision using it as an independent variable? And what could be better than political culture to blaze the trail for strategic culture....Why not turn to political culture as a means of "operationalizing strategic culture." - David
} 
object inward from the state will generate Canada's national security culture, what Duffield also considers a subcomponent of political culture. ${ }^{126}$

Although many IR scholars invoke the use of political culture ${ }^{127}$, domestic factors are rarely researched deeply nor addressed in a substantive manner beyond analysis of elite Canadian decision-makers. ${ }^{128}$ This is a mistake, as the state is only a reflection of the security norms embedded in its institutions and projected by its behaviour. To truly explain a state's national security behavior, one must understand the limits that society places on state sponsored security, and the institutional constraints applied by the polity to the decision-makers who represent the state. This is where Buzan's turn towards critical theory in his quest to deepen the understanding of national security was flawed.

Collective domestic agency has significant influence on the outcome of national security policy regardless of the international structural pressures, particularly in times of choice. In a liberal democracy, the 'audience' cannot be limited to the security elite and must include society writ large as the 'audience' who legitimizes the resource extraction by the state for national security purposes. This in effect brings one back to the problem which Buzan sought to avoid in People, States, and Fear (91), how to account for societal influence in state decisions. In effect, securitization theory is essentially the study

Haglund, "'Let's Call the Whole Thing Off'? Security Culture as Strategic Culture”, Contemporary Security Policy, Vol 32, No. 3, 2011, p. 509 (494-516).

${ }^{126}$ Duffield 1998, p. 5; ironically, Duffield eschews the constructivist approach, p. 252, preferring to focus on elites and is dichotomous in invoking national security culture as a subcomponent of political culture as he fails to pay any attention to the cultural origins of either.

${ }^{127}$ Although Croci, Kirchner, Sperling, Johnston, Duffield, Berger, Kier all use political culture, they insufficiently explain its use and limitations to their studies which generally leads to incomplete analysis of cultural factors.

${ }^{128}$ For examples see Croci, 2010; Ann Denholm Crosby, Dilemmas in Defence Decision-making: Constructing Canada's Role in NORAD, 1958-96 Research, New York: St. Martin's Press, 1998; For reasons why this is important see Theo Farrell, "Constructivist Security Studies: Portrait of a Research Program”, International Studies Review, Vol 4, No.1, 2002, pp. 49-72. 
of the 'ideational process in political debate and resolutions of security issues'. Analysis of the 'speech act' fails to take into consideration the social context in which attempts at securitization occur and the effects that security statements provoke in Canadian audiences. Not all states are alike and not all societies are the same. Causal mechanisms attributed to society-polity can be empirically tested and analysed through security norms of behaviour, thus deepening the concept of national security.

Of the existing explanatory literature, national security culture is the optimal approach to explain how Canada views national security in the post 9/11 world. Variations in national security policies do not fit within realist paradigms of power and perceived threats. Neo-liberal approaches to the complexities of Canadian interdependence with the US fail to capture the insecurities felt by Canadian society towards its survival as an independent, sovereign state. Although strategic cultural accounts offer insight, their use of decisions taken by the state as expressions of state behaviour fail to elicit the social factors that are causal to that decision. National security culture has the potential to explain how social factors shape different aspects of national security policy that at times contradicts other theories. However, the sole scholarly study of Canadian national security culture focuses too much on analysing international policy and limits its research to the behaviour of elite politicians and civil servants. This fails to take into account elites, such as Supreme Court justices, and all the institutions that affect elite decision-making. In other words, other agents and structures of the polity have causal power and need to be included.

The polity represents the organizing principles that shape decision-making in liberal democracies. When systemic factors precipitate change in a state's national 
security policies, the preferences or evaluative standards (norms and values) located in national society shapes the state's decision-making processes located in the cognitive standards (rules and models) of the polity of what society considers acceptable state security responses. Although political contestation over social and material interests provides specificity to elite decision-makers, analysis of the final 'moral judgment' requires application of other theoretical models. ${ }^{129}$ The concept of studying Canadian National Security Culture through state-level social factors embedded in the societypolity nexus holds the promise of providing greater explanatory power for post 9/11 Canadian national security policies.

Understanding how Canada perceives national security and the insecurities that are determined to be in need of state sponsored protection is important for several reasons. Power and material considerations are generally the catalyst for change and important determinates in the policy outcomes. However, ideational factors shape and at times determine final policy positions in Canada and explicating the cultural factors will provide a firmer foundation for policy analysis using other theoretical approaches. As well, uncertainties are created through perceived variations in security policies, particularly when linked to US insecurities and interests. Better understanding of the sociological processes inherent in national security policy formulation is key to understanding the rationale behind Canadian security policies that other theories deem 'irrational' and 'ad hoc', principally in challenging the traditional paradigm that national security is premised on foreign and defence policies. Improving and sustaining defence

\footnotetext{
${ }^{129}$ National security culture has the ability to explain the social and structural variables that lead to policy decision, but analysis of the specificity behind the final decision transcends political science towards theories in psychology. However, moving from national security culture to rational choice models found within political science theory will likely provide further fidelity on specific policy choices.
} 
and security relations with others, particularly the US, requires an understanding of the ideational foundations of national security in Canada.

\subsection{Hypothesis and Variables}

Hypothesis: Ideational factors shape the development of national security norms, identities, institutions, and interests over time that directly affects the perception of threats and the preferred methods for protection. The historical and sociological construction of Canadian society and polity resulted in unique national security concerns over the protection of acquired values, the articulation of dangers, and the subsequent behaviour of actors. A distinct Canadian National Security Culture has evolved from embedded security norms and values that lead to national security preferences (evaluative standards) in dealing with state sponsored protection of acquired values. These embedded norms of behaviour in the identities of actors and institutions limited and constrained the policy choices following the events of $9 / 11$. Short term crisis management decisions mitigated immediate national security concerns, but long term security commitments were kept in check by established Canadian national security norms.

Thus, the hypothesis that will be tested is that Canadian national security policy decisions post 9/11 resulted from policy choices that were limited and constrained by domestic institutional structures and a contemporary Canadian National Security Culture that views security broadly and endogenously as a value to be weighed against other competing values. Although initial policy decisions were shaped by domestic security norms found in this society-policy nexus, variation in final security policy outcomes was determined in large measure by the interrelated contestation of the intervening variables, identity, cultural-institutional structure, and interests. Stated simply, state protection of 
acquired values embodied in Canadian National Security Culture (IV) shaped the post 9/11 national security policy decisions while the interaction of the three social variables (IntV) determined the final policy outcomes (DV).

\section{Dependent Variable (DV): Outcomes of National Security policy decision(s)}

made by the government of Canada in the wake of the 9/11 attack, is the DV. Using the Martin Government's 2004 National Security Policy statement as the initial case study, I have chosen two specific security policy areas identified in the National Security Policy statement that are related, but separate, for additional case study analysis. The establishment of Marine Security Operations Centres (MSOCs) is the second case as it is centrally an interdepartmental, domestic security issue involving competing Canadian values with a bilateral nexus. The third case study involves the 2006 renewal of the binational North American Aerospace Defence (NORAD) Agreement and the post 9/11 reformation of NORAD within the reconstructed North American security complex.

Independent Variable (IV): Canadian National Security Culture at the time in question is the IV. National security culture varies over time within a state (as it is constantly in the process of construction ${ }^{130}$ ) and varies from state to state. The geostrategic location of Canada has allowed Canadian society and polity the luxury of defining national security, or the protection of acquired values, in wider domestic terms over time. National Security Culture refers to the set of evaluative standards, such as security norms and the acquired values, which are used to determine society's

\footnotetext{
${ }^{130}$ As norms and values evolve over time within society, emerging norms and values will transform society and the polity in various ways. This mutually constitutive process sees importance and intensity ebb and flow dependent on state circumstances. However, certain norms and values will remain consistent over time that will indicate national preferences. Contemporary national security culture is temporal, but within the limits and constraints of established national security norms and values.
} 
expectations of state sponsored protection. These evaluative standards are the result of preference formation, through recursive interaction of constitutive and regulative norms with evaluative norms that determine principal goals and values, during the social construction of the state.

Contemporary Canadian National Security Culture will be determined through security norm salience (strength) found in domestic political discourse, national institutions (procedures and laws) and national security policies. ${ }^{131}$ Process tracing allows for a rough baseline of expected norm salience to be established when it can be shown to have existed over a long period of time. In other words, Canadian National Security Culture is an ideational predisposition towards national security held by elements of the state.

\section{Stated Hypothesis:}

State protection of acquired values embodied in Canadian National Security Culture (IV) shaped the post 9/11 national security policy decisions while the interaction of three social variables (identity, cultural-institutional structure, and interests - IntV) determined the final policy outcomes (DV).

$\underline{\text { Intervening Variables (IntV): }}$

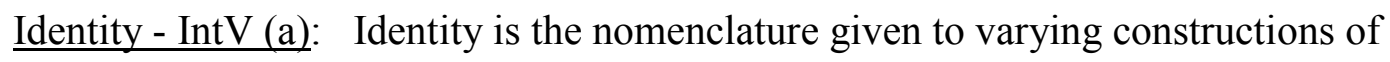
statehood which encompass evolving national ideologies of collective purpose and

\footnotetext{
${ }^{131}$ See Andrew P. Cortell and James W. Davis, Jr, "Understanding the Domestic Impact of International Norms: A Research Agenda" International Studies Review, Vol. 2, No. 1, Spring 2000, pp. 65-87; Theo Farrell, "Constructivist Security Studies: Portrait of a Research Program", International Studies Review, Vol 4, No.1, 2002, pp. 49-72; Jeffrey Legros, "Which Norms Matter? Revisiting the "Failure" of Internationalism”, International Organization, Vol 51, No. 1, 1997, pp. 31-63.
} 
distinctiveness. ${ }^{132}$ The process of identity construction is political and includes the engagements of conflicting actors towards political resolution, however temporal. The rules, regulations, and norms that inform the actors also shape their perception of reality (identity - who we are). ${ }^{133}$ Although I will make use of the term self/other, identities are intersubjectively constructed through several, often overlapping and complementary relations. In proceeding, I will make use of the specificity of the 'relationality principle $^{134}$ in analysing the Canadian identity as too often analysts mistake Canadian norms and values as 'anti-American' rather than as foundational constitutive norms and acquired values.

Cultural-Institutional Structure - IntV (b): The cultural-institutional ${ }^{135}$ context of environmental structures (domestic, states', global) acts as a social determinant of security policy. Although neo-liberalism offers a theory of the cultural-institutional context of state action, cultural-institutional contexts do more than simply regulate behavior and constrain actors by changing the incentives that shape their behavior, they also constitute the actors whose conduct they seek to regulate. It is this culturalinstitutional context in which states and governments define their interests and then act.

\footnotetext{
${ }^{132}$ Katzenstein, 1996b; Martha Finnemore and Kathryn Sikkink, "International Norm Dynamics and Political Change," International Organization, Vol 52, No. 4, 1998, pp. 887-917.

133 "The most common distinction is between regulative norms, which order and constrain behavior, and constitutive norms, which create new actors, interests, or categories of action. Some scholars have also discussed a category of norms called evaluative or prescriptive norms." - Finnemore Sikkink, 1998, p. 891. ${ }^{134}$ See Mary Bucholtz and Kira Hall, "Identity and interaction: a sociocultural linguistic approach", Discourse Analysis, Vol 7, No. 4-5, pp. 585-614. Relationality Principle - Identities are intersubjectively constructed through several, often overlapping complementary relations similarity/difference, genuineness/artifice and authority/delegitimacy. - p. 598.

135 "One difference between" norm" and "institution"(in the sociological sense) is aggregation: the norm definition isolates single standards of behavior, whereas institutions emphasize the way in which behavioral rules are structured together and interrelate (a "collection of practices and rules")"- Finnemore and Sikkink, 1998, p. 891.
} 
Culture is the nomenclature given to collective models of state identity or authority that are carried by custom or law. Culture refers to a set of evaluative standards, such as norms and values, as well as to a set of cognitive standards, such as models and rules, both of which define the social actors in the system, how they operate, and how they relate to one another. ${ }^{136} \mathrm{An}$ institutional perspective permits closer investigation of the context, both domestic and international, in which states and other actors exercise power.

Interests - IntV (c): Norms are not causal ${ }^{137}$; however, they do inform interests and policy choices through identity, culture, and institutions. Interests are not given and competition amongst actor interests is the essence of political discourse. Although power factors may be present, interests and choices are often normative in nature when actors are faced with matters of choice and norms can be the deciding factor when ideology competes with materialistic concerns. Instrumental values are often employed in pursuit of a particular interest that is more ideological than material, even when justification is presented through materialistic arguments. As analysis of all stakeholder interests is beyond the scope of this paper, only those competing interests identified by actors or that pertain directly to the case studies identified through discourse analysis will be considered.

\footnotetext{
${ }^{136}$ Katzenstein, 1996b, p.56.

${ }^{137}$ Friedrich V. Kratochwil and John G. Ruggie, "International Organization: A State of the Art on an Art of the State," International Organization 40, no. 4, Autumn 1986, pp. 753-76.
} 


\subsection{Framework}

\subsubsection{Framing the Research}

The answer to the research question hinges on understanding the Canadian concept of national security and identifying the underlying ideational tenets. In offering a sociological perspective on Canadian policies of national security, this dissertation argues that security policy is defined by actors who respond to cultural factors. This does not diminish the use of power as a tool for analysis, but places material factors into social context. Positing external insecurities and threats as the necessary conditions for national security policies presupposes conceptual clarification of security. Despite my agreement with Buzan's widening of the security agenda, he and the Copenhagen School limit security to those threats that are 'about survival [and pose] an existential threat to a designated referent object." 138 This demarcation is too restrictive and leads to a priori value judgment of security as a policy objective. Accepting Wolfers assertion that security is a value in competition for other values, however, avoids the conflation of state security measures with the nebulous concept of threat perception and is testable.

Therefore to assess my core argument, I will first problematize the concept of national security that Wolfers identified regarding the subjective/objective sense of security and use Baldwin's operationalization of the concept for measurement. I will then develop and identify the referent object of this study from first principles as being an integral part of Buzan's state components - the society-polity nexus. Variations of

\footnotetext{
${ }^{138}$ Buzan et al, 1998, p. 21.
} 
society ${ }^{139}$ and polity as determinates are found in complex neo-realism and the two approaches to national security culture. To overcome the amorphous paradigm of political culture studies, I have adapted four criteria to form the basis for a theory of Canadian National Security Culture from which the determinants of political behavior will be developed and tested.

\subsubsection{Methodology}

Through the use of 3 case studies and process-tracing, a variety of factors will be identified to explain Canadian security policy post 9/11. To begin, two fundamental tasks need to be accomplished in this study. The first is to establish the norms and values of various explanatory factors and the dependent variable, Canadian security policy post9/11. The second is to determine the degree to which each of the factors influences the policy outcomes. In the first instance, describing most of the potential causal variables of Canadian security policies, such as material and institutional factors, is relatively unproblematic; however, the principal challenge will be in delineating Canadian National Security Culture, especially when it requires the specificity to have clear behavioral implications. ${ }^{140}$ Although a distinct political culture has been confirmed in various studies, the analysis has been too broad and inclusive to be able to clearly identify those norms, beliefs and values that have relevance to the formation of national security policy.

To overcome these obstacles to measuring Canadian National Security Culture, this research study will first narrow the problem set by using International Relations

\footnotetext{
${ }^{139}$ Katzenstein endorses this approach - "Conceiving the state in relational terms and investigating the domestic sources of foreign policy focuses attention on the degree to which identities of actors are constructed by state-society relations." - Katzenstein, 1996b, p. 50.

${ }^{140}$ See David J Elkins, "A Cause in Search of its Effect, Or what does Political Culture Explain?", Comparative Politics, Vol 11, No.2, 1979, pp.127-145.
} 
theory to operationalize the measurement of security as a value and then minimize the set of beliefs and norms to be studied to those that directly relate to the state-society-polity nexus. ${ }^{141}$ This will avoid the perception of creating a tautological argument in making inferences from behavior that confounds the dependent and independent variables. The first task will be accomplished by cross-referencing established scholarly works on Canadian political culture, foundational security norms, beliefs and values embedded in society and the Canadian polity will be exposed. This will elicit distinct national security norms and values that form the foundation of Canadian National Security Culture and lead to identifiable contemporary security preferences or national predispositions towards national security.

The second task is more complicated as this study only makes use of three related cases. The strongest format for testing case studies involves two basic methods. First, the congruence procedures format ${ }^{142}$ will be used to ascertain key areas of congruence and incongruence between the dependent variable and the observed values of the various independent/intervening variables predicted by the test hypotheses within and between the cases. Given the variety of possible explanatory variables and the indeterminacy of most theories, some policy elements may be consistent with multiple approaches.

\footnotetext{
${ }^{141}$ By using IR theory to operationalize the measurements and derive the linkage between the state and society-polity, this study will avoid the criticisms of Duffield's use of national security culture in World Power Forsaken and establish society-polity as an integral part of state-level analysis as elaborated in Chapter 2; Moravcik argues Duffield fails to derive a specific theory of political culture or international regimes from theory despite all the references to IR theory - see Andrew Moravcsik, "World Power Forsaken: Political Culture, International Institutions, and German Security Policy After Unification John S. Duffield Stanford: Stanford University Press, 1998, Pp. Xvi, 385," Canadian Journal of Political Science, Vol 32, No.2, 1999, pp. 402-404.

${ }^{142}$ Stephen Van Evera, Guide to Methods for Students of Political Science, Ithaca: Cornell University Press, 1997; Alexander L. George and Andrew Bennett, Case Studies and Theory Development, Cambridge: MIT Press, 2004.
} 
Therefore this study will employ the process-tracing approach ${ }^{143}$ for comparison and to analyze the linkages between potential causes and observed outcomes. Process-tracing involves exploring the chain of events or decision-making processes by which initial case conditions are translated into case outcomes.

The nature of the data being used will involve both primary and secondary sources. In forming a Canadian National Security Culture baseline, I will need to use descriptive inferences of national security culture from other valid references ${ }^{144}$ found in political culture literature to address Canadian specific norms, interests, identity, and culture, since true historical analysis of primary sources is beyond the intent of this paper. By focusing on congruent observations of security norms and cultural behaviour made in previous research on national security policy choices ${ }^{145}$ and triangulation of observations with process-tracing information taken from related time periods, this study will consolidate and validate the Canadian National Security Culture baseline within acceptable tolerance. In order to overcome the oversimplified view of identity relations revolving around the single axis of sameness and difference, I will employ the principal of relationality ${ }^{146}$ in discourse analysis. As Canadian identity is most often described in relation to the US, making use of the three dimensions of relationality vice the single axis

\footnotetext{
143 Ibid.

144 "Harvesting relevant information from others' data, although often overlooked, may often be the best way to obtain relevant information" - G. King, R. Keohane, and S. Verba, Designing Social Inquiry: Scientific Inference in Qualitative Research, Princeton: Princeton UP, 1994, p 477.

145 This is the approach taken by Keohane and Nye in Power and Interdependence.

${ }^{146}$ I will employ analysis of identity as produced through discourse that is espoused by Mary Bucholtz and Kira Hall (2005). They offer a general sociocultural linguistic perspective of understanding the intersubjective construction of identity where identity is emergent in discourse. Of the five principals that they outline, the most relevant to securitization is the relationality principal where they deconstruct the oversimplified view of identity relations revolving around the single axis of sameness and difference into three dimensions of relationality that they have termed tactics of intersubjectivity. By locating identity as an intersubjectively achieved social and cultural phenomenon in my discourse I will be able to expose the underlying intervening variables embedded in the Canadian national security culture during my analysis of the case studies.
} 
will provide the fidelity to explain the uniqueness of Canadian security norms in comparative literature.

From initial examination of post 9/11 security behavior in Canada, I will identify specific actors and institutions for in-depth analysis to determine which norms, identity and cultural factors likely framed the specific national security policies. Armed with an understanding of key aspects that affected these decisions, I will be able to ascertain the causal mechanisms that led to the development and inclusion of key policy pieces found in the National Security Policy statement and the factors involved in determining final outcomes. This will elicit a contextualized appreciation of the unique cultural aspects that influence national security policy formulation in Canada. I will consolidate my findings and compensate for potential bias through elite interviews with senior decisionmakers who were central to policy decisions made in the research period as well as current government executives responsible for security policy. In order to draw descriptive inferences from political culture and causal inferences about the determinant of political behavior from data of this nature, this study employs an interpretive method of analysis.

This research looks to expand the understanding of causal effects of the domestic security culture and identity on Canadian security policies. To explore endogenous processes and operationalize this research, this dissertation will draw on the work of Peter Katzenstein in order to explain the causal mechanisms related to the policy choices and the challenges with implementation found in my case studies. He considers states as abstractions since governments act, not states, and it is through adoption of policies that governments reinforce or modify state structures that in turn shape future governments 
and the policies they pursue. ${ }^{147}$ The analytical approach established by Katzenstein departs from the dominant materialist assumptions in contemporary national security policy analysis by arguing that:

a) security environments are part cultural and institutional rather than simply material; b) cultural environments shape state identity, which in turn affects state behaviour. Thus, unlike realism, power is as much about culture as it is about structure, and interests develop from identity, placing meaning ahead of materialism.

Analysis of domestic politics usually scrutinizes individual decision makers or bureaucratic organizations involved in policy formulation and implementation, which Katzenstein argues are shaped by norms, culture, and identities. In The Culture of National Security: Norms and Identity in World Politics, he establishes five causal arguments about shaping national security policy and interests that revolve around two basic social determinates - political identity and the cultural-institutional context of the political environment (both domestic and international environmental structures). He argues that "the concept of 'identity' functions as a crucial link between environmental structures and interest" as cultural-institutional contexts do not just shape and regulate actors, they also help constitute actor identity. The second social determinate is developed from neo-liberalism that provides a theory of the cultural-institutional context of the state when it defines regimes as a particular combination of "rules, norms, principles, and decision-making procedures." ${ }^{148}$ Katzenstein argues that rationality and material interests alone cannot explain compliance, but that the conception of actor

\footnotetext{
147 Katzenstein, 1996a, p 33. - "States are abstractions. They do not act. Governments do, and through their policies they reinforce or modify the state structures that in turn shape them and the policies they pursue".

${ }^{148}$ Robert Keohane, After Hegemony: Cooperation and Discord in the World Political Economy, Princeton: Princeton University Press, 2005, p. 8.
} 
interests and behavior are also shaped by the domestic cultural-institutional context in which the contestation of norms and values occurs.

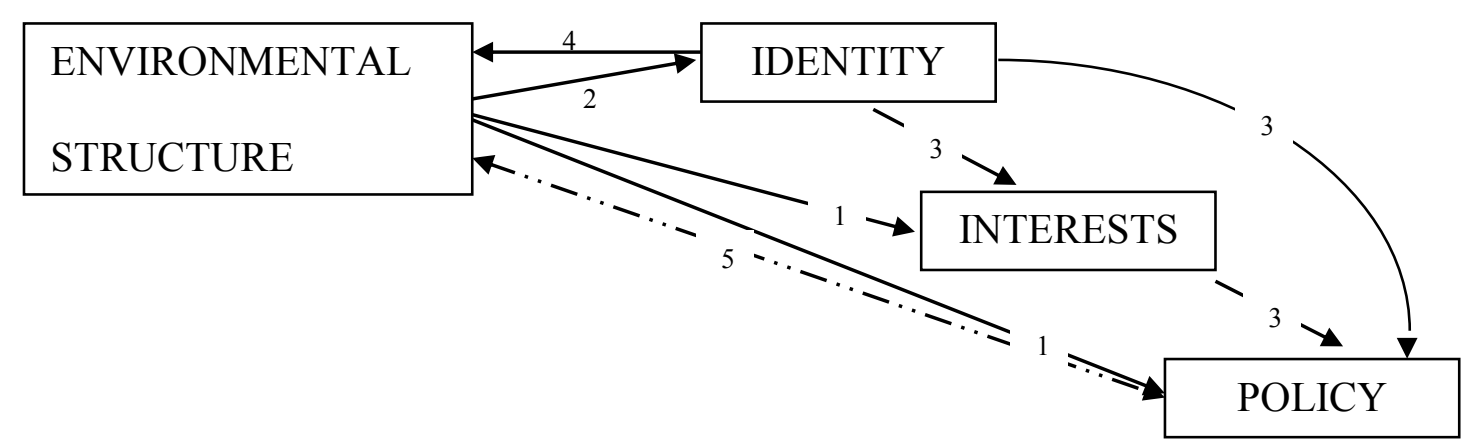

1. Effects of norms (I). Cultural or institutional elements of states' environments--in this volume, most often norms--shape the national security interests or (directly) the security policies of states.

2. Effects of norms (II). Cultural or institutional elements of states' global or domestic environments--in this volume, most often norms--shape state identity.

3. Effects of identity (I). Variation in state identity, or changes in state identity, affect the national security interests or policies of states.

4. Effects of identity (II). Configurations of state identity affect interstate normative structures, such as regimes or security communities.

5. Recursivity. State policies both reproduce and reconstruct cultural and institutional structure." The Culture of National Security $\quad$ http://www.ciaonet.org/book/katzenstein/katz02.html

\section{Figure 3: Lines of Argument ${ }^{149}$}

Katzenstein was very careful in presenting his theory as the culture of national security. He never uses the term 'national security culture', thereby avoiding the challenge of defining such an approach. Duffield considers 'national security culture' a sub-set of political culture where society as a whole and political elites in particular can be characterized as sharing well-defined set of fundamental beliefs and values that are of

\footnotetext{
${ }^{149}$ Katzenstein, 1996b, p. 52-53.
} 
potentially great relevance to national security policy". 150 "The overall effect... is to predispose societies in general and political elites in particular toward certain actions and policies over others." ${ }^{\prime 51}$ Unfortunately, Duffield eschews the constructivist approach, preferring to focus on elite behavior which prevents him from addressing the origins of the cultural system in a substantive way. ${ }^{152}$ This dissertation will fill the gap in understanding the genesis of the 'well-defined set of fundamental beliefs and values' that 'predisposes societies and political elites' towards national security preferences.

Similarly, 'national security culture' is simply defined according to four criteria used by Sperling to study international security governance ${ }^{153}$ but the concept is never actually defined. Therefore, this dissertation will define Canadian National Security Culture ${ }^{154}$ as the socially shared and transmitted ideas and beliefs within this collective identity that influence how Canadians perceive national security, security institutions, and the importance placed on security as an acquired value in competition with other acquired values. This leads to identifiable security preferences or national predispositions towards national security. Based on this definition, it is the intent of this dissertation to demonstrate that a Canadian national security culture exists through historical referencing and sociological analysis of norms and values using the prism of Katzenstein's determinants of security policy (identity, culture-institutional structure and interests) as

\footnotetext{
${ }^{150}$ Duffield, 1998, p.5

${ }^{151}$ Ibid, p. 25.

${ }^{152} \mathrm{Ibid}, \mathrm{p} 252$. "In contrast to constructivism, however, which stresses the potential malleability of state identities and interests and tends to reify the state, this study emphasises the potential stability of political culture as well as its location in society, or at least the political elite, rather than the state."

${ }^{153}$ Kirchner and Sperling, 2010, p.11.

154 This dissertation follows the conventional sociological usage of culture as a broad label denoting collective models of nation-state authority or identity, represented in custom or law.
} 
the construction of a national security culture represents historic recursive construction of national security norms, values, and beliefs.

After establishing a Canadian National Security Culture baseline of five sets of norms that shape security preferences, I will test for both material and ideational factors following Katzenstien's observable causal pathways in investigating the three cases of post 9/11 security policies that encompass both domestic and continental security. To provide an example of the process I will follow, I will use the Charter of Rights and Freedoms that is now part of Canadian identity and a structural variable that limits and constrains national security policy formulation. The creation and acceptance of the Charter was purely ideational in nature with no material causation. The intent of the Charter was to strengthen Canadian democracy, but also had the effect of unintentionally limiting the government's ability to address perceived threats through domestic contestation of acquired values. Through discourse analysis and process tracing methods, I will determine whether the causal paths in two of the case studies were affected in whole, in part, or not at all by the Charter or whether material aspects were more instrumental in determining the final policy outcome. I expect to uncover that the Trudeau Government's introduction of the Charter had unintended consequences on national security policy formulation and is an example of Katzenstien's "recursivity" causal pathway.

\subsubsection{Case Selection}

In order to demonstrate the empirical validity of this theoretical framework, it will be applied to and tested against the policy formation of specific Canadian security cases and subsequent implementation between 2001 and 2015. The first case I have chosen is 
the Martin Government's 2004 Securing an Open Society: Canada's National Security Policy statement. The second and third cases are the establishment of Marine Security Operations Centres (MSOCs) and the role of the bi-national North American Defence (NORAD) command in the defence of North America which are related but distinct. The National Security Policy statement case was selected as it was the official Canadian security response to the security threat posed by the $9 / 11$ attack and, as a unique national security statement, it has a number of dichotomous elements that will be explored. It is the only consolidated formal expression of Canadian national security policies produced by a Canadian government and, unlike expectations of traditional national security approaches, only refers tangentially to military and foreign policy issues.

The formulation of the National Security Policy statement and the subsequent actions provides a case of national security significance that facilitates assessment of threat perception, behavioral motivations and analysis of reactions. Along with the domestic nature of national security concerns, the cases represent security issues that intersect the domestic/ international divide, as well as overlapping interagency jurisdictions, providing holistic data points for comparison. These cases are also problematic as there appears to be no obvious existential threat based rationale for their inclusion / creation given the threat environment and the subsequent lack of progress in their implementation. As both the second and third cases involve traditional concepts of military-power policy formulation, their inclusion will ensure any material-power relationship and interest factors are revealed and considered.

Both the MSOC and NORAD cases are identified under the chapter on Transportation Security, where the key deliverables focused primarily on a six-point plan 
to strengthen Canadian marine security. Significantly, the National Security Policy statement links the international dimension of transportation security, "pursuing greater marine security co-operation with the United States"155, with the work of the Bi-national Planning Group (BPG) under the auspices of NORAD. The one common denominator in this comprehensive marine security plan is the formation of the Marine Security Operations Centres (MSOCs) that integrates five departments involved in national security into one operational unit, but its linkage to NORAD would not be revealed until two years later with the inclusion of a maritime warning role in the NORAD Agreement renewal. This dichotomous appearance of NORAD in the domestic chapter on transportation security rather than in the chapter on international security is both puzzling and revealing.

\subsection{Research Contribution}

This dissertation provides an original academic perspective in three ways: First, the theoretical framework develops a unique synthesis of the constitution of security issues that citizens believe are in need of state sponsored protection. Unlike existing studies of national security that ascribe universal concern with external existential threats to state sovereignty, this paper advances a first-principle based definition of national security originating from the expectations of Canadian society towards state sponsored protection, thus verifying the expansion of the referent object in security studies as well as exposing the distinctive relationship between society-polity and state. As external material threats are often simply risk factors to be assessed and considered, this dissertation proposes a definition of national security that addresses the inside/outside

${ }^{155}$ NSP, 2004, p. 35-36. 
dialectic that is unique to each state by advancing the concept of security as an acquired value that is determined endogenously within each state by society and the polity. Explanation of state security policy will be enhanced through a clearer understanding of embedded security norms and values that shape state behavior in matters of choice and possible options to pursue.

While this dissertation accepts Buzan's widening and deepening of the referent object in matters of national security, it challenges the conflation of society and state, "as state and society become increasingly indistinguishable," ${ }^{156}$ in People, States, and Fear's taxonomy of security levels. National security issues can be temporal and will vary over time; however, the policies that are adopted by society become institutionalized in the state, thus affecting future policy choices and options. Therefore, society and state must be dealt with separately in their symbiotic relationship as the construction of the state is dependent upon the society within which it is conceived. In framing this research through the Copenhagen School's expanding conception of security as a particular type of intersubjective politics, as well as through its security sector prism, this dissertation presents a more comprehensive understanding of national security as being primarily endogenous to the state and affected by exogenous factors.

Secondly, this dissertation is the only research work that analyses constitutive and regulative security norms embedded in identity and culture to explain the distinct Canadian National Security Culture that limits and constrains the policy options available to elite decision-makers. The power of the vote and the collective expectations of

\footnotetext{
${ }^{156}$ Buzan, PSF (91), 2009, p 52. This conflation is further supported in the paragraph on Levels of Analysis in Barry Buzan, Ole Wæver, and Jaap de Wilde, Security: A New Framework for Analysis, Boulder CO: Lynne Rienner Publishers, 1998, pp 6-7, where there is no mention of society in either the unit or subunit level.
} 
Canadian voters mean that the citizens of Canada have great influence on defining what constitutes 'national security', making political discourse a critical aspect in establishing voter preferences in a liberal democracy. According to Buzan, when political and special interests conflict with the perception of a threat to national security, the security interest issue must either be securitized as an existential threat, taking it above politics, or the policy will undergo scrutiny within the boundaries of established security norms, maintaining it in the realm of politics.

Buzan's analysis of individual security in Chapter One of People, States, and Fear is flawed in that he ascribes a uniform state model to an underspecified dialectic between security demands of citizenry and the resources/direction they provide the state. This omission was carried over in Security: A New Framework for Analysis, where the underspecified role of the audience further exacerbates development of securitization theory as it fails to account for variations in the determination of what constitutes an existential threat, i.e. variations in the securitization 'threshold' of audiences. This paper will demonstrate cultural variance in acceptance of securitization rhetoric.

This dissertation fills a gap in understanding the cultural specificity of securitizing a referent object, the reasons securitization theory is less applicable to Canada, and how culture matters when actors choose whether or not to present a threat as existential. Specific rational choice decisions made by the Canadian elite will entail political costs if securitizing a threat is required; otherwise, contestation of the ideational factors embedded within established institutions will determine the direction of a specific policy. Buzan believes that conventional constructivists see security as something to be explained and not as other deepeners believe, "a concept that is inherently contested and 
political". ${ }^{157}$ It is through the explication of security as an acquired value that is politically contested in Canada that Buzan's error in establishing his theory of national security becomes evident. The deepening he sought to explain through his turn to critical constructivism can be accomplished through conventional constructivism by empirically examining the political contestation of acquired values for state resources. This dissertation will demonstrate that explaining the security culture of the 'audiences' (society-polity) will provide a point of departure for deeper exploration of the political contestation of security.

Finally, this dissertation is the first in-depth, academic exploration of the National Security Policy statement as an expression of Canadian security concerns that require state protection. It establishes a widened concept of national security concerns that emanates from the domestic into the international arena. This is an important distinction as the majority of analyses of Canadian national security policies assume a traditional approach where the state is protected from perceived threats through defence and foreign policy decisions. Although a number of academics have written about the need for a Canadian national security strategy, they have all written from the perspective of the needs of elite decision-makers and stakeholders rather than that of the collective will of Canadian society. This dissertation fills a gap in understanding the Canadian political process that views national security as state sponsored protection of acquired values, in competition with other acquired values, rather than as protection from external threats. This sociological perspective can then be used in other theoretical approaches to assist in explaining of the effects and consequences of power and material factors.

${ }^{157}$ Buzan and Hansen, 2009, p 192. 


\subsection{Chapter Overview}

This dissertation is made up of seven chapters. While Chapter 1 provides the introduction, Chapter 2 develops the theoretical foundations for this research study. It first problematizes the concept of security through Wolfers' subjective lens and operationalizes his concept for measurement of security as a Canadian acquired value. The referent object for this study is then developed from Buzan's constructivist concept of national security in order to demonstrate its applicability to Canada. Unlike traditional accounts, Canadian society perceives national security threats less in terms of the military sector and more in terms of the societal and economic sectors due to predominantly US hegemonic concerns. Finally, in establishing the criteria needed for a theory of national security culture and by redefining security from first principles as the protection of acquired values, this chapter develops the concept of national security culture from first principles and provides the means to identify Canadian security norms and values in Chapter 3. This results in establishing Canadian National Security Culture for further use when operationalizing Katzenstein's culture of national security model.

Chapter 3 applies a historical sociological framework adapted from leading academic literature in developing a Canadian National Security Culture baseline that has varied over time. It uses secondary sources to identify and explicate documented Canadian constitutive and regulative security norms. Analysed under the prism of the three intervening variables (identity, culture / institution, and interests), the principal norms will undergo historical examination to demonstrate their origins and the process of preference construction. This chapter argues that, historically, Canadian society has 
approached national security within identifiable cultural traits that constitute national security preferences.

Significantly, national security has been seen as domestic and Canada has found creative ways in dealing with international security. By preferring to keep issues within the political 'rules of the game' and rejecting political discourse that portrays threats as existential, Canada has developed a national security culture that effectively protects society and the state from assimilation into the US. Secondly, an aversion to use of force to resolve social conflict has led to institutionalized processes that respect the 'rule of law' or established international norms as a means for conflict resolution. This chapter ends by identifying five sets of cultural traits that form the foundations of Canadian National Security Culture.

Chapter 4 begins by demonstrating that national security in Canada has historically referred to domestic security concerns and that over the past 50 years there has been a convergence of domestic and international security policies into one overarching policy in the form of the 2004 National Security Policy statement. The chapter then provides a description of the events of $9 / 11$ and the immediate reactions of both the US and Canada in order to put the National Security Policy statement into perspective. It will be shown that Canadian crisis management following the $9 / 11$ attack was not directed towards a perceived threat of terrorism, but more towards mitigating the immediate impact of American security reactions and preparing for the unintended consequences to Canada that would follow from inevitable changes in US security policies. Analysis of the National Security Policy statement provides evidence that contemporary Canadian National Security Culture reflects Buzan's argument for 
widening national security into five sectors and is an accurate summation of the security concerns where Canadians expect state sponsored protection of acquired values.

Chapter 5 explores the establishment and implementation of the MSOCs. The chapter begins with establishing marine security as an acquired value and traces the specific crisis management measures taken by the Martin Government that led to the development of the MSOC policy. Findings of the Auditor General of Canada that the MSOCs had fallen short on the National Security Policy statement vision illustrated the challenges, particularly with respect to significant problems in sharing data and information due to the government's inability to balance privacy with national security concerns. Examination of each partner department identifies the source of the problems as unexpected legal complications with the Privacy Act and cultural / institutional resistance to finding solutions to governance issues and the lack of mandates that were outside established norms.

Chapter 6 analyses the issues and events surrounding the 2006 NORAD Agreement renewal and the subsequent role of NORAD in the reconstruction of the North American security complex. The chapter establishes NORAD as a unique institution and follows its evolution from realist to constructivist paradigms where NORAD has become part of both Canada and American security identity. Although the renewal of the agreement in perpetuity was initially an exercise in political reassurance that eliminated a domestic political irritant, the chapter argues that Canadian National Security Culture rejected American overtures for an 'enhanced continental NORAD' and set about constructing a bilateral security complex that met Canadian national security norms. It then examines the process and reasons for including a new Maritime Warning mission in 
the agreement and the ideational reasons for the lack of progress in implementation.

Ultimately, the new Tri-Command (NORAD-NORTHCOM-Canada Command) security complex met the initial intent of an 'enhanced NORAD', but in a more bilateral fashion that preserved both nations' sovereignty concerns.

Finally, the dissertation concludes in chapter 7 with an overview of the theoretical framework and a summary of the case study findings. 


\section{Chapter: National Security Culture: Bridging The Theoretical Gaps}

\subsection{Changing the Paradigm}

The purpose of this chapter is to explicate the theoretical basis from which the operationalization of this study is founded. Although there is broad acceptance that national security studies needs to be deepened, there has been reluctance to expand the levels of analysis and disaggregate the unit known as the 'state' in the empirical literature on security culture. National security culture literature is primarily written from an IR perspective, using state security culture to explain state foreign policy decisions. ${ }^{158}$ Domestic factors are rarely researched deeply nor addressed in a substantive manner ${ }^{159}$, particularly with respect to Canada. This is a mistake, as the state is only a reflection of the security norms embedded in its institutions and projected by its behaviour. To truly explain a state's national security behavior in a liberal democracy like Canada, one must understand the ideational limits that society places on state sponsored security, and the institutional constraints applied by the polity to the decision-makers who represent the state. This aggregate, in effect, defines the 'nucleus' of the state that will be explicated in this chapter and the associated security norms and values that constitute the national security culture of a state.

This chapter problematizes two theoretical assumptions that dominate contemporary analysis of national security, perception of threats (the motivation behind resource extraction for national security) and the nature of the state as a referent object

\footnotetext{
158 Srdjan Vucetic, The Anglosphere: A Genealogy of a Racialized Identity in International Relations, Stanford: Stanford University Press, 2011; Emil Kirchner and James Sperling eds, National Security Cultures, New York: Routledge, 2010; Peter J Katzenstein, Cultural Norms and National Security: Police and Military in Postwar Japan, Ithaca, N.Y: Cornell University Press, 1996a.

159 Theo Farrell, “Constructivist Security Studies: Portrait of a Research Program”, International Studies Review, Vol 4, No.1, 2002, pp. 49-72.
} 
(disaggregation into its constituent parts). It examines the concept of security as a determinate of national security and how ideation can be the principal determinant in Canada's national security policy outcomes. The chapter begins with a critical examination of the concept of security based on Wolfers' critique of national security and Baldwin's operationalization to form the basis for analysis into Canada's perception of national security. Next, the state will be disaggregated into Buzan's four constituent parts in order to deepen the analysis beyond the 'shell' of the state. This will lead to an understanding that Canadian national security should be viewed and analyzed as an acquired value through society-polity as the referent object. Finally, the theoretical foundation for Canadian National Security Culture theory will be explicated.

Defining and redefining 'security' is a recurring event in academia. In reality, the discussion surrounding this 'essentially contested concept' 160 is no different than other 'contested' debates that draw on epistemological, ontological, and methodological divergences. "Theory is always for someone, for some purpose ${ }^{161}$," and the following review of national security literature will illustrate national security is "the product of a historical, cultural, and deeply political legacy." ${ }^{\prime 162}$ Most theories begin by privileging a predetermined interest or value ascribed to a referent object when defining national security. Conceptual explication is an essential component of this research design as it specifies the logical structure of the stated idiom (Canadian National Security Culture) that allows for the application of theory in the development of the hypotheses and the

\footnotetext{
160 Ibid

${ }^{161}$ Robert Cox, "Social Forces, States and World Orders: Beyond International Relations Theory" Millennium - Journal of International Studies, Vol 10, Issue 2, 1981, pp. 126-155.

162 Michael C Williams, Culture and Security: Symbolic Power and the Politics of International Security, New York: Routledge, 2007, p. 17.
} 
measurement of empirically observable variables. ${ }^{163}$ To understand the essence of security and avoid a taxological predisposition, I begin with Arnold Wolfers' prescient analysis of "National Security as an Ambiguous Symbol"164 as this represents the first attempt to provide serious conceptual debate on the meaning of state sponsored security.

\subsubsection{Wolfers' Problematization}

Writing in the early 1950s, Wolfers examined the basic assumptions of his era regarding the concept of security and the policies that states developed under the auspices of 'national interests' and 'national security'. His stated concern was that without a precise meaning attached to these idioms, it would permit anyone using them to imply that their proposed policy was so important that it subordinate other interests to those of the nation. He stated that due to the Cold War security environment, "the formula of the national interests has come to be practically synonymous with the formula of national security"165 and this national security 'symbol' suggests protection through power. By appealing to policies guided by national security, it is being assumed that the nation has made security its principal goal which Wolfers argued is not necessarily the case.

Wolfers defines security as a national value that is variable along the spectrum from complete insecurity to complete absence of fear. In an objective sense, security can be measured by the absence of threats to acquired values, and in a subjective sense, it is the absence of fear that such values will be attacked. ${ }^{166}$ The majority view of the era held

\footnotetext{
${ }^{163}$ J. Manheim, R. Rich, L. Willnat, and C. Brians, Empirical Political Analysis: Research Methods in Political Science, 6th ed., New York: Pearson Longman, 2007, Chapter 5.

${ }^{164}$ Arnold Wolfers, “'National Security' as an Ambiguous Symbol”, Political Science Quarterly, Vol 67, No. 4, December 1952, pp. 481-502.

${ }^{165}$ Wolfers, 1952, p. 482. In his first footnote, Wolfers assesses Hans Morgenthau's plea for American foreign policy to follow the National Interest as equating to national security interest where security is based on power alone.

${ }^{166}$ Ibid, p. 485.
} 
that national security could be objectively measured according to a state's geography, its military strength and the military capabilities of its competitors. However, Wolfers argued that the intentions of the other can never be measured objectively despite perceived indictors and the matter of potential aggression remains the subjective evaluation and speculation of leaders. ${ }^{167}$

In building his subjective/objective case, Wolfers invokes what can be considered today as ideational /material arguments. "It is a well-known fact that nations, and groups within nations, differ widely in their reaction to one and the same external situation..... Even if for no other reasons, this difference in the reaction to similar threats suffices to make it probable that nations will differ in their efforts to obtain more security."168 This ideational reference to threat perception and his later discussion on subjective reaction to the threat environment led him to conclude that the amount of security required was not determined by the external factors but by the nation itself based on its system of values.

National leaders determine the intentions of their neighbours / competitors and how to address any fears or concerns. These decisions are based on the leaders' subjective perception of threats to their nation's core values and their choices "will depend on a multitude of variables, including ideological and moral convictions, expectations concerning the psychological and political developments in the camp of the opponent, and inclinations of individual policy-makers." 169 All policy choices involve

\footnotetext{
${ }^{167}$ Development of this point continues to be the subject of much perception literature. See Robert Jervis, Perception and Misperception in International Politics, Princeton, N.J: Princeton University Press, 1976; and Janice Gross Stein, "Threat Perception in International Relations", in Leonie Huddy, David O. Sears, and Jack S. Levy, eds., The Oxford Handbook of Political Psychology, 2nd ed, Oxford: Oxford University Press, 2013.

168 Ibid, p. 485.

${ }^{169}$ Wolfers, Discord and Collaboration: Essays on International Politics, Baltimore: The John Hopkins Press, 1962, p. 156.
} 
degrees and tolerance of risk for which the leader holds ultimate responsibility. Should a nation pursue an objective policy of complete military security, its actions will create what Hertz described as a 'security dilemma' ${ }^{170}$ with its competitors thereby precipitating an arms race which, in a subjective sense, may result in less security.

In confronting a security threat, Wolfers stated that a nation has a number of noncoercive means at its disposal, such as negotiation through diplomacy and the use of international regimes, to induce an opponent to give up its aggressive intentions. This is not only the most cost-effective manner to achieve security but it is a stronger guarantor of security through satisfying the legitimate demands of others and morally superior when weighing the "calls for the sacrifice of other values, as any security policy is bound to do."171 Significantly, Wolfers pointed out that security is not cost-neutral and that every increment of security entails the sacrifice of other national values. At a certain point, the nation faces the economic law of diminishing return where the costs in achieving absolute security are no longer worth the expense. Wolfers describes security as a negative value for the burden it places on a nation and as a consequence nations will seek the lowest level of security that provides adequate protection. Importantly for this dissertation, he identifies "numerous domestic factors" that influence the level of security chosen. For states where the fear of attack is low, some nations will seek protection for more marginal values. This weighing of values requires normative judgment on the part of leaders with input from the "numerous domestic factors".

In challenging the contemporary, power-centric view of national security in his day, Wolfers advanced the concept of security in a number of ways and addressed some

\footnotetext{
${ }^{170}$ John Herz, Political Realism and Political Idealism, Chicago: University of Chicago Press, 1951, p. 4.

${ }^{171}$ Wolfers, 1951, p. 498.
} 
of the fallacies of his time. In focusing on the subjectivity of security, he highlighted the ideational aspects in perception of a threat and the manner in which a nation may choose to deal with this threat. Fear, uncertainty and risk are critical in determining the amount of security a state requires. Secondly, Wolfers expresses the symbiotic relationship between the nation (state/society/polity) and leadership in determining the level and nature of national security required by the state. By presenting national security as a negative value that does little to contribute to a nations wellness, he highlights the fact that security policy is "a subject for moral judgment"172 when other values are sacrificed at the altar of national security. Finally, Wolfers demonstrated that absolute security is theoretically unachievable and that security could be a means to an end rather than an end in itself. Although international regimes were no substitute for military strength, long term diplomatic efforts to balance international security concerns could be the most expedient means for the purpose of enhancing security.

\subsubsection{Operationalizing Wolfers' Concept}

It is important to note that, perceptive as Wolfers' article was, his goal was simply to highlight the ambiguity in the term 'national security' and the potential misuse of the concept as a means to its pursuit through policy. With security studies focusing on the Hobbesian nature of the military build-up during the Cold War period, there were sporadic attempts at redefining security over the next 30 years ${ }^{173}$ within the militaryforeign policy paradigm before Barry Buzan published People, States, and Fear: The National Security Problem in International Relations (1983). He argued that security

\footnotetext{
172 Ibid, p. 498.

${ }^{173}$ Barry Buzan, People, States \& Fear: The National Security Problem in International Relations, London: Harvester Wheatsheaf, 1983; Richard Ullman, "Redefining Security," International Security, Vol 8, No. 1, Summer 1983, pp. 129-153.
} 
studies could not solely focus on military force and that security was not just about states, but related to all human collectivities. In line with Wolfers' assertion that national security had a greater subjective dimension, this attempt at 'widening and deepening ${ }^{174}$, the concept of national security had much to offer, but was viewed as somewhat utopian until the collapse of the Soviet Union. ${ }^{175}$ Following the failure of the principal theories on national security to predict the end of the Cold War, the debate on redefining security was reinvigorated. David Baldwin challenged the various normative and empirical conceptions of security argued by Buzan ${ }^{176}$, Richard Ullman, and others ${ }^{177}$ in an essay, "The concept of security". In it he developed a set of 'specifications' for the concept of national security, demanded by Wolfers, from first principles by essentially addressing two questions, security for whom and security for which values?

By reformulating Wolfers' portrayal of security as "the absence of threats to acquired values" 178 into contemporary terminology as 'a low probability of damage to acquired values', Baldwin decouples the military-centric threat security matrix implicit in traditional security studies which in turn allows for discussion of an expanded concept of national security by focusing on the preservation of acquired values, rather than on preconceived threats to the integrity of the state. This approach provides for inclusion of

\footnotetext{
${ }^{174}$ Although this study focuses on Buzan's challenge to military state-centrism, the distinct widening and deepening perspective can be found under many labels: Constructivism, Human Security, Post-colonialism, Critical Security Studies, Post-structuralism, and Feminism.

175 Steve Smith, "Mature Anarchy, Strong States and Security," Arms Control, Vo1 12, No 2, 1991, p. 325.

${ }^{176}$ Buzan produced a revised publication of People, States, and Fear in 1991, People, States, and Fear: An Agenda for International Security Studies in the Post-Cold War Era.

177 J. Ann Tickner, "Re-visioning Security", in Ken Booth and Steve Smith, eds., International Relations Theory Today, Oxford: Oxford Press, 1995, pp. 175-97; Ken Booth, "Security and Emancipation", Review of International Studies, Vol 17, 1991, pp. 313-26; Martin Shaw, "There Is No Such Thing as Society: Beyond Individualism and Statism in International Security Studies," Review of International Studies, Vol 19, 1993, pp. 159-75.

178 Wolfers, 1951, p 485.
} 
security policies that do not directly address perceived security threats but provide security through risk management and lowered probability of damage, an important aspect of the 'spectrum of national security' that will be developed later in chapter 3 of this dissertation . Baldwin posited seven questions that form the specifications for defining security as a policy objective applicable to each state that will be used to operationalize the subjective analysis of national security in this study.

The first question, 'Security for whom?', addresses the specificity of the referent object and he argues that the choice will be dependent on the research question being asked. He points out that Buzan's explication that the 'search for a referent object must go hand in hand with that for its necessary condition, ${ }^{\text {, }}{ }^{179}$ confuses conceptual specification with empirical observation. In fact, the answer to the question, 'Security for whom?', according to Baldwin is applicable to any level of analysis (individual, family, society, state, international system, or humanity) depending on the question.

In asking, 'Security for which values?', Baldwin addresses Wolfers' distinction between objective (absence of threats to acquired values) and subjective (absence of fear or peace of mind) dimensions of security as a set of values that can be specified if a researcher chooses to do so given the question being answered. Importantly, this specification should not be made in terms of 'vital interests' or 'core values' as this makes an a priori value judgment of security as a policy objective that prejudices comparison of security with other policy objectives. Although these two specifications form the basic concept of security, five additional specifications are required to make alternative security policies comparable and with policies for pursuing alternative goals.

\footnotetext{
${ }^{179}$ Barry Buzan, People, States \& Fear: An Agenda for International Security Studies in the Post-Cold War Era, Second Edition, Colchester, UK: ECPR Press, 2009 (PSF (91)), p 26.
} 
In recognition of Wolfers observation that absolute security is unobtainable and that it comes at a price, Baldwin states the need to ask the interrelated question of 'How much security and at what cost?' Security must be conceived as a matter of degree as states must allocate limited resources among competing interests and values. This set of questions then begs the question of 'From what threats?' Threat perception is not a universal sensory phenomenon that provides unquestioned cognitive understanding and representation of the environment. Threats to acquired values come in many forms that only the referent object can correctly identify since the tolerance for risk is idiosyncratic. ${ }^{180}$ Common usage and arguments for the widening of the concept refer to pandemics, natural disaster and other non-coercive phenomena as threats to acquired values that are in need of protection and therefore the researcher needs to specify this dimension of security for clarity. ${ }^{181}$

Wolfers devoted considerable attention to the fact that perceived threats can be dealt with in many ways that do not exacerbate a perceived threat and can be accomplished through a more cost-effective means than military build-up. Therefore, unless a researcher specifies 'By what means?', the tendency is to prejudice the discussion of security policy in favour of traditional military solutions. The last specification is to identify 'In what time period?' Short term policies to perceived security threats may be counterproductive to the long term solutions to acquired values.

\footnotetext{
${ }^{180}$ See Mathias Albert, "From Defending Borders towards Managing Geographical Risks? Security in a Globalized World", Geopolitics, Vol 5, No.1, 2000; Global Society, Special Edition: "Risk, Globalisation and the State: A Critical Appraisal of Ulrich Beck and the World Risk Society Thesis," Vol 21, No.1, 2007. ${ }^{181}$ These widening phenomena appear as security issues in the National Security Policy statement that will be presented in the case study, Chapter 4.
} 
In articulating a concept of security in this manner, Baldwin meets the demand for specification within Wolfers' conceptual framework in a way that allows the researcher to tailor the explication of security to the question being asked about a specific referent object. As resource allocation is a fundamental political pursuit, ${ }^{182}$

security is only one of many policy objectives competing for scarce resources and subject to the law of diminishing returns. Thus, the value of an increment of national security to a country will vary from one country to another and from one historical context to another, depending not only on how much security is needed, but also how much security the country already has. ${ }^{183}$

Thus, political security, military security, environmental security, economic security and social security espoused in People, States, and Fear are different forms but not different concepts of security.

\subsection{Widening and Deepening National Security}

\subsubsection{Establishing the Referent Object}

In developing the concept of national security in the Canadian context that addresses the research question of this dissertation, I begin again with Wolfers who makes clear that national security policy is the purview of the 'nation' for which it is intended to protect ${ }^{184}$. The concept of nation, as used by Wolfers, was consistent with its usage of the era and combines the notions of society, state, and elite statesmen. ${ }^{185}$ Thus, it is important to determine which one, or combination, of these elements comprise the

\footnotetext{
${ }^{182}$ Wolfers, 1951; Frederick S. Dunn, 'The Present Course of International Relations Research', World Politics, Vol 2, 1949, p. 94; Bernard Brodie, "Strategy as a Science”, World Politics, Vol 1, 1949, pp. 46788; Charles J. Hitch, 'National Security Policy as a Field for Economics Research', World Politics, Vol 12, 1960, pp. 434-52.

183 Baldwin, 1997, p. 21

${ }^{184}$ Wolfers, 1951, p 481, "[National Security] emphasizes that the policy subordinates other interests to those of the nation" and p. 484, "Security is a value, then, of which a nation can have more or less...".

${ }^{185}$ See Hans J. Morgenthau, Politics Among Nations: The Struggle for Power and Peace, $5^{\text {th }}$ ed. New York: Alfred A. Knopf, 1973, Chapter 8 “The Essence of National Power”, pp103-111for a good understanding of the complex notion of the 'nation' prevalent in the 1950s and 1960s.
} 
'nation' ${ }^{186}$ in order to be used as the referent object in answering the question, 'Security

for whom?' Using the 'state' as the referent object has provided inadequate causal explanation ${ }^{187}$ for security policies of liberal democracies as the state does not possess values, it represents them. Secondly, a focus on elite decision-makers leads to methodological individualism which does not explain the relative consistency in state policy choices over time, nor the limits and constraints imposed on these policy decisions by the society which they represent.

Although Alexander Wendt famously stated that 'states are people too" ${ }^{188}$; states are simply the receptacle and purveyor of national security norms. It is Canadian society for whom national security policies are designed to provide state protection for acquired values. Canadian society sets the conditions for debate on national security issues and it is the Canadian polity that determines and articulates the norms that are embedded within the state structure that limit and constrain policy choices. ${ }^{189}$ Elite decision-makers make

\footnotetext{
${ }^{186}$ I generally try to avoid using the term 'nation' as it adds to the confusion of identification with a cultural group rather than a territorial community, however, at times it is the most appropriate descriptor of the Canadian human collective. See Ernest Gellner, Nations and Nationalism, Ithaca, NY: Cornell University Press, 1983; Liah Greenfeld, "Varieties of Nationalism", in Brown, Bernard E. ed., Comparative Politics: Notes and Readings, Belmont, CA: Wadsworth, 2006, 96-99. Although its use in the traditional sense is supported by Jack Snyder, From Voting to Violence: Democratization and Nationalist Conflict. New York: Norton 2000, p. 23. 'Nationalism' is different from 'ethnicity'. It is "the doctrine that a people who see themselves as distinct in their culture, history, institutions, or principles should rule themselves in a political system that expresses and protects those distinctive characteristics. A nation is, therefore, a group of people who see themselves as distinct in these terms and who aspire to self-rule."

${ }^{187}$ Peter J Katzenstein, Cultural Norms and National Security: Police and Military in Postwar Japan, Ithaca, N.Y: Cornell University Press, 1996a, p.33. "States are abstractions. They do not act. Governments do, and through their policies they reinforce or modify state structures that in turn shape them and the policies they pursue."

${ }_{188}$ Alexander Wendt, Social Theory of International Politics, Cambridge: Cambridge University Press, 1999, pp. 215-223.

${ }^{189}$ See Robert Boyd and Peter J. Richerson, "Norms and Bounded Rationality", pp. 281-296, and Joseph Henrich, "Group Report: What is the Role of Culture in Bounded Rationality?", pp. 343-359 in Reinhard Selten and Gerd Gigerenzer, Bounded Rationality: The Adaptive Toolbox, Cambridge, Mass: MIT Press, 2001.
} 
moral judgments within constraints ${ }^{190}$ and are held accountable by the power of the electorate for the choices they make on behalf of the state. It is Canadian society through its institutions and processes located in the polity that has and will provide the answers to the remaining conceptual questions.

Rather than using a taxonomy of 'core' values, which portends a level of subjectivity, this study operationalizes the concept of values by differentiating observed 'intrinsic' values (those values which define Canadian identity as an end-in-itself) from 'instrumental' values (those values which are used as a means to the end of achieving intrinsic Canadian values). 'Acquired' values are the aggregate of values that are embedded in society and generally the focus of political contestation within the polity as they range in strength. Intrinsic values are consistent over time while instrumental values vary ${ }^{191}$ and are used by decision-makers to justify and validate their 'moral judgment'. Over time ${ }^{192}$, Canadian society has established 'which values' are important enough for state protection and have developed identifiable security norms that limit and constrain threat perception, acceptable costs, and the means by which the state is able to deal with security issues. In other words, domestic security norms shape state preferences. The relationship between society, culture and polity in liberal democracies has deep roots in both comparative and IR literature. ${ }^{193}$ It is from this aspect that I will first problematize Buzan's development of the state as a referent object, and then reorient his widening /

\footnotetext{
${ }^{190}$ See Kersey, Constrained Elitism and Contemporary Democratic Theory, 2016.

${ }^{191}$ Instrumental values will vary from ideological predispositions of decision-makers to those preferred and imposed by the nation. This is the fundamental nature of the party system in a liberal democracy.

192 Wolfers, 1951, for previously acquired values see p. 484.

193 Seymour Lipset (sociologist), Kathleen Hall (new institutionalist), Robert Putnam (comparativist), Martin Shaw (IR), Peter Katzenstein (comparativist/IR), Louis Hartz (sociologist), Hedley Bull (IR), Gabriel Almond and Sidney Verba (comparativists) to name a few.
} 
deepening of the national security concept towards a constituent component of the state, society-polity, prior to developing the theory of Canadian National Security Culture.

\subsubsection{Essence of the State}

In 1983, Barry Buzan challenged the mainstream, realist military-centric perception of security and proposed a comprehensive theory of national security in his book, People, States, and Fear: The National Security Problem in International Relations (83) He started from first principles ${ }^{194}$ in developing his constructivist concept of security by differentiating it from the extremes of power and peace, which he stated were foundational in the traditional works of Realists and Idealists. ${ }^{195}$ Having established this theoretical baseline, Buzan set out to develop his own fully articulated framework based on this revised concept of security. He began with distinguishing between individual security and national security which he sees as incommensurable. ${ }^{196}$ Individuals face a myriad of threats that span the spectrum of health, poverty, injury, crime, and other social afflictions to which they can never be fully protected. ${ }^{197}$ They look to the state to reduce their insecurity and the state obliges through institutional programs that reduce the impact of hardships. In return for protection from other individuals, the state promises to provide deterrence and punishment to transgressions in exchange for limits on personal liberties and freedoms.

\footnotetext{
${ }^{194}$ It is Buzan's development of the state as a referent object from first principles that provides the framework for reassessment and revision of his basic logic for use in this study.

${ }^{195}$ Buzan PSF (91), 2009, p. 25-42. For a deeper explanation see, Barry Buzan, "Peace, Power, and Security: Contending Concepts in the Study of International Relations", Journal of Peace Research, Vol 21, No. 2, 1984.

${ }^{196}$ According to Baldwin, Buzan made the error of conflating security with national security through weaving conceptual analysis with empirical observation in distinguishing between individual and state security. Hence Baldwin's reconceptualization of security as a set of specifications used in this dissertation - David Baldwin, "The Concept of Security", Review of International Studies, Vol 23, No.1, 1997, p. 7.

${ }^{197}$ Buzan PSF (91), 2009, p. 2.
} 
The state is also expected to protect the individual from external threats and as such the state demands sacrifices from its citizens in the name of national security in the form of taxes, military service, and limits on freedoms and liberties. It is at this point where individual security and national security intersect; where "the security of individuals is inseparably entangled with that of the state." 198 Having to address both domestic and external security concerns through extraction of individual resources and imposition of limits on individual freedoms, the state is ontologically independent and separate from individuals with its own security concerns. Having established that the state is an independent entity, Buzan then proceeds to determine the attributes that define the essence of the autonomous political unit called the state.

According to Buzan, the state is a package of territory, polity, and society with three component parts (a physical base, ideas, and institutions) that are held together through the principle of sovereignty. These represent the metaphysical and concrete elements of the state and comprise the four elements that require state protection through national security. Following the Westphalian principle of territorial integrity, the physical base comprises a defined territory, resources and citizens and its protection is traditionally the most important national security function of the state. Protection of the physical base is a military task for which resources are extracted to create and maintain military power for both defensive and offensive use. Anarchy in the international system demands that states be capable of preventative use of force to ensure enemy forces are not able to inflict damage once deployed. However, the physical base does not constitute the entirety of the state and loss or damage to the state-body does not

\footnotetext{
${ }^{198}$ Ibid, p. 51.
} 
necessarily affect its survival as much as such a loss to the individual. ${ }^{199}$ To Buzan, this means that national security must also aim to protect the non-material or ideational elements of the state.

The idea of the state is a major object of national security to Buzan since "[i]t is the idea of the state that both provides the major bindings holding the territorial-politysociety package together, and defines much of its character and power as an actor in the international system." ${ }^{200}$ Hence this notion of purpose distinguishes ideas from the state's physical base and its governing institutions. The two main sources for the idea of the state are found in a state's concept of 'nation' and in organizing ideologies. To overcome the narrow interpretation of nation as a homogeneous group of people sharing the same cultural and ethnic heritage, Buzan explores national identity as the central component of the security problematique. In exposing the concept, he proposes four nation-state models that articulate the complex relationships found between nation and state. However, due to his superficial view of the construction of the state-society-polity relationship his taxology is flawed. In the multinational-state model that internally contains two or more substantially complete nations and represented by Canada, ${ }^{201}$ Buzan believes " $[\mathrm{s}] \mathrm{uch}$ states have no natural unifying principle and consequently are more vulnerable to dismemberment, separatism and political interference than are nation-

\footnotetext{
199 Ibid, p. 69.

${ }^{200}$ Ibid, p. 70 .

${ }^{201}$ This is a very flawed concept of Canada as shared values of multi-ethnic communities can forge a state that is stronger than the ethnic cleavages that may generate forces of division. Switzerland is a prime example of this as well as Canada. Buzan is mistaken in his assumption that state-nations such as the US and Great Britain are any less susceptible to dismemberment and political interference than other states. Scotland has a very vibrant separatist political cleavage that has been compared to that of Quebec's nationalism.
} 
states."202 As will become apparent in this dissertation, this assertion is too simplistic and conceptually faulty. ${ }^{203}$

As the concept of nation may be essential, a state's organizing ideology provides insights into other security implications as these notions of purpose tend to be less deeply rooted and more susceptible to disruption. Although organizing ideology is never precisely defined, Buzan explains that many forms of political, economic, religious and social ideologies can underpin the state. This ideological foundation will be closely connected to the state's institutional structures. Some organizing ideologies are foundational to the nation, such as the United States, whereas others are transitional, associated with changes in leadership, and have shallow roots amongst the population. They may represent various convictions about means to achieving state goals, such as material prosperity, or represent differing ideational ends. Thus a firmly established nation will evolve and reproduce itself through cultural transference to the young, making transformative change extremely unlikely. ${ }^{204}$ However, political organization is more fragile and susceptible to insecurity.

Regardless of the chosen organizational ideology, the independent ontological status of the state requires that this 'idea' be protected as a national security issue for the preservation of the state. Insecurity presents itself in many forms, particularly "if the ideas themselves are weak; or if they are weakly held within society; or if strongly held, but opposed, ideas compete within society: then the state stands on fragile political

\footnotetext{
202 Buzan PSF (91), 2009, p. 78.

${ }^{203}$ Buzan equates temporal political contestation of Quebec with national weakness rather than with strong liberal democratic processes. "Unless the idea of the state is firmly planted in the minds of the population, the state as a whole has no firm foundation."- Buzan PSF (91), 2009, p. 79.

204 Buzan PSF (91), 2009, p. 80.
} 
foundations." ${ }^{205}$ Domestic dissatisfaction with state policies, revolutionary groups with opposed ideologies, transnational actors, or foreign governments may attack the organizing principles of the state. Although Buzan argues that domestic security deals with threats to individuals from individuals, it is not the origin of the threat that makes organizing ideology a matter of national security, but the fact that the threat targets the state as an entity. Since organizing ideologies are so closely tied to state institutions, Buzan chooses to deal with their security side in the institutional component of the state.

The final component of the state are the institutions that "comprise the entire machinery of government including its executive, legislative administrative and judicial bodies and the laws, procedures, and norms by which they operate."206 Although essential to government processes, it is the interrelationship with organizing ideologies that Buzan sees as the critical aspect in national security. Institutions are crafted to reflect the organizing principles of the idea component of the state, such as the British North America Act that defined the organizing ideology of Canada and the subsequent government institutions that comprise the machinery of government. Institutions can be modified or destroyed more easily than ideas and, as more tangible objects than ideas, institutions are more vulnerable to physical threat by virtue of their physical existence.

The interdependence of organizing ideologies and institutions means that institutions are also objects of national security as the principles they reflect. As with the physical base, institutions can be overcome with physical force so military defence is the obvious solution. However, societies are never completely homogeneous in all respects and competing ideologies will and do exist. Protecting the ideological aspects of an

\footnotetext{
${ }^{205}$ Ibid, p. 80.

${ }^{206}$ Ibid, p. 83.
} 
institution is more complex as governing institutions do evolve without interrupting the continuity of the state. However, foreign interference in each other's domestic politics is the norm in international behaviour and constitutes an internal threat to national security when advanced by proxy. ${ }^{207}$ Recently, transnational threats from terrorist organizations as well as from economic market forces due to globalized interdependence have increased state institutional insecurities.

Sovereignty is the fourth element in Buzan's definition of the state. He defines it simply as self-government. It is essential as "Sovereignty provides the crucial element that divides states from all other social units. It is the glue that binds the territorial-politysociety package together." ${ }^{208}$ Without sovereignty over the three components of the state, a state is not self-ruling and is merely a 'country' or conquered territory. Sovereignty is the highest form of human collective such that it exercises supreme authority over the affairs of the state and therefore it is central to political analysis. Buzan argues that states may be similar, but the differences can be enormous and therefore cannot be seen as 'like-units'. Beside diversity in observable material factors, sovereignty over the state components also varies in degree amongst states. Sovereignty indicates choice, and its application explains differences and why the concept of national security will be as diverse as the different states to which it applies. ${ }^{209}$

\footnotetext{
207 The interdependent relationship of the Canada-US economies embodies the non-aggressive, no malintended convergence of interests that challenges the acquired values of an independent, sovereign state. Foreign interference appears in many guises and not all are politically based.

208 Buzan PSF (91), 2009, p. 72.

${ }^{209}$ Ibid, pp. 72-73.
} 


\subsubsection{Widening National Security}

In exploring the insecurities of the state as a referent object, Buzan analysed the threats and vulnerabilities of the four elements that comprise the state. He surmised a state has two options with respect to security policy; insecurities can be reduced by either reducing their vulnerability or by preventing threats. In assessing vulnerabilities, Buzan categorizes states as weak or strong in two areas, power and socio-political cohesion. However, he identifies two difficulties in distinguishing and measuring threats: 1 . The subjective/ objective problem of actual threats that are not perceived and perceived threats that are not substantive; and 2. The threshold between the viscitudes of life in a competitive international environment and those that constitute a threat to national security. ${ }^{210}$ To answer this dilemma he turned to unpublished research being conducted by Ole Waever on securitization and the speech act. In People, States, and Fear (91), Buzan suggests that a government's authoritarian behaviour that legitimizes exceptional means to address a particular set of threats or vulnerabilities could be used to analyse threats to national security. This was the initial move towards establishing Buzan's future collaboration with Ole Waever within the emerging critical constructivist school of thought.

From his analysis of the elements of the state, Buzan concludes that the range of possible national security threats is wide and covers five sectors: military, political, economic, societal, and environmental. ${ }^{211}$ Buzan then examines the character of threats within each sector to determine a legitimate national security agenda "keep[ing] in mind

\footnotetext{
${ }^{210}$ Ibid, p. 106.

211 Although People, States, and Fear (91) introduced the idea of security sectors, it was Buzan's collaborative follow-on book with Ole Waever, Security: A New Framework for Analysis (1998), that provides a more complete articulation of sectoral referent objects and will be used to explicate the concepts.
} 
the idea that national security is about the ability of states to maintain their independent identity and their functional integrity.",212

Military threats are distinguished by the potential or actual use of physical force by one state to coerce, control or assimilate another state. They are the essence of traditional national security concerns over the loss of territory and sovereignty through the exercise of military power. Political threats represent a class of threats "aimed at disrupting the organizational stability of the state...and...[s]ince the state is an essentially political entity, political threats may be as much feared as military ones." ${ }^{213}$ The targets of political threats are the two ideational components of the state, the idea of the state (national identity and organizational ideology) and the state's institutions. They can emanate from within the state or be transplanted via 'fifth columns' or insurgents by external entities.

Economic threats to national security are difficult to differentiate from the dominant free market economies where the norm for actors is acceptance of risk, aggressive competition, and uncertainty. Buzan believes that states are only one amongst many economic actors and intervention by the state must be limited as "a vast range of economic threats fall within the rules of the market game." 214 However, Buzan identifies the point at which economic threats transcend the military and political spheres as the region where economic threats become national security issues. As per mainstream schools of national security, economic-military threats rest on supply of key strategic

\footnotetext{
212 Buzan PSF (91), 2009, p. 107; It is important for this dissertation to point out at this point that Buzan continually refers to identity and values in his sector analysis without providing clarification, as well as to 'functional integrity' that one assumes equates to norms located within institutions. This is indicative of the sociological aspects of national security that were underexplored in People, States, and Fear (91).

213 Buzan PSF (91), 2009, p. 109.

214 Ibid, p. 112.
} 
materials, maintenance of the military-industrial complex, and secure lines-ofcommunication. Economic-socio-political threats involve domestic stability and occur when states rely on maximizing wealth through international trade. Over time social structures depend on increasing prosperity and are vulnerable to disruptions in the flows of trade and finance. Governments who face the socio-political consequences of impossible financial and economic choices may define the whole situation as a national security problem. Again, Buzan marginalizes society when he cautions, “[o]nly occasionally will specific economic threats deserve to be ranked as a national security problem." 215

Ecological threats are primarily directed towards the physical base of the state, but can affect its idea and institutions as well. Acts of nature, such as earthquakes, hurricanes, droughts, plagues, etc, have traditionally been seen as part of the struggle of humans against nature. However, human activity is having a fundamental affect on the environment and "[t]his steady uncovering of cause-effect relations puts ecological issues more and more into the human, and therefore political, arena." ${ }^{216}$ Societal threats are related to political threats but are targeted at social and cultural values. Often societal threats are part of larger package of military and political threats, however, as in the case of current global concern with American cultural hegemony ${ }^{217}$, will find genesis in forced penetration of foreign language, religion, norms and culture that threaten national identity. "The organizing concept in the societal sector is identity. Societal insecurity exists when communities of whatever kind define a development or potentiality as a

\footnotetext{
${ }^{215}$ Ibid, p. 117.

${ }^{216}$ Ibid, p. 119.

${ }^{217}$ See Peter J Katzenstein and Robert Keohane, eds., Anti-Americanism in World Politics, Ithaca: Cornell University Press, 2007.
} 
threat to their survival as a community." ${ }^{218}$ The main problem with defining societal threats as national security threats, according to Buzan, is that they mostly occur within the state. This is a rather myopic position to take given the role national society plays in constructing and defining the 'idea of the state' (state identity) and state institutions.

\subsubsection{The Deepening Dilemma}

Debate between Bill McSweeney and Buzan/Waever ensued over the ontological status of society and societal security ${ }^{219}$ and its relationship to identity expressed in People, States, and Fear (91); however, the discussion became tangential and entered into the "broader ontological, epistemological and ethical controversies in international theory as a whole."220 McSweeney argued that linking societal-security to the domestic dimension would require analysis of the sub-societal, societal and state interaction as identity is an ongoing process of negotiation and cannot be known a priori. ${ }^{221}$ By rejecting the tradition of sociology and widening the concept to include 'all the vicissitudes of life', he believed that the Buzan/Waever approach would inevitably lead to the misallocation of scarce resources in the pursuit of national security.

In addressing McSweeney's concerns, Buzan and Waever correctly pointed out that Durkheim held that society had sui generis features that were attributes of society as a whole and that at a certain point one could legitimately separate identities that were

\footnotetext{
218 Barry Buzan, Ole Wæver, and Jaap de Wilde, Security: A New Framework for Analysis, Boulder CO: Lynne Rienner Publishers, 1998, p. 119.

${ }^{219}$ See Bill McSweeney, "Identity and Security: Buzan and the Copenhagen School", Review of International Studies, Vol 22, No 1, 1996, pp. 81-93; Barry Buzan and Ole Waever, "Slippery? Contradictory? Sociologically Untenable? The Copenhagen School Replies", Review of International Studies, Vol 23, No 2, 1997, pp. 241-250; Bill McSweeney, "Durkehim and the Copenhagen school: A Response to Buzan and Waever", Review of International Studies, Vol 24, No 1, 1998, pp. 137-140.

${ }^{220}$ Michael C. Williams, "Modernity, Identity and Security: A Comment on the 'Copenhagen Controversy'," Review of International Studies, Vol 24, No. 3, 1998, p. 436.

${ }^{221}$ McSweeney, 1996, p. 84-86.
} 
functionally fixed in security discourse for analytical purposes from the process of identity constitution. However, in People, States, and Fear (91) Buzan chose to deal with societal threats through the prism of the state and state elites instead of society itself thus avoiding McSweeney's questions of moral choice and value judgement, "the messy complexity of human agency." 222 This is important as Buzan and Waever's segregation of the terms 'society' and 'nation' from 'societal'223 (expanded in Security: A New Framework for Analysis) are incongruous with their sui generis argument to McSweeney and with Buzan's use of 'society' in People, States, and Fear (91). If there is no possibility of an overarching understanding of 'society' that represents the human collectivity used by Buzan to define the state (territorial-polity-society), to what has Buzan been referring? The answer to this inconsistency and McSweeney's concerns lies in reassessing the state as the referent object.

The widening of the national security agenda in Buzan's reworked edition in 1991 offered a more holistic, inclusive interpretation that could be applied more consistently across the international system. However, it was imprecise and conceptually flawed in several aspects of national security, as discussed earlier. In particular, Buzan's analysis of individual security in Chapters One and Two of People, States, and Fear is faulty in that he ascribes a uniform state model to an underspecified dialectic between security demands of citizenry and the resources/ direction they provide the state. This omission was carried over in the seminal work on securitization, Security: A New Framework for Analysis, where the Copenhagen School underspecified the role of the audience or more

\footnotetext{
222 Bill McSweeney, Security, Identity, and Interests: A Sociology of International Relations, Cambridge: Cambridge University Press, 1999, p. 38.

${ }^{223}$ Buzan, Wæver, and de Wilde, 1998, p. 119-120.
} 
precisely, society. In turning to Waever's concept of securitization ${ }^{224}$ to solve the two difficulties in distinguishing and measuring threats (threat perception and constitution of threats to national security) ${ }^{225}$, Buzan ignored the wider society-polity link he established throughout the book in favour of focusing on the state elite and state behaviour.

\subsubsection{Society-Polity as the Referent Object}

Collective domestic agency has significant influence on the outcome of national security policy regardless of the international structural pressures, particularly in times of choice. In a liberal democracy, the 'audience' cannot be limited to the security elite and must include society writ large as the 'audience' who legitimizes the resource extraction by the state for national security purposes. This in effect brings one back to the problem which Buzan sought to avoid in People, States, and Fear (91), how to account for societal influence in state decisions. Buzan's turn to critical theory for deepening was flawed as securitization theory, in effect, is essentially the study of the 'ideational processes in political debate and in the resolution of security issues'. Analysis of the 'speech act' fails to take into consideration the social context in which attempts at securitization occur and the effects that security statements provoke in the audiences. Not all states are alike and not all societies are the same. Causal mechanisms attributed to

\footnotetext{
${ }^{224}$ Thierry Balzacq is a proponent of the sociological model for analysis and has focussed his research on the pragmatic act of security. He organizes securitization around three core assumptions which make the theory applicable to empirical studies: the centrality of audience, the co-dependency of agency / context and the structuring. However, as with all variants of securitization theory, Balzacq also leaves the audience underspecified and without specific identity for contextualization. As the audience is a fundamental factor in the securitization process, understanding the security culture of that audience is key to understanding the constraints and limitations that securitizing actors/agents are faced with when deciding and formulating state security policy. - Thierry Balzacq, Securitization Theory: How Security Problems Emerge and Dissolve, New York: Routledge, 2010, p 15-19.

${ }^{225}$ Buzan PSF (91), 2009, 106.
} 
society-polity can be empirically tested and analysed through security norms of behaviour, thus deepening the concept of national security. ${ }^{226}$

In accepting the logic of Waltz's three images, Buzan continued the binary view of individual / state and failed to deepen the concept of national security by capitalizing on the many perceptive insights on the relationships between state-society on which he bases his arguments. ${ }^{227}$ If as Buzan writes, "it is the idea of the state that both provides the major bindings holding the territorial-polity-society package together, and defines much of its character and power as an actor in the international system" 228 , then the state component 'idea' is divisible for analysis by its constituent parts, territorial-politysociety. He also states that "[sovereignty] is the glue that binds the territorial-politysociety package together." 229 Therefore, sovereignty is also divisible by the parts it holds together.

Although Buzan never specifically links institutions to territorial-polity-society, his argument regarding the interdependence of organizing ideologies and institutions implies the linkage. Finally, Buzan states that the physical base of the state comprises its population and territory. Amongst many material threats, he identifies human migration as a threat to the physical base in the societal sector as it can "weaken the governmentsociety-territory nexus." 230 It is evident that Buzan considers society and the polity an influential, if not a causal, factor regarding national security of the component parts of the

\footnotetext{
${ }^{226}$ Stage analysis of national security norms, as Finnemore and Sikkink espouse, is the best means of providing the specification needed in linking securitization theory to the 'audience'.

${ }^{227}$ Buzan PSF (91), 2009, p 43. "Extensive investigation is made into the different components of the state to which security might apply, and attention is focused on the socio-political cohesion of the state as a major factor in any attempt to think about national security. Conclusions are drawn about the centrality of state-society relations, and about the limitations of the concept of national security."

${ }^{228}$ Ibid, p. 70.

${ }^{229}$ Ibid, p. 72.

${ }^{230} \mathrm{Ibid}$, pp. 90-91.
} 
state. States remain legitimate to their citizens through protection from harm, thus

ensuring the provision of security connects the state with society in a significant manner.

Had Buzan provided a framework that included the territorial-polity-society prism he

would have truly succeeded in deepening as well as widening the concept of national security. ${ }^{231}$

At this point, it is worthwhile turning to an analogy in the natural sciences to illustrate the fact that analysis of a referent object can be done from many perspectives that contribute to overall understanding. ${ }^{232}$ The atom, once thought to be indivisible, is the smallest constituent unit of ordinary matter. It consists of three component particles (protons, neutrons, and electrons) held together by electromagnetic force. In other words, the four elements of the atom are the proton, neutron, electron and electromagnetic force. This is not unlike the state, the smallest constituent unit in the international system, which consists of four elements, territory, ideas, institutions and sovereignty. Every atom is also described as containing a nucleus, where all the bound protons and neutrons are concentrated. The protons and neutrons (called nucleons) are held together by a different force, the nuclear force. This is not unlike the state where the 'nucleus' consists of the

\footnotetext{
${ }^{231}$ Martin Shaw identifies this flaw of avoiding society as a referent object in PSF (91) as well. "I argue that, despite the welcome extension of the issue agenda of security studies to include a wide range of nonmilitary factors, its conceptual framework requires more radical revision than is provided by either side of this argument. What is needed is a deepening as well as a broadening of the agenda. The concept of 'social relations' (or 'society') needs to be interposed between and around the terms 'state' and 'individual' within which the debate has been conducted." Martin Shaw, "There Is No Such Thing as Society: Beyond Individualism and Statism in International Security Studies", Review of International Studies, Vol. 19, No. 2, 1993, pp. 159-175.

${ }^{232}$ By theoretically identifying how atoms constitute molecules, constitutive analysis contributed to causal explanations of various chemical, biological, and physical processes well before scientific technology provided the tools for direct observation. Likewise, an analysis of the constitutive dimensions of the elements of the state will contribute to causal explanations of national security norms.
} 
two bound components of the state ${ }^{233}$, ideas and institutions, held together by the "nuclear force' of society-polity.

Atoms are not like units and neither are states. The nucleus is used to identify to which chemical element the atom belongs as well as the isotope of that element. So too are the properties and characteristics of states. Each is defined by the uniqueness of its 'nucleus' (ideas and institutions) as well as the distinctive force holding the nucleus of the state together, its society and polity. This is the deepening that Buzan needed to pursue in People, States, and Fear (91). Aside from the Buzan/McSweeney epistemological debate that is incommensurable, the question is not one of ontology for constructivists but of methodology. If as Buzan insists, "Society is about identity, the self-conception of communities and of individuals identifying themselves as members of a community" 234 , then the study of norms, identity, values and interests located in the nuclear force (society-polity) provides the methodological avenue to analyse the nucleus of the state (ideas and institutions).

The second major problem with People, States, and Fear (91) is the assumption that states focus on threats and vulnerabilities to referent objects rather than protection of values within the referent sectors. Threats and vulnerabilities will be situational and in many cases temporal. Risk tolerance will vary amongst states as will methods for risk mitigation, avoidance, and management. "In the political vision sketched by Hobbes, fear and normality, security and politics are not divided: they are necessarily (and practically)

\footnotetext{
${ }^{233}$ Buzan PSF (91), 2009, p. 85 "The main point of interest for this discussion is that the ideas and institutions are inseparably entwined....This interdependence means that institutions and organizing ideologies tend to stand or fall together in the context of a particular state, and this has obvious implications for either, or both, as objects of security."

${ }^{234}$ Buzan, Wæver, and de Wilde, 1998, p 119
} 
related, and any attempt to draw an absolute divide between them is misleading." ${ }^{235}$ Both Buzan, and McSweeney follow this realist tradition of basing national security on the fear of 'perceived threats', but fail to explicate why fear is the motivating factor over the protection of values.

However, Baldwin and Wolfers see the protection of acquired values as the purpose for national security. Viewed from this prism; national security becomes a possession of the 'state' as a national value and not one ascribed exogenously. The international system may induce behaviour, but how that behavior manifests itself is dependent on the society-polity-state interface. Assessing the risks to acquired values is dependent on the norms and values of a state's society that are embedded in institutions and identities. These form the foundation for ideational contestation by elites and 'moral choice' by decision-makers. ${ }^{236}$ Risk tolerance is established in society-polity through the social construction of risk that defines the scope of action available. The politics of risk then follows from this social construction through contestation over the instrumental values that political action takes to minimize risk. ${ }^{237}$ A culture of national security for any

\footnotetext{
${ }^{235}$ Michael C Williams "The continuing evolution of securitization theory”, in Thierry Balzacq, Securitization Theory: How Security Problems Emerge and Dissolve, New York: Routledge, 2010, p 220. ${ }^{236}$ Morgenthau, Wolfers, and McSweeney all stipulate the central nature of morality in national security policy decisions. As the 'audience', society provides elements of direct agency within this framework on specific issues through polling data and intervention by special interest groups. Society's influence is particularly strong during periods of political elite vulnerability such as in minority government situations in Canada.

${ }^{237}$ Ulrich Beck provides the theoretical explanation: "We must distinguish between two forms of risk politics: a politics of risk construction (involving the social construction of risks) and a politics of risk minimization (involving prevention, mitigation, and cross-border intervention). The latter presupposes the former: the construction of risk also defines the scope for action minimization of the risk. Both involve a definition of reality, cognitively in the former case and through political action in the latter. Risk construction is typical of sociological constructivism, whereas risk minimization is more characteristic of realism in political science." - Ulrich Beck, "World Risk Society and Foundations of Transnational Politics," in Louis W. Pauly and Edgar Grande, eds, Complex Sovereignty: Reconstituting Political Authority in the Twenty-First Century, Toronto: University of Toronto Press, 2005, p 27.
} 
state will be evident over time as societal values set limits and the polity constrains acceptable state behaviour with respect to the provision of state sponsored security.

Not all societies are insecure regarding the state's physical base and, regardless of the existential arguments made by securitizing actors, will not be convinced to ascribe greater value to the military, hence higher resource extraction, than to other security values of equal or greater importance. Thus, Buzan/Waever's concentration on articulating the perception of threat through securitization theory should be seen as a tool to analyse the political process of policy debate where various securitization actors try to change or modify established security values of society, the polity, and elite decisionmakers. It is the contestation of national security as an acquired value within the societypolity nexus that shapes and determines national security policy.

\subsection{Establishing National Security Culture}

As with political culture, national security culture varies over time within a state and varies from state to state. As the state is constantly in the process of construction, emerging norms and values will transform society and the polity while receding ones will lessen in intensity. This mutually constitutive process is continuous, however, certain consistencies can be determined that form the foundations of national security preferences that have explanatory and predictive power. Within these established preferences, a contemporary national security culture can be determined that limits and constrains the options available to decision-makers and shapes the policy alternatives.

To legitimately use national security culture as an analytical concept, it must be operationalized as a theory by meeting four criteria. First, the functional role of national security culture must be specified and the concept must be defined in a way that 
maintains an analytical distinction between social and psychological variables due to their separate influences on preference stability. Second, preference formation must be grounded in a theory of motivation that specifies how and why people make choices that affect political life. Third, a national security culture must specify a sociological context in which hypotheses can be effectively tested. Finally, specification of the nature of the interaction between the normative level and the level of preference formation must be made, and then identification of how particular interconnections link the two levels and how and why behavior or discourse generated at one level has an effect on the other. ${ }^{238}$

The first criterion was explicated in chapter one. National Security Culture refers to the socially shared and transmitted ideas and beliefs within the collective identity that influence how Canadians perceive national security, security institutions, and the importance placed on security as an acquired value in competition with other acquired values. National security culture defines the range of acceptable possible alternatives from which groups or individuals may, other circumstances permitting, choose a course of action. The collective ideas and values about the protection of acquired values are important constitutive factors in the design and execution of state security policies, particularly in bounding the rationality ${ }^{239}$ of decision-makers when making 'moral

\footnotetext{
238 These criteria are adopted from those specified for a theory of political culture by Wilson. Richard W. Wilson, "The Many Voices of Political Culture: Assessing Different Approaches," World Politics, Vol 52, No.2, 2000, p. 273.

${ }^{239}$ In After Hegemony, Keohane departs from the canonical rational choice approach to embrace Herbert Simon's Bounded Rationality as a way of explaining cooperation amongst states in anarchy. In his preface to the 2005 edition, he specifically identifies one major shortcoming as lacking "a theory of how domestic politics and international institutions connect" - Keohane, 2005, p viii. This area of research has been taken up by Helen Milner (1997) who developed a theory of domestic politics based on rational choice theory that links domestic politics with international outcomes and Jonathan Bendor (2010) who shows that Simon's theory turns on the interplay between the cognitive constraints of political decision-makers and the complexity of their tasks. See Robert Keohane, After Hegemony: Cooperation and Discord in the World Political Economy, Princeton: Princeton University Press, 2005; Helen Milner, Interests, Institutions, and
} 
judgments'. Thus, social variables that shape options are kept analytically distinct from psychological variables that are embedded in rational choice models that address the specificity of a policy decision.

The preceding analysis of national security as Wolfers' subjective case and the operationalization of the concept through Baldwin's seven specifications for national security provide the answer to the second criterion. Preference formation is grounded in national security as an acquired value. The seven specifications are the basis of political contestation over the material and ideational need for specific increments of security. The geostrategic position of Canada provides the foundation from which intersubjective arguments are made by various actors in Canadian society to shape and influence decision-makers within the polity. As a matter of definition of national security, Canadian society is the recipient of state protection of acquired values, answering the first specification 'for whom'. However, the cultural contestation over values and material resources that shapes preference formation involves the remaining specifications, particularly with respect to 'from what threats' in the case of Canadian national security culture.

Hypothesis testing of Canadian national security culture can be conducted at the state level of analysis through the society-polity nexus as developed through earlier disaggregation of Buzan's components of the state, thereby meeting the third criterion. The problem with the majority of 'state-level' cultural theories, such as strategic 
culture $^{240}$, is that they take the choices made by states as evidence of the state's 'culture' without problematizing the internal processes that led to the final decision ${ }^{241}$. Political culture literature, on the other hand, is generally too far-ranging in breadth and depth of analysis of a state's society and polity to problematize the underpinnings of national security. The key to operationalizing national security culture is to limit its sociological context to those domestic security norms, values, and interests at the society-polity interface with the state.

Clifford Geertz's view of the symbolic content of culture ${ }^{242}$ was the crucial element that allowed for scientific analysis of society's key symbols and articulation of cultural variables as a tool for analysis in both international relations and comparative politics ${ }^{243}$. Thus evidence gathered and tested with respect to Geertzian 'symbolism' in the society-polity sociological context will inform a state's national security culture. ${ }^{244}$ Limiting the sociological context in this manner, addresses the criticism of using political

\footnotetext{
${ }^{240}$ Alistair Johnston reconceived 'strategic culture' into a theory that uses state level cultural analysis to explain grand strategy and approaches to war fighting. Johnston continued in the tradition of the previous generations in linking strategic culture with the concept of political culture which he calls a 'mind set' that limits and constrains institutions, ideologies or behaviours from the body politic.

${ }^{241}$ Both Thomas Berger and Elizabeth Kier analyse domestic cultural variables that affect state security policy outcomes through use of political culture, but the narrowness of their variables and their use of traditional concept of national security limit their explanatory usefulness - see Katzenstein, The Culture of National Security, 1996 b.

242 Clifford Geertz, The Interpretation of Cultures, New York: Basic Books, 1973, pp. 89-90. For Geertz, culture does not remain solely in the ideational realm as it can include ritual behaviour; however political scientists view culture is primarily ideational in order to differentiate it as the dependent variable from actual behavior.

${ }^{243}$ See David Haglund, “'Let's Call the Whole Thing Off'? Security Culture as Strategic Culture”, Contemporary Security Policy, Vol 32, No. 3, 2011, p. 494-516.

${ }^{244}$ The following Geertzian definition of national security culture is in line with Johnston's approach using society-polity as the referent object instead of the state. "National security culture is 'an integrated "system of symbols (e.g., argumentation structures, languages, analogies, metaphors) which acts to establish pervasive and long-lasting state sponsored security preferences by formulating concepts of the role and efficacy of state responsibility in protection of acquired values, and by clothing these conceptions with such an aura of actuality that the state sponsored security preferences seem uniquely realistic and efficacious." Alastair Iain Johnston, “Thinking about Strategic Culture”, International Security, Vol.19, No.4, 1995, p. 46.
} 
culture without theoretical reference to IR and allows national security culture to solve the causal/contextual impasse of strategic culture. ${ }^{245}$ The challenge to this approach will be in limiting the regional and sub-cultural variables to how they impact the state level society-polity determinates.

Finally, it is in linking the sociological aspects of the process of contestation with rational choice models that the interaction between the normative level and the level of preference formation occurs. Every state has both formal and informal processes where political socialization and contestation takes place. As a liberal democracy, freedom of expression ensures normative values and beliefs are conveyed through a multitude of informal processes within Canadian society ${ }^{246}$. Based on the Westminster model, formal processes for state preference formation occur within the polity, but are shaped by the contestation and preference articulation of elite norm entrepreneurs and elements of society. The effect of societal agency on elite decision-making is most evident in elite behavior during minority government situations where elites compete for approval and political power. As most rational choice models involve elite decision-making and only society in general, national security culture is a systemic means to discover, to define, or to incorporate multiple possible goals of actors. ${ }^{247}$

\footnotetext{
${ }^{245}$ Disagreement over whether strategic culture was causal or contextual was waged between Johnston and Colin Gray for many years. David Haglund argues that, if Gray's problem was in the definitional 'fuzziness' of culture such that it only offered context, then viewing strategic culture as group cognition (identity) holds the promise for definitional clarity. Haglund then noted, "Once the definition has been sufficiently 'precised', why not envision using it as an independent variable? And what could be better than political culture to blaze the trail for strategic culture... Why not turn to political culture as a means of 'operationalizing strategic culture." - Haglund, 2011, p. 509.

${ }^{246}$ Informal processes for normative discourse are found in, but are not limited to: mass media, religious organizations, special interest groups, social activism and educational institutions.

247 See Mira Sucharov, "Security Ethics and the Modern Military: The Case of the Israel Defense Forces," Armed Forces \& Society, Vol 31, No.2, 2005, p. 177; Ruth Lane, "Political Culture: Residual Category Or General Theory?", Comparative Political Studies, Vol 25, No.3, 1992, pp. 362-387; Emanuel Adler,
} 
Using sociological institutionalism (constructivism) to provide the context for rational choice institutionalism is one approach that links the recursive discourse and behaviour of the two levels. Rational choice institutionalism is organized around both exogenous and endogenous institutions. The first approach ${ }^{248}$ takes institutions as exogenous constraints while the second interpretation ${ }^{249}$ of institutions is deeper and subtler where the 'rules of the game' are provided by the players themselves. Political decisions are made within structured institutions of the polity which rational choice institutionalism links to social variables that shape political choice ${ }^{250}$. Society may provide context to security preferences, but it is exercised through the polity as the electorate, giving society significant influence as a causal factor in decision-making. ${ }^{251}$

Thus, "the ability of national elites to meet [Canadian] vulnerabilities and insecurities will be shaped and limited by the imperatives, prescriptions, and proscriptions of [Canadian] national security culture." ${ }^{252}$ In other words, "the socially shared and transmitted ideas and beliefs within this collective identity that influence how

"Constructivism and International Relations," in Walter Carlsnaes et al, ed., Handbook of International Relations, London: Sage Publications, 2002.

${ }^{248}$ Kenneth Shepsle, "Rational Choice Institutionalism", presentation Harvard University, January 2005.

${ }^{249}$ Barry Weingast, "Rational-Choice Institutionalism" in Political Science: The State of the Discipline, I. Katznelson and H. Milner, eds., New York: W.W. Norton, 2002, pp. 660-692.

${ }^{250}$ Shepsle, 2005, believes that RCI has had its greatest success in analysis of structured institutions since:

- Political actions can be determined in a relatively well-defined way

- Political objectives can be specified with some precision into office preferences and policy preferences

- Political behavioural repertoires are delineated by institutional rules and processes

- Outcomes are clearly implied by the configuration of rules in a structured institution

- Payoffs may be inferred from the objective functions of politicians

- Electorate preferences impact the institutional politician that they have chosen to act as their agent. ${ }^{251} \mathrm{Ibid}$, underlined point; Society and elites offer different perspectives that cannot be disassociated as causal factors. The importance of society in this equation is implicit as Mira Sucharov observes "messages about the legitimacy of war and peace will be found to a greater extent in the civilian community (including the less-informed elements of the populace), since judgements emanating from values are arguably more pervasive than judgements emanating from a cause-and-effect view of the world. The latter implies a more intensive knowledge base and would therefore be more the domain of elites or epistemic communities." Sucharov, 2005, p. 178.

${ }^{252}$ Kirchner and Sperling, 2010, p.14. 
Canadians perceive national security, security institutions, and the importance placed on security as an acquired value in competition with other acquired values", that this study defines as Canadian National Security Culture.

\subsection{Summary and Conclusions}

This chapter problematized the concept of security in terms of Wolfers subjective/ objective threat to acquired values and operationalized the concept using Baldwin's seven specifications. Wolfers' ideational reference to threat perception and his later discussion on subjective reaction to the threat environment led him to conclude that the amount of security required was not determined by external factors alone but by the nation itself based on its system of values. For states where the fear of attack is low, some nations will seek protection for more marginal values. This weighing of values requires normative judgment on the part of leaders with input from the "numerous domestic factors". By presenting national security as a negative value that does little to contribute to a nations wellness, he highlighted the fact that security policy is "a subject for moral judgment"253 when other values are sacrificed at the altar of national security.

Baldwin decouples the military-centric threat security matrix implicit in traditional security studies which in turn allows for discussion of an expanded concept of national security by focusing on the preservation of acquired values, not on threats to these values. He specifies seven questions that must be answered in order establish an increment of national security: Security for whom?; Security for which values?; How much security and at what cost?; From what threats?; By what means?; and In what time period? In doing so, Baldwin operationalizes the concept by providing measurable criteria.

${ }^{253}$ Wolfers, 1951, p. 498. 
In explicating Buzan's theory for widening and deepening the concept of national security, I established the baseline to firstly be able to deconstruct his definition of the state in order to develop the referent object of this study and secondly to provide the criteria that will be used later to establish Canada's view of national security. Buzan's premise of the individual / state security cleavage was deconstructed to show that his argument clearly indicated that society-polity was the binding force I have called the 'nuclear force' that holds the 'nucleus' of the state (its ideas and institutions) together. In establishing society-polity as the referent object, the study of historical construction of norms, identity, values, and interests located in the society-polity nexus provides the methodological avenue to analyse the ideas and institutions of the state.

Finally, it was necessary to establish the criteria for a theory of national security culture in order to provide sufficient evidence to prove its existence. The four specifications were determined to be:

- The functional role of national security culture defines the range of acceptable possible alternatives from which groups or individuals may, other circumstances permitting, choose a course of action.

- Preference formation is grounded in national security as an acquired value and determined in contestation with other acquired values.

- The sociological context is located in the society-polity nexus where national security norms, values, beliefs, and interests are located and contested.

- Wolfers links the subject choice of national security to moral judgment. Bridging sociological and rational choice models provides the connection for interaction 
between the normative level and the level of preference formation through political contestation.

Establishing a theoretical model such as this based on a political culture model opens up the opportunity for the use of established political culture literature from political science, sociology, and history to establish the contemporary Canadian National Security Culture through pluralistic consolidation of security norms and values over time. 


\section{Chapter: Establishing Canadian National Security Culture}

\subsection{Nucleus of Canada}

The 'nucleus' of the state is ever evolving. However, its collective identity and culture can be tracked and conceptually identified over time. Collective identity is a social category that varies along two dimensions, content (constitutive norms, social purpose, relational comparisons, and cognitive models) and contestation ${ }^{254}$. History is a process of change that leaves an imprint on collective and state identity. Although Nelson Wiseman argues that there is no Canadian political culture, only an amalgam of overlapping regional ones, it is difficult to accept there is no overarching political culture that has kept the state of Canada together for nearly 150 years ${ }^{255}$. As Will Kymlicka points out, "In one sense, 'being Canadian' is just one identity within this larger set of identities. ${ }^{256}$ Survival in a desolate, inhospitable land was undoubtedly a significant motivator in overcoming societal cleavages. The historic political processes of contestation, compromise and accommodation along the journey to statehood were built

${ }^{254}$ Rawi Abdelal et al, "Identity as a Variable," Perspectives on Politics, Vol 4, No.4, 2006, pp. 695-711; the authors "define a collective identity as a social category that varies along two dimensions-content and contestation. Content describes the meaning of a collective identity. The content of social identities may take the form of four, non-mutually-exclusive types:

- Constitutive norms refer to the formal and informal rules that define group membership.

- Social purposes refer to the goals that are shared by members of a group.

- Relational comparisons refers to defining an identity group by what it is not, i.e., the way it views other identity groups, especially where those views about the other are a defining part of the identity.

- Cognitive models refer to the worldviews or understandings of political and material conditions and interests that are shaped by a particular identity.

Contestation refers to the degree of agreement within a group over the content of the shared identity. Far from being understood as fixed or unvarying, collective identities, in this conceptualization, vary in the agreement and disagreement about their meanings. The relevant aspects of the content of collective identities vary a great deal, and it is impossible a priori to specify them all." pp. 696-697.

${ }^{255}$ One standard approach that explains the source of a pan-Canadian identity, derived from Rawlsian and Habermasian schools of thought, invokes shared constitutional values. According to this view, so long as all Canadians share a commitment to the basic political values enshrined in the Canadian constitution, they should identify with Canada as a country.

${ }^{256}$ Will Kymlicka, “Being Canadian”, Government and Opposition, Vol 38, No. 3, 2003, p.357. 
on a foundation of common norms and values shared between two principal cultures. Consolidated as a British colony with a large French population following the defeat of New France in 1759, the genesis of the Canadian state was the result of the American revolution a mere 20 years later. Although it has taken many forms over the years, the one persistent, and perhaps only, insecurity faced by Canada has been the fear of assimilation by the United States in each of Buzan's four elements of the state.

Security culture, as with political culture, is multifaceted and requires compatible theories to expose the sui generis norms and values of Canadian society. To accomplish this, I will employ three historically complementary applications to Canadian political/security culture written through the theoretical constructs of political science, political history and sociology. Recognized scholars ${ }^{257}$ have exposed national ideologies of collective purpose and distinctiveness that have been institutionalized through evaluative or cognitive standards to form a general consensus of overarching Canadian identity, values and culture. Evidence of constitutive and regulative norms can be found in national institutions (procedures and law), policy statements, public discourse, official documents and academic research. Norm strength can be gauged by specificity (how clearly it is codified), durability (how long it has been in effect), and concordance (how widely it has been accepted). By showing evidence that specific norms and values have existed over a period of time, I will have a baseline from which to determine the behavioral outcomes in this research. Although regression analysis of observed norms

\footnotetext{
${ }^{257}$ Louis Hartz, Gad Horowitz, Seymour Martin Lipset, Philip Resnick, James Curtis, Edward Grabb, Will Kymlicka, Norman Hillmer, J.L. Granatstein, and Nelson Wiseman are some of the more prominent academics.
} 
would be useful in consolidating the consensus found in literature on Canada, it is beyond the scope of this paper.

With the release of The Founding of New Societies in 1964, Louis Hartz introduced the 'fragment theory' that argued New World states which developed as settler colonies were ideological offshoots or 'fragments' of the Old World societies that founded them, cut off from the evolutionary experiences of the mother countries. To Hartz, French Canada was a fragment of feudal Europe, while English Canada and the United States were liberal fragments of Britain. In applying Hartz's theory to Canada, Gad Horowitz argued that English Canada was a product of Loyalist liberalism with significant traces of British toryism. Horowitz drew a link between socialism and 'toryism', interpreting the strength of Canadian socialism with 'tory' conservatism's collectivist norms. ${ }^{258}$

Seymour Martin Lipset argues that founding moments ${ }^{259}$ are pivotal determinants of political culture and the institutions and values that derive from them. His 'formative events' theory accounts for the subsequent developments that stem from trajectories set in motion in whole or in part by such formative events and the norms they produce. Lipset's most extensive work, Continental Divide, made abundant use of quantitative data to support his qualitative analysis of cross-national differences between Canada and the United States. Drawing on works of established Canadian scholars and covering a wide spectrum of sectors, he provided detailed analysis of many of the key values and institutions that directly affect security culture. His general observation is that "Canada...remains more respectful of authority, more willing to use the state, and more

\footnotetext{
${ }^{258}$ Nelson Wiseman, In Search of Canadian Political Culture, Vancouver: UBC Press, 2007, pp. 23-24. 259 'Founding moments' can be interpreted as 'critical junctures' in historical institutionalist taxology.
} 
supportive of a group basis of rights than its neighbor."260 Lipset's account of two foundational moments in Canada, the impact of the American Revolution and the 1982 incorporation of the Charter of Rights and Freedoms into the Canadian constitution, are important 'critical junctures' that directly impact the discussion on national security culture.

Canadian sociologists, Edward Grabb and James Curtis, provide an alternative perspective on Canadian and American societies in Regions Apart. Using the theory of 'deep structures', they argue that the English regions in Canada and the northern US "were imbued historically with a similar set of core values, or deep structural principles ... liberty, legal equality, popular sovereignty, and pluralism ... [that] w[ere] crucial for shaping, in kindred ways, the political, economic, legal, and other social structures in these two regions." 261 They argue that the lack of 'sameness' in the two countries is due to the influence of the two sub-regions, Quebec and the American South. Grabb and Curtis contend that "Lipset's argument is fundamentally incorrect"262 and that, although flawed, Hartz's fragment theory has some utility.

Although very useful in understanding the similarities between Canada and the US, Regions Apart focuses on intrinsic values of the citizens and fails to address the acquired and instrumental values that are embedded in the 'basic organizing principles' of the polity that is Lipset's central argument. ${ }^{263}$ Regions Apart provides sociological

\footnotetext{
${ }^{260}$ Lipset, Continental Divide, 1990, p. 3.

${ }^{261}$ Edward G Grabb and James E. Curtis. Regions Apart: The Four Societies of Canada and the United States. New York: Oxford University Press, 2005, p. 248.

262 Ibid, p. 249.

${ }^{263}$ Seymour Martin Lipset, "The Values of Canadians and Americans: A Reply”, Social Forces, Vol 69, No. 1, September 1990, pp. 267-272; Seymour Martin Lipset, "Defining Moments and Recurring Myths: A Reply," Canadian Review of Sociology \& Anthropology, Vol. 38, Issue1,February, 2001, pp. 97-100.
} 
specificity at the expense of Charles Tilly's theory of 'big structures, large processes',264 that is fundamental to explicating state-level causation. Lipset's approach is similar to historical institutionalism that "involves arguments about crucial founding moments of institutional formation that send countries along broadly different developmental paths...[and]..that institutions continue to evolve in response to changing environmental conditions and ongoing political maneuvering but in ways that are constrained by past trajectories. $" 265$

Philip Resnick and Will Kymlicka have produced more contemporary analyses of Canadian society from an identity perspective. Resnick looks from the 'inside-out', building on Horwitz and Lipset's observations, in arguing that Canada is in fact a "EuroAmerican state... that would fit remarkably well into the European Union."266 Canadian society is very similar to European societies in world view, cultural behaviour, and in its place as a sovereign state within North America. Kymlicka approaches the same analysis from the 'outside- in', claiming that Canadians see themselves as citizens of the world, disquieted at the closed nature of European societies, but with a 'moral superiority' towards the United States. This 'international dimension' of Canadian identity is largely shared across Canadian cleavages. Kymlicka argues that the identity diversity within Canada is the result of two ethno-cultural groupings, founding peoples (British, French

\footnotetext{
${ }^{264}$ Charles Tilly, Big Structures, Large Processes, Huge Comparisons, New York: Russell Sage Foundation, 1984.

${ }^{265}$ Kathleen Thelen, "Historical Institutional ism in Comparative Politics", Annual Review of Political Science, Vol 2, 1999, p. 387; Lipset, 2001, p. 98 - in specific response to Grabb and Curtis's assertion that the Loyalists were culturally homogeneous with their American counterparts, Lipset says "The native-born Loyalists were Americans, more egalitarian. But I would insist that, on average, those who chose British North America had to be different in significant ways from those who did not .... We know, as my critics correctly assert, that the cross-border elites, both secular and religious, differed substantially in their beliefs and actions, the masses less so."

${ }^{266}$ Philip Resnick, The European Roots of Canadian Identity, Peterborough, Ontario: Broadview Press, 2005, p 96-97.
} 
and Aboriginal) and immigrants. He sees the negotiation of a Canadian identity and accommodation of sub-state identities as an application of the same liberal-democratic values shared by all Western democracies. ${ }^{267}$

Through the prism of political culture, Nelson Wiseman provides critical analysis of diverse historical approaches in the development of his central thesis that Canada has no overarching political culture, only an amalgam of regional cultures. He challenges the macro-ideological 'fragment' theory associated with Louis Hartz and Gad Horowitz that "David Bell .... likened ... to a search for a 'genetic code', one seeking to identify the implanted ideological genes of the founding people"268, as well as Lipset's 'formative events' theory and Harold Innis's 'staples' theory in political economy. In formulating his argument, he applies aspects of the three theories through the 'prism' of waves of immigration to explain Canada's regional cultures. Wiseman believes that the concepts of culture and ideology are both abstractions that deal with fundamental values but in fundamentally different ways. "Culture is an ordered system of symbols; ideology is an ordering of symbolic terms." Culture has 3 levels: 1. Fundamental abstract values or ideology; 2. Time-honoured policies; and 3. Ritualized practices. ${ }^{269}$

Wiseman says that these three levels of political culture are nothing more than focal points for analysis. His typology of ideology, policy, and practice makes no causal

\footnotetext{
${ }^{267}$ Kymlicka, 2003.

${ }^{268}$ Wiseman, 2007, p 20. Wiseman goes to great lengths to demonstrate the limitations of this theory, particularly in arguing the regional disparity of Canadian support for socialist policies that are not linked to areas of Loyalist migrants in which he cites significant works that refute these findings as evidence (p 10). His greatest criticism of this theory is its pan-nationalism that treats national political cultures as homogeneous ( $p$ 24). Wiseman also disputes sociologist Lipset's macro-sociological "formative events" theory in lumping English and French Canada together arguing that founding moments are formative events that are regional and not homogenous across demographics. He instead suggests the addition of the term 'quakes' which unlike formative events are catalysts for evolutionary change.

${ }^{269}$ Ibid, p. 13.
} 
claims since they constantly interact such that the boundaries between them are blurred. ${ }^{270} \mathrm{He}$ uses the ideology behind support for Medicare of the three primary Canadian political parties to illustrate his point that practice and policy can be supported from three quite different motivations. This, however, is a flawed conclusion as becomes evident when applying Katzenstein's causal model, where instrumental values and ideational causal links are made between culture and behaviour. The communitarian norms of Canadian society accepted the concept of state sponsored medical insurance (universal health care) and it has since become an acquired value of Canadian society (part of Canadian identity). As universal health care is an acquired value in Canadian society, the three political parties are constrained into supporting the concept. However, they do so through ideological policies of collective purpose and particularistic instrumental values that meets each party's norms. This said, Wiseman's real contribution to this dissertation is in linking sub-state regional cultures with the state nucleus and exposing the regional impact on national security discourse.

\subsection{Establishing a Cultural Baseline}

\subsubsection{Security as a Value}

Canada is bounded on three sides by large, intractable oceans and the 'longest undefended border' in the world. Time and space are strategic realities that provide relative tranquility in an anarchic world. In Wolfers' subjective sense of security, Canadians are secure in their belief that there are no direct threats to the physical base of their state. ${ }^{271}$ Without a clear and present danger, security becomes a value that competes

\footnotetext{
${ }^{270}$ Ibid, p. 15.

${ }^{271}$ See Norman Hillmer and J. L. Granatstein, For Better Or For Worse: Canada and the United States into the Twenty-First Century, Toronto: Thomson/Nelson, 2007; Seymour Martin Lipset, Continental Divide:
} 
with other values for attention and resource extraction. This is not to say that Canadians do not invest in security as threats to acquired values do exist in Wolfers' objective sense, but that the investment is more like a risk-management insurance policy than a response to perceived threats in Hobbesian terms. This is a critical ideational aspect that challenges the traditional threat-based approach to national security found in the majority of academic analysis since the prism through which threat perception and resource extraction occur is dependent on the national security culture of the state's nucleus (ideas and institutions) and the nuclear force (society-polity) that binds them, not the material strength and assumed Hobbesian intentions of the 'other'.

Given Canada's geo-political position of interdependence with the world's lone superpower, Canada benefits from the layered defence strategy of United States. The United States National Defense Strategy 2008 specifically identified "the need to strengthen alliances and build new partnerships to defeat global terrorism and prevent attacks against us, our allies and our friends"272 through an 'active layered defense'. Joel Sokolsky and Philippe Lagassé interpret the first layer as being global intervention in countries, such as Iraq and Afghanistan, while the third layer is the American homeland itself. 'Stuck in the middle' is Canada in the second layer, providing perimeter protection. ${ }^{273}$ Thus, it is not only bilateral amity with the US that is sufficient to maintain an undefended border, but there is an expectation that Canada will ensure its territory will

The Values and Institutions of the United States and Canada, New York: Routledge, 1990; Keohane and Nye, 2012; Wiseman, 2007; Klymicka. 2003; Resnick, 2005.

${ }^{272}$ Department of Defence, 2008 National Defense Strategy, Washington, DC, June 2008.

${ }^{273}$ Joel Sokolsky and Philippe Lagassé, "Suspenders and a Belt: Perimeter and Border Security in CanadaUS Relations," Canadian Foreign Policy, Vol 12, No 3, 2006. "To the United States, a continental security perimeter serves to guard the approaches to the American homeland, not to stretch the third layer of defence to include of all of North America.........Hence, those who expect that the presence of North American security perimeter will compel the United States to renounce restrictive border policies ignore the way Washington is fighting the war on terror.....". 
not be used as an avenue of attack on the US. This necessary condition significantly changes the objective value of the security equation for Canadian society and elite in the polity, given the complex interdependence that is well documented by Keohane and Nye. ${ }^{274}$ Assuaging American insecurities therefore takes on a measure of value in its own right.

Although sovereignty ${ }^{275}$ is a value deeply held by the state nucleus, it is a concept in constant negotiation. ${ }^{276}$ State sovereignty requires that a society and polity make basic investments in security institutions for survival and to maintain democratic legitimacy, such as fielding a balanced military to defend and enforce state and international laws at territorial perimeters; providing domestic security and intelligence institutions to enforce sovereignty; a judiciary to apply the laws; and a government to create the laws. The definition of absolute sovereignty is to live in 'splendid isolation' where the national will is never challenged or compromised. As with security, the notion of absolute sovereignty is unattainable. Cooperation and compromise are essential in all aspects of state interaction and are the basis for international institutions and globalized economies. Absolute sovereignty is incompatible with being part of the international system and a

\footnotetext{
${ }^{274}$ See Keohane Robert and Joseph Nye Jr., "Introduction: The Complex Politics of Canadian-American Interdependence", International Organization, Vol 28, No 4, Autumn, 1974.

${ }^{275}$ Sovereignty is what defines the state and is the principle that claims the ultimate right of selfgovernment, as defined by Buzan and discussed in chapter 2 of this dissertation, - See Buzan, PSF (91), 2009, pp. 72-73; Also Buzan, Waever and de Wilde expand upon this concept of sovereignty as selfgovernment in their chapter on threats to the Political Sector - See Buzan, Wæver, and de Wilde, Security: A New Framework for Analysis, 1998, pp. 150-154.

${ }^{276}$ Although there are adherents to the juristic theory of the state that views state sovereignty as the "personal expression of a supreme omnipotent will" and has no proper application in the field of IR (pp. 83-90), most contemporary IR scholars deem it is inconsistent with modern conditions of interdependence. This has lent legitimacy to the pluralist conception of the state and the view of sovereignty as a negotiated variable (pp. 167-178). - in Schmidt, 1998 - also see Louis W. Pauly and Edgar Grande, eds., Complex Sovereignty: Reconstituting Political Authority in the Twenty-First Century, Toronto: University of Toronto Press, 2005; However, in the parsimony of structural realism, sovereignty is binary, and by definition, "Each state, like every other state, is a sovereign political entity." - Waltz, 1979, p. 96.
} 
member of international society. Therefore, negotiating individual state sovereignty in return for multilateral agreements on the 'rules of the game' in an anarchic world is not unlike the individual trading personal sovereignty for state protection by the sovereign in Hobbesian theory. Rules establish order and create a level of security by mitigating the arbitrary use of power.

Canadian society has constantly been renegotiating its relationship with its more powerful hegemonic partner, first with Britain and then with the US. Louis Pauly and Christian Reus-Smit call this 'complex sovereignty', where "the persistent, complicated, and never-completed negotiation over legitimacy"277 leads to trade-offs in governing principles that are much more than Keohane/Nye's concept of 'complex interdependence'. Thus the Canadian polity finds its monopoly on defining the common good and making collectively binding decisions eroded as it is drawn into networks that facilitate bargaining in conflict resolution with the US. However, Canada has been adept in most forms of negotiation with its larger partner. Canadian society and polity have demonstrated that cultural distinctiveness and commitment to political autonomy are important values when it comes to security policies of choice with the US. Although generally not recognized, Canadian sovereignty is in fact very apparent in the most integrated security institution in the world, the unique, bi-national North American Aerospace Defence (NORAD) Command. Not only does NORAD provide physical protection, this collective security arrangement actually increases Canadian sovereignty in many respects, as will be demonstrated in the relevant case study.

\footnotetext{
${ }^{277}$ Louis Pauly and Christen Reus-Smit "Negotiating Anglo-America: Australia, Canada, and the United States" in Peter J. Katzenstein, ed, Anglo-America and its Discontents: Civilization Identities beyond West and East, New York : Routledge, 2012, p. 129.
} 
Importantly, Canada cannot ignore the security concerns of its neighbour. Whether real or perceived, the security measures that a sovereign United States implements for its own protection normally has global implications that are exacerbated in Canada as a result of its proximity and interdependent economy. Thus, Canadian domestic security issues take on a higher degree of importance due more to the potential threat to acquired values from a recalcitrant US Congress than from international security concerns. US domestic policy poses a far greater existential threat to Canada than military confrontation in the international system. National security for Canadian society begins at home, and then moves bilaterally to continental security followed by international security. This reality is evident in Canada's national security norms whereby Canada capitalizes on its geopolitical position to leverage the resources needed for physical security through reliance on US military power to protect the continent. Although the lack of defence spending is a constant annoyance to America ${ }^{278}$, the cost savings for Canada are used for state protection of other acquired values. Unlike realist assumptions, security options are socially bounded in matters of choice when there is no perception of a clear and present physical danger.

\subsubsection{Foundations of Canadian Society and Polity}

The norms and values of Canadian society are embedded in identities and institutions that form the foundation for 'moral' choice by elites. Canadians share the same intrinsic values that constitute other liberal democracies, particularly with those of the Anglosphere (Australia, Canada, Great Britain, New Zealand, and the US). Therefore,

\footnotetext{
${ }^{278}$ See Norman Hillmer, and J. L. Granatstein, For Better Or For Worse: Canada and the United States into the Twenty-First Century, Toronto: Thomson/Nelson, 2007; Paul Cellucci, Unquiet Diplomacy, Toronto: Key Porter, 2005.
} 
uncovering the specificity of intrinsic, acquired, and instrumental values inherent in Canadian society-polity will lead to an understanding of its national security culture. The national security culture for any state will be evident over time as societal values set limits and the polity constrains acceptable state behaviour with respect to the provision of state sponsored security. To some academics, security culture is a subcomponent of political culture, but seeking to define a national security culture solely within a nation's political culture is too limiting as security norms emerge from society and are mutually constituted with the polity into an evolving political culture. To understand Canadian national security preference formation, three aspects of Canadian society need to be determined prior to identifying security norms.

First, establishing society's relationship with the self and other, ${ }^{279}$ both domestically and with international society, will ascertain the foundations of Canadian collective identity (who we are) and its basic value sets, as well as exposing its worldview. Secondly, determining society's expectations (evaluative norms and values) and instrumental preferences for conflict resolution will lead to establishing state sponsored security preferences. Finally, a strong, functioning liberal democracy has established checks and balances embedded in its polity to protect fundamental, acquired values. However, some acquired values are in greater need of state sponsored protection than others and can only be determined by decision-makers in negotiation with society. Over time, continuous state protection of key national values and interests indicates society's national security concerns. Linking these concerns with recurring policy choices and institutionalization of values provides evidence of national security preferences.

\footnotetext{
279 "Definitions of identity that distinguishes between self and other imply definitions of threat and interests that have strong effects on national security policy." - Katzenstein, 1996b, p. 18-19.
} 
Canadian national security culture becomes evident through understanding Canadian identity, the norms for conflict resolution, and the acquired values where Canadian society expects state sponsored protection. Confirmation of Canadian national security culture is located in the behaviour of actors, the institutions of the polity and the resulting security policies.

\subsubsection{Foundations of Canadian Identity}

Whether one adheres to Lipset's 'foundational moment' theory or new institutionalist theory of 'path dependency and critical junctures', the genesis of a distinct Canadian identity occurred with the schism in British North America caused by the American Revolution. Until that pivotal moment in world history, the British colonies shared common traits; however, those who refused to embrace the new American political identity and values articulated in the Declaration of Independence were forced to leave. Those 'Loyalists' who chose to emigrate to Canada brought with them liberalized 'tory' values that added to the strong conservative character of the two established French and English communities ${ }^{280}$. This created a 'critical mass' of like-minded 'counterrevolutionaries' that would eventually find common ideational ground for the construction of a new state, Canada.

In that period of history, ${ }^{281}$ Canada was merely a strategic pawn in global hegemony. Up until 1759, Quebec was France's strategic hedge against the dominance of the British North American colonies and, after the American Revolution, a British

\footnotetext{
${ }^{280}$ Lipset, 1990, pp. 1-18.

${ }^{281}$ It is important to highlight the fact that the cultural-institutional environment of that time period was dominated by a few elites who projected norms and values to those being governed. Gradually, as the foundations of a Canadian liberal democracy evolved, the impact of the governed became more significant and participatory.
} 
hedge against American expansionism. Two important pragmatic aspects of British control of Canada had to do with its policies towards the conquered French population and aboriginal peoples. The Quebec Act of 1774 guaranteed French language rights, the continued use of civil law, and religious freedom thereby neutralizing, if not in effect winning, the loyalty of French Canada. Based on an original pre-revolutionary French population of less than 55,000 settlers from a quasi-feudal conservative society, a preEnlightenment Catholic clergy filled the leadership vacuum created by the departure of monarchist elites following the British 'Conquest', ensuring a conservative, hierarchical ideology was maintained well into the $20^{\text {th }}$ century. The Roman Catholic Church became the de facto guardian of French Canadian society and cultural values. Survival of Quebec as a 'distinct nation' rested more on greater commonality with British conservative political norms and values than the rival American liberal ones. To French Canadian elites, the universality of American ideology represented an existential threat to French Canada through forced assimilation. "The clergy supported the British crown, condemned the Enlightenment, and assaulted change. Confederation merely offered Quebec a consolidation of its traditions." 282

In addition, First Nations people represented a significant military factor in control of new world territory. In following the successful policies used by the French to respect Aboriginal territorial claims, the British allied themselves with many indigenous groups, thereby eliminating a potential security threat, while at the same time adding a force multiplier to its military presence against an American adversary. Britain's support of indigenous land claims against the onslaught of American westward expansion and its

${ }^{282}$ Wiseman, 2007, p. 179. 
respect for the treaties it signed paid security dividends by transforming a military threat, which would have required extensive resources to address, to one of peaceful law and order. $^{283}$

As Lipset noted, the law preceded settlers and cattlemen in the west of Canada and not just law, but law enforcement. The North West Mounted Police (NWMP) were egalitarian in their application of the law and a nascent Canada was duly rewarded in the non-violent settlement of the prairies. ${ }^{284}$ Although recent scholarship argues that the NWMP were as complicit in the political objectives and economic imperatives of clearing the prairies for settlement as Americans, they agree that the use of violence to achieve these aims differed significantly. ${ }^{285}$ This non-violent, pragmatic approach to reconciling both the French Canadian and First Nations insecurities while meeting political objectives would be the hallmark of future Canadian policy approaches when dealing with security concerns of the 'other'.

Although Lipset's portrayal of the American Revolution as a 'foundational moment' and the impact of Loyalist immigration are academically debated ${ }^{286}$, virtually

\footnotetext{
${ }^{283}$ See Hillmer and Granatstein, 2007, pp 4-8.

${ }^{284}$ For a firsthand account see the autobiography of Sam Steele who was a member of the NWMP at its inception and was a pivotal figure in Canadian national security from 1865 to 1918. His account of arresting Louis Riel, encouraging Sitting Bull to return to the US, and thwarting American plans to annex the Klondike provide direct evidence of the pragmatic, rules based, less-violent approach to national security operations from Confederation to WWI. See Sam Steele, Forty Years in Canada: Reminiscences of the Great North-West with some accounts of His Service in South Africa, Toronto: Prospero Books, 2000, particularly with reference to Chapters VII and VIII regarding the signing of First Nations' Treaties and the amity with Sitting Bull.

285 "While the methods of the police may have diverged sharply - contrast the [Texas] Rangers' enthusiastic dispensation of violence with the relative restraint of the Mounties - the goals and the net results of their efforts were virtually indistinguishable." - Andrew Graybill, Policing the Great Plains: Rangers, Mounties, and the North American Frontier, 1875-1910, Lincoln: University of Nebraska Press, 2007 , p. 4.

${ }^{286}$ Hartz and Horowitz do not see the revolution as important as the common traits that set both North American societies apart from their European roots. See Gad Horowitz, "Conservatism, Liberalism, and Socialism in Canada: An Interpretation,” The Canadian Journal of Economics and Political Science, Vol.
} 
all agree that the immigration of close to 40,000 British subjects loyal to the Crown (Loyalists) had a significant impact on the construction of Canada as an independent country. Although strongly British, Loyalist immigrant culture was modified by the liberal, Lockean ideation of the American colonies and the norms they carried were foundational to the political culture of Upper Canada, as Horowitz and Wiseman have argued. However, their choice to remain loyal to Britain and the organizing principles of the Crown is evidence of their continued fundamental support of the prevailing British political culture of the era, 'toryism'. Given the rejection of revolutionary principles by British colonists in Canada, this influx of like-minded Loyalists consolidated the firm ‘tory'-influenced foundation from which Canadian society would evolve.

Importantly, it must not be forgotten that Canada was governed for much of the next century from England through military commanders with little input from the colonists. An independent Canadian polity evolved slowly under considerable influence of British parliamentarians, British military governors, and the clergy, all of whom were profoundly partial to 'tory'/feudal values ${ }^{287}$ and counter-revolutionary in character. From

32, No. 2, 1966. pp. 143-171; Gad Horowitz, "Notes on 'Conservatism, Liberalism and Socialism in Canada'," Canadian Journal of Political Science, Vol. 11, No. 2, 1978, pp. 383-399; Edward Grabb, James Curtis, and Douglas Baer, "Defining moments and recurring myths: Comparing Canadians and Americans after the American Revolution" The Canadian Review of Sociology and Anthropology, Vol 37, No. 4, Nov 2000, pp. 373-419.

287 Tom Truman, "A Scale for Measuring a Tory Streak in Canada and the United States. ", Canadian Journal of Political Science, Vol 10, No. 3, 1977, pp 597-614.The following are Truman's summary of tory values upon reading of tory and conservative thinkers and statesmen. These seven themes include most of the attitudes which Gad Horowitz described as "tory" in his 1966 essay but at the same time they present a broader conception of toryism-conservatism than his.

(1) Distrust of human nature, pessimism about the future of mankind, and flowing from these convictions, the belief in the necessity of strong authoritative governments.

(2) A religious view of the basis of civil obligation and a conviction that society cannot operate properly and the government cannot rule successfully unless rulers and subjects have religious beliefs.

(3) The organic-corporate-hierarchical-community view of the proper ordering of society and the justification of classes and elitism.

(4) "The right of the community to restrain freedom in the name of the common good." 
a common heritage, the seeds of divergence in national security norms between Canada and the United States developed.

During the formative years of the emerging nation, the fundamental importance of law, order and stability were 'tory' values that underpinned the development of the Canadian national security culture. In promoting a 'rules based society', the British laid the foundation for Canada's approach to conflict resolution both domestically and internationally. Establishing the 'rules of the game' with the 'other', adhering to those rules, and ultimately enforcing those rules in the face of competing interests built trust in the 'other' that allowed for negotiated settlement of insecurities. This minimized the need for violence to resolve frontier issues and, in effect, was the precursor to Canada's approach to international relations. The Quebec Act of 1744 and the 'Great White Mother's' treaties with the First Nations people ensured not only order and stability from within, but loyalty and protection from without against the one enduring existential threat to Canadian society, the United States. As historians Norman Hillmer and J.L.

Granatstein observe, "In practically every way - cultural, religious, legal and political the roots of modern Canada lie in the effort to secure the northern colonies against the United States and prevent the domination of North America by the new nation." ${ }^{288}$ It would be a century before their national identities would go from hostile to coexistent competitors and by the time identities became amicable following the Second World War, Canadian security norms and values were well institutionalized.

(5) The fundamental importance of law, order and stability.

(6) The love of tradition and custom; reverence for the past; and the importance of continuity with the past.

(7) A cautious and somewhat reluctant attitude to change.

${ }^{288}$ Hillmer and Granatstein, 2007, p 5. 
From 1775 until the Treaty of Washington in 1871, there existed a direct military threat to the physical base of Canada from the United States. "After that treaty there was a genuinely undefended border, in great part because the causes of tensions between the two neighbouring communities had been removed." ${ }^{289}$ Although much animosity remained amongst the former belligerents, it brought about international stability on the continent and paved the way for a peaceful and ultimately familial ${ }^{290}$ coexistence in North America. However, removal of the physical threat of annexation to the US did not alleviate Canadian insecurities. As the ties with Britain ebbed and economic interdependence with the US grew, so too did Canadian fears of homogenization and assimilation into the rising American 'empire'. National security became as much about protecting Canadian acquired values 'in practically every way - cultural, religious, legal, [economic], and political' from American hegemony as from perceived threats in the international system. The National Policy of 1879 was one of many Canadian economic protectionist policies designed to safeguard what was distinctively Canadian from the aggressive US competitor. ${ }^{291}$

Conversely, Canadian security norms have been shaped through a reliance on 'imperial' power, first with Britain and now with the US. Canada depended on the British army and navy to protect its territory for 100 years, from the American Revolution, through the War of 1812, the 1837 Rebellions of Upper and Lower Canada, the American Civil War and the Fenian Raids. "Canada could not stand alone as an

\footnotetext{
${ }^{289}$ Ibid, p 38. C.P. Stacey, historian, quoted in For Better Or For Worse.

${ }^{290}$ I use the term familial since the two states are much like siblings, born of the 'same' parents, separated in early 'adolescence', and growing up with similar but different identities. Canadians are not truly 'antiAmerican' so much as they are 'not my sibling'. The anti-American rhetoric used by Canadians is similar to the discourse one hears between siblings when they have differences of ideation and material interests.

${ }^{291}$ Robert Craig Brown, Canada's National Policy, 1883-1900: A Study in Canadian-American Relations, Princeton, NJ: Princeton University Press, 1964; Hillmer and Granatstein, 2007, pp. 40-43.
} 
independent republic, John A Macdonald said many times during his long political career. It needed England at its back.” ${ }^{292}$ Canada may have contributed militia troops throughout, but it required British power to maintain independence.

Although Canada raised world class military forces during two World Wars, it reverted to previous paternalistic security norms by intimately allying itself with the US following rapprochement during the Second World War. Why? Primarily for the same reason that the British departed Canada: money. The costs associated with fielding a large military capable of defending Canada's extensive landmass are excessive and unnecessary so long as the US felt secure. In partnering with the succeeding global hegemon, Canada's physical base would be secure and its costs for national security reduced significantly through continental collective defence. Without global ambitions, the Canadian military could be kept to minimum strength for sovereignty missions and used as an extension of foreign policy goals when available. Resource extraction could be used by society for other security purposes.

Lipset and Resnick ${ }^{293}$ point out the convergent 'tory' and conservative European values held by both English and French Canadian societies following the American Revolution. "Two ethnies, English and French Canadian, each with its own particularistic identity, coexisted side by side within the same federal state."294 Both had respect and deference for authority and accepted the need for strong state leadership, endorsed by hierarchically organized religions that supported and were supported by the state and were strongly communitarian. They were traditionalists that were distrustful of

\footnotetext{
292 Hillmer and Granatstein, 2007, p. 35.

${ }^{293}$ Lipset, 1990, pp. 42-56; and Resnick, 2005, pp.11-29 and 73-82.

294 Resnick, 2005, p.28.
} 
radical change, preferring gradual evolution of the status quo over revolution.

Importantly, the elites in both communities perceived that the greatest threat to their particular societies emanated from American aggression and, although the societies remained apart in fundamental ways, the elite negotiated a partnership in 1867 to address this existential threat, leading to the construction of the larger political community of Canada.

The strong counter-revolutionary character of the Loyalist immigrants added further validation to rejection of American security norms, specifically the use of violence and existential rhetoric to solve political problems. The universalistic set of values embodied in the American Revolution resulted in the United States being in a perpetual state of warfare ${ }^{295}$; a fundamental ideational cleavage in the security norms of the two countries. Although Wiseman argues that Canadian political culture is regional and the result of five waves of immigration, the construction of Canada was built on the sociological foundation and security norms that existed in 1867 and in many cases still prevail today. The ideational influence of post-Confederation immigrants in the evolution of contemporary Canadian security norms has been significant but constrained by the mutual constitution of institutions and value systems established in 1867 .

\footnotetext{
${ }^{295}$ Following the American Revolution the expansion of the original 13 colonies the US remained in a state of war/tension with Britain until 1871. The expansion westward involved significant acts of violence and use of force against the 'other', specifically the First Nations (War of 1812, 1838 Trail of Tears, US Army versus 'Indians' from 1860 to Wounded Knee in 1890) and the Mexicans (1836 Battle of Alamo, 1848 Mexican-American war). In 1898 US expansionism led to the Spanish-American War and assimilation of extra-territorial possessions. Shortly thereafter, the US began its ascension as a global hegemon beginning with WW1 through today. Conflict, violence, and use of force, have been ideational hallmarks in the construction of the United States as a unit of the international system/society.
} 


\subsection{Canadian Culture, Institutions and Security Norms}

It is beyond the scope of this dissertation to holistically investigate all aspects of security norms in Canada and therefore I will consolidate key cross-scholarship Canadian attributes that I will link to security norms that form the Canadian National Security Culture. I will establish the norms and values used to set the evaluative standards for national security found in Canadian culture and identify the cognitive standards embedded in institutions that provide the models and rules that define the social actors, how they operate and how they relate to one another. In 1867 , the fathers of Confederation consciously chose an alternate political path to the prospect of North American political union in the aftermath of the American Civil War. The British North America Act established the institutions from which a pluralist society would emerge, preventing the 'Britishness' assimilation expectations of the early English-Canadian elite, and, in time, selectively embedding many of the virtues of American liberalism through the 1982 Charter of Rights and Freedoms. Canadians willingly remain in a US-led security community, but retain a distinct and independent national security culture. ${ }^{296}$ This section will establish the explanatory baseline for Canadian National Security Culture.

\subsubsection{Foundations of the Canadian Security Culture}

Both the English and French communities in Canada rejected the universalism that emerged out of both the American and French Revolutions. The British 'tory' values were collectivist, where society was hierarchically ordered and individuals fulfilled their

\footnotetext{
${ }^{296}$ Wiseman argues that with modernization and global homogenization there will be a convergence in cross-national values with the US but that significant differences will prevail that will lead to distinctive Canadian and American political cultures. - Wiseman, 2007, p. 42.
} 
duties as social members of an organic community. ${ }^{297}$ This view was reinforced through Anglican and French Catholic religious beliefs in the fallibility of humankind and deference of society to the clergy. English Canadian elites remained staunchly British with no sense of a differentiated Canadian nationality until after the Second World War following the increased trust and economic ties with the US forged in war. The eventual liberalization of the individual would be slow and evolutionary in Canadian culture, given the 'tory' and French Catholic belief that the common good took precedence over individual freedoms. British pragmatism ensured particularistic principles were the cornerstone of Confederation negotiations that established the pluralistic, multicultural foundation of Canadian society.

French Canada, on the other hand, was a community defined by language, religion, and ethnic culture, isolated within an English dominated political structure. Not only did the French-Canadian elite reject the universalism of the American Revolution, the conservative Catholic clergy "instilled a horror of the French Revolution" 298 within French-Canadian society. However, 'la survivance' of French Canada was hotly debated internally and never expressly linked to a larger federation than the Province of Canada (Upper and Lower Canada) imposed by the British government in 1841. Although Sir John A. Macdonald found an ally in Quebec's George-Étienne Cartier, the powerful Bishop of Montreal was less than impressed with Confederation and Cartier's own

\footnotetext{
${ }^{297}$ Horowitz, 1966, p. 393. "In the tory version of collectivism, the individual is an unequal cooperator; his individual rights, duties, welfare, his very being, are aspects of his "station," his social nature, his "membership" in an organic community, a body politic. Society, therefore, is fundamentally a community of hierarchically ordered communities or classes ("estates") and not fundamentally an association of primordially free and equal individuals."

${ }^{298}$ Lipset, 1990, p. 47. Quoted from Mason Wade, “Quebec and the French Revolution of 1789”.
} 
newspaper expressed it as the route to "l'indépendence politique."299 Two distinct societies with idiosyncratic national visions sought state sponsored protection from a common threat, the US, and within the union, Quebec won state sponsored protection for 'the right to be different'. The compromises ${ }^{300}$ made for national security reasons that enabled Confederation were embedded in the British North America Act and the resultant structure of the polity ensured that national unity (pluralism) would always remain an intrinsic, acquired value in Canadian society.

The non-revolutionary character of the founding nations in Canada was instrumental in shaping the basis of national identity, and the ethnic, rather than civic, identity of each founding ethnie reinforced the particularistic nature of Canadian identity. According to Lipset, the particularistic identity of Canada is rooted in the decision of the Francophone clerical elite to remain loyal to the British monarchy as a means of protection from American universalism. ${ }^{301}$ From this point on, the construction of the state slowly took on a bi-national character that legitimated a collectivist approach to rights, paving the way for full acceptance of a multicultural society. Although the two 'founding nations' held universalistic beliefs within their communities, the pre-eminence of the British Empire on the one hand and the Roman Catholic Church on the other, the parallel values each society engendered allowed for a negotiated political accommodation to protect their common acquired values from American aggression, resulting in the particularistic identity of Canadian society.

\footnotetext{
${ }^{299}$ Richard Gwynn, Nation Maker - Sir John A. MacDonald: His Life, Our Times, Volume Two, Toronto: Random House Canada, 2011, p.5.

300 This integration of two communities to form one society is suggestive of Tönnies ideal types, gemeinschaft and gesellschaft, where two social communities established through Wesenwille (natural will) create an associational society by virtue of Kürwille (rational will).

${ }^{301}$ Lipset, 1990, pp. 172-192.
} 
The emergence of a distinctly Canadian identity was slow and evolutionary. The results of the Alaska Panhandle Dispute in 1903 and Canada's treatment by Britain and the US following the First World War amply demonstrated to Canadian political elite that Canada's interests would forever be sacrificed in the competition between the two Anglo 'egoist' superpowers unless Canada could find an independent way to balance competing interests. However, the 'Britishness' of political elite identities continued to be apparent until the exit of Prime Minister Mackenzie King ${ }^{302}$ in 1948 and even then, the transition was slow. Yet, American military and economic hegemony could not be easily ignored, particularly in light of the demise of the British Empire and the challenges of the postSecond World War era. Although the roots of Canadian institutions would remain consistent with the intrinsic values of the 'two founding nations', the transition in Canadian identity towards a more liberal, American-influenced one was facilitated by the realities of Canadian immigration.

In English Canada, nation-building activities conspired to defeat the entrenchment of British ethnic nationalism. As Wiseman's immigration theory showed, the need for workers in a growing economy led to an influx of non-British immigrants that significantly changed the country's demographics. This not only diluted the ethnocultural ties to Britain but introduced a milieu of norms and values that were assimilated into an evolving English Canadian nationalism. The success of Anglo-conformity in language and education had the unintended consequence of creating an immigrant

\footnotetext{
302 John Deutsch negotiated a 'free trade' agreement on behalf of the Canadian Government in 1948, however, PM King feared this agreement would destroy the unity of the British Empire and would provide fodder for his political opponents to tarnish his image as abandoning Canada's proud British tradition in capitulating to the US. See Hillmer and Granatstein, 2007, pp. 173-177.
} 
population that increasingly internalized the conception of Canada as an Englishspeaking nation rather than as a British ethnic nation.

The impact of these changes manifested itself in significant ways. Speaking English became a means of communication and was no longer associated with cultural affinity or a symbol of group membership. The boundaries of ethnic and religious coincidence became increasingly obscured. Group membership in the Canadian nation had to be defined irrespective of ethno-cultural origins. Finally, the historical basis of the collective identity could no longer be identified in Anglo-Saxon terms. As English Canada developed, the nation was forced into a new conception of itself, marking the transformation of English Canadian nationalism from an ethnic to a civic orientation. It was slowly moving towards a multicultural form of nationalism where membership had moved from the culturally exclusive to an inclusive acceptance of ethnic diversity. ${ }^{303}$

In a similar fashion, this was the transformative process that was ongoing in Quebec. With the end of the conservative Roman Catholic social hegemony of ' $\mathrm{La}$ Grande Noirceur' and the period of intense socio-political and socio-cultural change of the Quiet Revolution in the 1960's, a 'habitant' society began the transformation towards modernity. ${ }^{304}$ The resulting decreased birth rate and strict French language laws meant Quebec has seen a significant increase in immigrants who speak French but have diverse

\footnotetext{
${ }^{303}$ See Raymond Breton, "From ethnic to civic nationalism: English Canada and Quebec", Ethnic and Racial Studies, Vol 11, No. 1, 1988, pp. 85-102; Also an unpublished paper by Alan Stephenson, "Canadian Nationalism / Nationalisme Québécois" submitted to meet requirements for Carleton University, PSCI 6105.

${ }^{304}$ Rand Dyck, Canadian Politics: Critical Approaches, $6^{\text {th }}$ edition, Toronto: Nelson Education, 2011, p. 106; La Grande Noirceur is a Quebec term referring to the conservative policies undertaken in close cooperation of the Roman Catholic Church by the government of Quebec premier Maurice Duplessis in the 1936-1939 and 1944-1959 period.
} 
cultural backgrounds. ${ }^{305}$ As more and more immigrants populate Quebec, they dilute the cultural affinity to Old Quebec as they assimilate as Québécois(e) into French Canadian society. The sovereignty of Quebec was seen by Jacques Parizeau and the Parti Québécois as the solution to the existential threat to 'pure laine' culture. Although a majority of Québécois(e) rejected the specificity of the perceived threat to this ethnic nationalist cultural value, they will undoubtedly continue to seek state protection for Quebec's particularistic cultural needs, as have English Canadians. The foundational values of both the British 'tory' and Quebec's 'pure laine' are institutionally embedded in the polity and state through the negotiated compromises and accommodations made during Confederation in 1867 , but continue to adjust as a distinctly Canadian identity evolves.

The rise of Quebec nationalism in the 1960s prompted Prime Minister L.B. Pearson to put the Constitution on the national agenda and he turned to Pierre E. Trudeau, a recognized expert on federalism, to lead the way. Intellectually, Trudeau considered nationalism the enemy of individual freedom and material well-being by preventing any cross-fertilization among cultures. According to law professor Lorraine Weinrib, "Trudeau admired the federal state as an antidote to nationalism." He viewed the compromises among countervailing visions, powers, and priorities required of democratic federalism in Canada as the solution to the chauvinism and intolerance found in unitary

\footnotetext{
${ }^{305}$ Immigration averages 50,000 newcomers a year in Quebec. Of these $40 \%$ are non-French speaking. Since 1991, Quebec has had control over immigration policy for the province - confidential interview with Citizen and Immigration Canada.; Alan Stephenson, "Canadian Nationalism / Nationalisme Québécois", unpublished paper, November, 2011.
} 
nation-states. "[B]y accommodating the pluralist, multicultural societies of the postwar world, federalism would facilitate the developing patterns of interstate cooperation."306

Trudeau's ideological position found fertile ground in the intrinsic values of Canada's pluralist society and after much negotiation with the provinces, the popular “peoples' package" of constitutional reforms was adopted. The implications of the Charter will be discussed later, but the resultant product was based on ideological factors and not material forces. A reconstituted Canadian Bill of Rights could have taken on many forms, but unlike the majority of other states which acquired their bill of rights following periods of upheaval, the Charter was a negotiation of acquired values. Trudeau's ideational imprint is indelibly embedded in Canadian identity through the Charter of Rights and Freedoms. Significantly, this ideational shift in the nucleus of the state (ideas and institutions) from communal norms towards individualism has altered the instrumental norms available to the nuclear force (society-polity) in addressing security concerns.

\subsection{Framing Canadian National Security Culture}

Five distinct sets of norms emerge from analysis of the literature on Canadian society with respect to identity, values, culture, and interests that shape national security preferences; sovereignty, particularism, collectivism, respect for authority and pragmatism. Sovereignty is the force that holds Buzan's three elements of the state together and is therefore the paramount constitutive norm, as well as the primary security interest as an intrinsic value, of any national society that chooses to remain a defined

\footnotetext{
${ }^{306}$ Lorraine Weinrib, "Trudeau and the Canadian Charter of Rights and Freedoms: A Question of Constitutional Maturation", pp. 258-282, in Andrew Cohen and J.L. Granatstein, eds., Trudeau's Shadow: The Life and Legacy of Pierre Elliott Trudeau, Toronto: Random House of Canada, 1998, p. 262.
} 
state. State protection of Canadian sovereignty and identity is defined endogenously with respect to domestic rather than Waltzian systemic factors. Particularism is both the organizing principle of the Canadian polity and a world view held by Canadian society. As there is no one universal set of security norms for Canadians, contestation for the protection of acquired values is to be expected amongst actors and therefore, in general, national security becomes a matter of 'moral choice' by decision-makers.

Collectivism is not only a foundational constitutive norm in Canada, but a fundamental security norm. Collective security has not only grown in the traditional national security sense from a domestic response to American aggression to international alliance participation in security communities, but has also expanded to include state protection of acquired values found in all of Buzan's five sectors. Respect for authority has a profound effect on security norms as Canada is not only a rule oriented, law abiding society domestically, but has expectations that the security norms of international society should be based on the same principles. Therefore, Canada's efforts in building international regimes that provide stability through knowing and enforcing the 'rules of the game' not only create interdependence but are fundamental to non-violent, conflict resolution.

Canadian pragmatism is the final constitutive norm that explains its security culture and is closely linked to respect for authority. Use of force is viewed as an act of last resort in Canada and as such, Canadian elites have found pragmatic, non-violent solutions to solve potential threats to national and international security. Non-violent resolution of French and aboriginal security concerns in the first hundred years, followed by risk managing the threat of assimilation by America in the next hundred years, created 
national security norms that hold fast to liberal democratic values, but provide flexibility to decision-makers in applying instrumental values in the pursuit of pragmatic national security policies. In the following section, the strength of these five norms will be demonstrated through evidence of specificity, durability, and concordance 307 of both regulative and constitutive norms.

\subsubsection{Sovereignty and Security Norms}

The most important observed security norm regarding Canadian sovereignty is that Canadians do not perceive a realistic, clear and present military threat to the physical base of the state. ${ }^{308}$ This specific absence of fear of a direct military threat in Wolfers' subjective sense has significant impact on determination of what intrinsic and acquired values constitute national security values in the objective sense. Certainly Canadians are realistic enough to understand the dangers posed by a rising China and a resurgent Russia, but other than at the height of the Cold War ${ }^{309}$, Canada's military force only amounted to a modest, professional contribution in Europe rather than a robust, standing power prepared to repel 'the enemy at the gate'. Despite surges during the

\footnotetext{
${ }^{307}$ See Jeffrey Legro, "Which Norms Matter? Revisiting the 'Failure' of Internationalism", International Organization, Vol 51, No 1, 1997, pp. 31-63; For a succinct discussion on the strengths and weaknesses of norm research see, Paul Kowert and Jeffrey Legro, "Norms and identity and their limits: A theoretical reprise", in Katzenstein, The Culture of National Security, 1996b.

${ }^{308}$ See the current Harper government's 2008 Canada First Defence Strategy; the Martin government's 2004 National Security Policy and 2005 International Policy Statement; Elinor C. Sloan, Security and Defence in the Terrorist Era: Canada and the United States Homeland, 2nd ed., Montréal: McGill-Queen's University Press, 2010; Stéphane Roussel, The North American Democratic Peace: Absence of War and Security Institution-Building in Canada-US Relations, 1867-1958, Montreal: McGill-Queen's University Press, 2004.

309 “.....after an initial burst of commitment that carried its military to Europe on a wave of defence spending in the early 1950s, Canada let its security-building enthusiasm wane. Canada preferred to regard NATO as a political arrangement, doing only as much militarily as was necessary to maintain a modicum of credibility inside the alliance. ..... Witness Prime Minister Pierre Trudeau's 1969 decision to withdraw half of the Canadian force from NATO Europe, and the malnourishment of the military which has followed over the decades since." - Norman Hillmer, "NATO: When Canada Really Mattered", The Canadian Encyclopedia, Historica Canada, 04/03/15 found online on 03 November 2015 at $\mathrm{http} / / / \mathrm{www}$.thecanadianencyclopedia.com/en/article/nato-when-canada-really-mattered-feature/
} 
Second World War and early Cold War, Canada has maintained a minimalist approach towards its military force through chronic underfunding ${ }^{310}$ such that American leaders have made defence an issue in Canadian-American relations from F.D. Roosevelt onwards. ${ }^{311}$ This undermines realist assumptions of a state's natural desire for the domination over others and the need for a powerful military for security-maximization in an anarchic world. It is even questionable, given the continued US consternation over Canada's lack of defence spending, whether Canada's military power even constitutes 'influence maximization'.

However, in line with realist assumptions, Roosevelt made it quite clear to Canadian elites, in his famous "the people of the United States will not stand idly by if domination of Canadian soil is threatened" speech at Queen's University in August $1938,{ }^{312}$ that Canada had little choice but to provide adequate national security or it would be provided for them. This was the first of many reminders to Canada that Canadian sovereignty depended on keeping America's northern border (ie the second layer of United States National Defense Strategy 2008) safe and secure. This stated reality resulted in the establishment of instrumental values that balance Canadian identity with cooperative security norms. In effect, Canadian security policies must take into

\footnotetext{
${ }^{310}$ Dave Perry, "Defence Budget 2015: The Promise of Long-term Funding, but Short-term Deficits Remain" in The Dispatch, Volume XIII, Issue II, Calgary: Canadian Global Affairs Institute, 2015; Douglas L Bland, Canada without Armed Forces?, Montreal: McGill-Queen's University Press, 2004; J.L. Granatstein, Who Killed the Canadian Military?, 1st ed., Toronto: Harper Flamingo Canada, 2004.

${ }^{311}$ See Hillmer and Granatein, 2007, p. 133 - "Roosevelt made defence an issue in Canadian-American relations, bringing it up in every encounter with King from their meeting in Quebec City [1936] until the outbreak of war in Europe.”; Paul Cellucci, Unquiet Diplomacy, Toronto: Key Porter, 2005.

${ }^{312}$ Receiving an honorary degree from Queen's University on 18 August 1938, Roosevelt used the occasion to make an important foreign policy speech as war was looming in Europe. Balancing domestic isolationist imperatives with international realities, he declared, "The Dominion of Canada is part of the British Empire. I give to you assurance that the people of the United States will not stand idly by if domination of Canadian soil is threatened by any other empire."
} 
consideration the continuing primacy of security in the United States and manage Canadian sovereignty accordingly in what Pauly/Reus-Smit defines as 'complex sovereignty'. In other words, a key evaluative norm in Canadian National Security Culture is whether or not a Canadian security policy will positively or negatively impact US insecurities.

With the signing of the 1940 Ogdensburg Agreement and subsequent integrated economic/military cooperation throughout the Second World War, the CanadianAmerican security relationship transitioned from initial enmity to continental competitor to cooperative neighbour to eventual amity/alliance. Throughout the journey, the one existential security concern to sovereignty has been the threat of assimilation by the US, whether by force or acquiescence. Robert Cox's cogent essay on Canada's dilemma of whether to orient its culture and economy east-west or north-south encapsulates the historic Canadian struggle. ${ }^{313}$ The evolution of Canada was east-west because of history, although as Wiseman points out, the regionality of North America naturally orients economic and cultural forces north-south. The question of economic sovereignty has ebbed and flowed between the protectionist 1879 National Policy and the integrated 1993 North American Free Trade Agreement (NAFTA). Every debate has revolved around the balance between sovereignty and prosperity amidst the concern that economic alignment is tantamount to tacit absorption and annexation to the US. Importantly though, prosperity is another key evaluative norm in Canadian National Security Culture as the polity understands that Canadian national power is primarily derived from its relative prosperity and Canadian society sees prosperity as a central acquired value.

\footnotetext{
${ }^{313}$ Robert W Cox, "A Canadian Dilemma: The United States Or the World," International Journal, Vol 60 No.3, 2005, pp. 667-84.
} 
As British influence and culture waned and technology enabled mass media communication, Canadian nationalists began to see American mass culture as an existential threat to Canadian identity. To counter the enormity, proximity, and allure of the US marketplace and its homogenizing effect, the government began state intervention to protect Canadian culture through high tariffs that discouraged importation of magazines in 1928 and the enactment of the 1932 Canadian Broadcasting Act that created a publicly owned and controlled national radio network. ${ }^{314}$ State protection of culture is fundamental to the particularist acquired values found in Canadian identity. State sovereignty over culture remains a cornerstone of Canadian national security norms as demonstrated in the 1989 Canada-US Free Trade Agreement (FTA) that specifically included the right for Canada to protect its cultural industries and specific culturally important sectors such as health and education. State sovereignty and protection over culture is central to Canadian unity as the state, and its institutions, are the arbiter and defender of often politically charged decisions in a multicultural society. ${ }^{315}$

The absence of a direct military threat to Canada's physical base has meant that the size of Canada's military was dependent on factors other than realist balance-ofpower calculations, providing Canada with greater flexibility in developing international security policy. Autonomously, Canada would require a significantly large army, navy and air force to provide complete sovereign protection of the second largest country in

\footnotetext{
${ }^{314}$ Hillmer and Granatein, 2007, pp. 102-104.

${ }^{315}$ National unity has been a central preoccupation with the Canadian federal government in both political and practical terms from Confederation onward. PM Macdonald understood the political importance of ensuring Quebec's cultural concerns as Quebec not only represented close to half the electorate, but ignoring French particularities would have been, in his words, "enough to secure the repudiation of Confederation by the people of Lower Canada." (Quoted in Gwyn, 2011, p. 366). Institutionally, cultural rights have been embedded in the legal institution from the Quebec Act to the Charter of Rights and Freedoms which requires state protection in some form as a matter of law.
} 
the world. Bilateral agreements with the US, such as NORAD, and multilateral agreements, such as the North Atlantic Treaty Organization (NATO), allow Canada to maintain a minimal military force to ensure Canadian sovereignty at home while providing any excess capability to the international community as an extension of Canadian foreign policy. Importantly, sovereignty over foreign policy in national security affairs is an acquired value that Canada has imaginatively exercised within realist paradigms. Through application of national security norms consistent with Canadian National Security Culture, Canada has pursued internationalist foreign policies that have in turn supported both allies and international institutions.

Challenging the prevailing Canadian identity with Britain, the St. Laurent Government drew on national security norms to work through the United Nations (UN) in creating and fielding the first major peacekeeping force to address the combined British-French-Israeli invasion of Egypt in the Suez Crisis of 1956. In providing a pluralistic solution, Canada provided Britain with a face-saving exit from the venture, drew the appreciation of the US, demonstrated the utility of the UN in non-violent dispute resolution, and established peacekeeping as a Canadian instrumental value in international relations for decades. The dilemma for Canada has been in balancing sovereign preferences with international politics. This has been problematic at times for Canada's bilateral relationship as some sovereign Canadian national security policies have drawn the ire of the US, such as with Prime Minister Pearson's Temple University talk on Vietnam and Prime Minister Jean Chretien's rejection of Canada's participation in 
the 2003 invasion of Iraq. ${ }^{316}$ Without the burden of global leadership responsibilities and the lack of power projection, Canada prefers to find pragmatic solutions to security issues, in line with its particularistic and communitarian values that are within the established 'rules of the game'. All of these international policy choices are explicable in terms of Canadian National Security Culture.

\subsubsection{Particularism and Security Norms}

The consequences of the non-revolutionary trajectory for the emerging Canadian society are well documented. The American and French Revolutions inculcated a universalistic set of values in their respective societies that were rejected by both English and French Canadians who remained adherents of pre-revolutionary, old European values. ${ }^{317}$ The ethnic character of the nascent Canadian identity also reinforced a particularistic version of nationality due to the requirement for negotiation and accommodation rather than through a universal civic prism. Each society held particularistic values for different reasons, but was able to overcome significant differences to develop the pluralistic, multicultural identity of contemporary Canada.

The sense of 'Britishness' in the social identity of the English Canadian elites was a "highly particularistic and racially tinged notion of origin" 318 that was instrumental in defining and constructing state institutions. However, the governing elite also recognized that for demographic and economic reasons particularistic compromise and accommodation with French and non-British immigrants were essential in nation-

\footnotetext{
${ }^{316}$ See Eddie Goldenberg, The Way it Works: Inside Ottawa, Toronto: McClelland \& Stewart, 2006, pp. 293-295.

${ }^{317}$ Lipset, 1990, pp. 52-56, quotes a number of leading academics in demonstrating that both French and English societies rejected many of the American universal values (contempt for authority, lack of respect for the law, concern over order and harmony) through sociological surveys and studies of the content from educational institutions. ${ }^{318}$ Resnick, 2005, p. 25.
} 
building. Additionally, as a member of the British Empire, Canada was automatically part of a larger international framework. Being part of a larger whole meant accepting the limitations of Canada's position within the Empire as well as the security obligations that such membership entailed. Thus, within the dominant English Canadian political class, Canadian national security norms have been mutually constituted within the context of particularistic values defined by both the international and the domestic environments from the beginning.

Although it can be said that French Canada retained the universal values of Catholicism, it preserved its particularistic identity within the framework of the new nation. The negotiations towards Confederation resulted in the particularistic organizing principles of the Canadian polity that guaranteed French Canada would be granted significant powers through government decentralization and representation in the polity. ${ }^{319}$ This, in effect, allowed two particularistic nationalities (Hugh MacLennan's Two Solitudes) to "dwell within the bosom of a single state, each rooted in its own version of the European past....What membership in empire was for one, membership in a universal religion was for the other." ${ }^{320}$ Quebec always suspected the EnglishCanadians who owed their highest loyalties to Britain and not to their homeland. 'Les Canadiens' identified themselves first and foremost as French North Americans and vehemently opposed participation in the defence and foreign policy vortex of the British Empire.

The conscription crisis of the First World War highlights the particularistic nature of Canadian security norms. French-Canadian opposition to the war is well known. In

\footnotetext{
${ }^{319}$ Dyck, 2011, pp. 459-461; Landes, 2002, p. 79.

${ }^{320}$ Resnick, 2005, pp. 28-29.
} 
1917, Prime Minister Sir Robert Borden decided to introduce conscription by forming a coalition government with Laurier, the Liberal Opposition leader. Although Borden achieved his aim by bringing most English speaking MPs onboard, Laurier refused and the country was seriously split along cultural-linguistic lines. Easter riots in 1918 were sparked by French-Canadian nationalist frustrations over perceived English-Canadian imperialist domination. This cultural schism had the lasting effect of Borden's Conservative party being all but shut out of Quebec for the next 50 years. ${ }^{321}$ Upon succeeding Laurier as Liberal leader and wary of the residual resentment in Quebec, Prime Minister King skillfully pursued Liberal party reconciliation and avoided repeating the politically damaging divisiveness inherent in the question of conscription during the First World War.

King understood Quebec's cultural reticence to becoming involved in foreign wars and 'imperial crusades'. French Canada did not have the internationalist inclinations of English Canada, particularly in the use-of-force. King also understood the political ramifications of alienating a significant section of the electorate that in many cases held the balance of power in making or breaking future governments. The regionalist, or particularistic, norms of Canadian society have a significant impact on the polity, particularly with respect to decision-makers who must balance the competing subcultures and interests. As Wiseman points out, the Prairies have an American-style universalistic leaning in their political culture. Naturally, this at times will be in contestation with the more particularistic political culture of Quebec. Divisive national security policies have real domestic consequences that decision-makers must take into

\footnotetext{
${ }^{321}$ Although R.B Bennett actually did fairly well in the 1930 election, the Conservative party never regained a prominent federal role in Quebec until the re-election of John Diefenbaker in 1958.
} 
account when making 'moral choices' and the particularistic structure of the Canadian polity increases the variables for decision-makers to consider.

Therefore, it is insufficient to analyse Canadian national security policy simply at the level of the state. It leads to misunderstanding causal mechanisms behind "Canada's Irrational International Security Policy” or in making sweeping causal claims about Canada's anti-American identity to explain "Canada as a unique nation with a necessarily ambiguous foreign policy." 322 National security in Canada is determined in large measure through domestic contestation of intrinsic and acquired values as well as regional interests. National unity has been a preoccupation of successive leaders from Confederation onward as this is the second most important national security priority behind sovereignty. ${ }^{323}$ Talcott Parsons has identified the tensions between particularism and universalism as 'dilemmas of choice', and, as Wolfers pointed out, national security involves a 'moral choice' amongst competing values. National unity is a particularist acquired value that relies on state protection and is in competition with security for national resources.

Canadian elites have generally avoided universalistic approaches to foreign and defence policy, preferring pragmatic, particularistic solutions that fit within the security norms of the pluralist Canadian society. Outside of collective defence responsibilities, which will be discussed later, international security policies have remained independent and collaborative, balancing the English School's concept of order and justice with

\footnotetext{
${ }^{322}$ Massie, 2009; Vucetic, 2011, p 21.

${ }^{323}$ See Steven Kendall Holloway, Canadian Foreign Policy: Defining the National Interest, Peterborough: Broadview Press, 2006.
} 
Canada's role in international society. ${ }^{324}$ Contrary to realist assumptions, national security policies are not necessarily linear and linked to power associations. Canada has been able to avoid entanglement in American-led military ventures, such as Vietnam and the 2003 Invasion of Iraq, through provision of alternative forms of military support operations that appeal to Canadian National Security Culture. This has manifested itself in national security policies, such as playing a major role in the United Nations Peacekeeping Force in Cyprus (UNFICYP) that significantly assisted the US in maintaining NATO solidarity as well as increasing Canada's military contribution to the NATO-led Afghanistan mission in lieu of participation in the 2003 Invasion of Iraq. Canadian independence has been maintained and alliances preserved through pluralistic assessment of common goals and particularistic policy choice that are designed for the common good, but may be contrary to the political desires of the presiding US authorities.

Although foreign and defence policy decisions rest with the Canadian government executive, maintenance of its power in office is dependent on justification for their 'moral choices' to the society that elected it. Thus the instrumental values chosen to justify policy choices must fit within Canadian National Security Culture if the government is to retain support. Although many link peacekeeping with Canadian identity, peacekeeping is not the only means available that is in concert with Canadian acquired values. Peaceenforcement operations, such as Korea (1950-53), Gulf War 1990, and the Libya Civil War 2011, are well within Canadian security norms and are instrumental options that also must meet national security culture norms. Canada's so-called 'irrational international

${ }^{324}$ Keating, 1993, p. 246 
security policy' is very rational when understood as a particularistic policy choice based on domestic security norms found in Canadian National Security Culture that takes exogenous factors into consideration by elites in making 'moral choices'.

\subsubsection{Collectivism/Communitarianism and Security Norms}

Collectivism is a social pattern in which individuals construe themselves as parts of collectives and are primarily motivated by duties to those collectives. Collectivism was a foundational norm of both feudal and 'tory' societies. Horowitz distinguishes 'tory' collectivism from American individualism "in terms of an organic-class-cooperative as opposed to a Hobbesian or Lockean social contract view of the relationship between individual and society." ${ }^{325}$ Communitarianism is also used to describe Canadian identity and was an evolution of the collectivist / particularist ${ }^{326}$ foundational norms. Like collectivism, which stresses human interdependence and the importance of a collective,

\footnotetext{
${ }^{325}$ Horowitz, 1966, p. 393 - "In the tory version of collectivism, the individual is an unequal cooperator; his individual rights, duties, welfare, his very being, are aspects of his "station," his social nature, his "membership" in an organic community, a body politic. Society, therefore, is fundamentally a community of hierarchically ordered communities or classes ("estates") and not fundamentally an association of primordially free and equal individuals."

${ }^{326}$ The following account of Charles Taylor's particularistic analysis of human rights norms is indicative of the process that applies to the communitarian analysis of national security norms within Canada and applied to international society. "Charles Taylor has put forward the following proposal. He imagines a cross-cultural dialogue between representatives of different traditions. Rather than argue for the universal validity of their views, however, he suggests that participants should allow for the possibility that their own beliefs may be mistaken. This way, participants can learn from each other's 'moral universe'. There will come a point, however, when differences cannot be reconciled. Taylor explicitly recognizes that different groups, countries, religious communities, and civilizations hold incompatible fundamental views on theology, metaphysics, and human nature. In response, Taylor argues that a 'genuine, unforced consensus' on human rights norms is possible only if we allow for disagreement on the ultimate justifications of those norms. Instead of defending contested foundational values when we encounter points of resistance (and thus condemning the values we do not like in other societies), we should try to abstract from those beliefs for the purpose of working out an 'overlapping consensus' (to borrow from Rawls's 1993 terminology) of human rights norms. As Taylor puts it, 'we would agree on the norms while disagreeing on why they were the right norms, and we would be content to live in this consensus, undisturbed by the differences of profound underlying belief' (Charles Taylor, 'Conditions of an Unforced Consensus on Human Rights', in J. R. Bauer and D. Bell eds., The East Asian Challenge for Human Rights, New York: Cambridge University Press, 1999, p. 124)" quote found in Daniel Bell, "Communitarianism", The Stanford Encyclopedia of Philosophy, Fall 2013 Edition, Edward Zalta, ed., URL = $<$ http://plato.stanford.edu/archives/fall2013/entries/communitarianism/>.
} 
communitarianism focuses on community and society, and seeks to give priority to group goals over individual goals.

Communitarianism is a $20^{\text {th }}$ century political doctrine that emphasizes the public mobilization of state resources to fulfill group objectives and is a more appropriate term to describe Canadian norms, as collectivism and socialism are often associated with authoritarian, non-capitalist regimes in contemporary academia. Horowitz interpreted the strength of Canadian 'socialism' with 'tory' conservatism's collectivist norms; however, Wiseman goes to great lengths to demonstrate the limitations of this theory, particularly in arguing that the regional disparity of Canadian support for socialist policies are not linked to areas of Loyalist migrants. Wiseman cites evidence of social democratic values being strongest in the west but weakest "where the Loyalist tory imprint was formative and most profound" to refute Horowitz's findings. ${ }^{327}$

Wiseman describes Saskatchewan and Manitoba as a social democratic region where the fourth wave of Canadian immigration (1890-1920) had the greatest impact. The transplant Ontarians brought 'tory' and liberal ideologies with them and the new immigrant Britons established labour-socialist parties and trade unions, while East Europeans brought socialist-communist ideologies. Economically challenged, the majority were subsistent farmers supporting the 'staples' economy. These settlers developed a radical agrarian political culture that demanded constitutional control over their natural resources from the federal government. The social democratic traditions in

${ }^{327}$ Wiseman, 2007, p 10. 
Canada found their genesis in the Midwest as the home of medicare and of the social democratic parties. ${ }^{328}$

Although the genesis of communitarian policies may have emerged in the Midwest, the evolution of Canada as a welfare state has ideological roots in all regions. Social and economic state intervention, in fact, was used by the British in establishing Canada through chartered companies such as the Hudson's Bay Company and immigration policies that in the 1750 s provided a full year's supplies to German immigrants to populate Nova Scotia. The size and geographical nature of Canada demanded state protection of social and economic values as a means of nation building ${ }^{329}$ and protection from American assimilation. Prime Minister Brian Mulroney’s expression of Canadian state welfare provisions as a 'sacred trust ${ }^{330}$ and the rise of the NDP party to opposition status in Canada's $41^{\text {st }}$ Parliament as a result of strong support in Quebec are contemporary examples of this.

Economic prosperity and social welfare are closely tied in Canada, making economic security an acquired value. Capitalism and communitarianism are in ideological tension as the individualistic, liberal form of US capitalism conflicts with the more state

\footnotetext{
${ }^{328}$ The Co-operative Commonwealth Federation (CCF), the precursor to the social democratic New Democratic Party (NDP), had significant success in provincial politics. In 1944, the Saskatchewan CCF formed the first socialist government in North America. Today, the NDP form the official opposition in Canada's $41^{\text {st }}$ Parliament.

${ }^{329}$ Hillmer and Granatstein, 2007, p.41, explain the appeal of the 1879 National Policy. "If there was to be a Canada, therefore, the construction of a strong economy with an industrial base and secure markets was not desirable but imperative. Brown sees the tariff as having fairly rapidly become synonymous with 'the nation,' a way of safeguarding the distinctive."

${ }^{330}$ Michael Prince and James Rice, "Governing through Shifting Social-Policy Regimes: Brian Mulroney and Canada's Welfare State", in Raymond B Blake, Transforming the Nation: Canada and Brian Mulroney, Montreal: McGill-Queen's University Press, 2007, pp 166-168. "Mulroney began his first term as prime minister with his famous election promise of maintaining "sacred trust".... This promise, and his rhetorical choice of phrase, reflected a long-standing pattern of support for the central role that social welfare played in the Canadian psyche."; "Canada's version of a welfare state moved from a policy regime that was rooted in a set of ides influenced by Keynesian economics, and that focused on social justice, social rights, and financial-resource enhancements, towards a style intellectually based in 'Reaganomics".
} 
controlled and socially oriented economic policies favoured by Canadians. Since Confederation, politics have revolved around the Canadian dilemma of the desire for beneficial economic ties with the US against the existential threat that closer economic ties will lead to the loss of acquired values and assimilation. The social contract that retains legitimacy between the state and its citizens has favoured public involvement in the economy and a redistribution of wealth through federal equalization payments to the provinces to support state sponsored social programs. "Pierre Trudeau adopted the 'just society' as his slogan, further legitimizing a more activist role on the part of government in the social arena." ${ }^{" 331}$ Government support of socio-economic programs is an acquired value that is instrumental in nation-building as well as for protection from Canada's economically powerful neighbour.

Lorraine Eden and Maureen Appel Molot have identified three periods of nationbuilding in Canada that they term 'national policies'. The "National Policy" of defensive expansionism (1867-1940) relied on tariffs for industrialization, state sponsored railway construction, and land settlement to build the country. A second 'national policy' (194181) committed Canada to international regimes such as General Agreement on Tariffs and Trade (GATT) to ensure the flow of Canadian goods, Keynesian macroeconomic policies that produced many Crown corporations, and the construction of a domestic social welfare net. The third 'national policy' began with the Mulroney government and relies on free trade agreements such as NAFTA, market-based social policies and reduced state intervention. ${ }^{332}$ Over these three periods, Canada has struck a balance between

\footnotetext{
${ }^{331}$ Resnick, 2005, p. 50.

${ }^{332}$ See Lorraine Eden and Maureen Appel Molot, "Canada's National Policies: Reflections on 125 Years", Canadian Public Policy, Vol 19, No.3, 1993, pp. 232-251.
} 
communitarianism and capitalism that has resulted in an economy almost equally balanced between public and private sectors. ${ }^{333}$

The reality for Canadians is that some form of harmonization with the US economy is inevitable, but economic independence can only be assured through negotiation and establishing 'rules of the game' through multilateral and international regimes. Canada's economic survival has depended largely on its history of negotiating favorable terms for trade with the US. The economic crisis of 1947 forced Canada to consider accepting a "special form of customs union" 334 with the US; however, astute diplomacy and American geo-strategic interests provided Canada with access to the Marshall Plan funds, thus averting the loss of Canadian economic independence. ${ }^{335}$ Although, at the time, King rejected a negotiated reciprocity treaty, the process of negotiation continued to establish bilateral 'rules of the game' that protected Canadian acquired values from American arbitrary exercise of power and the unintended consequences of an American style free-market economy, from the 1965 Auto Pact to NAFTA.

As a middle-power member of international society, establishing a multilateral web of international norms was a priority in Canadian foreign and defence policy in the aftermath of the Second World War to ensure a world of peace and prosperity, with institutions such as United Nations (UN), Bretton Woods and GATT. There was a recognized need for addressing the wide spectrum of insecurities that had led to two

\footnotetext{
${ }^{333}$ Rand Dyck, Canadian Politics: Critical Approaches, $6^{\text {th }}$ edition, Toronto: Nelson Education, 2011, p.257.

${ }_{334}$ Hillmer and Granatstein, 2007, p. 174.

${ }^{335}$ Ibid, pp 167-177. John Deutsch of the finance department was one of the principle negotiators who were "positively eager to speed the process of [closer economic] integration" with the US. Deutsch told a journalist, "The price of a customs union with the U.S. is the loss of political independence in the sense that we would no longer be in effective control of our policies." - p. 174. Although Deutsch believed that King was favourable to the deal, King ultimately decided the political price was too high to approve the free trade deal. - p. 176.
} 
World Wars through multilateral institutionalization. Concerned with superpower collaboration and domination in the post-war reconstruction of the international system, Canada took the position that, "The government of any nation, however small, must desire to participate in the great task of ensuring its own security. Moreover, multilateral associations were widely recognized as the most effective means for dealing with Canada's "American problem." ${ }^{336}$ Canada recognized the multifaceted insecurities that brought states to the brink of war and therefore championed broad multilateral resolution mechanisms to security concerns in a number of emerging international institutions, such as the inclusion of the 'Canadian article' in the North Atlantic Treaty. ${ }^{337}$ To Canada, security meant more than just military power; it meant addressing the sources of insecurity as well.

The UN was seen by Canada as a universal, multipurpose organization that would recognize the capabilities and interests of the lesser powers as well as provide collective security. It would be an institution that would provide conflict resolution when other means failed. In pursuing 'internationalism' as a foreign policy, Canada drew on the intrinsic values of its communitarian society in establishing a more stable, orderly world based on recognized rules. It was also recognized at the time as the most effective means for dealing with Canada's 'American problem', as international norms could be effectively leveraged against American bilateral interests. To Canada, national security entailed more than just military power and foreign relations. It also included all of the causal linkages that led to state insecurities and the eventual use of force to address them.

\footnotetext{
${ }^{336}$ Tom Keating, Canada and World Order: The Multilateralist Tradition in Canadian Foreign Policy, Toronto: McClelland and Stewart Inc., 1993, p. 21.

${ }^{337}$ Hillmer and Granatstein, 2008, p. 180.
} 
The idealism of collective security provided by the UN was short-lived as the Canadian government realized in 1948 that the veto power of the UN Security Council would limit any meaningful security cooperation amongst major powers. Although Kantian world peace was unobtainable through the UN, Canada was keen on forming a security alliance with like-minded nations to counter American isolationism, promote freer trade tied to defence, and provide collective security of democratic values. ${ }^{338}$ In 1949 Canada was one of the twelve original signatories to the North Atlantic Treaty that created NATO, a collective defensive organization designed to protect democratic states from communist aggression. Whether one uses the layman terminology of 'strength in numbers', or realist taxonomy of bandwagoning, or constructivist security regimes, the fact remains that Canada has a history of collective security, beginning with Confederation. That communitarian concept is part of the Canadian National Security Culture.

As noted earlier, Canadian identity has increasingly moved away from the British towards the American value system, a development that Lipset cautioned would likely move Canada away from communitarian values. A critical juncture occurred in Canadian society with the inclusion of the Charter of Rights and Freedoms (Charter) into the Canadian Constitution, which altered the communitarian proclivity towards political involvement in the common good to one of privileging individual rights under judicial restraint. Rand Dyck identifies three eras en route to the Charter. The first era began with the Westminster parliamentary system inherited by Canada. It is based on parliamentary restraint within parliamentary supremacy whereby civil liberties were

\footnotetext{
${ }^{338}$ Hillmer 2007, pp. 179-180.
} 
dependent on the respect of the political elite. In the second era, violations of civil liberties and the impotency of the judiciary to challenge communal decisions persuaded Prime Minister John Diefenbaker to enact the Canadian Bill of Rights in 1960, which provided basic rights and freedoms in Canada, but was not sufficiently powerful or indeed precise to be of much guidance to the courts. Rand considers the adoption of the Charter in 1982 with the focus on individual rights and judicial oversight as the beginning of the third era.

Lipset was concerned that application of the Charter would stress the enforcement of personal rights through adversarial procedures rather than governmental adjudication and would result in the Americanization of Canadian values. ${ }^{339}$ The Charter has had a profound effect on the polity as well as operational aspects of national security institutions. ${ }^{340}$ Government's concern over the use of its Crown prerogative and the 'Charter challenges' ${ }^{341}$ that would inevitably ensue have limited the traditional latitude normally enjoyed within majoritarian politics and created tensions with the judiciary. It is, however, the quasi-constitutional Privacy Act of 1983, an extension of the Charter, which has caused significant concerns in the normal sharing of information between departments and security institutions. ${ }^{342}$ After 33 years, it does not appear as though the Charter has caused Canada to lose its communitarian values, as Lipset surmised. As Supreme Court Justice Beverley McLachlin explained, "The reality comes down to this:

\footnotetext{
${ }^{339}$ Lipset, 1997, pp. 3, 93-94, 101-108, 225-226.

340 See Rand Dyck, Chapter 19 "The Charter of Rights and Freedoms", for an excellent overview of the Charter issue, particularly the 'Implications of the Charter' section, pp. 510-515.

${ }^{341}$ Operation Dismantle Inc. vs the Queen, 1985, set an important judicial precedent that there was no automatic state protection against Charter challenges to foreign policy and national security decisions. See Peter H Russell, Rainer Knopff, and F. L. Morton, Federalism and the Charter: Leading Constitutional Decisions. 5th ed. Vol. 155, Ottawa: Carleton University Press, 1989, Ch 43, pp. 415-425.

${ }^{342}$ See Auditor General of Canada, 2009 March Status Report of the Auditor General of Canada, Chapter 1-National Security: Intelligence and Information Sharing.
} 
Parliament and the legislatures are the supreme arbitrators of the social course of the nation, subject only to the constraints imposed by the constitution and its traditions. The courts, by contrast, are the interpreters of the law and the constitution." ${ }^{343}$ There is currently a rebalancing of communal and individual rights within the responsibilities of three branches of power that is challenging Canadian identity and affecting the formulation of national security policy, but is consistent with the communitarian values found in Canadian National Security Culture.

\subsubsection{Respect for Authority and Security Norms}

What may have begun as deference to social and religious authority at its foundation has evolved in a pluralistic way in Canada as a respect for the 'other' and for responsibilities the 'other' may hold within a communitarian society. Faced with the anarchy of the American Revolution, the Loyalists turned to the Monarch to provide order and social stability. The Fathers of Confederation included the principles of Peace, Order, and Good Government (POGG) in the British North America Act. Historian William Stahl interprets POGG as the subordination of the individual to the community with the Monarchy considered as the 'family writ large'. ${ }^{344}$ Order in the 'family' allows for the peaceful resolution of differences and equal application of the rules. ${ }^{345}$

As mentioned earlier, law and order preceded settlements in the Canadian West through the establishment of the North West Mounted Police (NWMP) in lieu of creating

\footnotetext{
343 Beverley McLachlin, “The Judiciary’s Distinctive Role in our Constitutional Democracy”, Verbatim: Policy Options, September 2003.

344 Lipset, 1998, pp. 44-45.

${ }^{345}$ Frederick Vaughan provides a Hobbesian explanation for POGG in the Canadian context where "Peace and order go together. Good government is a perpetual necessity requiring constant vigilance." However, he states that neither Hobbes nor Locke ever countenanced the existence of an independent judicial body. Vaughan, Frederick. The Canadian Federalist Experiment: From Defiant Monarchy to Reluctant Republic. Montreal: McGill-Queen's University Press, 2003, pp. 86-90.
} 
a military force. This police force maintained peace and stability through less-violent application of the law that engendered a continuing respect for its authority by society. It is no surprise that the authoritative figure of a Royal Canadian Mounted Police (RCMP) officer in a red surge uniform has become a symbol of Canadian identity as he/she is representative of Canadian intrinsic values. However, the NWMP could only enforce laws in the 'anarchic' west through 'imaginary' presence; order and stability depended not only on perceived enforcement but in the creation of legitimate laws in the first place. This is representative of the domestic foundation on which Canadian society has chosen to deal with the international 'other' in foreign affairs.

The desire for order in Canadian society closely follows the English School theorists who are principally concerned with explaining the high level of order which exists between independent political communities in the condition of anarchy in international society. "[Martin] Wight argued that the fundamental political task of all time [is] to provide order, or security, from which law, justice and prosperity may afterwards develop." 346 Order is a founding principle upon which the ontology of the international society is built. In Hedley Bull's seminal work, The Anarchical Society, he articulated the English School view of order in world politics in which social order is the conformity of human behavior to rules of conduct or rules of law. In principle, Bull says that order in society can exist without rules; however, rules are a means of creating order. He contends that humans attach value to order as they value greater predictability to the elementary goals of society. Order is not the only goal that has value, so does justice,

\footnotetext{
346 Scott Burchill et al, Theories of International Relations, New York: Palgrave Macmillan, 2005, p. 88.
} 
power, institutions, and many more; however, order precedes the attainment of many other values.

In developing his idea of the international society, Bull uses the same logic. He defines "international order [as] a pattern or disposition of international activity that sustains goals of the society of states that are elementary, primary, or universal" ${ }^{\prime 347}$ which are: 1) the goal of system preservation; 2) the goal of maintaining the sovereignty of states; 3) the goal of peace; and 4) maintenance of the goals of social life (life, truth, and property). Bull says that a system of states exists when sufficient contact is maintained to impact on their decisions and cause them to act as parts of a whole. However, an international society is formed when these states bring about order through sharing a common set of rules and working in shared institutions. Institutions are required for rules to be communicated, administered, interpreted, enforced, legitimized, adapted, and protected. In other words, 'Order' precipitates 'Peace' and robust institutions provide 'Good Governance'; the very values articulated in the Canadian Constitution.

Tom Keating observes that, "Canada has sought to support international order by a system of international law and institutions seen to be essential for the successful pursuit and protection of Canadian interests.... guided in part by an interest in preserving what Hedley Bull described as the anarchical society of states." ${ }^{348}$ Whether dealing with the aboriginal, American, or international 'other', Canadian security norms demand the establishment of the 'rules of the game' to first create order. By respecting institutional authority and working within the rules to maintain stability, Canadians have maximized

\footnotetext{
${ }^{347}$ Hedley Bull, The Anarchical Society: A Study of Order in World Politics, $3^{\text {rd }}$ ed. Columbia: Columbia University Press, 2002, p. 16.

${ }^{348}$ Keating, 1993, p. 246.
} 
their security in every dimension through ideational rather than simply material means.

To Wight and to Canadians, order is synonymous with security. Thus pluralistic multilateralism in both domestic and international security policy formulation is consistent with the Canadian National Security Culture value of order.

The enemy of order is anarchy. By attempting to raise an issue above the 'rules of the game', the possibility of anarchy is introduced, a condition that had significant impact on Loyalist attitudes towards the use of force and revolutionary rhetoric. Thus, the "deliberate draining of emotion from public policy debates" 349 in Canada is indicative of the resistance to the securitization of important issues in Canadian National Security Culture. Prime Minister Macdonald rejected imperialist cries to support the Empire in the 1885 Nile River crisis; Canadians were not swayed by the US to participate in the war against communism in Vietnam; and the securitization rhetoric of the 'Bush narrative' justifying the invasion of Iraq failed to change Canadian acquired values. ${ }^{350}$

Securitized rhetoric such as the Global War on Terrorism and the Axis of Evil, designed for American domestic consumption as a 'framing concept' to 'rally the nation around the flag', are reminiscent of American Revolutionary rhetoric and antithetical to Canadian security norms. As demonstrated by the Harper Government's attempt to

\footnotetext{
${ }^{349}$ Pauly and Reus-Smit, 2012, p. 139; Lipset, 1998, p. 45, also provides an example of the hostage-taking event in Ottawa, 1 April 1989, in which journalist Charles Gordon discussed the 'Canadian-style' minimalized response by authorities (desecuritization in Waever's taxology).

${ }^{350} \mathrm{McGuire}, 2013$, provides substantive proof of Canadian disinterest in the securitization used by Bush; however, her conclusion is incorrect with her dismissal of the identity causation as being Anti-American rather than deeper intrinsic value differentiation. Culture matters; Also see Jennifer Mustapha, "Threat Construction in the Bush Administration's Post-9/11 Foreign Policy: (Critical) Security Implications for Southeast Asia." The Pacific Review 24.4, 2011, pp. 487-504; Geoffrey Hale, So Near Yet so Far: The Public and Hidden Worlds of Canada-US Relations, Vancouver: UBC Press, 2012, Chapter 4, "Neighbo(u)rs, Friends, and Strangers: The Psychological-Cultural Dimension".
} 
securitize the murders of two servicemen into 'acts of terrorism' in October $2014,{ }^{351}$ Canadians preferred to keep the issue within the political 'rules of the game', contrary to securitization theory's cultural homogenization of the 'audiences'.

Establishing order to material issues reduces the need for realist powermaximization and creates stability through voluntary interdependence. This applies equally to the domestic as well as the international. Peace is achieved through reducing insecurities and the perceived need for the use of force. This is facilitated by providing order and security through laws and collective agreements. Egalitarian application of these cognitive norms through good government provides stability and trust. Thus Canada's tripartite motto of Peace, Order, and Good Governance not only articulates societal norms and values regarding national security, but the institutionalization of these cognitive norms limits and constrains the polity on national security issues as well.

The jurisprudence of the Judicial Committee of the Privy Council defined sections 91 and 92(13) of the Constitution Act, 1867, which invoke POGG into three branches: Emergency Branch, Gap Branch, and National Concern Branch. ${ }^{352}$ The Emergency Branch allows parliament to invoke emergency powers to intervene in provincial jurisdiction, such as war, famine and economic emergencies. The Gap Branch covers unforeseen contingencies, where federal jurisdiction is deemed appropriate, that the drafters of the Constitution overlooked or in issues that have since transpired in

\footnotetext{
${ }^{351}$ See Paul Wells, “Word Politics”, MacLean's, Vol 127, No. 45, 17 November 2014; Mark Gollom, "Ottawa attack: Was Michael Zehaf-Bibeau's attack a terrorist act: Mulcair calls Ottawa gunman's attack a 'criminal act'", $C B C$ News, 30 Oct 2014 online at http:/www.cbc.ca/news/canada/ottawa-attack-wasmichael-zehaf-bibeau-s-attack-a-terrorist-act-1.2818329; Angus Reid, "Attack on Parliament Hill: terrorism or mental illness? Canadian public opinion is divided", November 25, 2014, online at http://angusreid.org/homegrown-terrorism-radicalization-canada-overblown-serious-threat/\#II

352 Patrick J Monahan. Constitutional Law, Third Edition, Toronto: Irwin Law Inc., 2006, p. 254; Also see Dyck, 2011, pp 461-466 for a good summary of judicial interpretation of POGG.
} 
modernity, such as aeronautics security. The National Concern Branch allows parliament to invoke POGG powers on matters that fall within provincial jurisdiction but are of such importance to concern the entire country. However, the Supreme Court of Canada has provided a narrow interpretation of POGG to ensure its judicious use in matters of national security. ${ }^{353}$ The principles of POGG have proven to transcend the domestic to the international in guiding national security policy and are embedded in the Canadian National Security Culture.

\subsubsection{Pragmatism and Security Norms}

I use the word pragmatism in its common form, rather than in its philosophical form, to indicate the Canadian norm of seeking practical approaches to complex problems and affairs, although what unites the two forms of the word is a shared skepticism toward certainties derived from abstractions. ${ }^{354}$ This is an important aspect of conflict resolution in both domestic and international society. 'Reasonable

${ }^{353}$ In a leading constitutional decision of the Supreme Court of Canada, Justice Le Dain identified the
governing principles of POGG in $R v$ Crown Zellerbach Canada Ltd [1988] 1 S.C.R. 401 as

1. The national concern doctrine is separate and distinct from the national emergency doctrine of the peace, order and good government power, which is chiefly distinguishable by the fact that it provides a constitutional basis for what is necessarily legislation of a temporary nature;

2. The national concern doctrine applies to both new matters which did not exist at Confederation and to matters which, although originally matters of a local or private nature in a province, have since, in the absence of national emergency, become matters of national concern;

3. For a matter to qualify as a matter of national concern in either sense it must have a singleness, distinctiveness and indivisibility that clearly distinguishes it from matters of provincial concern and a scale of impact on provincial jurisdiction that is reconcilable with the fundamental distribution of legislative power under the Constitution;

4. In determining whether a matter has attained the required degree of singleness, distinctiveness and indivisibility that clearly distinguishes it from matters of provincial concern it is relevant to consider what would be the effect on extra-provincial's interests of a provincial failure to deal effectively with the control or regulation of the intra-provincial aspects of the matter.

${ }^{354}$ I chose pragmatism as a contrast to egoism as it fits with other Canadian security preferences that seek 'mutual accommodation' such as particularism and collectivism. See William James, Pragmatism: A New Name for some Old Ways of Thinking: Popular Lectures on Philosophy, 1st ed., New York: Longmans, Green, 1925; and R Ormerod, "The History and Ideas of Pragmatism", The Journal of the Operational Research Society, Vol 57, No.8, 2006, pp. 892-909. 
accommodation', minimum use of force and peacekeeping, are but a few examples of instrumental values that have evolved from seeking pragmatic solutions to security concerns. "Pragmatic accommodation has entered our collective mindset and has become part of our way of life, indeed, part of our very identity as Canadians..... Each of the conflicts and disagreements we have encountered in our history has become a knot that ties our federation together." ${ }^{355}$ Although pragmatism as a philosophical doctrine can be traced to classical antiquity, it was the British experience in governing the Empire that provided the operational foundation used so effectively in the construction of Canada.

The argument that culture influences national security policy is grounded in the classic works on war. Carl von Clausewitz, in On War, describes war as “...a continuation of political intercourse, carried on with other means." ${ }^{356}$ This clearly places the use of force as a means of conflict resolution at the heart of political culture. Following the 1763 Treaty of Paris, the British exhibited Clausewitz's axiom that "the conqueror is always a lover of peace; he would prefer to take over a country unopposed" in proclaiming the Quebec Act, a pragmatic military solution to a significant security dilemma. The British also demonstrated Sun Tzu's (The Art of War) maxim that 'the pinnacle of excellence in war is subjugating the enemy without fighting, ${ }^{357}$ in their nonviolent, pragmatic approach to the potential security problem of aboriginal disenchantment through the Royal Proclamation of 1763 that established guidelines for settlement of aboriginal territories.

\footnotetext{
355 See Senator Pierre Claude Nolin, “Accommodation as a Canadian Tradition”, Canadian Parliamentary Review, Vol 31, No. 2, 2008.

${ }^{356}$ Michael Howard and Peter Paret, ed., Carl von Clausewitz: On War, Princeton: Princeton University Press, 1984, p. 87.

${ }^{357}$ Sun Tzu, Art of War, translated by Ralph Sawyer, Oxford: Westview Press, 1994, p. 177.
} 
In realist terms, the perceived threat of the 'Native Indian' was the same in both the US and Canada, but the example of how Sitting Bull, the slayer of General Custer, was treated by each is indicative of the two countries' ideational differences in the perceived need for the use of force in resolving security problems. Although the maltreatment of Aboriginals in Canada has been well documented in the Truth and Reconciliation Commission of Canada Final Report ${ }^{358}$, it is the distinct non-violent manner in dealing with perceived security threats that is important. This passive approach to conflict resolution is a significant norm in Canadian National Security Culture and not ‘just the Canadian way’ of making ad hoc security policy, as many academics dismissively argue. Not all security issues are perceived as threats.

Minimal use of force is an acquired value in Canadian identity. It has its roots in both the British military principles of governance as well in the evolution of policing as a constabulary "responsible to the Crown, but representative of the communities they served." ${ }^{359}$ As William Beahen explains in "Evolution of Use of Force by Police in the Canadian Context", the basis for policing in Canada was laid by Sir Robert Peel, Home Secretary in Britain in 1820, who established nine policing principles of civil police services of which two elaborated on the minimal use of force. In 1893, the 'use of force' principles were codified in the passage of the Criminal Code of Canada. Section 25 of the Criminal Code states "a person using force intended or likely to cause death or grievous bodily harm is only justified to use this force if it is necessary to protect the

\footnotetext{
${ }^{358}$ Canada, Truth and Reconciliation Commission of Canada, Honouring the truth, reconciling for the future: Summary of the final report of the Truth and Reconciliation Commission of Canada, 2015, found online on 3 November, 2015at http://www.trc.ca/websites/trcinstitution/File/2015/Honouring the Truth_Reconciling_for_the_Future_Jul y 23 2015.pdf.

${ }^{359}$ William Beahen, "Evolution of Use of Force by Police in the Canadian Context", prepared for Commission for Public Complaints Against the RCMP, June 16, 2008, p 3.
} 
person or others from death or grievous bodily harm and that the person is responsible for any excess force employed." Although the section is primarily intended to protect peace officers, it is written such that it covers and protects all individuals who "acts on reasonable grounds, justified in doing what he is required or authorized to do and in using as much force as is necessary for that purpose." ${ }^{360}$ In other words, force can only be used as a last resort and it must be proportional to the situation.

Although it is not the intention of this dissertation to provide comparative analysis, the use of force norms in Canada stand out in sharp contrast to those of its neighbour to the south. Canadians have the 'right to bear arms', but must do so responsibly within the communal restraints of the Criminal Code of Canada and the Firearms Act. There are no liberal, American-style 'Stand Your Ground' laws that permit the use of lethal force to protect person and property with no question. In Canada, a person using excessive force on an intruder will likely be prosecuted, just as police officers were in the 2007 Dziekanski and 2010 G-20 Summit cases, if unjust force is used on another person. Security norms that restrict the option to use physical force as a means of resolution compel pragmatic solutions and the creation of non-violent approaches. This is true from the domestic to the international and is embedded in Canadian National Security Culture.

Thus when President G.W. Bush addressed the UN General Assembly on 12 September 2002 to emphasize that the US would pursue unilateral action against Iraq if Baghdad did not stop producing weapons of mass destruction, the evidence he produced did not sufficiently pass scrutiny with many countries to justify American actions. Prime

\footnotetext{
${ }^{360}$ Criminal Code of Canada (R.S.C., 1985, c. C-46), Section 25, Protection of Persons Administering And Enforcing The Law, online at http://laws-lois.justice.gc.ca/eng/acts/C-46/page-8.html
} 
Minister Chrétien's position that Canada would only act through the UN was based on the lack of "concrete findings by weapons inspectors of evidence of mass destruction in Iraq. ${ }^{361}$ Chrétien's choice to not participate in the illegitimate use of force was consistent with Canadian National Security Culture, in that there were no 'reasonable grounds' for justification and other means were available to preclude the use of force as per the institutionalized use of force norms in Canada.

Securitization theorists, such as McGuire, mistake 'reasoned excuses' for 'normative reasons'. Her conclusion that the Canadian government's framing of the Iraq decision was simply a "desire to pursue a distinctly Canadian response to the attacks on the US" ${ }^{\prime 62}$ fails to take into consideration the underlying security norms found in Canadian National Security Culture. Chrétien was well aware of the consequences of his decision, but acquired values overrode the instrumental value of 'bandwagoning' with the US in realist terms and defied the cultural homogeneity of values and principles assumed in securitization theory.

Under Chrétien, Canada did not wait for a UN mandate to participate in the USled invasion of Afghanistan because there was justifiable evidence. In Iraq there was not. Placing Canadian military lives at risk for international security reasons is amongst the highest 'moral judgments' a national leader must make. Contestation between national interests such as sovereignty, unity and prosperity become factors to be considered when survival of the country is not directly threatened. Politically, Chrétien could have been less overt towards the US in his rejection of Canadian participation. However, with

\footnotetext{
${ }^{361}$ Goldenberg, 2006, p. 188.

362 "While the government could have ostensibly framed the Iraq decision in terms other than independence and multilateralism, doing so would have detracted from the desire to pursue a distinctly Canadian response to the attacks on the US." - McGuire, 2013, p. 96.
} 
Quebec sovereignty still an issue and the majority of Canadians not supporting the invasion of $\operatorname{Iraq}^{363}$, issues of sovereignty, unity, and prosperity became highly politicized. Comprehending Canadian National Security Culture and the implied constraints in domestic politics were important facets in choosing an appropriate course of action in this specific matter of choice.

The spectrum of conflict ranges from individual arguments to the mutually assured destruction (MAD) of total war. In between, the pragmatic 'use of force' norms inherent in Canadian identity were instrumental in conceiving and constructing the UN Peacekeeping mission. "Canadian policy-makers had long taken an interest in more peaceful methods of conflict resolution." ${ }^{364}$ It fit well for a 'middle power' that saw itself as an 'honest broker' in international affairs. Peacekeeping became the mantra of successive Liberal governments as it aligned well with Canadian security norms and justified the continuing expense of fielding a balanced military for collective security requirements. Detractors will point out that Canada has never been a 'Pollyanna' nation with its participation in two World Wars and the Korean War. Although it is often argued that peacekeeping is part of the Canadian identity, it is only a preferred instrumental value. The choice to 'use lethal force' in war must meet Canadian 'use of force' norms in the protection of intrinsic values in order for the 'moral judgment' of decision-makers to be accepted by society. Both peacekeeping and peace-making fit within Canadian National Security Culture.

\footnotetext{
${ }^{363}$ In March 2003, a poll conducted by EKOS Research Associates for the Toronto Star and the Montreal newspaper La Presse found 71\% of those questioned did not support the United States-led invasion, with $27 \%$ expressing disapproval. The greatest support for Chrétien's position was in Quebec - Tim Harper, "Canadians back Chrétien on war, poll finds", Toronto Star. 22 March 2003 found online on 05 October 2015 at http://www.ekospolitics.com/articles/torstar-24-03-2003c.html .

${ }^{364}$ Keating, 1993, p. 103.
} 
The most important pragmatic security norm is found in Canada's risk management of its relationship with the US, the only true existential threat to Canada as an independent, sovereign state. "Eighty-five percent of our foreign policy resides in our relations with the United States. That is the brutal fact, and that is the interest we most zealously and effectively protect." 365 Virtually all security concerns in Canada are weighed through the prism of this bilateral relationship since the two states have the largest trade relationship in the world and the US market takes seventy-six percent of Canadian exports. Prosperity and security are intimately linked through the need for free movement of people and goods. Given the American preoccupation with security ${ }^{366}$, maintenance of the 'longest undefended border in the world' is premised on Canada meeting stringent American security standards in all aspects of domestic security policies. Through constant negotiation and pragmatic solutions, Canada has managed to balance sovereignty and independence with friendship and support to the mutual benefit of both countries. ${ }^{367}$ On any one issue, the power of the US would undoubtedly prevail; however, it is in this disparity of power that the intrinsic values of liberal democracy are judged. World insecurities of globalization can be weighed against the success and failures of the Canada-US (CANUS) complex interdependence. Global concerns regarding loss of state sovereignty through international agreements can be judged through the complex sovereignty of the CANUS relationship. Conflict and cooperation

\footnotetext{
${ }^{365}$ Norman Hillmer, “The Secret Life of Canadian Foreign Policy”, Policy Options, Vol. 26, Montreal: Institute for Research on Public Policy, 2005.

${ }^{366}$ Frank P Harvey, The Homeland Security Dilemma: Fear, Failure and the Future of American Insecurity, New York; London: Routledge, 2008. Harvey argues that the US preoccupation with security and the enormous investments made serves to increase public expectations and amplifies public outrage after failures thus 'the more security you have, the more security you will need'.

${ }^{367}$ See Thomas d'Aquino, "Security and Prosperity in the Canada-United States Relationship: Two Sides of the Same Coin", Canadian Defence \& Foreign Affairs Institute, March 2011.
} 
are inevitable in any relationship and the political policies chosen by Canada may not have always been the most efficacious, but Canadian National Security Culture has kept Canada secure and sovereign through pragmatic norms and intrinsic values.

\subsection{Defining National Security in Canada}

Contrary to US government policy and academic parsimony, Canada does not view 'national security' as an amalgam of defence and foreign policy. National security in Canada is domestic-centric with safety and defence providing bracketing roles. This is evident in historic practice and contemporary government organizing principles and discourse. Canada has produced white papers on Defence and External Affairs since the early 1960s, none of which have referred to National Security. The first instance of the term national security being used in official white papers is in the 2004 NSP. Reference to 'national security' can be traced back to the ' 60 's where it appeared as a topic involving public safety and national security under the Standing Committee on Justice and the Solicitor General. The Standing Committee on Public Safety and National Security was only established in 2006 and is separate from the Standing Committee on Defence and the Standing Committee on Foreign Affairs. The Standing Committee on Public Safety and National Security has considered a number of socio-legal studies and bills pertaining to criminal law, corrections, terrorism, border security, policing and law enforcement, crime prevention and emergency management, all of which are domestic issues. It is evident that the government deems 'national security' to be domestic-centric and separate from international security.

The separation of national security and international security also occurs within the bureaucracy where the Privy Council Office retained a separate Foreign and Defence 
Policy Advisor as well as a Security and Intelligence Advisor to the Prime Minister until amalgamated recently under the National Security Advisor, a position only created in the 2004 National Security Policy statement. The evidence of domestic centricity of national security is also understood when considering the two principal institutions involved in Canadian national security by definition. The RCMP provides federal and some provincial constabulary services, while the Canadian Security and Intelligence Service (CSIS) is focused primarily on domestic threats to national security emanating from foreign intelligence agencies and terrorist activities in country. CSIS is not a foreign intelligence agency. Neither Foreign Affairs nor Defence (external electronic intelligence gathered by the Communications Security Establishment Canada) have the capacity to gather foreign intelligence which is critical in determining the intentions of the 'other'. The primary institutions involved in 'national security' are domestic-centric, founded in Canadian jurisprudence. ${ }^{368}$

\footnotetext{
${ }^{368}$ See Irvin Studin, The Strategic Constitution: Understanding Canadian Power in the World, Vancouver: UBC Press, 2014, "For our purposes, it is instructive that the broad federal criminal law power has strategic import in the peculiar context of Canadian national security. As a strategic concept, national security refers to the protection of critical Canadian assets and interests against a variety of threats, domestic and international, human and natural, deliberate and accidental - a state of affairs that lies somewhere between the spheres of personal safety and international security. And, on this conceptualization, national security can be said to have strategic import to the extent that it involves protection of critical Canadian assets and interests specifically against foreign or foreign-related threats, whether manifested in Canada proper or abroad.

Protection against these threats may well be provided in part by the diplomatic and military instruments of the state, but in general terms, it stands to reason that the provision of this national security, as a function of the executive potency factor, should be seen as a supporting (in some cases, "defensive" or "enabling") condition for the proper functioning of these two instruments. At the federal level, the term national security or one of its cognates appears in at least thirty statutes, with less than a third of these attempting — with great difficulty — to define the term.

Taken together, statutes like the Emergencies Act, Emergency Management Act, CSIS Act, Royal Canadian Mounted Police (RCMP) Act, Security of Information Act (formerly the Official Secrets Act), Canada Evidence Act, Citizenship Act, Immigration and Refugee Protection Act, Aeronautics Act, Canadian Transportation Act and indeed, inter alia, the National Defence Act make up the nucleus of Canada's national security legislative framework. And, for all practical intents and purposes, the leading strategic assets or agencies of the Canadian state in the national security sphere are the RCMP and CSIS. The former exists on the basis of the RCMP Act and the latter on the basis of the CSIS Act. However,
} 
If, as realism assumes, national security is simply an amalgam of military and foreign affairs policies to deal with the absence of authority in the Hobbesian anarchy of the international system, where security is scarce and self-help is the norm, then Canada is institutionally ill-prepared. The structural evidence and security norms of actors indicate that Canada perceives national security to be central along a spectrum from safety to defence. Canadian National Security Culture necessitates that rules and regulations be established as a prevention tool that creates order and safety first. Security is provided domestically through the constabulary and associated agencies in order to enforce sovereign laws and protect societal values. Finally, a modest military defence is provided to ensure sovereignty is enforced and the physical base protected from without. This pragmatic approach can be summarized as the 'Spectrum of Security' (Safety/ Security/ Sovereignty; Regulatory/Constabulary/Military; Personal/National/ International). The spectrum is endogenously focused, but the principles are applied exogenously to International Society when formulating Canadian defence and foreign policy. National security is a continuum with its focus on the protection of Canadian society and its acquired values.

Why is establishing the nature of 'national security' in Canada so important? Precisely because consistency in the definition of variables is fundamental to the process of political inquiry. It is analytically critical to establish the specification of variables, particularly when they are used as dependent or independent variables. The validity of

national security, especially given its troubled susceptibility to precise legal definition, is in many important respects given constitutional salience and expression by federal criminal law. As such, a number of provisions of the Criminal Code of Canada are highly strategic. For instance, the Anti-Terrorism Act of 2001 amended the Criminal Code to define terrorism and created several offences related to terrorism (with significant extraterritorial effect), including terrorism financing and participation in, facilitation and execution of terrorist acts." 
findings will be put into question if the theoretical concept is in tension with the chosen variable, such as using an American-centric realist definition of national security when analysing Canadian security behaviour. External validity is also compromised when generalizing from one set of research findings to another based on a perceived commonality of the concept of national security.

To illustrate this paradigmatic trap, I turn to realist analysis of the Martin Government's 2004 National Security Policy statement and 2005 International Policy Statement found in Security and Defence in the Terrorist Era, second edition. The analysis begins by stating the National Security Policy statement "delivers less than its title promises. It is, in effect, a homeland security document and is better equated to America's National Strategy for Homeland Security than to the National Security Strategy of the United States." ${ }^{\prime 39}$

This is an empirically correct observation: the National Security Policy statement is a 'homeland' security document because in Canada homeland is equated to 'national' and the International Policy Statement is the 'international' security document. However, this misperception of national security in Canada leads to normative analysis in suggesting that the title, National Security, does not deliver what it is supposed to deliver and implies that it should be more like the National Security Strategy of the United States. This analytical prism colours the remaining commentary in not recognizing the cultural reality that Canada views national security differently than the American-centric definition, particularly when labeling that the post 9/11 funding for domestic national

\footnotetext{
${ }^{369}$ Elinor C. Sloan, Security and Defence in the Terrorist Era: Canada and the United States Homeland, 2nd ed. Montréal: McGill-Queen's University Press, 2010, p 25. Identity and culture matter as they shape reality and the interpretation of concepts through language.
} 
security as "the so-called 'security budget" ",370 when it did not address military underfunding.

Empirically, it is well defined in Canada. National Security in Canada is similar in principle to Homeland Security in the US. Failure to recognize this fact brings into question the external validity of comparative arguments and leads to misunderstanding of Canadian security policies. Although the tenor of the most often quoted definition of Canadian National Security ${ }^{371}$ was derived from a realist perspective by the National Defence College of Canada in 1980, the words and meaning are consistent with the empirical evidence that was "implicit in the actions and statements of the various governments over the years" 372 and the cultural arguments of this paper. The National Defence College definition speaks to the 'preservation of a way of life acceptable to the Canadian people' which is the state sponsored protection of society and 'freedom from the erosion of [acquired] values which are essential to the quality of life in Canada'. Overcoming Wolfers' assertion that national security is an ambiguous symbol demands the specificity that can only be found through analysing national security culture. Once this has been accomplished, analysis of material factors, competing interests, and chosen instrumental values and processes will elicit more comprehensive causal explanations.

\subsection{Canadian National Security Culture Conclusion}

The ideas and institutions that form the 'nucleus of the state' are held together by the 'nuclear force' of norms and values embedded in society and the polity. These norms

\footnotetext{
370 Ibid.

${ }^{371}$ Buzan, PSF (91), 2009, p.36. Course documents, National Defence College of Canada, Kingston 1989; "National Security is the preservation of a way of life acceptable to the Canadian people and compatible with the needs and legitimate aspirations of others. It includes freedom from military attack or coercion, freedom from internal subversion, and freedom from the erosion of the political, economic, and social values which are essential to the quality of life in Canada."

372 Sloan, 2010, p. 7.
} 
and values form the fabric of society and are instrumental in shaping the construction of reality in the individuals who are the decision-makers passing 'moral judgment' on national security policies. The mutual construction of the Canadian state and society has been an historic journey of political contestation, cooperation and accommodation. From a pivotal moment in world history, two countries emerged from the anarchy of revolution, one a national security egoist that chose the revolutionary path, the other a national security pragmatist that chose to evolve from within.

It is given that all true liberal democracies share the same intrinsic values that are the foundation of this form of government, such as individual rights and free speech. State protection of these values will take many forms through acquired and instrumental values that are unique to each state. In analysing the norm salience of Canadian National Security Culture, the specificity, durability, and concordance of five sets of intrinsic Canadian norms and values emerge that are fundamental in determining security concerns: national sovereignty, particularism, communitarianism, respect for authority, and pragmatism. Each of these form preferences or evaluative standards that influences the construction of statehood through varying ideologies of collective purpose and distinctiveness, particularly when identifying which acquired values deserve state protection.

Canada's geostrategic position in the world has been instrumental in shaping its identity. The only true existential threat to Canada throughout its history has come from the United States. Surrounded on three sides by major bodies of water and currently an undefended border providing security on the fourth, Canadian society and polity have an absence of fear that Canada's physical base will be attacked in Wolfers subjective sense 
of security. However, in Wolfers objective sense, the US threatens Canadian acquired values through non-violent means of assimilation and homogenization due to growing interdependence. This has led to the primary focus of Canadian national security to be endogenous. If national security is merely the protection of the state, and society becomes assimilated with the 'other', the state ceases to exist as an independent, sovereign entity. ${ }^{373}$ Thus, national security in the Canadian context is for the protection of the acquired values of Canadian society, the human collective that is the raison d'être of the state.

The five sets of norms and values that constitute security preferences in Canadian identity have been evident from domestic frontier conflict resolution between self / other to contemporary international security policies and are indicative of Grotian ${ }^{374}$ rather than Hobbesian or realist assumptions. This Grotian tradition of common values, rules, and institutions that bind communities together as a society has resulted in a worldview that is reflective of Canada's domestic / continental experience. The historical evidence of strong security norm salience in these five areas answers the first of the three criteria in exposing that a Canadian National Security Culture exists and has been relatively consistent over time.

Investigation into the way that this national security identity has shaped Canada's approach to conflict resolution answers the second criteria. ${ }^{375}$ Canada is not afraid to take a sovereign approach to conflict resolution, but it will normally not be unilateral,

\footnotetext{
${ }^{373}$ Buzan et al, 1998, p. 119.

374 A. Claire Cutler, "The 'Grotian Tradition' in International Relations," Review of International Studies, Vol. 17, No. 1, January, 1991, pp. 41-65.

${ }^{375}$ Kirchner and Sperling, 2010, pp. 292-293, provide further confirmation of this set of Canadian national security norms in an alternate form.
} 
preferring to seek multilateral, pragmatic, non-violent solutions. Establishing order and adhering to the 'rules of the game' are central to Canada's concept of particularism in resolving issues peacefully. Diversity and regionalism are domestic political factors that affect the polity directly and have generally been addressed through communitarian policies when possible. However, they do inform national interests and can be in conflict over specific national security policy issues, leading to contestation over acquired values.

Debating the acquired values that deserve state sponsored protection is political, and specific policies chosen are highly dependent on the instrumental values of the parties in power. However, in answering the third criteria, three consistent intrinsic/ acquired values that necessitate state sponsored protection have become evident and are often referred to as 'national interests' ${ }^{376}$ : national independence and sovereignty, national unity, and economic prosperity. Significantly, state sponsored protection of these acquired values is less dependent on international security policies ${ }^{377}$ as domestic ones. Canada needs to play a role in ensuring the security of international society, but in Canada, domestic protection of society and its values is 'national security' and established in Canadian National Security Culture.

Understanding the implications of Canadian National Security Culture is very important in the case of Canada, as national security is not power-centric as realists assume. Canada does not perceive a Hobbesian world where it needs to be a powermaximizer. The consequence of geo-strategic positioning means that the only existential

\footnotetext{
${ }^{376}$ See Steven Kendall Holloway, Canadian Foreign Policy: Defining the National Interest, Peterborough: Broadview Press, 2006 for another perspective on these three acquired values, particularly in how successive governments portrayed them, p. 17.

377 This refers specifically to security policies and not to international diplomatic, development or economic policies.
} 
threat to Canadian society is assimilation into the US. This has resulted in the security policy dilemma of not being seen as too close nor too far from US policy in an interdependent relationship. National security in Canada is an acquired value that competes against other values for resource extraction. Maximizing military power is not the goal of Canadian society, because it will not provide the tangible results that state protection of other acquired values may. In other words, ideation is of greater relevance in providing causal explanations regarding Canadian national security polices than could be acquired through exclusive analysis of material factors.

In the following case study, I will examine the 2004 National Security Policy statement in detail as an expression of Canadian National Security Culture. The separation of the National Security Policy statement and the International Policy Statement into national and international security public policy statements was not solely the act of Prime Minister Martin, but was the result of the public service developing and producing the concept under Prime Minister Chrétien. This is more indicative of Canadian National Security Culture than of political ideology. Often in politics opportunities present themselves whereby decision-makers can move legislation forward that promotes their ideological views and serves their political interests. Although the statements were consistent with Canadian National Security Culture, the decision to issue the National Security Policy statement and International Policy Statement was one of those instances that served political interests and was used to launch the political fortunes of a new Prime Minister. 


\section{Chapter: Case Study - The NATIONAL SECURITY POLICY \\ Statement: An Expression of Canadian National Security Culture}

\subsection{National Security in Canada}

Simply accepting the definition of 'national security' as pertaining to military and defence policies that meet perceived global threats, as the term is used by the United States government and leading academics, is misleading when universally applied to state sponsored-protection of a given state's human collectivity, its society. In theory and in practice, the construction of the 'nuclear force' in Canada (society-polity) has led to the delineation of domestic 'national security' from external 'international security' through security norms in government organization and policy articulation. ${ }^{378}$

Although in the Canadian system of government, the prime minister and cabinet have the mandate to govern, the public servants, who provide continuous support to whichever party is in power, hold significant influence in policy outcomes and have been instrumental in constructing the institutions of government. ${ }^{379}$ It is fitting then to quote Oscar D. Skelton, the founder of the Department of External Affairs, who in a 1922 address to the Canadian Club stated that foreign policy was "simply an extension of domestic policy. ${ }^{380}$ As a leading civil servant and key advisor on both domestic and foreign policy during the Mackenzie King and Bennett governments, Skelton's fifteen years as under-secretary of state for External Affairs were definitional in establishing the

\footnotetext{
${ }^{378}$ As discussed in chapter 3.

${ }^{379}$ See Savoie, Donald J. Governing from the Centre: The Concentration of Power in Canadian Politics. Toronto: University of Toronto Press, 1999; 2003; Dyck, 2011, pp. 586-587; Norman Hillmer, O.D. Skelton: A Portrait of Canadian Ambition, Toronto: University of Toronto Press, 2015.

${ }^{380}$ Norman Hillmer, 'National Independence and the National Interest: O.D. Skelton's Department of External Affairs in the 1920's", in Greg Donaghy and Michael Carroll, eds., In the National Interest: Canadian Foreign Policy and the Department of Foreign Affairs and International Trade, 1909-2009, Calgary: University of Calgary Press, 2011, p. 12.
} 
ideational division between national and international security as Canada was transforming itself as a nation independent of Britain.

"Skelton's understanding of the national interest, beginning with state autonomy and moving through Canadian unity, security, and economic progress to North American solidarity and, when feasible and necessary, international cooperation" ${ }^{n 81}$ fits precisely contemporary Canadian national interests today. Skelton viewed diplomacy in concrete, common-place terms that concentrated in the economic sphere, where most issues were directly related to consequences at home. As will become evident in this chapter, the Martin government's bifurcation of security into the National Security Policy statement and International Policy Statement was consistent with the foundations first established by Skelton and the evolution of Canadian National Security Culture over the past 90 years.

This chapter will provide evidence that modern Canadian society and polity view national security in the widened sectoral concept articulated by Buzan and that the National Security Policy statement is a contemporary expression of the acquired values that Canadians expect from state sponsored protection. The chapter begins by showing the convergence of Canadian stand-alone international defence and domestic security policies over the past 50 years due to ideational shifts in norms and values as Canadian society and the international system evolved. This convergence results in the first holistic articulation of Canadian national security by the Martin Government in 2004. Analysis of the crisis and consequence management measures taken by Canada following the 9/11 attack provides evidence of Canadian National Security Culture shaping the policy

\footnotetext{
${ }^{381} \mathrm{Ibid}$, p. 23. It is informative that this ideational approach to national interests was identified nearly 90 years ago and remains central to Canadian international policies today as evident later in this chapter.
} 
choices made by government officials and the subsequent development of the National Security Policy statement. Finally, analysis of the National Security Policy statement provides evidence that national security in Canada is domestic-centric and wide in its interpretation of state sponsored security for acquired values that align with Canadian National Security Culture.

\subsection{Security Policy Convergence}

Although Canadian National Security Culture can be described in general terms, it is not static and evolves with the times. Following the Second World War, individual institutions responsible for national security were socially constructed by society-polity (the nuclear force of the state), evolving into the spectrum of national security expressed in the 2004 National Security Policy statement. The intrinsic values that are foundational to Canadian identity and culture shaped the cognitive standards of security institutions through policy decisions, political debate, and commissions of inquiry. Advances in technology and changes in the international system, from globalization to unipolarity, have altered threat typology and the tools available to threaten the state. Domestic security norms have not kept pace with change and were reactive in the face of the 9/11 acts of terrorism that challenged democratic intrinsic values as well as Canadian acquired values. The following review highlights key developments in the construction of the current national security system that have direct impact on the evolution of Canadian National Security Culture.

\subsubsection{The Changing International Defence Policy Environment}

As argued earlier, Canada has always referred to domestic security as national security with defence and foreign policy being identified separately. In reviewing 
Canadian White Papers on Defence since 1964, however, a clear convergence of defence policy with national security begins to occur in the articulation of the military's role in protection of Canada as Cold War demands for high readiness subsided. ${ }^{382}$ Minister of National Defence Paul Hellyer's 1964 White Paper was Cold War centric with no substantive reference to domestic priorities. In Minister of National Defence Donald S. Macdonald's 1971 White Paper, however, we see an ideational shift in Canadian security policy and the Trudeau Government's nationalist leanings in the policy's opening statement that "provision of adequate Canadian defence resources for this purpose [Sovereignty and Independence] must therefore be a matter of first priority." 383 For the first time, a Canadian Defence White Paper highlights the military's roles in internal security, assistance to the civil power, and surveillance and control (sovereignty) of Canadian territory and, in particular for this dissertation, the first references to Canadian airspace, territorial seas, marine environmental control zones and maritime economic zone above the continental shelf.

\section{Interestingly, Minister of National Defence Perrin Beatty's 1987 Challenge and}

Commitment: A Defence Policy for Canada, dismissed the 1971 White paper as full of

\footnotetext{
382 The central observations made in sub-section 4.2.1 is also reflected in Brian W. Tomlin, Norman Hillmer, and Fen Osler Hampson, Canada's International Policies: Agendas, Alternatives and Politics, Toronto: Oxford University Press, 2008, Chapter 7, "The Evolution of National Defence Policy". ${ }^{383}$ Government of Canada, Defence in the 70s: White Paper on Defence, Department of National Defence, Ottawa, 1971, p. 8. Significantly, this reference in the 1971 White Paper falls within the chapter entitled 'The Basis for Defence Policy in the 70s' which expressly links defence policy with foreign policy to "reflect and serve the national interests". This post WWII ideational shift has often been lost in contemporary analysis and portends the Liberal party shift towards a more national focus on the raison d'être of defence policy that culminates 33 years later with international security policy falling within the NSP; In Stephen Azzi, Reconcilable Differences: A History of Canada-US Relations, Don Mills, Ontario: Oxford University Press, 2015, pp 192-193, Azzi explains that Trudeau thought Canadian foreign and defence policies did not reflect Canadian interests and shook up the Ottawa establishment in questioning the basic tenets of the current policy regimes. The overview booklet of the 1970 Foreign Policy for Canadians policy statement "set out a self-interested foreign policy, one with more emphasis on fostering economic growth and protecting Canadian sovereignty, and less on promoting international peace and security."
} 
optimism for "international peace and security" and based its return to the Cold War "realities". ${ }^{384}$ However, extracting resources from Canadian society for defence expenditures proved to be politically problematic and controversial. As historian J.L. Granatstein observed in Who Killed the Canadian Military?, Prime Minister Brian Mulroney "raised the military's hopes repeatedly, but failed to deliver." Beatty focused Defence policy on threats to the international system, Canada's role in collective security, and the economic benefits generated by Defence projects, but moved away from domestic defence roles. Token reference to peacekeeping failed to appeal to Canadian security norms that do not favour a robust military role in policing the international system unless presented with an imminent threat, which appeared to be dissipating. In the 1993 landslide election victory, Liberal leader Jean Chrétien used the EH-101 helicopter procurement program to illustrate the wasteful spending of the Mulroney Government that he claimed caused the huge deficits that Canadians faced at the time. ${ }^{385}$ Minister of National Defence David Collenette's 1994 White Paper was preeminently a reflection of the government's fiscal challenges inherited from the previous Conservative government and the inevitable pain that the Department of National Defence would face. However, the White Paper reintroduced and reinforced the "ongoing

\footnotetext{
${ }^{384}$ Government of Canada, Challenge and Commitment: A Defence Policy for Canada, Department of National Defence, Ottawa, 1987, p.2; Also for analysis see Joel J. Sokolsky, "Canada, Getting It Right This Time: The 1994 Defence White Paper”, May 31, 1995, paper presented at the U.S. Army War College Sixth Annual Strategy Conference April 26-28, 1995 accessed online at http://www.dtic.mil/doctrine/doctrine/research/canada.pdf, 30 August 2015.

385 "The fall of the 1987 White Paper was even more spectacular [than the 1971 White Paper]. Arguably an anachronism on the day of its release, it was mortally wounded by the budget of April 1989 and rendered an historical curiosity by the end of the Cold War shortly thereafter." Martin Shadwick, "The Chrétien Legacy" Canadian Military Journal, Winter 2003 - 2004, accessed online on 16 September 2015 at http://www.journal.forces.gc.ca/vo4/no4/doc/comment-eng.pdf ; Shadwick's article provides a succinct defence policy analysis of the 1971, 1987 and 1994 White Papers in terms of their effect on the Canadian military and the Chrétien legacy.
} 
role for the Canadian Forces at home", particularly with respect to protecting Canadian sovereignty in the maritime area of jurisdiction. ${ }^{386}$ Receiving 12 new Maritime Coastal Defence Vessels, the Canadian navy was assuming greater responsibilities closer to home. Although General Rick Hillier and others declared the next ten years the 'decade of darkness' for the Canadian Forces, analyst Joel Sokolsky considered the White Paper finally 'got it right' with its consistency regarding foreign policy objectives, its level of ambition with respect to funding, and the likelihood of broad public support. ${ }^{387}$ Slowly, succeeding Liberal governments were shaping Canadian security culture and institutions to a new paradigm reflective of the evolving international environment and public expectations.

As evident in the title, Minister of National Defence Peter MacKay’s 2008 Canada First Defence Strategy followed the previous Liberal governments’ 1994 and

${ }^{386}$ Government of Canada, 1994 White Paper on Defence, Department of National Defence, Ottawa, 1994, p. 19 found online at http://publications.gc.ca/site/eng/429769/publication.html .

The decline in the direct military threat to Canadian territory has not eliminated an on-going role for the Canadian Forces at home. We will maintain a level of military capability sufficient to play an appropriate role in the defence of Canada. The Forces will honour the statutory requirement to respond to requests for Aid of the Civil Power. Through the assistance they provide to civil authorities, the Canadian Forces will help protect Canadian sovereignty, and carry out a wide variety of secondary roles.

The Forces will be capable of mounting effective responses to emerging situations in our maritime areas of jurisdiction, our airspace, or within our territory, including the North. Specifically, the Canadian Forces will:

- demonstrate, on a regular basis, the capability to monitor and control activity within Canada's territory, airspace, and maritime areas of jurisdiction;

- $\quad$ assist, on a routine basis, other government departments in achieving various other national goals in such areas as fisheries protection, drug interdiction, and environmental protection;

- be prepared to contribute to humanitarian assistance and disaster relief within 24 hours, and sustain this effort for as long as necessary;

- maintain a national search and rescue capability;

- maintain a capability to assist in mounting, at all times, an immediate and effective response to terrorist incidents; and,

- $\quad$ respond to requests for Aid of the Civil Power and sustain this response for as long as necessary. 387 Sokolsky, 31 May 1995; Also see Shadwick, Winter 2003-2004; General Hillier's “decade of darkness" comment was made in a speech at the Canadian Defence Association's annual conference, 16 February 2007. 
$2004^{388}$ positions in articulating the military's primary role in supporting domestic national security. Although the Harper Government made great efforts to distance itself from the lexicon of the 2004 National Security Policy and 2005 International Policy Statement, it continued to embrace the centrality of the national security concept. Of the six major core military missions identified, the first four were domestic-centric and were consistent with the priorities expressed by the Martin Government in A Role of Pride and Influence in the World: Defence policy statement, reiterating the navy's responsibility for maritime sovereignty and adding NORAD's new maritime warning role. Whether officially stated or simply inferred, it is evident that defence policy has become an extension of Canada's domestic-centric national security policy.

\subsubsection{The Changing Domestic Security Policy Environment}

A similar trend towards consolidation of domestic institutions under the umbrella of national security can be seen prior to 2004. At the end of the Second World War, the defection of a Russian cipher clerk, Igor Gouzenko, became the catalyst for the establishment of the modern Canadian national security structure. Gouzenko provided evidence of a Russian spy ring within critical security institutions of Canada, the US and UK. Canada's response to the proven existence of subversive activities was to pursue a broad spectrum of security initiatives. With sparse evidence that could be used in court, Mackenzie King authorized the RCMP to seize and interrogate suspects under the War Measures Act and later established the Kellock-Taschereau Commission ${ }^{389}$ to investigate allegations of abuse. Although the Commission report was not released publicly until

\footnotetext{
388 The 2004 National Security Policy statement will be discussed at length later in this chapter.

${ }^{389}$ Officially known as the Royal Commission to Investigate the Facts Relating to and the Circumstances Surrounding the Communication by Public Officials and Other Persons in Position of Trust of Secrets and Confidential Information to Agents of a Foreign Power.
} 
1981, the government had acted quickly; security measures were tightened within government, the role of the RCMP was strengthened, the Examination Unit that intercepted wireless communications during the Second World War was spared to eventually become the Canadian Security Establishment (CSE), and security screening became part of civil service and immigration policies. ${ }^{390}$

Twenty years later in 1977, the Government of Canada established the Royal Commission of Inquiry into Certain Activities of the RCMP, the McDonald Commission, to investigate a number of allegations of unlawful activities performed by the RCMP Security Section in the name of national security and intelligence. The Commission found that the RCMP's law enforcement role was in conflict of interest with its domestic intelligence gathering activities. Upon McDonald's recommendation, the Canadian Security Intelligence Service (CSIS) was established by an Act of Parliament as a civilian agency with a mandate for gathering national security intelligence and conducting national security investigations. As well as to improve effectiveness, the McDonald Commission recommended this structural change "to ensure our security system also met the requirements of democracy." 391

\footnotetext{
${ }^{390}$ See Norman Hillmer and J. L. Granatstein, Empire to Umpire: Canada and the World into the 21st Century, 2nd ed., Toronto: Thomson Nelson, 2008, p. 165-169.

${ }^{391}$ D.C. McDonald., et al. Freedom and Security under the Law: Second Report of the Canada Commission of Inquiry Concerning Certain Activities of the Royal Canadian Mounted Police, Ottawa: Supply and Services Canada, 1981, p. 1055 "4. Freedom and security are fundamental to the preservation of the democratic process. They are interdependent for without security, freedom is imperilled, and without freedom the attainment of security will be to no avail. In striving for security we expect that our security intelligence agency and our police service will not only be effective in doing so but also will respect the rights of citizens. 5. Throughout this Report we have been uncompromising in our insistence on the obedience to the law by members of our national police force and our security intelligence agency. Thus we have insisted that adherence to the Rule of Law is inseparable from attempts to attain the objectives of freedom and security. Without the Rule of Law, we do not believe that freedom and security can be attained."
} 
However, the 1985 Air India Flight 182 bombing demonstrated the fallibility of the emerging national security structure, when the RCMP and CSIS failed to stop Canadian Sikh militants from planting bombs on two Air India flights. Systemic failures were identified in the long, drawn-out investigation and prosecution, but it required the specificity of the Commission of Inquiry into the Investigation of the Bombing of Air India Flight 182, the Air India Commission ${ }^{392}$, to publicly identify the complexity of roles in an evolving construction of the security and intelligence institutions. As Justice John C. Major concluded, "A cascading series of errors contributed to the failure of our police and security forces to prevent this atrocity." ${ }^{393}$ Although inadequate legal mandates, transition issues, inexperience, and duplication of effort were identified as playing a role in the failure of CSIS and the RCMP to identify and prevent the terrorist attack, it was their failure to share the critical information they had already obtained that was the most egregious problem..$^{394}$

It seemed at the time that Justice Major's call for the reform of Canadian institutions ${ }^{395}$ would be marginalized by political expediency, as many commission

\footnotetext{
392 The public Commission of Inquiry may never have taken place under the Inquiry Act had the recommendation in the Bob Rae Lessons to be Learned Report been taken; Government of Canada, The report of the Honourable Bob Rae, Independent Advisor to the Minister of Public Safety, on outstanding questions with respect to the bombing of Air India Flight 182, accessed online at http://www.publicsafety.gc.ca/cnt/rsrcs/pblctns/lssns-lrnd/index-eng.aspx\#toc10 on 02 Sep 2015.

${ }^{393}$ John C. Major, Commission of Inquiry into the Investigation of the Bombing of Air India Flight 182, "Remarks by Commissioner John C. Major, June 17, 2010", accessed online 30 August 2015 at http://epe.lac-bac.gc.ca/100/206/301/pco-bcp/commissions/air_india/2010-0723/www.majorcomm.ca/en/reports/finalreport/default.htm

394 John C. Major, Commission of Inquiry into the Investigation of the Bombing of Air India Flight 182, Vol 2, Part 1: Pre-Bombing, 1 May 2006, pp. 239- 440, accessed online 30 August 2015 at http://epe.lac-bac.gc.ca/100/206/301/pco-bcp/commissions/air_india/2010-0723/www.majorcomm.ca/en/reports/finalreport/default.htm

${ }^{395}$ Major, 2006, Vol 1, Chapter VII: Recommendations and Observations, as well as Opening Remarks on Release of Air India Commission Report.
} 
reports had been in the past ${ }^{396}$. In response to the final release of the Air India

Commission's Final Report in 2010, the Harper Government consolidated a number of ongoing initiatives into its Action Plan and promised to:

- introduce legislation to clarify the authorities for information sharing for the purpose of national security;

- leverage technological innovation to facilitate and foster information sharing; and

- enable the review of national security activities involving multiple departments and agencies, and create an internal mechanism to ensure accountability and compliance with the laws and policies governing national security information sharing. ${ }^{397}$

Justice Major expressed 'disappointed bafflement' in the Conservative government's

rejection of key recommendations, particularly the call to create a national security "czar"

to manage horizontal security issues that Minister of Public Safety Vic Toews dismissed

as unnecessary "new bureaucracy." 398 It would take a further five years and the murders

of two Canadian military personnel in October 2014 to precipitate the promised

legislation in form of Bill C-51.

Where the Air India Inquiry identified a severe failure to share security

information amongst security partners, the case of Maher Arar demonstrated the dangers

of improper handling and sharing of information by government. Caught up in the

\footnotetext{
396 See Stuart Farson and Reg Whitaker, "Public Inquiries in Canada: Making Espionage, Organizational Culture, Wrongdoing and Mass Murder More Transparent," in Mark Phythian and Anthony Stuart Farson, Commissions of Inquiry and National Security: Comparative Approaches, Santa Barbara, California: Praeger, 2011.

${ }^{397}$ Government of Canada, Action Plan: The Government of Canada Response to the Commission of Inquiry into the Investigation of the Bombing of Air India Flight 182, 2010, p. 7, accessed online 30 August 2015 at http://www.publicsafety.gc.ca/cnt/rsrcs/pblctns/rspns-cmmssn/rspns-cmmssn-eng.pdf .

398 Tonda MacCharles, “Air India inquiry head baffled by Ottawa’s response”, Toronto Star newspaper, published 07 December 2010 found online at http://www.thestar.com/news/canada/2010/12/07/air_india_inquiry_head_baffled_by_ottawas_response.ht $\underline{\mathrm{ml}}$; In the article, Justice Major expresses his frustration at producing substantive recommendations only to have them ignored by government. "Justice Major said his role is now over. He noted when Justice John Gomery, who conducted the inquiry into the sponsorship scandal, tried to take an active role in getting its recommendations implemented, "he got absolutely nowhere." "I gave it - we all gave it - our best effort. This (press release) may be just a summary but I'm really at a loss as to what this means." ",
} 
disarray of American and Canadian security systems still coming to terms with the 9/11 attack one year earlier, Arar was detained and deported ${ }^{399}$ to Syria by US authorities - on general information rather than concrete evidence supplied by the RCMP - where he was subsequently tortured and only repatriated to Canada one year later. An internal report into the RCMP's role, the 'Garvie Report', identified systemic failures due to the fluidity of events and acknowledged several instances of impropriety with regard to information sharing. However, the final report of the 'Commission of Inquiry into the Actions of Canadian Officials in Relation to Maher Arar' (the O'Conner Commission) that exonerated Arar of any wrongdoing went much further and provided recommendations to rectify the problems that lay at the heart of the Arar 'nightmare'.

According to analyst Reg Whitaker, "O'Conner's task was to reconcile the expansion and enhancement of integrated antiterrorist operations - integration and information sharing being unanimously understood by experts as keys to responding effectively to the transborder threat of terrorism - with protection for the rights of individuals." ${ }^{400}$ In the Factual Report, the Commission found that deficiencies rather than negligence on the part of the RCMP had led to Arar being an "innocent" victim of torture. It was highly critical of the Canadian government's lack of concern for Arar's situation and provided compelling condemnation of the use of torture through the first documented description of the US practice of 'extraordinary rendition'. The

\footnotetext{
${ }^{399}$ Most analysts have called this deportation an example of extraordinary rendition for torture by a proxy state, as the Syrian government was notorious and well documented for using torture on detainees; however, the US continues to defend their actions as an immigration issue. See Reg Whitaker, "Arar: The Affair, the Inquiry, the Aftermath", Institute For Research on Public Policy, 28 May 2008, online at http://irpp.org/research-studies/policy-matters-vol9-no1 .

${ }^{400}$ Reginald Whitaker, "Arar: The Affair, the Inquiry, the Aftermath", Institute for Research on Public Policy, Vol 9, No. 1, 2008, p. 17.
} 
Commission's investigation led to renewed attention on the criticality of respecting 'third party' release of information caveats in formal information-sharing agreements.

In a prescient move, the Commission established a parallel policy review process that O'Conner decided needed to extend beyond the RCMP's role to the national security system as a whole. This resulted in an early determination by the Commission that the Arar case was actually anomalous to how the government of Canada was conducting national security investigations and allowed the Commission to focus more attention on recommendations to balance the state's need for security against the right to privacy and civil liberties of its citizens. ${ }^{401}$ In A New Review Mechanism for the RCMP's National Security Activities ${ }^{402}$, O'Conner not only provided a comprehensive overview of the national security landscape, but made several recommendations for enhanced review mechanisms.

\subsubsection{Convergence of Rights}

Although critics will point out the political nature of Commissions of Inquiry and the lack of action taken by governments on recommendations, Commissions provide independent, arms-length authority and transparency in investigating issues of public concern and problems of governance. However, it is not necessarily the outcome that leads to the greatest changes, but the transformational process itself. While the KellockTaschereau Commission brought to light the new realities of Cold War domestic threats, it unintentionally raised concerns about individual rights of those abused by the process that Whitaker says directly contributed to the 1960 Bill of Rights. Later, the MacDonald

\footnotetext{
${ }^{401}$ Ibid, p. 27.

${ }^{402}$ Dennis O'Conner, A New Review Mechanism for the RCMP's National Security Activities: Commission of Inquiry into the Actions of Canadian Officials in Relation to Maher Arar, 2006a, accessed online 30 August 2015 at http://www.sirc-csars.gc.ca/pdfs/cm arar_rcmpgrc-eng.pdf .
} 
Commission attempted to "balance the obligations of a democratic state to protect itself against threats to its national security and its obligation to protect the rights and liberties of its citizens" ${ }^{403}$ that Whitaker links to provisions in the Charter of Rights and Freedoms (Charter). The Air India Commission may have been delayed, but internal investigations early on revealed the criticality of information-sharing between security partners to detect, deter and defeat terrorism.

The commissions are not directly causal to policy change as they have generally emphasized matters of propriety over systemic efficacy but, along with transparent parliamentary committees, they provide evidence of the ideational construction of Canadian security identity. The War Measures Act proved to be an unacceptable means in dealing with domestic insecurity for Prime Minister King as it trampled on the democratic rights of Canadian citizens in the name of state protection. ${ }^{404}$ The Diefenbaker Government changed Canadian cognitive norms with the introduction of the Bill of Rights to provide protection for individuals. However, it lacked sufficient precision for individuals to challenge state decisions and thus did not provoke substantive systemic change.

The creation of the Charter was meant to balance the government's rights and obligations to both the individual and collective society through provision of a greater ideational role for the judiciary. Thus the Charter represents a critical juncture in the construction of Canadian identity, as the judiciary now had a voice in interpreting the regulative norms of the Constitution between security stakeholders. Although the trend towards an integrated, domestic-centric security system was becoming evident,

\footnotetext{
${ }^{403}$ Farson and Whitaker, 2011, p. 43.

404 Ibid.
} 
government lethargy and institutional resistance were responsible for systemic failures identified by the Air India and O'Conner Commissions. Rather than quickly addressing key commission findings, such as the lack of information-sharing, contestation issues between individual rights and collective rights with respect to national security were marginalized by successive governments due to political sensitivities and generally left to the courts to resolve as Charter challenges. However, the events of 9/11 became the catalyst for substantive debate of this Canadian security identity dilemma as the bureaucracy needed government decisions and the issues could no longer be avoided.

\subsection{Processes and Policies}

\subsubsection{9/11 Crisis Management}

On the morning of 11 September 2001, a new form of transnational warfare materialized as terrorist operatives used domestic airliners as weapons of war to attack symbolic targets in the United States. At 8:46 Eastern Daylight Time, American Airlines Flight 11 struck the North Tower of the World Trade Centre in New York City and 17 minutes later, United Airlines Flight 175 struck the South Tower killing all onboard and causing a huge loss of life as the two towers disintegrated. As knowledge and understanding of the attacks slowly crystallized, two more hijacked flights were inbound to their planned targets. American Airlines Flight 77 struck the Pentagon at 9:37, while passengers on United Airlines Flight 93 heroically forced the hijackers to abort their planned attack on what was presumed to be "symbols of the American Republic, the Capital or the White 
House" ${ }^{405}$ by plowing into an open field in Pennsylvania at 10:02. In total 2,996 people lost their lives that day, 2,977 victims and 19 perpetrators.

Although many individual sectors of the American security complex identified varying aspects of the attacks as the diverging airliner patterns began, the lack of connectivity and command/control/communication (C3) nodes amongst agencies inhibited information flow and decision-making processes. This was particularly evident between the Federal Aviation Authority (FAA) and the only security institution that could have stopped the attackers, NORAD. As the 'National Commission on Terrorist Attacks upon the United States' (9/11 Commission) concluded in its final report, given the lack of information and distances, NORAD would have likely been unable to intercept the final airliner before it reached Washington had it not crashed in Pennsylvania. The US President stated that he authorized the killing of innocent Americans aboard American Flight 77 by American pilots in order to stop an attack on an 'American symbol' ${ }^{406} \mathrm{He}$ made this 'moral choice' on the grounds of national security as American acquired values collided at that instant of time.

The attack by Osama bin Ladin's al-Qaeda organization lasted less than 2 hours, achieved all 9 principles of war $^{407}$ and set in motion a new trajectory in domestic and

\footnotetext{
405 Thomas H Kean and Lee Hamilton, and National Commission on Terrorist Attacks upon the United States, The 9/11 Commission Report: Final Report of the National Commission on Terrorist Attacks upon the United States, Official government ed. Washington, DC: National Commission on Terrorist Attacks upon the United States, 2004, p. 14.

406 Ibid, p. 40.

407 According to the Army Field Manual FM-3 Military Operations: Mass (concentrate power at the decisive time and place); Objective (seize, retain, and exploit the initiative); Surprise (strike the enemy at a time, place or in a manner for which he is unprepared); Economy of Force (allocate minimum essential combat power to secondary efforts); Maneuver (place the enemy at a disadvantage through the flexible application of combat power); Unity of Command (for every objective, ensure unity of effort under one responsible commander); Security (never permit the enemy to acquire an unexpected advantage) ; and Simplicity (prepare clear, uncomplicated plans and clear, concise orders to ensure thorough understanding).
} 
international security. Within hours, normalcy ceased in the US, borders were shut, airplanes were ordered to land, and sea ports closed. In Canada, the 'fog of war' was evident too. With no real-time information available, security protocols were invoked and autonomous decisions made. Upon the request of the FAA, Minister of Transport David Collenette, in concert with his Deputy Minister Margaret Bloodworth, unilaterally authorized the diversion of all US inbound airliners to Canadian airports. Prime Minister Chrétien called on his senior security advisors, who were unable to provide any substantial information as they too lacked integrated connectivity. To many observers, "in political and official terms... the response was underwhelming" as Canadian authorities were seen as "being confused, slow and uncoordinated in their initial response", as "no one had a [complete] picture of the national response within government. ${ }^{, 408}$ However, as it became clear that Canada was not a target, the unintended consequences of the attack to Canadian national security quickly surfaced.

Within a day, border crossing points were clogged and lineups stretched for twenty kilometers as American customs agents methodically searched every car and truck. Unsubstantiated rumours quickly circulated about the origins of the 'terrorists' with respected American politicians such as New York Senator Hillary Rodham Clinton wrongly charging that the terrorists had entered the US from Canada. The 'porous' border immediately became a critical bilateral issue. The largest trading relationship in the world ground to a halt with critical implications to Canada. American national security actions to protect its citizens superseded economic interests as "the United States will place its physical security above the free flow of goods, services, capital and people

\footnotetext{
${ }^{408}$ Jennifer M. Welsh, At Home in the World: Canada's Global Vision for the 21st Century, p. 11.
} 
across the border." 409 As Chrétien's Chief of Staff observed, "The Canadian government had to put in place - and fast - new ways to deal with our common security issues and to meet legitimate American security preoccupations" ${ }^{\text {410 }}$; crisis management would continue for some time in Canada.

By 14 September, the Bush administration had decided to reorganize its security complex and create a homeland security advisor and Homeland Security Council paralleling the National Security Council System. At the same time, an early version of what was to become the USA PATRIOT Act ${ }^{411}$ was taking shape. On 20 September, Bush announced that Tom Ridge would become the first Homeland Security Advisor in charge of the emerging Department of Homeland Security (DHS), precipitating the largest US government reorganization since 1947 with DHS officially standing-up a mere 18 months later in March 2003. On 26 October 2001 the USA PATRIOT Act was passed by Congress that gave the administration significant additional powers for domestic security and surveillance. Significantly for Canada, under the Unified Command Plan President Bush created the United States Northern Command (NORTHCOM) on 25 April 2002 "to ensure that overall defense is as layered and seamless as possible..... NORTHCOM will help coordinate military support to other federal, state, and local agencies and is responsible for security cooperation and coordination with Canada and

\footnotetext{
${ }^{409}$ The 105th American Assembly Columbia University, Renewing the US - Canada Relationship, p. 2, found online at http://www.wilsoncenter.org/publication/105th-american-assembly-renewing-the-uscanada-relationship

${ }^{410}$ Goldenberg, 2006, p. 264; A good summary of the challenges and reactions of the Canadian government can be read in Norman Hillmer, Fen Hampson, and David Carment, "Smart Power in Canadian Foreign Policy", in Canada among nations 2004: setting priorities straight, Montreal: McGill-Queen's University Press, 2005, pp. 3-17.

${ }^{411}$ The actual title of the USA PATRIOT Act is the 'Uniting and Strengthening America by Providing Appropriate Tools Required to Intercept and Obstruct Terrorism Act'. See Kean and Hamilton, pp. 325330 for the timeline emergence of both Homeland Security Advisor and the USA PATRIOT Act.
} 
Mexico."412 The US was moving quickly and deliberately with focused attention on strengthening the seams of American democracy with little regard to any collateral damage that might ensue to others.

Understanding this American security norm, Chrétien's solution was to create a cabinet committee to make recommendations on domestic security matters, the CanadaUS border, and all other ramifications of the 9/11 attack. He appointed Foreign Affairs Minister John Manley as chairperson with ministers from Finance, Defence, Transport, Justice, Immigration, Health, Revenue, the Solicitor General, and the Deputy Prime Minister as members, instructing them to "examine everything through both a security lens and civil liberties lens."413 This group eventually became the Ad Hoc Cabinet Committee on Public Security and Anti-terrorism, responsible for generating many of the resulting national security policies. By December 2001, as a result of this committee's deliberations, $\$ 7.7$ billion of new money was allocated for emergency preparedness, intelligence and policing, air travel security, immigrant and refugee screening, and border security and infrastructure. Although the government saw this as spending on national security, the traditional defence establishment did not, and "continue[d] to argue that the government was negligent in not increasing the traditional defence budget, which they did, and do, vociferously." 414

\footnotetext{
${ }^{412}$ Stanley Weeks, “The Department of Homeland Security: Will It Address The Threat?", Continental Security and Canada-US Relations, Halifax: Dalhousie University, 2003, p. 77.

413 Goldenberg, 2006, p. 269.

414 Ibid, p. 267.
} 
During the alleged decade of darkness ${ }^{415}$ of Liberal spending cuts to the Canadian Forces (CF), it was understandable that critics called for greater funding for the Department of Defence (DND). However, it is clear that Canada's domestic security structure, the essence of its 'national security', was in greater need of the $\$ 8 \mathrm{~B}$ in 2001 to bring it into line with changing security landscape. More tanks, ships, or aircraft in the CF inventory would not have enhanced national security if the very domestic security infrastructure left the country vulnerable to penetration and attack. ${ }^{416}$ Most importantly, any denigration of Canada's domestic security apparatus by a security obsessed United States would have had far greater consequences to Canada's national security than any external threat, a point of convergence between constructivists and realists. The problem with most realist accounts is in assuming the state is prepared and capable to deter, defend and defeat internal threats; yet, transnational aggressors do not play by those assumptions. Defence has and must play a role in the security spectrum, but Canadian national security starts at home and the most pressing need following 9/11 was to ensure credibility to both Canadian society and to Canada's American 'nemesis', the US Congress. ${ }^{417}$ Canadian National Security Culture demands domestic protection of acquired values first and foremost of government.

${ }^{415}$ CDS Rick Hillier spoke publically about the $25 \%$ cut in funding that DND/CF had witnessed under the Chretien government at the Conference of Defence Association Institute conference in Ottawa, 16 February 2007 saying, "Those actions ... have now led to some deep wounds in the Canadian Forces over this past what I would call a decade of darkness."; Also see, Elinor C. Sloan, Security and Defence in the Terrorist Era: Canada and the United States Homeland, 2nd ed. Montréal: McGill-Queen's University Press, 2010, pp 22-25, for a succinct summary of the effect of the Chretien years on Defence.

416 See David G Haglund, "North American Cooperation in an Era of Homeland Security," Orbis, Vol 47, No.4, 200, pp.675-691.

${ }^{417}$ Douglas A Ross and Hira Anil, "Canada, a Land of Deep Ambivalence: Understanding the Divergent Response to US Primacy After 9/11," Canadian-American Public Policy, no. 68, December, 2006, p.11; also see Alexander Moens and Gabler Nachum, What Congress Thinks of Canada, Studies in Canada-US Relations, Fraser Institute, 2011. 
Proud of his role in bringing the Charter of Rights and Freedoms to fruition, Chrétien was concerned that the events of $9 / 11$ would be used as a pretext to introduce policies contrary to these newly acquired values. ${ }^{418}$ Balance was required between the needs of security and the protection of civil liberties. In the House of Commons, the Prime Minister emphasized these security norms:

If laws need to be changed, they will be. If security has to be increased to protect Canadians it will be. We will remain vigilant. But we will not be giving in to the temptation, in a rush to increase security, to undermine the values that we cherish and which have made Canada a beacon of hope, freedom and tolerance to the world. Immigration is central to the Canadian experience and identity. We welcome people from all corners of the globe: all nationalities, colours and religions. This is who we are. And let there be no doubt: we will allow no one to force us to sacrifice our values under the pressure of urgent circumstances. ${ }^{419}$

Although this form of subdued rhetoric was castigated in the Canadian press and by analysts ${ }^{420}$, Chrétien was adamant that $9 / 11$ would not be securitized as an existential threat to Canada. Sara McGuire is correct in her analysis that the Chrétien narrative to the 9/11 attack described "the events more as a criminal act than a catastrophic event". Also accurate are her observations that Canada would "adopt a distinctly Canadian response to terrorism", "emphasize the importance of multilateralism over the American 'go it alone' strategy", and articulate "a recognition that Canadian security was intrinsically linked to the economics and the maintenance of the Canada-United States trading relationship". ${ }^{421}$

\footnotetext{
418 Goldenberg, 2006, p. 267.

419 PM Chretien speech in the House of Commons found in Goldenberg, p 268.

${ }^{420}$ See Jeffrey Simpson, "Timing is Everything for PM's New York Trip", The Globe and Mail, Friday, September 28, 2001, A.7; Christie Blatchford, “Tepid Speech, Tepid Nation: Chretien's Yawner Illustrates How Soft the Country Has Grown", National Post, September 29, 2001; Sara McGuire, "'Securing' the Homeland? A Comparison of Canadian and American Homeland Security Policy in the Post-9/11 Period", McMaster University, 2013; Graham Fraser, “Liberal Continuities: Jean Chretien's Foreign Policy, 1993 2003", in Norman Hillmer, Fen Hampson, and David Carment, eds., Canada among Nations 2004: Setting Priorities Straight, Montréal: McGill-Queens University Press, 2005.

${ }^{421}$ McGuire, 2013, pp. 86-87.
} 
However, her homogeneous application of securitization theory conflates two distinct national audiences that do not share common national security norms.

McGuire's observations are consistent with Canadian National Security Culture norms. As catastrophic an event as 9/11 was to 'Canada's best friend and neighbour', Chrétien maintained a pragmatic approach by focusing foremost on the national security concerns of Canada. He opposed calls from the business community and conservative editorialists to create a common security perimeter around North America as this would require the harmonization of laws, which Chretien viewed as a diminution of Canadian sovereignty. The 9/11 attack did not require a wholesale change in Canadian acquired values to address concerns. ${ }^{422}$ It did, however, require a particularistic approach to determine the essential security norms that needed to be changed or improved.

The creation of the Manley committee was wise and pragmatic. Having one point of contact allowed for domestic multilateralism amongst stakeholders and focused resolution of bilateral concerns between Canada and the US. In this approach, Canada was able to address and risk manage US security concerns while shaping both bilateral and domestic security policies to meet Canadian acquired values to the maximum extent possible. McGuire's discourse analysis was correct in stating that the Canadian elite failed to securitize $9 / 11$, but her conclusions ${ }^{423}$ failed to understand the cultural

\footnotetext{
${ }^{422}$ Donald Barry, "Managing Canada-US Relations in the Post 9/11 Era: Do We Need a Big Idea?", in Duane Bratt and Christopher John Kukucha, Readings in Canadian Foreign Policy: Classic Debates and New Ideas, Toronto: Oxford University Press, 2007.

${ }^{423}$ McGuire, 2013, "Despite the emergence of Canadian homegrown terrorists, the Canadian government has not securitized its state approach to homeland security and counter-terrorism. One of the reasons for this is that, while the United States witnessed an actual terrorist attack on its own soil, Canadian authorities have prevented attacks from taking place in Canada. There is a belief that 'securitizing' the state's response to these events would have a negative effect on Canadian citizens." P. 285; and "In Canada, the populist audience's response to the $9 / 11$ attacks on the U.S. was a study in contrast. While the Canadian public demonstrated a short-lived desire for stricter security measures, it ultimately favoured the protection of civil
} 
underpinnings of Canadian National Security Culture that reject American-style securitized rhetoric.

As expected, the US moved forward unilaterally on many fronts without consultation, but the impact of the policy decisions to Canada was mitigated by the forward-leaning, proactive dialogue initiated by the Chrétien government as a national security reflex. Being 'inside the tent' allowed Canada to witness the ab initio security policy initiatives of the US, such that Canada was in a position to prepare its own response to American security choices. Given the importance of coordinated action against transnational threats and the passage of the USA PATRIOT Act, Canada enacted its own legislation to address deficiencies in Canadian jurisprudence six weeks later. As a Library of Parliament document ${ }^{424}$ shows, Bill C-36, the Canadian 'Anti-terrorism Act', was similar in intent to the USA PATRIOT Act, but protected Canadian security norms and values. The omnibus bill extended the power of government and security institutions to respond to terrorism by amending cognitive standards of security already established in Canadian legal institutions. Canadian security norms do not neatly line up with other states as realist accounts would have us believe or discursive analysts proclaim. ${ }^{425}$ Jurisprudence matters in Canadian National Security Culture.

liberties and multiculturalism. Likewise, while the public supported a distinctly "Canadian" response to counter-terrorism, there was a notable rise in Canadian Islamophobia following the 9/11 attacks.", pp. 288289.

${ }^{424}$ Jennifer Wispinski, "The USA PATRIOT Act and Canada's Anti-terrorism Act: Key Differences in Legislative Approach", Library of Parliament PRB 05-83E, 31 March 2006.

${ }^{425}$ Wispinski's paper also provides explanation as to the legal obligations entailed in creating a separate Anti-terrorism Act to address Sara McGuire's simplistic conclusion that a lack of elite interest in securitization resulted in Canada "chart[ing] a uniquely Canadian approach to homeland security." McGuire, 2013, p. 9. The 'rule of law' norms in Canadian National Security Culture mean these legal obligations supersede philosophical securitization processes regardless of the audience, pp. 134-149. 
Additionally, in December 2001 Manley and Ridge signed the US-Canada Smart Border Declaration and associated 30-point Action Plan ${ }^{426}$ in recognition of the economic importance of trade. The goal of the declaration was to enhance the security of the shared border while facilitating the legitimate flow of people and goods. This declaration and its swift implementation is evidence of the affirmative risk management engaged by Canada in the arena of 'complex sovereignty'. Rather than dither over border jurisdictional issues, pragmatic solutions such as the Integrated Border Enforcement Teams (IBET) that comprise two Canadian and three US law enforcement agencies were in ten locations within the year, ensuring overlapping deterrence to crime and terrorism.

Through multilateral agency discussions on Joint Enforcement Coordination, Canadian sovereignty was assured as bilateral obstacles to law enforcement were identified, prioritized, and brought to the attention of policy-makers for resolution. This particularistic approach to national security issues ensures American decision-makers are aware that their northern border is secure and minimizes the traction of US securitized rhetoric about 'terrorists entering the US from Canada'. Canadian sovereignty and access to its most important market are maintained through collective national security

\footnotetext{
${ }^{426}$ US Government fact sheet, “US-Canada Smart Border/30 Point Plan Update”, December 6, 2002, online at http://2001-2009.state.gov/p/wha/rls/fs/18128.htm . The 30 Points include: biometric identifiers, permanent residence cards, single alternative inspection system, refugee/asylum processing, managing of refugee/asylum claims visa policy coordination air preclearance advance passenger information / passenger name record joint passenger analysis units maritime security and ferry terminals, compatible immigration databases, immigration officers overseas, international cooperation, harmonized commercial processing, clearance away from the border, joint facilities, customs data, container targeting at seaports, infrastructure improvements, intelligent transportation systems, critical infrastructure protection, aviation security, integrated border and marine enforcement teams, joint enforcement coordination, integrated intelligence, fingerprints, removal of deportees, counter-terrorism legislation, freezing of terrorist assets, and joint training and exercises.
} 
arrangements negotiated via multilateral talks that establish common 'rules of the game'. ${ }^{427}$

In October 2001, the US invaded Afghanistan with Canada providing troops in December to root out al-Qaeda operatives and topple the Taliban government that had collaborated with the terrorist organization responsible for $9 / 11$. This response by the US to an unprovoked attack was considered legitimate under international law and had the backing of a multilateral coalition. Although Canadians are normally reticent about the use of force, Chrétien agreed that it was in Canada's national interest to participate in eliminating a rogue regime as a threat not only to Canada and its allies, but to international society as well. The evidence against the Taliban government was uncontroversial. Canada then supported and encouraged the multilateral approach to Afghanistan reconstruction through UN Resolution 1386, which created the International Security Assistance Force (ISAF), and later NATO's leadership of ISAF in 2003.

By 2004, Canada held command of ISAF and was the largest troop contributor at the time. Canadian National Security Culture supports the application of deadly force when international law is broken and when armed interdiction results in providing greater order and stability to international society. Chrétien was the first NATO leader to publicly propose the invocation of Article Five of the NATO Charter, which declares an attack on one member is an attack on all member states. Both this substantive pronouncement and the Afghanistan mission demonstrate the Canadian understanding of

\footnotetext{
${ }^{427}$ Christopher Sands, "Fading Power or Rising Power: 11 September and Lessons from the Section 110 Experience," in Duane Bratt and Christopher John Kukucha, Readings in Canadian Foreign Policy: Classic Debates and New Ideas, Toronto: Oxford University Press, 2007.
} 
collective security and the responsibilities that are entailed within Canadian National Security Culture.

The American invasion of Iraq involved far less international legitimacy and Canada chose to stand on principles rather than acquiesce in the instrumental values that some claimed were in the national interest. Where President Bush had sought international support prior to commencing the Global War on Terrorism in Afghanistan, the President's new policy of unilateral military intervention was clearly evident in his approach to Iraq. This troubled Chrétien and his cabinet as they "rejected unilateralism as the best way to respond, except in the most extreme circumstances of direct and obvious threat." 428 Chrétien was clear to Bush in September 2002 that, without sufficient proof that Iraq had weapons of mass destruction (WMD), the international community would not support an invasion.

I was very skeptical about the claim that Iraq had weapons of mass destruction. I told US President George W. Bush that if he did not have the support of the UN, Canada would not be going to war. We were briefed on almost the same information as the Americans, but I did not see any proof. A year before the US invaded Iraq, I told Mr. Bush that we wouldn't go if they didn't meet the conditions. In the end, the UN did not sanction the invasion of Iraq, so we did not go. ${ }^{429}$

Chrétien's insistence on requiring a UN resolution was not rote articulation of the primacy of the UN, but a means for ensuring legitimacy of a questionable international intervention. Quiet diplomacy did not change the Bush administration's determination to 'go it alone', so the only alternative was to insist on the transparency of the UN's inspection team or wait for greater proof. The American insistence on pre-emptive strikes on Iraq contravened international law and order. It violated many democratic values in its

\footnotetext{
${ }^{428}$ Goldenberg, 2006, p. 289.

${ }^{429}$ From an essay by Jean Chretien found online at http://arts.lgontario.ca/lestweforget/essays/jean-chretien/
} 
lack of concrete evidence and prejudiced US leadership of international society. Containment as a strategy was working, so the use of force at that time was unnecessary. The 2003 invasion of Iraq contravened all the security norms and values embedded in Canadian National Security Culture; however, there were those who viewed the question through the instrumental values of loyalty and prosperity to argue that it was in the national interest to support the US. In the end, Chrétien's 'moral choice' to avoid exchanging soldiers' lives for Canadian national interests proved prescient.

An international initiative of note that transpired following 9/11 was the establishment of the Bi-national Planning Group (BPG) at NORAD headquarters headed by the Canadian Deputy Commander. It was formed on 6 December 2002 by Foreign Affairs Canada and the US Department of State via the Enhanced Military Cooperation Agreement with a mandate to enhance bi-national military planning, surveillance, and support to civil authorities and included seven taskings. Given the recent reorganization of US government security institutions into Homeland Security and USNORTHCOM, this initiative was foundational to many of the Canadian policy changes and revisions to its bilateral defence relationship with the US. As well, these discussions led to the CF's revised approach to domestic security with the creation of Canada Command in 2006.

The BPG will be discussed later in greater detail, but importantly for this dissertation, the National Security Policy statement was identified as the "overarching guidance" in the Canadian Strategic Planning System as specified in the BPG final report with the International Policy Statement on Defence as the subordinate planning 
document clarifying goals and objectives. ${ }^{430}$ Although to the Americans national security is articulated in the US National Security Strategy, to Canadian Foreign Affairs and Defence officials, national security in Canada was articulated by the National Security Policy statement.

\subsubsection{9/11 Consequence Management}

"[W]hen crunch time comes, issues move to the centre as key actors become increasingly involved. The Smart Border initiative moved along this trajectory after 9/11, with a unit of PCO [Privy Council Office] doing most of the heavy lifting on this dossier. So did the formulation and projection of the National Security Policy up to December 2003." 431 While crisis management was ongoing, a portion of the public service was engaged in the longer term consequence management. Serendipitously, in May 2001, the newly-formed Standing Senate Committee on National Security and Defence (SCONSAD) began public hearings to determine the state of major security and defence issues with a view to preparing a detailed work plan. The committee had a fair understanding of the diffuse state of the national security system in Canada when 9/11 occurred and was able to make important contributions to the evolving public policy discourse on national security.

The Committee learned that at present Canada does not have a specific National Security Policy that would place defence policy, foreign policy and internal security in context, and relate them to one another. While the constitutional division of powers represents a challenge, the time may have come to develop and

\footnotetext{
${ }^{430}$ Bi-National Planning Group, The Final Report on Canada and the United States (CANUS) Enhanced Military Cooperation, 13 March 2006, p. 8-9.

431 Andrew F Cooper and Dane Rowlands, "A State of Disconnects", Canada among Nations, 2005 : Splitting Images, Montreal: McGill-Queens University Press, 2005, p. 15.
} 
promote a national security policy that can be endorsed by all levels of government. ${ }^{432}$

As a result of continuing public hearings, three SCONSAD reports (Canadian Security and Military Preparedness - February 2002; Defence of North America: A Canadian Responsibility - September 2002; Canada's Coastlines: The Longest UnderDefended Borders in the World - October 2003) outlined the thoughts of elite decisionmakers and subject matter experts on the direction public policy should take, expressing the security norms and values found in Canadian National Security Culture. The February 2002 report contained nineteen recommendations of which four were on defence and fifteen on 'national security'. Recommendation 4 proposed that defence policy flow from foreign policy, thus again separating international security issues from national security. However, more importantly, recommendation 19 stated, "Given the importance of National Security issues, and the need to have procedures and policies in place before incidents happen, the Committee recommends that a study be undertaken to develop a National Security Policy, which will examine the roles of all levels of government." The justification for this and the other 14 recommendations under "national security' clearly focused on domestic security concerns and mechanisms of government. ${ }^{433}$

The House Standing Committee on Foreign Affairs and International Trade (SCFAIT) under the chairmanship of the future Foreign Minister Bill Graham was in the

\footnotetext{
432 Standing Senate Committee on National Security and Defence, "Canadian Security and Military Preparedness", First Session Thirty-Seventh Parliament, February 2002, pp 49-50; The SCONSAD reports can be found online at http://www.parl.gc.ca/sencommitteebusiness/CommitteeReports.aspx?parl=39\&ses=1\&Language=E\&com $\mathrm{m}$ id $=1076$

${ }^{43} \overline{3}$ Ibid, pp. 125-132. Appendices I and II contain Canadian security issues of broad concern that include items of Buzan's widening sectors such as health and the environment. - pp. 135-149.
} 
process of examining Canada-US relations when 9/11 occurred. SCFAIT's December 2002 committee report covered many of the themes that eventually found their way into the 2005 International Policy Statement, particularly the linkages across the ' 3 Ds' (diplomacy, development, and defence) for more effective management of the CANUS relationship. In particular, senior bureaucrats voiced caution and concern about protecting Canadian sovereignty when dealing with the emerging reorganization of the American security complex, and economists linked the security issues of trade homogenization with Canadian fears of US hegemony. ${ }^{434}$

As became standard procedure for the Chrétien Government ${ }^{435}$, along with political level ad hoc committees, senior public servants also established ad hoc Deputy Minister (DM) committees that provided input to centralized PCO teams for consolidation. There were eight principal departments with direct national security mandates, and many others that had consequent management missions, that required intermestic coordination. ${ }^{436}$ One such DM committee looked into CANUS Security and

\footnotetext{
${ }^{434}$ See Standing Senate Committee on National Security and Defence, "Canadian Security and Military Preparedness", First Session, Thirty-Seventh Parliament, February 2002, testimony that includes: "If there are real threats to Canada that we feel we cannot cope with on our own and we need to deal with them on a bilateral basis, then we must negotiate arrangement[s] that will protect Canadian sovereignty and enhance it by ensuring that we have a cooperative relationship with the United States, or whoever the other partner would be, that affords us that enhanced security but does not diminish our sovereignty. That is in the negotiations. However, it can be very difficult ... to ensure that we hold the line." Jill Sinclair, A/ADM, Global and Security Policy, DFAIT; and "... it should be noted that Canadian policy-makers and academics have no tradition of examining NAFTA through the lens of security. Indeed they can be quite hostile to the suggestion of such a possibility. This reflects the extent to which the concept of free trade was contested in Canada, its links in those debates to the question of sovereignty, and also lingering Canadian discomfort with American hegemony. For better or worse, however, participation in NAFTA has had significant implications for Canadian security, broadly defined. The events of 11 September made those implications far clearer."

${ }^{435}$ Roy Rempel is highly critical of the Chretien Government's 'Reactive and Ad Hoc Decision-Making'. See Roy Rempel, Dreamland: How Canada's Pretend Foreign Policy Has Undermined Sovereignty, Montreal: McGill-Queen's University Press, 2006, pp. 138-140.

${ }^{436}$ Solicitor General (Department/CSIS/RCMP/CSC/Oversight Committee); Minister of Justice (DoJ); Clerk Privy Council (Dept Clerk-SI Coord: S\&I Secretariat: Intel Sec); Minister of National Defence (DND/ OCIPEP/ CSE/ CF); Minister of Foreign Affairs (DFAIT); Minister of National Revenue (CCRA);
} 
Intelligence roles and relationships in late 2001 and by April 2003 had come to agreement on interdepartmental positions on key issues that included the need for a National Security Policy Statement. In June 2003, PCO formed a team to develop the National Security Policy statement that would eventually be officially released ten months later. It is important to note that the genesis of the National Security Policy statement was at the political level in 2001 and evolved in Ministerial and DM committees during on-going crisis management and emerging US security policy change until the decision to proceed with full development was made in April 2003. These decisions were all taken under the auspices of Prime Minister Chrétien's Government, a full six months before he resigned as Prime Minister ${ }^{437}$ Paul Martin basically inherited a finished product in December 2003 and only had to make the decision on whether to release the National Security Policy statement or not.

A significant factor that is often forgotten during this time period was the impact of the 1990s deficit reduction initiatives, which left most departments and agencies with substantially reduced personnel and resources. ${ }^{438}$ These capacity problems exacerbated the known lateral and hierarchical jurisdictional challenges in not only addressing the immediate security crises but producing the basic staff work required to advance longterm solutions. The particularistic organization of the Canadian polity means that national security involves all levels of government, crosses interdepartmental jurisdictions, and depends on key players in industry, non-government organizations

Minister of Transport (TC); Minister of Finance (FINTRAC); Minister of Citizenship and Immigration (CIC) have direct roles in security with consequence management by Health Canada, Agriculture Canada, CFIA, Environment Canada ; Natural Resources Canada, and others that are issue specific. ${ }^{437}$ Confidential interviews.

${ }^{438}$ See Geral Schmitz and James Lee, "Split Images and Serial Affairs: Reviews, Reorganizations, and Parliamentary Roles", in Andrew F Cooper and Dane Rowlands, Canada among Nations, 2005: Split Images, McGill-Queens University Press, 2006, p. 252-253. 
(NGO) and international regimes, particularly those in the US, who must all be consulted in development of such an omnibus policy as the National Security Policy statement.

\subsubsection{Development of the International Policy Statement}

A separate DM committee was meeting in parallel to the CANUS Security and Intelligence committee to develop an International Policy Framework (IPF), which included many of the same agents and their staffs. In September 2002, a Task Force was established to: describe the expanding scope of the government's international activities and the roles of international and domestic departments in support; identify key issues facing Canada in the world, and support the development of a coherent international policy based on clearly defined interests and values; and set out horizontal management tools to help the government respond more effectively in meeting future international challenges and opportunities. The IPF focused on the globalization of the international system and relating the intermesticity to Canadian domestic institutions. Of the 71 page report, only one page dealt with "The Changing Nature of Security", saying simply that the trend was that "Public, national and international security have become inseparable and embrace a wider range of concerns from terrorism to communicable diseases." ${ }^{439}$

Outside of mentioning the events of 9/11 and how disruptions such as this can affect Canada's economic well-being, there was no mention of any international security threats to Canada in the IPF and no references to any intelligence information that might impact Canada's international policies. The only significant references to specific states in the international system were three pages dedicated to how Canada should manage the CANUS relationship. Completed in July 2003, this Foreign Affairs-centric document

\footnotetext{
${ }^{439}$ Confidential information.
} 
was never released publicly as it was felt that the report was too long, repetitive, and contradictory between analysis and recommendations. DND in particular was concerned with the 'world coming to Canada' approach and its lack of a defence component. ${ }^{440}$

Realist theory maintains that the $9 / 11$ attack would precipitate a strong military reaction to the new security threat as seen by Canada's role in Afghanistan and that Canada would be looking to 'balance' or 'bandwagon' to meet the external threat. However, the evidence clearly shows that realist assumptions were not present in any form in the IPF, the precursor to the International Policy Statement. Terrorism, the new threat, barely received a mention. In the aftermath of $9 / 11$, the focus was on how the international system impacted the domestic security of Canadian citizens from the economy to terrorism to communicable diseases. Canadian National Security Culture views the external world as influencing national security domestically, according to the IPF.

Feeding into the post-9/11 discourse on bilateral security relations, a number of factors caused delays and uncertainty with respect to formulating national security policy. The International Policy Review (IPR) process, begun by Foreign Affairs Minister Bill Graham in December 2003, became the most protracted review ever with the rejection of PCO's Toward an International Policy Framework for the $21^{\text {st }}$ Century in July 2003. Then the unexpected and divisive reorganization of DFAIT, planned by Prime Minister Martin once in power, negatively affected international security advice, while the $a b$ initio attempt at a 'whole of government' approach to international activities by the new

\footnotetext{
${ }^{440}$ Confidential information.
} 
government created delays in operationalizing policies as departments negotiated common operating norms.

DFAIT documents acquired through the Access to Information Act point to three or more draft versions of the final International Policy Statement that emerged following the IPF process and that were in circulation from May 2004 until its release in April 2005. In reviewing the 1100 plus pages of drafts, it is clear that the government's approach was not based on a realist Hobbesian world, as there was no evidence of an intelligence based threat analysis used to guide the formulation of the International Policy Statement. The five working titles ${ }^{441}$ used in the formulation of the final version, $A$ Role of Pride and Influence in the World, were all indicative of a Grotian approach to Canadian international policy. Significantly, there was only moderate indication of any material power factors (found in neo-liberal complex interdependence theory) that shaped the International Policy Statement policy approach and these were generally about the security concerns that restricted the flow of trade. It is apparent that both the public servants creating the policy and the politicians directing the effort viewed national security culturally and ideationally as an acquired value focused on protecting other Canadian acquired values from the vicissitudes of an unpredictable, but manageable, global environment.

The January 18, 2005, draft, Making a Difference in the World, was the only version to have a significant 'Security' portion, and even that draft took the position that

${ }^{441}$ Draft working titles that were accessed through ATI were Building Canada's Global Advantage, Meeting the Challenges of Globalization, Making a Difference in the World, and finally Canada's Agenda for Global Engagement which was the closest draft to the final International Policy Statement produced, $A$ Role of Pride and Influence in the World. - Department of Foreign Affairs, Trade and Development Canada, Access to Information Request A-2005-00275 previously released and made available through an informal request, 04 May 2015. 
national security meant keeping Canadian society 'safe and secure' at home and abroad. Again, there was no 'threat analysis' presented to establish a baseline for defence of Canada and its interests in international security. The vague references to external threats, such as infectious disease, that transcend national borders leads one back to the premise taken in this dissertation that state protection of society begins at home. It was made clear in the draft that the National Security Policy (NSP) statement was the foundational document in Canada's "Comprehensive Security Strategy" with such references as "the NSP provides the blueprint for action" and the Government will focus and invest our defence diplomacy, and development institutions, building on the NSP framework." ${ }^{442}$ This is in line with analyst Rob McRae's assertion that with the blurring of the domestic and international domains in all areas of Canadian life. Canadian international policy needs to be "rooted in the domestic" and that the "domestic roots of our international policy" flow from the "top five public policy concerns of Canadians, three [of which] have significant (and well recognized) international components." ${ }^{443}$ Although many of the 'security' issues identified in this draft were eventually redistributed in a diluted fashion throughout the International Policy Statement, the process of formulation in all drafts has the hallmarks of Canadian National Security Culture. National security is endogenous and is a value that competes with other values for attention and funding. Of the five Canadian evaluative security norms, sovereignty was a paramount focus; division into the 3Ds facilitated particularistic, multilateral

\footnotetext{
${ }^{442}$ Government of Canada, Making a Difference in the World: Canada's International Policy Statement, January 18, 2005, DRAFT - NOT FOR CIRCULATION, acquired through the Access to Information Act from DFAIT, 04 May 2015, p. 6.

${ }^{443}$ Rob McRae, "International Reviews in Perspective”, in Norman Hillmer, Fen Hampson, and David Carment, eds., Canada among nations 2004: setting priorities straight, Montreal: McGill-Queen's University Press, 2005, pp 56-61.
} 
international concerns; Canada was viewed as shaping international society in a

communitarian fashion by encouraging respect for international authority; and the nonviolent, pragmatic approach ${ }^{444}$ was consistent with Canada's domestic mutual accommodation. ${ }^{445}$ Where McRae identifies interests, Jennifer Welsh speaks of the construction of interests through Canadian identity and values, but is quick to point out that "it is artificial to juxtapose interests and values .... [i]n reality, values and interests work much more in tandem." 446 Both McRae and Welsh's analysis of Canadian security norms that determine international policy are consistent with Canadian National Security Culture.

\subsubsection{Development of the National Security Policy Statement}

Throughout the development of both the National Security Policy statement and International Policy Statement, government documents demonstrate an early separation of domestic national security with external international security. In establishing the terms of reference for the development of the National Security Policy statement, a number of Canadian security norms and values were emphasized. Respect for the 'rule of law' was paramount in formulation of key information sharing policies, particularly with respect to legal rights to privacy and expectations under the Charter that would otherwise risk litigation and Charter challenges. The Solicitor General was tasked to develop a

\footnotetext{
${ }^{444}$ Although Canada's operations in Afghanistan involved the use-of-force as a means of last resort, the principles involved and articulated in the 3D approach were consistent with promoting order and stability in the international system.

${ }^{445}$ Further evidence can be found in Chapter 7, "The Evolution of National Defence Policy" in Brian W. Tomlin, Fen Osler Hampson, and Norman Hillmer, Canada's International Policies: Agendas, Alternatives and Politics, Toronto: Oxford University Press, 2008.

446 Jennifer Welsh, "Reality and Canadian Foreign Policy", in Andrew F Cooper and Dane Rowlands, Canada among Nations, 2005: Split Images, McGill-Queens University Press, 2006, p. 36.; For a full analysis of the elements pertaining to Canadian security norms, see pp 23-46 in Welsh and McRae, 2005, pp. 55-72.
} 
vision and strategy for interdepartmental information sharing in a system that claimed more than twenty departments/ agencies with security roles that spanned the spectrum from safety to security to defence. Not only did these institutions not possess the security norms needed for information sharing, but any new security initiatives needed to be supportable with trained effective people and the necessary equipment first.

In the interim, an information sharing policy that respected privacy rights needed to be balanced with the comprehensive information sharing needs of the current ad hoc arrangements used in the aftermath of 9/11. The Cabinet Committee on Public Security and Anti-terrorism found that cooperation was inhibited by legislation that was departmentally focused and did not provide the authorization for information sharing. This along with a lack of shared processes and priorities resulted in a lack of accessibility to critical information. Information sharing was key to the safety and security of society and the state; however related legalities, affordability, relevance and cost-effectiveness were intractable issues impeding progress. The problem was greater and farther reaching than the departmental system in place was designed to handle; therefore, it was managed by the Cabinet Committee on Public Security and Anti-terrorism, where the benefits of interoperability with the US could be determined as well.

The Spectrum of Security: In pragmatic and particularist fashion, the designers of the National Security Policy statement sought to make Canadian society and the state central to the security problématique. They defined 'de minimus' security as the protection of life, infrastructure, and territory and the 'de maximus' dimensions as global strategic stability and world peace. The goal of the National Security Policy statement was to create a seamless security continuum through time and space (domestically, 
continentally, and internationally) that operated intermestically, ${ }^{447}$ vertically (municipally, provincially, and federally), horizontally, and inter-sectorally. In order to accomplish this, a division of labour and responsibilities needed to be fostered by the creation of an effective Canadian security community (policy, operations, and stakeholders), a cross-government security culture, effective machinery, and incentives, and a sense of urgency communicated from the very top of government. Peace, Order, and Good Government (POGG) would be used as the baseline. ${ }^{448}$ This very ambitious project was purely ideational, demonstrating all five Canadian National Security Culture norms.

Prior to its release, Canada experienced three formative events that would be very influential on the depth and breadth of the National Security Policy statement. On 23 June 1985, Air India Flight 182 out of Montreal, bound for London, was destroyed by a bomb south-west of the Irish coast. Sikh terrorists had committed the largest mass murder in Canadian history and the single deadliest terrorist attack involving an airplane until 9/11. Failures in the Canadian security system were notable, with questions of jurisdiction and a debilitating lack of information sharing in the 'cascading series of errors' by the government of Canada and its security institutions. The second event was the global outbreak of the Severe Acute Respiratory Syndrome (SARS) that demonstrated the extreme vulnerability of Canadian society to transnational health risks in the age of globalization and the poor preparations of the Canadian government in dealing with the unexpected health threat in March 2003. Finally, the 2003 two-day Electrical Blackout in seven northeastern US states and Ontario demonstrated the interconnectedness of the two

\footnotetext{
${ }^{447}$ Intermesticity refers to interaction between the domestic and international political spheres.

${ }^{448}$ Confidential information.
} 
economies and the vulnerability of critical infrastructure. These formative events, as well as the 9/11 attack, reinforced the need for an integrated security solution.

It was known that Canada lacked cross-government strategic coherence and coordination in planning and executing intermestic security activities. The important new feature of the emerging security context was simply illustrated by $9 / 11$, not redefined by it. It was the interconnection, the blurring of domestic and international seams, that was the new development. The National Security Policy statement captured this spectrum of national security in the Venn diagrams that for the first time visually defined the government's concept of national security under the rubric 'The Scope of the National Security Policy' (see figure 2). This figure is not simply political 'window dressing' to promote the National Security Policy statement, but a very prescient illustration of Canadian National Security Culture that places state sponsored protection of acquired values between the individual's responsibilities for personal security and the state's responsibility to promote and defend international security. As demonstrated earlier, the nucleus of the Canadian state has always viewed endogenous protection of society/state as central to national security with international security, being the domain of defence and foreign affairs policy.

The Venn diagram below succinctly presents the interrelationship of security issues from the personal through citizen of the state to member of international society; however, it is the overlapping presentation that presents an intuitive representation of threats across the spectrum, conveying a sense of the level of state sponsored protection that could be expected within the particularistic structure of the Canadian polity. This dynamic portrayal illustrates that security issues are not necessarily static, that many 
agencies at many levels of government may be involved, and that the magnitude of effort will be dependent on the level of state response required to address the specific threat.

Threats undermine the secunty of ...

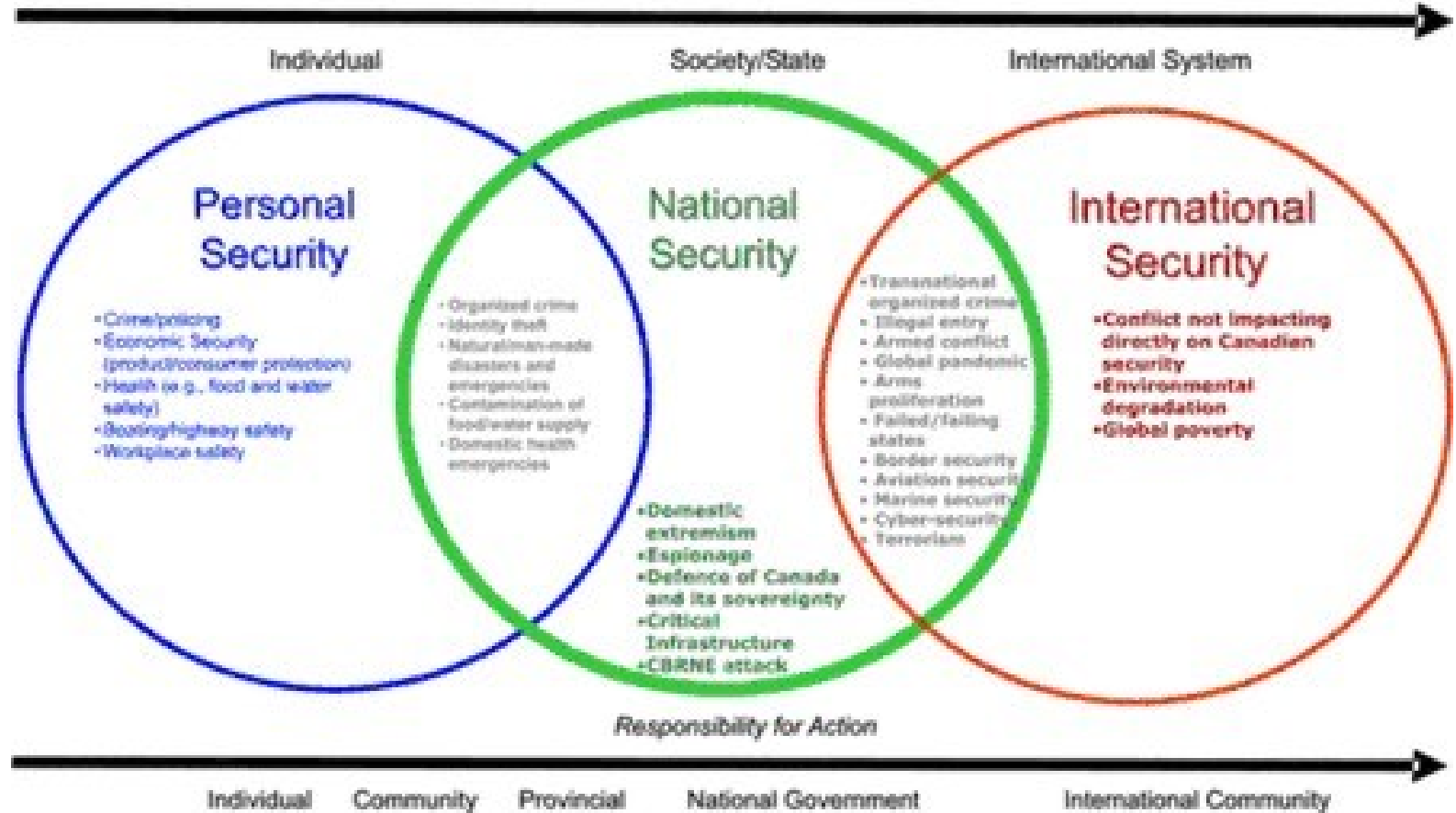

Figure 2: The Scope of the National Security Policy. ${ }^{449}$

The salient feature of this presentation is that it captures the government's articulation of Canada's three core national security interests: protecting Canada and the safety and security of Canadians at home and abroad; ensuring that Canada is not used as a base for threats to our allies; and contributing to international security. ${ }^{450}$ The approach taken in the development of the National Security Policy statement was uniquely Canadian, embodying the national security norms and values held by Canada's society and polity, its 'nuclear force', contrasting sharply with the trends in National Security statements of others in the Anglosphere. It is unfortunate that the drafters of the National

\footnotetext{
${ }^{449}$ Government of Canada, Securing an Open Society: Canada's National Security Policy, (NSP), April 2004, p. 4. See appendix for a larger image with higher resolution.

${ }^{450}$ NSP, 2004, p. vii.
} 
Security Policy statement were not clearer that the National Security Policy statement would be the parent document from which international security, the third core security interest, would obtain granularity following the International Policy Review.

A National Security Strategy: Sagacious commentators have often demanded that Canada produce a National Security Strategy ${ }^{451}$ and consideration was given to producing such a document. However, a number of issues arose as a result of Canadian National Security Culture. In analysing the 2002 National Security Strategy of the United States, 1998 United Kingdom Defence Review, and the Australian 2003 Defence White Paper, PCO found the majority of acquired democratic values resonated with Canadians. However, each country had a particular reason to view the international system as more threatening to their state than did Canada and were trending from soft human security towards hard physical security and the process of subordinating and/or instrumentalizing international agreements and institutions to hard security needs and imperatives. ${ }^{452}$ Secondly, 'all strategies recognized or authorized pre-emptive action against the most dangerous terror threats ${ }^{453}$ and called for enhanced military and intelligence capabilities to enable this to occur.' Canada's National Security Culture did not subscribe to the need for hard power following the 9/11 attack and therefore the government avoided the

\footnotetext{
${ }^{451}$ See Don Macnamara and Ann Ftiz-Gerald, "A National Security Framework for Canada”, IRPP Policy Matters, Vol 3, No. 10, October 2002; Various authors in David McDonough, ed, Canada's National Security in the Post-9/11 World: Strategy, Interests, and Threats, Toronto: Toronto University Press, 2012; Several articles in Conference of Defence Associations and CDA Institute, On Track, Vol 20, No 1, 2015, particularly "Making a Canadian National Security Strategy" by Dr. Peter Layton, pp. 37-40.

${ }^{452}$ Confidential information.

${ }^{453}$ The 2006 NSS reaffirmed three significant foreign policy shifts that were first promoted in the early days following 9/11 through Presidential addresses and the 2002 NSS. First, the United States maintains a strategy of pre-emptive and preventive action to address both real and perceived threats. Second, those threats that present an imminent danger would be pre-empted while emerging threats would be subject to preventative action. Third, prior warning by soliciting international authority through multilateral institutions such as the United Nations may not necessarily be petitioned beforehand. The premise being, the national interest would not be served in giving prior warning to non-state actors who neither adhere nor respect international rules of conduct.
} 
definitiveness of a National Security Strategy by publishing the National Security Policy statement.

In fact, it is evident that neither society nor the polity is interested in a formal Canadian National Security Strategy as Don Macnamara ${ }^{454}$ and Ann Fitz-Gerald have advocated in "A National Security Framework for Canada". Although security experts from academics to practitioners have all provided solid arguments for the utility of such a definitive approach to national security, neither the polity nor society want one. As Denis Stairs notes, "setting priorities in politics is a risky business, and in a democratic environment especially, the most powerful of incentives yield a preference for riskavoidance, rather than for risk-taking. It is largely for this reason that 'incrementalism' is the preferred pattern of policy development." ${ }^{, 55}$ Secure in 'fortress North America', politicians know that Canadians are not interested in aggressive international policies. Canada's relationship with the US is its only "vital international interest... Overseas there is greater room for choice, if only because most of what Canada does outside North America is elective and voluntary. ${ }^{, 456}$ With no votes to be had, only lost, in terms of international defence policy, politicians are keen to make use of the largest discretionary 'pot of money', that of National Defence, to fund 'other' national security concerns, such

\footnotetext{
${ }^{454}$ Don Macnamara, "Canada's National and International Security Interests", p 45-46, in McDonough, 2012. Don Macnamara proposes a definition of national security that is in line with contemporary Canadian National Security Culture: National security is the first and most important obligation of government. It involves not just the safety and security of the country and its citizens. It is a matter of guarding national values and interests against both internal and external dangers - threats that have the potential to undermine the security of the state, society and citizens. It must include not just freedom from fear of attack against themselves, their property, community or national sovereignty, but also the preservation of the political, economic, and social values - respect for democracy, the rule of law, individual freedom, and human rights - that are central to the quality of life in a modern state.

${ }^{455}$ Denis Stairs, "The Making of Hard Choices in Canadian Foreign Policy", in Norman Hillmer, Fen Hampson, and David Carment, eds., Canada among nations 2004: setting priorities straight, Montreal: McGill-Queen's University Press, 2005, p.22.

${ }^{456}$ Ibid, p. 21.
} 
as balancing budgets or national unity. Canadian society is only too eager to accept this ad hoc approach to government funding as special interests vie for federal monies. It is only by understanding the causal mechanisms found in Canadian National Security Culture that security experts will be able to advance prescient arguments for focused policies and sustained funding for Canadian national security institutions through some form of National Security Strategy.

Reshaping the Canadian National Security Structure: The whole-ofgovernment approach taken by the Martin Government was both a necessity and an encumbrance, as it needed to link into the fast paced changes occurring in US security establishments. Attempting to create a culture of intermesticity required wholesale cultural change in the polity and significant commitment both in terms of political capital and government funding. As balancing the CANUS relationship is always a preoccupation of any given Canadian government, the fundamental challenge is in understanding issue specificity and in issue management, where the majority of policies have both a domestic and international component. The National Security Policy statement drafters therefore focused their efforts on effective management of the complex relationship, emphasizing the maintenance of a professional approach to the accrual of interests and benefits to both countries on economic, security, and defence matters as well as bilateral cooperation on the international scene. ${ }^{457}$ Although anti-Bush sentiment was strong in Canadian society at the time ${ }^{458}$ and was fundamentally about differing

\footnotetext{
${ }^{457}$ Confidential information and interviews.

458 “Anti-Bush sentiment continued to grow in Canada. A Maclean's magazine poll earlier in 2004 had found that only fifteen per cent of Canadians supported the president's re-election." Found on page 19 of Stephen Azzi and Norman Hillmer, "Intolerant allies: Canada and the George W. Bush administration, 2001-2005, Carleton University, 2015 unpublished work.
} 
values, the polity ensured the hubris of the Bush Administration did not impact the fundamentals of the National Security Policy statement and later the International Policy Statement. US Administrations are temporal and Canadian National Security Culture understands the vicissitudes of such a relationship, where "we may agree with the US on many over-arching objectives, we can still disagree on the best means to achieve them." 459

As the National Security Policy statement was nearing completion, Paul Martin became Prime Minister and one of his first acts was to announce the creation of Public Safety and Emergency Preparedness Canada (PSEPC), which centralized key federal intelligence and law enforcement agencies under one Minister. PSEPC was charged with the "coordination of all federal departments and agencies responsible for national security and the safety of Canadians". ${ }^{460}$ It integrated the functions of the former Department of Solicitor General, notably the Royal Canadian Mounted Police (RCMP) and Canadian Security and Intelligence Service (CSIS); the former Office of Critical Infrastructure Protection and Emergency Preparedness (OCIPEP), and created a new agency, the Canada Border Services Agency (CBSA), which brought together the operational sections from Canada Customs, Citizenship and Immigration Canada (CIC), and the Canadian Food Inspection Agency (CFIA). Within CSIS, the government created the Integrated Threat Assessment Centre (ITAC) to centralize the collation and analysis of intelligence, prepare assessments on emerging threats and distribute their assessments to security stakeholders. Within PSEPC, a new Government Operations Centre (GOC) was

\footnotetext{
${ }^{459}$ McRae, 2005, p. 69.

460 Public Safety Canada website online at http://www.publicsafety.gc.ca/cnt/bt/index-eng.aspx on 26 July 2015.
} 
established to ensure 24/7 coordination of key agents at all levels of government during national emergencies. These structural changes were necessary and critical to the success of the new National Security Policy.

A measure of the National Security Policy statement's true relevance and its basic articulation of Canadian National Security Culture is that, although the Harper Government indicated in the 2007 Speech from the Throne that it would release a new statement on national security, the National Security Policy statement was still used by the government of Canada as its foundational national security document throughout Harper's tenure as Prime Minister.

Securing an Open Society: Canada's National Security Policy is a strategic framework and action plan designed to ensure that Canada is prepared for and can respond to current and future threats. The focus is on events and circumstances that generally require a national response as they are beyond the capacity of individuals, communities or provinces to address alone. ${ }^{461}$

Although the 'instrumental values' used to justify the 'moral choices' made in the name of 'national interest' by various political parties in power will vary, the structure of the National Security Policy statement was sound and corresponds to the national security norms and intrinsic values of Canadian society and polity (norm salience).

\subsection{The National Security Policy Statement}

Securing an Open Society: Canada's National Security Policy opens with words from Prime Minister Martin that were shocking to some analysts for its widening of national security concerns and the lack of focus on traditional mainstream understandings of national security, defence and foreign policy. The message was succinct and in line

\footnotetext{
${ }^{461}$ Minster of Public Safety Blaney, online at the Department of Public Safety Canada website http://www.publicsafety.gc.ca/cnt/ntnl-scrt/scrng-eng.aspx , 26 Jul 2015.
} 
with Canadian National Security Culture, particularly in stating "there can be no greater role, no more important obligation for a government than the protection of its citizens" through fixing and funding domestic security gaps. The National Security Policy statement is a collage of security sector policy statements with an articulation of significant structural changes to the machinery of government.

The eight chapters of the National Security Policy statement can be divided into two broad thematic sections: Defining Canadian National Security and Advancing Key Activities. The first two chapters define Canadian National Security as discussed above and explain the concept of an integrated security system. Of the eight 'current threats' identified, two are international (proliferation of weapons of mass destruction, and failed and failing states), four are intermestic (terrorism, foreign espionage, organized crime and pandemics), and two are domestic (natural disasters, and critical infrastructure vulnerability). In order for the state to protect acquired values, "the evolving nature of threats to Canadians requires a fully integrated government approach ... connected to key partners - provinces, territories, communities, first line responders, the private sector, and Canadians." ${ }^{463}$ The National Security Policy statement explained that a fully integrated system will protect society through threat assessment, protection and prevention capability, consequence management, and through evaluation and oversight.

This broadening of the traditional threat spectrum and designing an integrated security system is sensible in that it acknowledges that not one defined threat poses any greater danger than another as well as accounting for the interrelationship of the government agencies, mechanisms, and procedures in addressing security events. By

\footnotetext{
${ }^{462}$ NSP, 2004, p. vii.

${ }^{463}$ Ibid. p. 9.
} 
drawing attention to the complexities of national security and the interrelationship of stakeholders, the government was not only defining a new way of doing business but also educating society and the polity on their roles within the system. The earlier ad hoc approach to crisis management through PCO had proven cumbersome and unsuited for fast-moving complex security issues. The integration of national security institutions under PSCEPC (now Public Safety Canada) and the creation of the National Security Advisor within PCO produced measurable improvements in connectivity, both vertically and horizontally. However, the integrated system that was envisaged was based on fusing cross-government information for intelligence and operational analysis, which was a flawed or poorly researched premise, as earlier legislation involving Charter rights had demonstrated. Execution of the National Security Policy statement would be and has been hindered across the board due to this oversight, as will be discussed in detail later.

The second section, Advancing Key Activities, consists of six chapters, each dedicated to key security activities: intelligence, emergency planning and management, public health emergencies, transportation security, border security, and international security. These functional groupings are in program areas where one or more agencies may have lead roles, but also consist of many other stakeholders. At first glance, the activities seem disjointed, but when viewed as a risk strategy they make greater sense. The spectrum of risk runs the gamut from avoidance, mitigation, management to engagement. Good information and preparation are important in avoiding security risks. Identifying key areas prone to security risks helps in mitigation and management strategies. If and when necessary, security institutions need to be prepared to engage risk to ensure the protection of Canadian acquired values. 


\subsubsection{Intelligence}

Chapter 3 establishes intelligence as a key enabler and identifies CSIS and the Communications Security Establishment (CSE) as the responsible institutions for collecting and distributing the information collected. As the National Security Policy statement points out, the problem with intelligence is not obtaining it, but making sense of the "fragmented and sometimes contradictory information" ${ }^{464}$ and sharing it. This known point-of-failure was corroborated by the recommendations contained in the $9 / 11$ Commission report, published shortly after the release of the National Security Policy statement, that identified two key factors behind the failure to prevent the 9/11 attacks under titles 'Unity of Effort in the Intelligence Community' and 'Unity of Effort in Sharing Information'. ${ }^{465}$ It is important to note that intelligence information is a heavily regulated function amongst stakeholders and has separate regulations covering its use and distribution compared to 'information sharing' amongst government departments, which falls under the Privacy Act.

CSE provides the bulk of foreign intelligence collected through signals intelligence, which it shares collaboratively with other intelligence partners in return for data they have collected by other means. The National Security Policy statement does not advocate for expanded intelligence services beyond the limited security intelligence mandate given to CSIS pertaining to threats to the security of Canada. Elinor Sloan explains that the difference between security and foreign intelligence is one of scope. “"Foreign intelligence' refers to information on the capabilities, activities, or intentions of foreign countries, organizations, or individuals. Such intelligence serves a country's

\footnotetext{
464 Ibid, p. 16.

465 9/11 Commission Report, 2004, pp. 407-419.
} 
national (not just security) interests, including economic, political, military, technological, and environmental objectives." ${ }^{466}$ The limited 'security intelligence' mandate is indicative of Canada's desire to be less intrusive on the international stage, while providing a useful contribution to security partners through CSE and CSIS.

\subsubsection{Emergency Planning and Management}

The particularistic organization of the Canadian polity and the responsibilities for security assigned to each level of government is captured in Chapter 4, Emergency Planning and Management (EPM). Rather than leave each level to their own devices, the National Security Policy statement sets out a communitarian agenda to ensure federal support is available when needed and as desired to first responders nationwide. Using a backdrop of recent major disasters, the National Security Policy statement identifies several transnational and natural threats that require government engagement at a number of levels and cross-jurisdictions in a time-sensitive manner to minimize human and economic losses as the rationale for revising the emergency response sector.

The National Security Policy statement identifies several federal resources with specialized skills, equipment and training that are available to respond to national security emergencies. The Canadian Forces were always available for 'aid to the civil power' through the National Defence Act, but the National Security Policy statement specifically targets chemical, biological, radiological, or nuclear (CBRN), Disaster Assistance Relief Team and natural disaster consequence management skill-sets as specific areas of federal support to EPM. The establishment of PSEPC was instrumental in moving this agenda forward as it took on the tasks of modernizing the Emergency

${ }^{466}$ Sloan, 2010, p 82. 
Preparedness Act, producing the cyber security strategy, developing the Federal Emergency Response Plan, and engaging the provincial emergency management organizations in progressing the National Emergency Response System. Protection of acquired values requires state support on many levels, and Canadian society has come to expect communitarian federal assistance as a matter of Canadian National Security Culture.

\subsubsection{Public Health Emergencies}

As stated earlier, universal health care is an acquired value precious to Canadian society. Following the experience of the 2003 SARS outbreak and with the distinct possibility of bioterrorism being another weapon of choice, the National Security Policy statement created the Public Health Agency of Canada (PHAC) as the operational wing of the Department of Health. Its mandate was to develop strategies for managing infectious disease, respond to public health emergencies, be the central point of contact for global health issues, and strengthen intergovernmental health cooperation. As an area of common concern, the National Security Policy statement pursued cooperation with the US on a number of fronts as part of the Smart Border Initiative, as well as through various bilateral agreements.

As a leader in microbiological research, Canada was to play a leading role in the Global Health Initiative partnering with the World Health Organization and countries around the world to develop a network for improving global health security. In applying the communitarian norms regarding state responsibility for protection of health to the international, Canada would build domestic capacity and experience that could be shared with international society. Prevention is the first step towards security and Canada, as a 
world leader, was prepared to share its knowledge and expertise to ensure pandemics could be contained early. Attacking the health of soldiers had long been a tactic in warfare, so it was inevitable that vulnerable state populations would be threatened by terrorist CBRN bio-weapons. Building the capacity to deal with such emergencies, whether natural or man-made, is central to Canadian National Security Culture.

\subsubsection{Transportation Security}

The Air India bombing caused stronger aviation security measures to be implemented in Canada, but it was the American reaction to 9/11 that significantly changed aviation security measures globally. Improvement to the overall security of the system would be accomplished through the implementation of background checks for employees in all sectors of the transportation system. Specific goals in each of the marine, land and air transportation sectors were articulated in the National Security Policy statement with a focus on increasing the security of air passengers and cargo, and the security of the intermodal cargo, mass transit and rail systems.

The National Security Policy statement, however, focused most of its attention on surface transportation, primarily in marine security. Maritime security had been of great concern well before $9 / 11$ as it was seen as particularly vulnerable due to the complex environment of overlapping jurisdictions by numerous stakeholders. A six-point plan was included in the National Security Policy statement that aimed at creating order and respect for authority through:

- clarifying responsibilities and strengthening co-ordination

- establishing Marine Security Operations Centres (MSOC)

- increasing the Canadian Forces, RCMP, and Canadian Coast Guard on-water presence as well as the Department of Fisheries and Oceans aerial surveillance

- securing fleet communications

- pursuing greater marine security co-operation with the United States 
- strengthening the security of marine ports and facilities ${ }^{467}$

The Maritime dimension would be taken up by the BPG and ultimately find its way into the renewal of the 2006 NORAD Agreement as the additional bi-national mission of Maritime Domain Awareness (MDA). The MSOCs would be established, but were stillborn due to a critical problem with information sharing amongst partner departments. These interrelated issues are the other two cases that I will explore to determine the effect of Canadian National Security Culture on the formulation of the policies and subsequent problems with implementation. A desire for order and respect for authority became entangled with another national security norm, the Charter.

\subsubsection{Border Security}

As previously mentioned, the aim of the border security effort was on developing a system which balanced security with the need to maintain the flow of goods and passengers in and out of Canada. This required a risk management approach, centered on preventing "high-risk travelers and cargo from entering Canada." ${ }^{\text {"68 }}$ Embracing emerging technology in facial recognition biometrics, finger printing, and passport security measures provided last chance protection at the border. However, cooperation with international partners and intelligence communities was required to identify these "high risks" before they arrived. Immigration screening processes needed to be improved in a country proud of its immigrant past and multicultural society.

In line with Canadian National Security Culture, "Canada took the lead in proposing to the United States, a comprehensive smart borders strategy that would

\footnotetext{
${ }^{467}$ NSP, 2004, p. 35.

${ }^{468}$ Ibid, p. 41.
} 
enhance North American security and prosperity." ${ }^{469}$ As described earlier, this pragmatic approach to risk managing the CANUS relationship is indicative of the security norms and values that evolved over time. Sovereignty is maintained when negotiating mutually acceptable 'rules of the game' that create order and stability. Importantly, security and prosperity were accommodated to the mutual satisfaction of both countries.

\subsubsection{International Security}

The National Security Policy statement proved to be a unique, sovereign approach to national security in that it subordinated defence and foreign policy within the security structure of the National Security Policy statement. It is unfortunate that this was not made clearer, both in chapter 1 and more precisely in Chapter 8 - International Security. To simply state, "National security will be one of the top priorities in our International Policy Review”, was insufficient contextual explanation, which led to a conceptual misunderstanding of the National Security Policy statement. This is surprising given that the 1994 Defence White Paper was “the first time since Brooke Claxton’s defence statement of 1947, before NATO was created, there was no section devoted to NATO. Rather, Canada's contribution to the alliance is detailed in the chapter on contributing to international security. $" 470$

The trend toward contributing to international security through international regimes such as the United Nations as well as collective security alliances was continued in the National Security Policy statement. It was reinforced later in the subordinate document, A Role of Pride and Influence in the World: Defence policy statement contained in the International Policy Statement. Canada's international security

\footnotetext{
${ }^{469}$ Ibid, p. 43.

${ }^{470}$ Sloan, 2010, p. 24.
} 
contribution is specifically delivered via multilateral organizations in a particularist, nonviolent pragmatic Canadian way, unless of course, international law or the UN sanctions the use of deadly force when legitimate and necessary.

Peace, Order, and Good Government ${ }^{471}$ (POGG) are part of Canadian identity and were foundational values used by drafters of the National Security Policy statement and especially the International Policy Statement. To some ${ }^{472}$, POGG is a euphemism for the 3Ds: Diplomacy, Development and Defence. Although it can be argued that the bureaucracy was just parroting the Liberal government mantra of the day, the fact that the 3D concept, adapted in different language, continues to underpin Canadian international policy eleven years later is testament to its causal force. ${ }^{473}$ Most notable in this section is, again, the distinct lack of an intelligence based threat assessment on which to launch a discussion on international security. This is indicative of a self-secure state with an absence of fear that its values will be attacked, in Wolfers sense, seeking to protect its own acquired values by contributing to POGG in international society, but willing to defend its values when necessary.

\subsubsection{National Security Policy Statement Summary}

The National Security Policy statement laid out a novel Canadian approach to state security, making 'national security' the centrepiece between 'individual' and

\footnotetext{
${ }^{471}$ NSP, 2004, p. 50.

${ }^{472}$ See Michael Ignatieff, Peace, Order and Good Government: A Foreign Policy Agenda for Canada, O.D. Skelton Memorial Lecture, 2004, who lays the foundation for the linkage in this lecture, accessed 09 November 2015 online at http://www.international.gc.ca/odskelton/ignatieff.aspx?lang=eng ; Houchang Hassan-Yari, “A Diminishing Middle Power: Canada's National Security and Peacekeeping” in Conny Steenman-Marcusse and Aritha van Herk, eds, Building Liberty: Canada and World Peace, 1945-2005, Gröningen, Netherlands: Barkhuis Publishing, 2005.

${ }^{473}$ See Andrew B Godefroy, Canada's International Policy Statement Five Years Later, Calgary: Canadian Defence \& Foreign Affairs Institute, 2010, p. 3; Nathan Funk, “Applying Canadian Principles to Peace and Conflict Resolution in the Middle East" in Bessma Momani and Paul Heinbecker, Canada and the Middle East: In Theory and Practice, Waterloo: Wilfrid Laurier University Press, 2007.
} 
'international' security. It was written in succinct, simple terms to provide the context for the structural changes taking place within the mechanisms of government post-9/11. The National Security Policy statement's “existence sheds light on the Martin government's approach to Canadian security. Specifically, it points to the importance the government placed on the homeland as an organizing principle for Canadian security and defence efforts. ${ }^{, 474}$ Had the circumstances been different and the IPR not delayed, the National Security Policy statement may have been presented as a whole package, along with the International Policy Statement, in order to better understand Canada's differing approach to the mainstream understanding of national security. Nevertheless, the roots of Canadian identity and security norms are evident throughout the document and the policies show evidence of being shaped by Canadian National Security Culture.

\subsection{Canada's Inclusive View of National Security}

The unfortunate truth about conceptual misunderstandings of national security by analysts using the American-centric definition is illustrated in an essay, "National Security Strategies: Security from What, for Whom and by What Means", by Sharon Caudle. She argues that countries such as Canada, Switzerland, Finland and the Netherlands have recently widened their identification of threats and united their military defence and homeland security strategies. In an era of global interdependence, "the focus appears to be on the preservation of that which makes a country unique and that includes the intangibles of its culture as well as what physically lies within its borders. ${ }^{\circ 75}$ The reality for many countries, especially Canada, is that national security has always

\footnotetext{
${ }^{474}$ Sloan, 2010, p. 24.

475 Sharon Caudle, "National Security Strategies: Security from What, for Whom and by What Means", Journal of Homeland Security and Emergency Management, Vol 6, No.1 Art 22, 2009, p.1.
} 
favoured domestic protection when the international system has not been a direct threat. Canada is not changing its fundamental approach to national security, as much as it is adapting to an evolving environment within the confines of Canadian National Security Culture.

\subsubsection{Widening of National Security}

Canada has developed a security culture that does not conform to mainstream academic theory. Canadian security norms and values are more representative of Buzan, Waever, and de Wildes's security sectors articulated in Security: A New Framework for Analysis (1998). ${ }^{476}$ Although securitization theory is flawed in many ways as described earlier, the broadening of the concept of security into five sectors (military, environmental, economic, societal, and political) provides a better understanding of the causal mechanisms behind Canada's security policies. Change following the 9/11 attack was precipitated by realist and neo-liberalist assumptions of the 'logic of consequences'; however, the process followed in the formulation of the National Security Policy statement and International Policy Statement were ideational, following the 'logic of appropriateness' based on Canadian identity.

Military Sector. The major flaw in this section of Security: A New Framework for Analysis is the assumption that the military is used exclusively as a coercive instrument of the state. In basing their analysis on threats rather than protection of acquired values, Buzan et al conclude "When the perceived threat is internal, military security is primarily about the ability of the ruling elite to maintain civil peace, territorial

\footnotetext{
${ }^{476}$ Although first introduced in Barry Buzan, People, States \& Fear: The National Security Problem in International Relations, London: Harvester Wheatsheaf, 1983, the sectoral articulation is more refined in Security: A New Framework for Analysis and will therefore be used in analysis.
} 
integrity and ... the machinery of government in the face of challenges from its citizens." 477 This may be true in many instances, but in Canada the military's role is perceived as protecting Canadian society from harm rather than protection of the ruling elite. This sector not only provides defensive protection to the state, it protects other acquired values of society that overlap with other security sectors through its use in emergency situations, in nation building, and in social change. This is also true when invoking 'international society' as the referent object of military security when applied to Canada. $^{478}$

Canada's history of armed aggression in defence of intrinsic values during two world wars and many conflicts is indisputable; however, the Canadian 'audience' (society-polity) does not need to construe military action through the prism of an 'existential threat'. The International Policy Statement makes it perfectly clear that Canada views its military's international role in the same manner as its domestic role. "The first challenge is to strike the right balance between the Canadian Force's [CF] domestic and international roles" where "a greater emphasis must be placed on the defence of Canada and North America than in the past."479 Although the statement acknowledges NATO alliance obligations, the international roles for the CF focus on the use of soft military power, "Failed states and the challenge of restoring stability", "Military training assistance", "Defence diplomacy and forward presence" and "Arms control.”480 This 'balancing' reflects Canadian society's view of use-of-force as a means

\footnotetext{
${ }^{477}$ Barry Buzan, Ole Wæver, and Jaap de Wilde, Security: A New Framework for Analysis, Boulder CO: Lynne Rienner Publishers, 1998, p. 50.

478 Ibid. p.55.

${ }^{479}$ Government of Canada, Canada's International Policy Statement: Defence, 2005, p. 2

${ }^{480}$ Ibid, pp. 24-29.
} 
of last resort while making use of the $\mathrm{CF}$ as an instrument of nation building and social change in international society.

Buzan et al discount the influence of sub-state actors in shaping military policy as the "familiar world of bureaucratic politics" 481 , preferring to attribute causation to imagined securitization processes. This fails to understand the significant impact that Canadian National Security Culture had on setting the military roles and goals to be attained in the National Security Policy statement and International Policy Statement. Evidence that social factors are central in shaping policy decisions can be found in issues such as Canada accepting the threat of nuclear weapons, but rejecting their use by the CF, preferring to its use military expertise towards multilateral attempts to eliminate WMD. In analysing Canada within the military sector, many of the traditional military security concerns remain relevant to Canada; however, Buzan et al's analysis is faulty when it assumes that rhetoric is the prime motivator for military security in matters of choice.

Environmental Sector. The environment is an emerging area of Canadian acquired values. Buzan et al identify "the existence of two different agendas: a scientific agenda and a political agenda." ${ }^{282}$ The scientific agenda is about articulating the existential threat to the environment and ultimately to civilization ${ }^{483}$, whereas the political agenda is about responsibility and accountability in public policy. The general public is at the mercy of often conflicting professional advice and must make intuitive based political

\footnotetext{
${ }^{481}$ Buzan et al, 1998, p. 56.

482 Ibid, p. 71.

${ }^{483}$ Ibid, p. 76.
} 
choices. "Critical for the political agenda is not whether specific threats to the environment are real or speculative but whether their presumed urgency is political."484

Canada has a significant interest in environmental security that has been taken on by the political agenda and become matters of national security. The Great Lakes Water Quality Agreement of 1972 and the ‘Acid Rain Treaty’ of 1991 are two examples of pragmatic bilateral environmental security agreements with the US, both initiated by Canada. ${ }^{485}$ Environmental security is on the political agenda in areas of domestic logging and chemical pollution through industrial effluent and emissions that not only affect local populations, but impact collective sustainability in other parts of the country. The recently approved Combined Assistance Plan between Canada and the US allows bilateral use of military support in times of national disasters. ${ }^{486}$ Internationally, Canada is in the global environmental spotlight over the Athabasca oil sands and the seal hunt. These security issues take on expansive importance as they transcend and compete with economic and societal security interests. The seal hunt is economically critical to many east coast communities and the loss of markets also threatens Inuit society's traditional way of life. Both the National Security

\footnotetext{
${ }^{484}$ Ibid, p. 73.

${ }^{485}$ Although bi-national International Joint Commission (IJC) has been in existence since 1912 to resolve disputes between Canada and the US under the 1909 Boundary Waters Treaty, it acts as a facilitator and an advisor to the two governments. It is therefore incumbent on governments to initiate treaty negotiations. In the case of the 1972 Great Lakes Water Quality Agreement, the IJC provided the scientific study behind the initiative. "However, the United States was not yet prepared to approve the IJC's recommendation s to move towards taking remedial action in order to deal with the cleanup of the Great Lakes, nor was it prepared to begin negotiations. ...Canadian diplomatic pressure on the US government ensued, and the task force report was submitted to the president."- Mark Sproule-Jones, Restoration of the Great Lakes: Promises, Practices, and Performances, East Lansing: Michigan State University Press, 2002, p.40; It was the Mulroney Government that championed the 1991 US-Canada Air Quality Agreement popularly known as the "Acid Rain Treaty" with negotiations beginning in 1986 under the Reagan Administration. - See Thompson, John Herd, and Stephen J. Randall. Canada and the United States: Ambivalent Allies. 4th ed. Athens: University of Georgia Press, 2008, pp. 267-270.

486 See chapter 6 for further details.
} 
Policy statement and the International Policy Statement identify environmental factors as security issues, from pandemics to man-made disasters, that are at the root of international conflict. "The environmental sector provides a lens that enables us to highlight root causes of existential threats that become manifest in other sectors." ${ }^{487}$

Economic Sector. Although extremely important, analysis of the economic sector by Buzan et al is faulty. Concerned more about the misuse of security rhetoric in this sector for political objectives, they fail to develop the concept as a tool of 'war', dismissing "gunboat diplomacy [as] no longer acceptable"488, and failing to understand the insecurities that economic sanctions have on society and polity. The coercive diplomacy ${ }^{489}$ of economic sanctions was instrumental on bringing Iran to the negotiation table regarding nuclear weapons and is being applied to Russia over its aggression in Crimea and the Ukraine. Although it is true that "existential threats constitute a fairly narrow range of conditions ${ }^{\prime 490}$, security is not always about existential threats but about protecting acquired values.

This is the case for Canada. From Confederation, Canadian independence and prosperity have relied upon establishing security norms and values that balance sovereignty with trade. Whereas security was the focus of concern after 9/11 in the US, it was prosperity in Canada. In treating economic security at either the individual or state level, Buzan et al fail to understand the significant cultural interplay norms and values in one sector have on those in another sector. As Sloan points out, "Economics figured

\footnotetext{
${ }^{487}$ Ibid. p. 84.

${ }^{488}$ Ibid, p. 105.

${ }^{489}$ See Alan Stephenson, "Shades of Gray: Gradual Escalation and Coercive Diplomacy", Chairman Joint Chiefs of Staff Strategy Essay Competition 2002, Washington, DC: National Defense University Press, 2002, pp. 1-20.

${ }^{490}$ Buzan et al, 1998, p. 109.
} 
centrally in the Martin government's approach to security. Describing North America as Canada's "anchor" in the global economy, the "Overview" [of the International Policy Statement] stresses the importance of Canada's economic relationship with the United States. ${ }^{491}$ Economic security is central to Canadian identity and Canadian National Security Culture.

Societal Sector. Paradoxically, Buzan et al identify the societal sector as a security unit, but never consider society as a referent object. "The organizing concept in the societal sector is identity. Societal insecurities exist when communities of whatever kind define a development or potentiality as a threat to their survival as a community." 492 This concept can also be understood as 'identity security' when applied to society as a whole. As the only existential threat to Canadian society is assimilation into the US, identity security has established itself as a defining feature of Canadian National Security Culture. All issues with respect to CANUS relations flow through the prism of societal security. Buzan et al simply do not understand the concept of multiple, complementary identities when they identify Quebec and Canada as binary intra-state cultural competitors horizontally and then use Canada and the US as binary inter-state cultural competitors. Societal security is not so much about threats to identity as protecting the acquired values that are inherent in that identity both within and between states.

Canada is a multicultural country where individuals have many overlapping identities. Mutual accommodation is the norm and has become an acquired value. As argued earlier, Canada has three principal interests: sovereignty, unity and prosperity. ${ }^{493}$

\footnotetext{
${ }^{491}$ Sloan, 2010, p. 26.

492 Buzan et al, 1998, p. 119

${ }^{493}$ Kendall, 2006.
} 
The processes of preparing the National Security Policy statement and the International Policy Statement were about securing Canadian identity through policies that ensured sovereignty was maintained and not a pretext that accepted American-centric security policies contrary to Canadian norms and values. "Canada's story shows that mutual accommodation is one of the better ways to conduct human governance that emerged from the 20th century." ${ }^{, 94}$ Societal security is foundational to Canadian National Security Culture.

Political Sector. The political sector is about threats to state sovereignty and the organizational stability of social order. As expected, the 'nuclear force' of the state, those norms and values that bind society and polity, is inextricably linked in the political and societal sectors. Threats to identity transpose into threats to sovereignty and vice versa. "Beyond political units, ... political security ... is about threats to the legitimacy ... of essential structures, processes, or institutions." ${ }^{495}$ This is the essence of security in the political sector for Canada: protection of the organizing principles and security institutions that have become either intrinsic or acquired values. Harmonization with the US in law, standards, or other institutions without consideration to Canadian security norms and values threatens the loss of acquired values over time.

"The main linkages in this sector seem to be in terms of principles rather than power. Principles travel relatively more easily than (military) power." ${ }^{\text {"496 }}$ As Canada and the US share many intrinsic values, most of the security disagreements do stem from matters of principle over the use of power, whether domestically, continentally, or

\footnotetext{
${ }^{494}$ William A. Macdonald, "A new role for Canada and the U.S. in a world of persistent Menace”, Globe and Mail, July 31, 2015.

${ }^{495}$ Buzan et al, 1998, p. 144.

${ }^{496}$ Ibid, p. 160.
} 
internationally. Canadian law restricts the use of force domestically. This pragmatic

solution to conflict resolution has shaped the CANUS relationship and was an instrumental principle in Canada declining to participate in the US invasion of Iraq. As argued throughout this paper, security of acquired values found in society-polity is the essence of Canadian National Security Culture.

\subsection{Conclusion and Analysis}

Culture is a broad label denoting collective models of nation-state authority or identity, carried by custom or law. In the previous chapter, five sets of intrinsic Canadian norms and values that 'encompass evolving national ideologies of collective purpose and distinctiveness' (identity) emerged that are fundamental in determining security concerns and constructing national security preferences: national sovereignty, particularism, communitarianism, respect for authority, and pragmatism. These evaluative standards (norms and values) form the basis of Canadian National Security Culture and have been instrumental in establishing the cognitive standards (rules and models) found in security institutions as well as shaping the interests involved in pursuing specific security policies.

In tracing the policy choices and outcomes following the events of 9/11, it is clear that Canadian society and polity have a distinct approach to national security ${ }^{497}$ that is not congruent with materialist assumptions. Contemporary society and polity (the nuclear force of the state) continue to differentiate domestic 'national security' from external 'international security' through security norms in government organization and policy

\footnotetext{
${ }^{497}$ Edna Keeble uses similar logic in arguing that 9/11 changed the course of Canadian national security. She argues that the Martin Government's "rethinking of state-society relations" allowed the articulation of Canadian values and brought "in societal voices to the making of state policy" through the National Security Policy statement and the International Policy Statement. Edna Keeble, "Defining Canadian Security: Continuities and Discontinuities," American Review of Canadian Studies, Vol 35. No.1, pp. 1-22.
} 
articulation. Canadian society and polity view national security in the widened sectoral concept articulated by Buzan, but do not subscribe to viewing national security as simply a defence against threats, but as protection of acquired values. This established the paradigm in which elite contestation of national security as an acquired value took place.

As threats can be politically temporal and span a wide spectrum from persistent, transient, occasional, possible, to unpredictable, applying a threat typology to Canada is problematic since each case has its own specificity to political contestation. However, adopting Wolfers' view that the state offers protection to acquired values allows for a more holistic analysis and understanding of Canadian national security by eliminating $a$ priori value judgments of policy choices based on the inconsistencies of identifying perceived threats. Widening the concept of national security provided greater exploration when related security values competed for funding, as evident in the $\$ 8 \mathrm{~B}$ dedicated in the National Security Policy statement to non-defence related security institutions as well as the inclusion of such non-traditional threats as natural disasters and epidemics.

Further evidence that national security is viewed as state sponsored protection of Canadian acquired values was visually demonstrated in the Venn diagram contained in the National Security Policy statement where domestic institutions are central to national security policy articulation. Separation of domestic and international policy is never clear-cut, particularly with respect to the Canada-United States interdependent relationship because there is a symbiotic policy relationship between domestic and bilateral issues that involves complex sovereignty. As the US is Canada's only direct international existential 'concern', Canadian National Security Culture instinctively seeks the preservation of acquired values located in identity and sovereignty. This produces 
international policies that vary between continentalist and internationalist approaches as Canada has choice in most international policy decisions due to its secure geopolitical position. As Skelton observed, national interests start at home, then progress "to North American solidarity and, when feasible and necessary, international cooperation." ${ }^{498}$ The convergence of norms and values over time was social and involved contestation of the three intervening variables in a recursive process that culminated in Canada's only formal articulation of national security in 2004. The National Security Policy statement was designed to be the central expression of a new integrated way of approaching national security ${ }^{499}$ that begins domestically and emanates outward. In fact, it is a prescient systems approach to national security where modern networking and integration act as force multipliers, much as the Revolution in Military Affairs (RMA) did for military effectiveness. Ideationally, the National Security Policy statement provided a 'road-map' that addressed the emerging security challenges of transnationalism, the blurring of domestic and international security seams; however, implementation of this whole-of-government approach has proven to be highly problematic, as will become evident in the next chapter.

As the BPG identified, the National Security Policy statement is the foundational document that expresses Canada's integrated security system. In releasing the International Policy Statement, the government was articulating its intentions regarding its goals and objectives on the far right of the Venn diagram; particularly where it overlapped National Security, since Canadian law and domestic policies already

\footnotetext{
${ }^{498}$ Hillmer, 2011, p. 23.

${ }^{499}$ Keeble draws similar conclusions regarding the centrality of the National Security Policy statement to the International Policy Statement, See Keeble, 2005, pp. 9-12.
} 
encompasses the far left. Negotiation of the Smart Border Declaration and implementation of the associated 30-point Action Plan demonstrated the impact that Canadian National Security Culture had in the intermestic security overlap with the US during the crisis management phase. All five sets of intrinsic norms and values influenced and shaped the initial policy reactions. This provided time and space for longterm determination of appropriate security policy measures by the Ad Hoc Committee on Public Security and Anti-terrorism that led to final outcomes, supporting the core argument of this study.

Mutual accommodation, the willingness to compromise in order to settle a dispute or move an agenda forward is part of Canadian identity and a critical norm in Canadian National Security Culture. This was the pragmatic approach Canada historically took domestically and bilaterally with the US. Canada has built an international reputation on this particularistic norm, such that even when circumstances do not seem promising, the impact that such flexibility demonstrates improves the chances of non-violent conflict resolution. Collective rather than unilateral action, broadening the inclusive order that starts at home and extends abroad, containing rather than defeating what cannot be accommodated at a particular time, are all seminal aspects of Canadian National Security Culture and clearly demonstrated during the aftermath of the 9/11 attack.

Defence has and must play a role in the security spectrum, but its role starts with Canadian national security at home. Without the imperative of a direct existential threat to Canada, the CF becomes a tool of foreign policy on the world stage to be used by government when collective security responsibilities allow. Canadian National Security Culture supports collective security and understands its responsibilities. It supports the 
application of deadly force when international law is broken and when armed interdiction results in providing greater order and stability to international society. However, Kerry Duncan McCartney of Project Ploughshares perhaps expressed the view many Canadians held $^{500}$ at the time in her testimony before SCONSAD:

On increased military spending, we feel it's likely the Canadian public could accept a small increase in spending to better achieve civil defence priorities, particularly as they have been identified since September 11. We do want to stress that increases to defence spending are one thing; funding that would support military aggression is quite another. ${ }^{501}$

With no imminent external threat, security issues stay within the realm of political discourse (within the rules of the game). As former Speaker of the US House of Representatives Tip O’Neill famously said, "All politics are local" ${ }^{502}$ and therefore security interests compete with other acquired values within the Canadian polity. The use of force without cause is contrary to Canadian norms, and the international use of the CF for any purposes other than direct alliance obligations and humanitarian relief is politically divisive. The decision to participate in the invasion of Afghanistan while avoiding Iraq involved contestation of all three intervening variables and ultimately rested with the 'moral judgment' of the Prime Minister, given many competing interests expressed by elites and society.

\footnotetext{
${ }^{500}$ See Scott Fitzsimmons, Allan Craigie, and Marc André Bodet. "Canadian Public Opinion about the Military: Assessing the Influences on Attitudes Toward Defence Spending and Participation in Overseas Combat Operations," Canadian Journal of Political Science, Vol 47, No.3, 2014, pp. 503-518. ${ }^{501}$ Standing Senate Committee on National Security and Defence, "Canadian Security and Military Preparedness", First Session, Thirty-Seventh Parliament, February 2002, testimony.

502 This common phrase is most closely associated with former Speaker of the US House of Representatives, Tip O'Neill. It encapsulates the principle that a politician's success is directly tied to the person's ability to understand and influence the issues of their constituents. Politicians must appeal to the simple, monotonous and everyday concerns of those who elect them into office. According to this principle, it is these personal issues that are often what voters care most about rather than big and intangible ideas.
} 
Politicians know that assertive international policies do not generate votes, but domestic linkages do; therefore, due to its large discretionary budget, the CF is often sacrificed to fund other national interests when other competing acquired values trump resource extraction for defence. Actors in the polity know the regional (particularistic) make-up of Canadian society and how the 'special interest game' is played within Canadian National Security Culture. This aspect of politics is not unique to Canada, but the domestic-centric protection of acquired values in Canada makes the contestation for defence spending that much more challenging. Until security professionals understand the causal mechanisms embedded in Canadian National Security Culture, a National Security Strategy that links resources to goals will be elusive.

Although Ross and Hira claim that Canada is a land of deep ambivalence ${ }^{503}$ towards national security, Canada's reaction to the $9 / 11$ attack was not ambivalent but cultural. ${ }^{504}$ The National Security Policy statement was a contemporary expression of the acquired values that Canadians expected from state sponsored protection in 2004. It is not a consistent manifestation of fixed values and interests, but it is an expression of Canadian National Security Culture, the evaluative standards (norms and values) that will ebb and flow but that are relatively consistent over time. Canadian security norms do not neatly line up with other states, as realist accounts would have us believe or discursive analysts portend. Jurisprudence matters in Canadian National Security Culture, as will

\footnotetext{
${ }^{503}$ Douglas A Ross and Hira Anil, "Canada, a Land of Deep Ambivalence: Understanding the Divergent Response to US Primacy After 9/11”, Canadian-American Public Policy, no. 68, December, 2006, pp. 165.

504 This argument is supported by a comparative study of the NSP with the US NSS. See Colonel D.A. Cooper, "Canada's Silhouette is Distinct in the Shadow of the Empire: Canada's National Security Policy reflects distinct National Interests", Canadian Forces College, June 2006, p.29, "A comparison of the American 2006 NSS and Canada's 2004 NSP from a thematic approach clarifies the distinctiveness of Canada's national interests..... [and] confirms that the NSP reflects the distinctiveness of Canada's own national interests highlighting the vital importance of its economic relationship."
} 
become evident in the following chapters, where Katzenstein's causal mechanisms will demonstrate the three interrelated intervening variables: identity, institutions, and interests.

The Martin government's bifurcation of security into the National Security Policy statement and International Policy Statement was consistent with the evolution of Canadian National Security Culture over the past 90 years. The fact that the National Security Policy statement is considered a flawed document by many analysts does not diminish the fact that it was a reflection of Canadian National Security Culture. As with all such government statements, the catalyst for change and the processes followed in policy formulation were just as important to understand as the policy outcome itself. Separation of domestic and international policy is never clear-cut, particularly with respect to the Canada-United States (CANUS) interdependent relationship.

In following the actions the Canadian government took in response to the $9 / 11$ attack and tracing the processes that occurred in the formulation of the National Security Policy statement and International Policy Statement, the effects of Canadian National Security Culture on policy choices and outcomes became evident. Tom Axworthy's observation about the International Policy Statement as "new bottles for old wine", where "the interests and values proclaimed by the International Policy Statement would be instantly recognized by the founders of Canada's post-war Foreign Service...,",505 illustrates that the International Policy Statement was representative of long held beliefs on international security. However, the National Security Policy statement was unique in

\footnotetext{
${ }^{505}$ Tom Axworthy, "New Bottles for Old Wine: Implementing the International Policy Statement", in Andrew F Cooper and Dane Rowlands, Canada among Nations, 2005: Splitting Images, McGill-Queens University Press, 2005, p.272.
} 
that it officially articulated in a single document the long held belief that national security was endogenous. A measure of its true relevance is that the National Security Policy statement was never replaced by the Harper Government over its ten year lifespan and continued to be referenced as the singular policy statement on Canadian National Security. For Canadians, National Security is 'the Home Game' and International Security is 'the Away Game'.

Although Canada's reactions to the events of $9 / 11$ were precipitated by changes in the international system, the overall policy outcomes to address this event were determined in large measure by sociological causal mechanisms found in Canadian National Security Culture. Embedded security preferences shaped elite choices during the crisis management phase and led to the security policy decisions articulated in the National Security Policy statement. Although the statement may never have been released had it not been in the political interest of Prime Minister Martin, the National Security Policy statement represented the underlying concept of national security, held by both society and the polity in Canada, which is domestic-centric in the protection of acquired values. Material factors may have precipitated the need for post 9/11 Canadian national security policies, but social factors played an important causal role in shaping the final outcome, thus supporting the hypothesis of this study. 


\section{Chapter: Case 2 - Marine Security Operations Centres}

\subsection{When Ideas and Values Clash}

The 2004 National Security Policy statement identified six Key Activities that required state sponsored advancement to ensure national protection of Canadian society, polity and the state. Of the six activity areas, five were areas of domestic security while Chapter 8, International Security, outlined Canada's intentions towards promoting security in international society. The National Security Policy statement makes it clear that Canadian national security is a continuum where the roots of a strong security system begin at home with a sound national security structure that then enables Canada to engage in extraterritorial security. To further test the hypotheses of this dissertation, I have chosen to analyse cases that are contained in Chapter 6 of the National Security Policy statement, Transportation Security, representing the traditional military-power context in which security policy is developed and implemented. This will ensure any material power relationships and interests are captured and given equal scrutiny in determining causal mechanisms. Both originate domestically, but are integrated continentally and thus demonstrate the interrelationship (ideational construction) of domestic and international policy formulation. The case of the Marine Security Operations Centres (MSOCs) will be presented here, and the role of NORAD in Chapter 6 of this thesis.

Under Transportation Security, the key deliverables focused primarily on a sixpoint plan to strengthen Canadian marine security. The vulnerability of this complex transportation system to asymmetric warfare had been known and identified as a security concern for many years, particularly with the rise of transnational threats and the 
potential use of unconventional weaponry ${ }^{506}$ such as weapons of mass destruction (WMD) and uninhabited airborne vehicles (UAVs). The events of 9/11 proved to be the catalyst for action and change in both Canada and the US, particularly with respect to domestic structural and institutional change to the security complex that sought a seamless interface in an interdependent continent. Significantly, the National Security Policy statement links the international dimension of transportation security, "pursuing greater marine security co-operation with the United States" ${ }^{\prime 507}$, with the work of the Binational Planning Group (BPG) under the auspices of NORAD. The one common denominator in this comprehensive marine security plan is the formation of the Marine Security Operations Centres (MSOCs) that integrates five functional areas involved in national security into one operational unit and is therefore a logical place to start.

The importance of national identity was particularly apparent in Canadian national security policy formulation following the 9/11 attacks on the US. The five basic beliefs and values described earlier that are foundational to Canadian security identity helped shape and produce national security interests. As developed in the previous chapters, Canadian National Security Culture refers to the socially shared and transmitted ideas and beliefs within this collective identity that influence how Canadians perceive national security, security institutions, and the importance placed on security as an acquired value in competition with other acquired values. Cultures are not static entities and the cognitive beliefs about the world held by Canadian society-polity were tested with the events of $9 / 11$. This case study will examine whether acquired beliefs and values

\footnotetext{
${ }^{506}$ Karl W. Eikenberry. "Thoughts on Unconventional Threats and Terrorism”, Working Group on Foreign Policy and Grand Strategy, Hoover Institution, Stanford University, 2014, online at www.hoover.org/taskforces/foreign-policy .

${ }^{507}$ NSP, 2004, p. 35-36.
} 
were altered by $9 / 11$ and what ideational compromises may have been necessary to effect legitimate policy implementation. This legitimization process of contestation and resolution of values and beliefs then becomes part of national security culture and has lasting impact on future state behaviour.

As the National Security Policy statement was designed to be the policy foundation for an integrated, whole-of-government national security system ${ }^{508}$, establishment of the MSOCs represents the focal point where both domestic and continental structural and cultural challenges need to be resolved within the marine security system. Articulation of policy is one thing, but execution of the policy plan brings to light causal mechanisms and structural impediments that must be resolved for successful implementation. Analysis of the decisions made with respect to jurisdictional, legal, and structural obstacles will provide evidence of the underlying factors behind the genesis of the policy and the actual deliverable. As previously discussed, adoption of the Charter has significantly altered Canadian identity and affected state behaviour. Investigation into the MSOCs will reveal how Canadian National Security Culture's balancing of individual and communal security rights influenced the dialectical relationship between structure and agency.

In creating an integrated, network-centric marine security system by bringing the Department of National Defence (DND)/ Canadian Forces (CF/CAF) ${ }^{509}$, Canadian

\footnotetext{
${ }^{508}$ Ibid, Chapter 2, pp. 9-13. The euphemism used to express the Whole-of-Government approach in the NSP was "integrated approach to security issues across government", p. vii.

${ }^{509}$ In 2006, the Harper Government renamed a number of departments and agencies. For historical accuracy, I will use the proper names at the time. Therefore, the terms Canadian Forces (CF) that became the Canadian Armed Forces (CAF) under Harper and Public Safety and Emergency Preparedness Canada (PSEPC) that became Public Safety Canada (PS) under Harper will be used interchangeably to refer to the same department at the time in question. Other changes to note under Harper: Department of Fisheries and
} 
Border Services Agency (CBSA), the Royal Canadian Mounted Police (RCMP), Transport Canada (TC), and the Canadian Coast Guard (CCG) together into one unit, the MSOCs became the key enablers for interagency/ interdepartmental collaboration. However, the National Security Policy statement was not specific in defining how integration was to be achieved. Security norms are embedded in institutions - legal (cognitive) and cultural (evaluative) - and require clear direction, leadership and oversight to ensure intended change occurs. In the traditional Westminster model of government, responsibility and accountability rest with the respective Ministers in each department and resolution of competing interests is the business of Cabinet. ${ }^{510}$ However, developing a Whole-of-Government (WoG) approach in order to combat the silo effect of departmental processes and cultures requires substantive effort to overcome the inherent challenges. If the post $9 / 11$ policies were designed to address imminent, contemporary threats, one would expect to find evidence of the government working aggressively towards overcoming horizontal management issues in the name of security. In addition, evidence of the ideational foundations of national security in Canada will be measurable through contestation of specific interests and values within the polity and society.

This chapter will present background information to understand the identified vulnerabilities to the Canadian marine system as well as the complex nature of the problem. Many of the challenges in implementing the MSOCs were known early, but a lack of imperative (perceived threat) kept the process within the bureaucratic 'rules of the

Oceans became Fisheries and Oceans Canada in 2008 but maintains the DFO acronym; Maritime Command (MARCOM) became the Royal Canadian Navy (RCN) in 2011.

${ }^{510}$ Herman Bakvis and Luc Juillet, "The Horizontal Challenge: Line Departments, Central Agencies and Leadership", 2004 accessed online http://publications.gc.ca/Collection/SC103-1-2004E.pdf, 18 August 2015, pp. 9-10; Auditor General of Canada, 2009 March Status Report of the Auditor General of Canada to the House of Commons, "Chapter 1-National Security: Intelligence and Information Sharing", para 1.26, pp. 12-13, online at www.oag-bvg.gc.ca. 
game', hindering early completion of fully integrated operations centres. Organization/ bureaucratic politics ${ }^{511}$ theory can account for some of the challenges in implementing a WoG approach, such as issues of accountability / responsibility and resistance to change due to institutional structure / culture, but fails to provide sufficient sociological context when dealing with the third challenge, barriers to information-sharing. Contestation over acquired values within the polity, regarding the consequences of information sharing, will be used to demonstrate how norms, culture, and identities impacted MSOC policy formulation and implementation.

Canadian National Security Culture was evident in the genesis of the National Security Policy statement and can be seen throughout the eleven year period it took for the MSOCs to become fully functional. Through analysis of the intervening variables (identity, institutions, and interests), it will become evident that the MSOCs have become somewhat of a misnomer. Originally perceived to "have the authority and capacity, through interagency staffing, to bring to bear all civilian and military resources necessary to detect, assess, and respond to a marine security threat" ${ }^{\prime 512}$, the MSOCs are neither 'operations' nor 'security' centres today, but marine information fusion centres. Lacking an unambiguous perceived threat and with no clear vision from a Ministerial champion, Canadian national security policy followed a path prescribed by Canadian National Security Culture to a logical conclusion.

${ }^{511}$ See Graham T. Allison, Essence of Decision: Explaining the Cuban Missile Crisis. Boston: Little, Brown and Company, 1971; Jonathon Bender and Thomas Hammond, "Rethinking Allison's Models," American Political Science Review, Vol 86, No. 2, June 1992, pp.301-322; Tom Christensen and Per Lægreid, "The Whole-of-Government Approach to Public Sector Reform," Public Administration Review, Vol. 67, No.6, 2007, pp. 1059-66.

512 NSP, 2004, pp. 38-39. 


\subsection{Marine Security - An Acquired Value}

Canada is a trading nation that relies on effective, efficient transportation of people, commodities, and products to ensure economic prosperity. With a landmass of 10 million square kilometers and a coastline stretching 200,000 kilometers, it has one of the largest and most complex transportation systems in the world. As the marine sector is a critical component of the overall system, it is understandable that state sponsored security of this vital trade gateway was identified as a key deliverable in the National Security Policy statement. Prior to 9/11, attention to the marine domain focused largely on the safe and effective movement of marine traffic and criminal activity associated with transnational trading activities. However, the consequences experienced to the free flow of trade in the aftermath of the 9/11 attack accelerated rectification of known vulnerabilities and security deficiencies in the marine domain.

\subsubsection{Reaction to $9 / 11$}

In the crisis management phase, the Ad Hoc Committee of Ministers on Public Safety and Anti-terrorism conducted hearings and allocated resources to departments identifying the most urgent security needs. In the maritime domain, Transport Canada (TC) was directed to lead a comprehensive threat assessment and analyse vulnerability gaps in the transportation system. The Department of National Defence (DND), the Canadian Coast Guard (CCG) and Department of Fisheries and Oceans (DFO) were tasked to increase surveillance of oceanic approaches, and the Canada Customs and Revenue Agency (CCRA) was instructed to increase container security at ports. ${ }^{513}$ Criminality had long

\footnotetext{
${ }^{513}$ Peter Avis, "Surveillance and Canadian Maritime Domestic Security", Canadian Military Journal, Department of National Defence, Spring 2003, found online at http://www.journal.forces.gc.ca/vo4/no1/policy-police-eng.asp
} 
been a problem with port security, but the potential for terrorists to leverage criminal corruption to deliver WMD to the heart of major cities via maritime vessels demanded immediate action. ${ }^{514}$

The Cabinet Committee on Public Security and Anti-terrorism established an Associate Deputy Minister (ADM) Interoperability Working Group (IWG) in October 2001 'to identify opportunities to enhance public safety, establish a list of 'quick hits' (fixes) and medium-term initiatives to be pursued immediately, and propose a long-term vision and strategy to harmonize and improve information sharing." ${ }^{\text {515 }}$ The quick hits were identified in February 2002, submitted to the Cabinet Committee on Public Security and Anti-terrorism in June 2002, and approved by the Cabinet Committee on Public Security and Anti-terrorism Chairperson in September 2002, but they were never submitted to Cabinet. The ADM IWG was disbanded in June 2002, resulting in the loss of centralized WoG senior level leadership that dealt directly and holistically with the events of 9/11. The Auditor General and the O'Conner Commission did note that new efforts at integrating activities, such as the Integrated Border Enforcement Teams (IBETs) and Integrated National Security Enforcement Teams (INSETs), were good initiatives but there was a notable lack of participation amongst security partners. ${ }^{516}$

\footnotetext{
514 "In the words of Supt. Hansen: "Any organized crime presence in a port will increase the potential for terrorist attack, because there is the possibility of corruption ... you do not have control over what is in the containers, where the port workers are, where the containers are, and so on."', testimony found in Standing Senate Committee on National Security and Defence (SCONSAD), "Canada's Coastlines: The Longest Under-Defended Borders in the World", Vol 1, Thirty-Seventh Parliament - Second Session, October 2003, p 29.

515 Auditor General of Canada, "Chapter 3: National Security in Canada - The 2001 Anti-terrorism Initiative", Report of the Auditor General Of Canada to the House of Commons - March 2004, Ottawa: Public Works and Government Services Canada, 2004, p 20.

${ }^{516}$ Ibid., pp. 11-12 and 15-16; Dennis R. O'Connor, "Analysis and Recommendations," A New Review Mechanism for the RCMP's National Security Activities - Commission of Inquiry into the Actions of
} 
The Cabinet Committee on Public Security and Anti-terrorism created two interdepartmental working groups to examine aviation and marine domain security deficiencies and to make recommendations for improvements. The Minister of Transportation was given responsibility to form the Interdepartmental Marine Security Working Group (IMSWG) with representation from 17 departments and agencies ${ }^{517}$ responsible for varying aspects of the marine environment in their mandates. Their task was "to coordinate federal response to marine security, analyze our marine systems for security gaps, and develop possible mitigation initiatives to address these gaps." ${ }^{218}$ Within the year, IMSWG produced the first Canadian Marine Security Plan that identified gaps in the existing system and provided a roadmap towards obtaining maritime domain awareness (MDA) ${ }^{519}$, a critical first step in providing state sponsored

Canadian Officials in Relation to Maher Arar, Ottawa: Public Works and Government Services Canada, 2006, pp 316-323.

517 The 17 Interdepartmental Marine Security Working Group (IMSWG) Partners are Canada Border Services Agency (CBSA), Canadian Food Inspection Agency (CFIA), Canadian Security Intelligence Service (CSIS), Canadian Space Agency (CSA). Defence Research and Development Canada (DRDC). Department of Fisheries and Oceans / Canadian Coast Guard (DFO/CCG), Department of Justice (DOJ), Department of National Defence (DND), Environment Canada (EC), Finance Canada (FIN), Department of Foreign Affairs and International Trade (DFAIT), Government Operations Centre (GOC), Privy Council Office (PCO), Public Safety Canada (PS), Royal Canadian Mounted Police (RCMP), Transport Canada (TC), and Treasury Board Secretariat (TBS).

${ }^{518}$ Senate Standing Committee on National Security and Defence (SCONSAD),October 2003, p. 110.

${ }^{519}$ The definition of maritime domain awareness found at Transport Canada's website online 06 Sep 2015 https://www.tc.gc.ca/eng/marinesecurity/initiatives-235.htm - "Maritime domain awareness means having true and timely information about everything on, under, related to, adjacent to, or bordering a sea, ocean or other navigable waterway. This includes all related activities, infrastructure, people, cargo, vessels, or other means of transport. For marine security, it means being aware of anything in the marine domain that could threaten Canada's national security."; According to the SCONSAD, October 2003, p. 36, "Domain awareness" refers to the degree that Canadian enforcement authorities know what is going on in their jurisdiction - both on Canada's land mass and in its coastal waters. Those coastal waters include: TERRITORIAL SEA: Canadian territory stretching 12 nautical miles off coastal base lines and charted according to treaties in the Great Lakes and border rivers; (see appendix XII, Volume 2) CONTIGUOUS ZONE: An additional 12 nautical miles beyond territorial seas; by international law, Canada is allowed to prevent infringement of customs, fiscal, immigration or environmental laws up to 24 nautical miles from its coasts; (see appendix XII, Volume 2)

EXCLUSIVE ECONOMIC ZONE: Areas of the high seas extending beyond the contiguous zone extending out to 200 nautical miles from the coastline in which Canada is allowed jurisdiction over natural resources. Canada can generally only intercept and board vessels with permission of the flag state, if there 
maritime security. Two of the principal deficiencies noted were the lack of informationsharing amongst partners and a centralized centre for operationalizing the information. As IMSWG was being established, the Canadian navy created the Maritime Operational Surveillance Information Centres (MOSIC) project in response to the need for a more comprehensive Recognized Maritime Picture (RMP) ${ }^{520}$ The navy understood that an integrated structure that fused modern command, control, communication and intelligence $\left(\mathrm{C}^{3} \mathrm{I}\right)$ systems with contemporary information management structures was needed to provide real-time, actionable awareness of the complex maritime domain. ${ }^{521}$ However, this stand-alone, navy-centric initiative was insufficient to produce a National Maritime Picture $^{522}$ (NMP) of all marine activity without the active participation of all domestic stakeholders. Thus the MOSIC project formed the cornerstone for the WoG operations centre recommended by IMSWG and identified in the National Security Policy statement as the Marine Security Operations Centre. ${ }^{523}$

is a national security concern, or if Canadian authorities are in hot pursuit from territorial waters (see appendix XII, Volume 2).

The SCONSAD reports can be found online at http://www.parl.gc.ca/sencommitteebusiness/CommitteeReports.aspx?parl=39\&ses=1\&Language=E\&com $\mathrm{m} \mathrm{id}=1076$

${ }^{520}$ Laurence Hickey, The Canadian Navy and Domestic Maritime Enforcement, Halifax: Centre for Foreign Policy Studies, Dalhousie University, 2011, pp. 214-216.

${ }^{521}$ For an in-depth understanding of the complexity of the variables in the marine domain SCONSAD, "Canada's Coastlines: The Longest Under-Defended Borders in the World", Vol 2, October 2003.

522 The NMP should not be confused with the military derived RMP that is shared with other defence allies. The RMP contains information from unclassified as well as classified sources and, while the two products may overlap at the unclassified level, the NMP does not contain classified military information. Sourced at Department of National Defence, Marine Security Operations Centres: Concept of Operations for Initial Operational Capability (IOC), Ottawa: Chief of Maritime Staff, 2008, p. 7.

${ }^{523}$ In another indication that national security is domestic-centric, the name of the operations centres was changed to 'Marine' Security Operations Centre vice the navy preferred 'Maritime' nomenclature by members of IMSWG as a sign that the centres would focus on domestic marine traffic rather than the navy's preferred global maritime traffic. "“This', groused a number of naval officers during interviews, "was ridiculous", in another small indication of the culture clashes that are inherent in interdepartmental working relationships. 
As one of the key deficiencies was in information-sharing, IMSWG commissioned a study to examine information exchange requirements between marine security stakeholders. To empower the MSOC construct and achieve MDA, IMSWG subsequently approved the development of a net-centric, inter-agency information system project called the Marine Security Information Management and Data Exchange (MIMDEX) system in 2002. It was envisioned that the MIMDEX system would not only provide the platform for the sharing of vital information and enable inter-agency communication and coordination, but also act as an intelligence/operations interface for proactive threat assessment. Not only did the MIMDEX project need to develop the technical specifications for a WoG secure integrated system, but the concept of information-sharing required a cultural shift in traditional departmental paradigms from one of 'need to know' to a 'need to share'. 524

MIMDEX was scheduled to be fielded in 2005 in concert with the planned Initial Operating Capability (IOC) of the MSOCs, demonstrating that solutions were available to address security deficiencies had the $9 / 11$ terrorist attack been perceived as existential threat. However, with the initial crisis contained, the MIMDEX and MSOC projects stalled as security concerns became evolutionary and bureaucratic. Notably, the difficulties that lay ahead in establishing these two marine security initiatives were foreshadowed by two government accountability bodies. Both the Auditor General and

\footnotetext{
${ }^{524}$ See Greg Aikens, "Network-Centric Operations and Interdepartmental Marine Security," Canadian Naval Review, Vol 1, No. 3, Fall 2005; and LCdr B. Henry, "The Whole of Government Approach Applied to Canadian National Security", Canadian Forces College Master of Defence Studies Research Project, JCSP 34, pp. 51-56 found online at http://www.cfc.forces.gc.ca/303/171/171eng.html?action=author .
} 
the Senate Standing Committee on National Security and Defence recognized the inherent challenges of the prevailing Canadian National Security Culture.

\subsubsection{Indications of Cultural Challenges}

The Auditor General (AG) of Canada examined various aspects of national security shortly after 9/11, publishing findings and recommendations in "Chapter 3 : National Security in Canada - The 2001 Anti-terrorism Initiative" of the Report of the Auditor General of Canada to the House of Commons - March 2004. The audit focussed on the overall management of the Cabinet Committee on Public Security and Antiterrorism initiatives and the coordination of intelligence within government institutions, particularly with respect to the interoperability of security and intelligence systems and the sharing of information. ${ }^{525}$ The report limited itself to the situation prior to the reorganization of government institutions in December 2003 (creation of Public Safety and Emergency Preparedness Canada, Canada Border Services Agency, a National Security Advisor, and a Cabinet Committee on Security, Public Health and Emergencies). As the National Security Policy statement was intended to rectify many of the problem areas identified in the AG's report ${ }^{526}$, the AG's report provides a solid baseline from which to explore subsequent causal mechanisms with additional evidentiary support from the AG's March 2009 status report.

The AG found that the majority of the activities funded under the Cabinet Committee on Public Security and Anti-terrorism initiative were connected to stated objectives. However, some of the fundamental problems that were observed and acknowledged by the government were more than mere bureaucratic issues, but were

\footnotetext{
${ }^{525}$ Auditor General of Canada, Chapter 3, March 2004, p. 8-9.

${ }^{526}$ NSP, 2004, p.9.
} 
synonymous with Canadian security norms. There were indications in the AG's report that security was no longer a key priority for the polity now that the initial crisis had been addressed. The report voiced concerns that, with the disbandment of the ADM IWG, the AG "found no evidence to show that central direction had reassigned its responsibilities elsewhere" and used the lack of movement on information-sharing as evidence of a "lack of central direction". ${ }^{527}$

Secondly, there is a distinct lack of ownership to the National Security file expressed throughout the entire report. This is especially evident in the section on interoperability and information-sharing, where the AG cited ambivalent security norms as causes for decisions not to share information ${ }^{528}$ as well as in finding "no evidence that officials ... had based their review of departmental proposals on national threat and risk assessment." 529 The AG's recommendation for the "balancing of privacy concerns with national security concerns" would presage an ideational contestation within government of significance to Canadian identity.

As expected, the Privy Council Office (PCO), Public Safety and Emergency Preparedness Canada (PSEPC/PS), Justice Canada (DoJ), and Treasury Board (TB) Secretariat all pledged in 2004 to rectify the situation in their responses to the AG's recommendations, and some progress was made over the next five years. Although many of these observations can be explained through temporal application of organizational theory, the AG's 2009 status report provides further evidence that the issues were much

\footnotetext{
${ }^{527}$ Auditor General of Canada, Chapter 3, March 2004, paragraph 3.81.

${ }^{528}$ Ibid, para 3.92. The AG identified of Canadian laws that "prevent the sharing of information within government" and that decisions not to share information between departments was "based on the assumption that it would contravene the principles of the Privacy Act ... [and] ... were made without a proper examination of potential security concerns."

529 Auditor General of Canada, Chapter 3, March 2004, p.10.
} 
deeper and ideational in nature as the many departmental pledges went unfulfilled by March 2009. In reading these comments in hindsight, it is evident that each department stayed within its cultural paradigm of assisting others when no department or Minister was given overarching ownership. ${ }^{530}$

From early 2001 to March 2004, the Senate Committee on National Security and Defence (SCONSAD) held special studies and released six substantive reports dealing with security issues that had a direct nexus to the events of $9 / 11$. In the October 2003 SCONSAD report, "Canada's Coastlines: The Longest Under-Defended Borders in the World", the committee focused on the marine security issues most pertinent to this dissertation. The transcripts expose the norms of Canadian security culture a priori to the subsequent empirical observations that this dissertation will make regarding the challenges of policy implementation. The relativism that Canadian society-polity places on national security as an acquired value was captured in the testimony of Dr. Dan Middlemiss, "Canadians and their governments do not take national defence or national security seriously, in part because, first, they have historically been blessed with good luck, and, second, because of their fortuitous geostrategic position alongside our friendly superpower to the south." ${ }^{\prime 531}$ This perception was articulated throughout the report by

\footnotetext{
${ }^{530}$ For example, in the 2004 report DoJ responds, "We look forward to providing our expertise to government agencies to assist in enhancing our national security" (Para 3.94) and in the 2009 Status Report stated "Justice Canada will continue to assist other departments by providing advice on the balance between the very real information sharing needs of the government and important values such as privacy and other human rights." (para 1.47). Although the AG's report clearly identified legal impediments that required DoJ analysis, DoJ stayed within its solicitor/client cultural norms of only providing advice when 'the client(s)' requested such advice. Without one department taking ownership of the issue or a Minister taking holistic interest in the interoperability/information-sharing problem, the necessary legal analysis would cause stagnation of the whole MSOC project.

${ }^{531}$ SCONSAD, October 2003, p. 10. Also see Tom Axworthy's quote on p. 149, "We have this tradition of unpreparedness. Ethelred the Unready should be the patron saint of Canada. At the same time, we have this enormous accelerating rate of threat." And "The Committee could not agree more. Never has a
} 
other expert witnesses as they identified the gaps in structure and agency that needed attention in order to "defend [Canada's] territorial waters and help police the continental coastline." 532

Dr. Thomas Axworthy identified structural impediments and lack of focused leadership on the issues of national security, principally as they pertained to intelligence and structural reform. He testified that without dedicated attention from the centre of power, there was little hope that there would be any substantive change in the system as a whole. Horizontal issues need the "muscle of the Prime Minister's Office [PMO] and the Privy Council Office" for the bureaucracy to understand that a specific issue is a priority. In the paper that Axworthy submitted to SCONSAD, he called for the creation of a cabinet committee on national security with the support of a dedicated staff to work horizontal issues much like the National Security Council in the US. ${ }^{533}$ The Committee expressed concern over unfocussed senior leadership and the problem of allowing ad hoc committees to solve security problems that "is indicative of the government's general approach to national security: call fiefdoms together every now and then to discuss the issue. ${ }^{, 534}$ Notably, the Committee expressly cast doubt over the efficacy of the post $9 / 11$ effort to reform the marine security complex. Individual departmental legislation and mandates make it "doubtful that IMSWG will ever create policy, or gain the authority to 'direct that things happen'., 535

combined physical and economic threat to the Canadian homeland been more palpable, but rarely have Canadians been more sanguine about their well-being."

532 Ibid, p. 11.

533 Ibid, p. 114-115.

534 Ibid. p. 122.

535 Ibid, p. 113. 
The SCONSAD Committee rejected cultural arguments that the CCG should not assume a constabulary role and recommended it be moved back to TC from DFO, where it had been removed in 1995 for cost-effectiveness, and be legislated to take up a more active national security role. In addition, the Committee expressly endorsed the introduction of MIMDEX as a priority and expanded information-sharing within the confines of the Charter and Privacy Acts. It acknowledged, however, the horizontal implementation challenges that this project entailed. With respect to international aspects, the Committee pointed to their previously released September 2002 report, "Defence of North America: A Canadian Responsibility" in recommending closer cooperation with US and the international community in general.

When the issue of the BPG was discussed and the Canadian Forces co-director stated that “...it's very fair to say that they're [the BPG] just beginning their work", the Committee's reaction was dismissive: "It is probably also very fair to say that this may be a good idea going nowhere - slowly." 536 This is a further example of the Committee's understanding of Canadian National Security Culture in predicting the behaviour of government actors and the implications with respect to the process of formulating national security policy. Security issues are of concern to Canadian governments only when the consequences of ignoring the problem become critical; otherwise, decisions can be put aside through political delaying mechanisms. ${ }^{537}$ The BPG will be addressed in greater detail in the next chapter.

\footnotetext{
536 Ibid, p. 140.

${ }^{537}$ Use of time and space for advantage is not only part of Canadian National Security Culture but is a time honoured tool in all politics. In sporting terms, it is known as 'ragging the puck' in hockey.
} 


\subsubsection{Structural Change}

One of Paul Martin's first acts as Prime Minister was to restructure the Canadian security complex. The creation of the Department of Public Safety and Emergency Preparedness in December 2003 was designed to unify the primary domestic security actors under one Minister to overcome the structural horizontal coordination challenges of a WoG approach. The operational sections of CCRA, Citizenship and Immigration Canada (CIC), and Canadian Food Inspection Agency (CFIA) were separated out to form the Canadian Border Services Agency (CBSA), and along with the RCMP, CSIS and the Office of Critical Infrastructure Protection and Emergency Preparedness, provided PSEPC with a vertical accountability structure of all the domestic security functions necessary to address internal and border security issues. Leadership gaps were addressed with the establishment of a Cabinet Committee on Security, Public Health and Emergencies (CCSPHE), as well as the creation of the new National Security Advisor (NSA) position within PCO to provide direct advice to the Prime Minister. With the release of the National Security Policy statement in April 2004, many of the policy pieces were already in place to facilitate the transformation of the Canadian national security landscape.

From the beginning, these bold initiatives were fraught with problems. Although consolidation of domestic security agencies into PSEPC superficially addressed cultural integration challenges between actors, this structural reformation not only neglected to amend legal mandates, accountability structures, and cultures of responsibility internally, but failed to address how this new entity would integrate within the WoG approach. Virtually all departments have internally differentiated entities with their own units, 
networks and subcultures. ${ }^{538}$ Shaving off units from various agencies and consolidating them within a super-department is as problematic as attempting cross-departmental WoG integration. Each aspect in the spectrum of national security, from safety through security to defence, manifests itself differently in unit actors' identities and cultures, making it difficult to inculcate a new departmental or WoG culture quickly without dedicated leadership and clear direction. The PSEPC mandate was specific in restricting its authority over functions mandated in other departments ${ }^{539}$, which effectively meant PSEPC could not be considered the lead department for national security.

The National Security Policy statement did include measures to provide holistic oversight of national security through the creation of the 'Cabinet Committee on Security, Public Health, and Emergencies' and in the National Security Advisor position in PCO. Both of these measure fall squarely within the political culture of the Westminster political system, but were ultimately insufficient to address the leadership needed to transform the security complex quickly. By their very nature, Cabinet Committees are ad hoc arrangements determined temporally by the presiding Prime Minister. Their relative impermanence and transitory composition makes them poor instruments to ensure sustained oversight of any long-term initiative. Cabinet Committees tend to deal with transactional issues and have insufficient understanding of the interrelationship of policies, depending on an understaffed PCO to provide insight and issue management. ${ }^{540}$

\footnotetext{
${ }^{538}$ D. Kavanagh, "Departmentalism and Joined-Up Government," Parliamentary Affairs, Vol 54, No.1, 2001, pp. 1-18.

${ }_{539}$ Canada, Department of Public Safety and Emergency Preparedness Act, Section 4.

${ }^{540}$ Bakvis, and Juillet, 2004, p. 55.
} 
Although the creation of the NSA position in PCO provides greater focus on national security issues, the NSA's mandate is to provide information, advice, and recommendations to the Prime Minister and to ensure the effective coordination of Canada's security and intelligence community. Under Stephen Rigby, this role was expanded to include foreign and defence policy. As the current NSA, Richard Fadden, explained to SCONSAD on 27 April 2015, “...while I do not have an operational role, an important part of my function includes the coordination of the national security community." ${ }^{541}$ Coordination is not leadership. With no Minister or senior bureaucrat responsible and accountable for national security, the task falls to the Prime Minister to whom all mechanisms of government report. Without a Prime Minister whose sole focus is on ensuring horizontal integration of national security, the security complex retains its cultural norms where only issues of significant importance, which make it vertically through departmental filters, are coordinated and negotiated by senior leaders. Thus, the changes needed for WoG effectiveness are impeded as very few of the horizontal problems make it vertically to the Prime Minister's attention.

The national security policy framework also included a number of operational level initiatives, such as creation of the Integrated Threat Assessment Centre (ITAC), Government Operations Centre (GOC), Canadian Air Transport Security Authority

\footnotetext{
${ }^{541}$ Standing Senate Committee on National Security and Defence "Evidence on the subject of Bill C-51 An Act to enact the Security of Canada Information Sharing Act and the Secure Air Travel Act, to amend the Criminal Code, the Canadian Security Intelligence Service Act and the Immigration and Refugee Protection Act and to make related and consequential amendments to other Acts", Forty-first Parliament Second Session, 27April 2015 found online 12 Sep 15 at http://www.parl.gc.ca/content/sen/committee/412/SECD/52069-e.HTM ; additionally see Canada, Privy Council Office, The Role and Structure of the Privy Council Office, November 2008, archived 2010, accessed online 12 Sep 15 at http://www.pco-

bcp.gc.ca/index.asp?lang=eng\&page $=$ information $\& s u b=$ publications \&doc $=$ aarchives $/$ role/role2008eng.htm ; it is notable that the Harper Government continues to obfuscate government information as there is no accessible updated replacement for this information on PCO roles and responsibilities available.
} 
(CATSA), Public Health Agency of Canada (PHAC), and the Marine Security Operations Centres (MSOC). Of these the MSOCs were unique as they not only required a WoG approach but significant interdepartmental integration in order to achieve the high level of expectation of ensuring "that the MSOCs can use all the civilian and military resources necessary to detect, assess and respond to a marine security threat.."542 Departmental processes and accountabilities will mitigate many of the WoG coordination problems of redundancy, incoherence and lacunae through negotiation, but integration problems involve horizontal accountabilities that are not easily resolved and inevitably revolve around ideational issues of identity and culture. ${ }^{543}$

Wolfers' Specifications and the MSOC Concept. Although it can be argued that the National Security Policy statement answers Wolfers' seven specifications for the government's focus on marine vulnerabilities as a national security policy objective, the conclusions would be superficial without deeper analysis as the specifications also refer to the means for its pursuit. ${ }^{544}$ As resource allocation is a fundamental political pursuit, the amount of material resources and political capital invested in the drive towards marine domain awareness will provide evidence of the importance of this policy objective as an acquired value. In final analysis, the value of this increment of national security will be determined through the choices and actions of actors.

Announced in the National Security Policy statement in 2004, it was not until November 2005 that Treasury Board approved the establishment of the MSOC project.

\footnotetext{
542 Government of Canada, Securing an Open Society: One Year Later, Progress Report on the Implementation of Canada's National Security Policy, April 2005, p. 34.

${ }^{543}$ See Bakvis, and Juillet, 2004, p.23-24; Tom Christensen and Per Lægreid, "The Whole-of-Government Approach to Public Sector Reform." Public Administration Review, Vol. 67, No.6, 2007, pp. 1059-66; and Guy B. Peters, "Managing Horizontal Government: The Politics of Co-Ordination", Public Administration, Vol 76, No.2, 1998, pp. 295-311.

${ }^{544}$ David Baldwin, "The Concept of Security", Review of International Studies, Vol 23, no.1, 1997, p. 6.
} 
Based on the Canadian navy's MOSIC project, two MSOCs were to be built, one on each coast in Halifax and Victoria, to provide detection, assessment and response to marine threats in a similar fashion as the interdepartmental National Search and Rescue (SAR) Program construct. ${ }^{545}$ The challenges posed by the concept became very evident to IMSWG during its formative stage. Technical incompatibilities, policy constraints, procedural impediments, personnel issues, and a distinct lack of national information exploitation capabilities were only a few of the national-level issues that needed to be resolved. However, the critical support needed to address these significant hurdles was soon lost as the Martin government's attention was diverted to survival as a minority government.

To ensure national security received focused attention from the beginning of his mandate, Prime Minister Martin placed Deputy Prime Minister and Minister of PSEPC, Anne McLellan, in charge of overseeing all national security policy issues as chair of CCSPHE, while he took an active role in shaping foreign policy. ${ }^{546}$ This was structurally similar to SCONSAD's recommendations in Chapter 5 of their October 2003 report; however, six months later the Liberal government lost its majority. As could be expected, attention to mid-level issues raised at IMSWG was limited and usually left to

\footnotetext{
${ }^{545}$ In accordance with the Rush-Bagot treaty with the US, a third MSOC - MSOC Great Lakes Saint Lawrence Seaway - was authorized as a separate project and is led by the RCMP. It has been operating in Niagara Falls, Ontario since July 2005 and is also staffed with personnel from five partner federal departments and agencies, based in facilities owned and managed by the RCMP. Online information accessed on 10 Sep 2014 at http://www.msoc-cosm.gc.ca/en/about-us.page ;Additionally, the Harper government recently announced the transfer of the National Search and Rescue Secretariat from DND to Public Safety, 24 July 2015. The SAR Secretariat website has been taken down and not replaced, however, the principles of the SAR construct have not changed and a good overview is available on the DND website http://www.forces.gc.ca/en/operations-canada-north-america-current/sar-canada.page accessed on 14 Sep 2015 that includes the announced change.

${ }^{546}$ Nelson Michaud, "Setting the Canadian Foreign Policy Agenda, 1984-2009: Prime Ministers as Actors", in Greg Donaghy and Michael Carroll, eds., In the National Interest: Canadian Foreign Policy and the Department of Foreign Affairs and International Trade, 1909-2009, Calgary: University of Calgary Press, 2011, pp. 194-196; also see NSP, 2004, p.24.
} 
the WG to resolve. This problem was exacerbated when the Liberal minority government was replaced by a Conservative minority government under Stephen Harper in January 2006 and the governance framework Martin had established for national security slowly disappeared. Though important, the national security initiatives instituted in the wake of the 9/11 attacks and articulated in the National Security Policy statement were temporal and lost momentum.

With no clear vision other than that expressed in the National Security Policy statement and three lead Ministers responsible for varying aspects of marine security, the MSOC project experienced the challenges portrayed in bureaucratic organization theory. Each department was naturally focused on its particular objectives within its own mandate and, without proper authority, mid-level participants were restricted to adhering to departmental interests and programmatic. ${ }^{547}$ As the Minister of Transport was responsible for policy coordination, the job of refining marine security policy fell to IMSWG, notably for the articulation of the roles and responsibilities of the MSOC. With only a general national security framework as a starting point, progress was slow as each member department held its own interpretation of national security as seen through the prism of their specific contributions to the spectrum.

The five core governmental partners identified to form the MSOCs were DND, RCMP, DFO/CCG, TC, and CBSA. With various mandates that included aspects of marine security, each partner was solely accountable to their respective Minister and constrained by legislation that articulated its unique roles and responsibilities. As expected, each institution had fully developed internal structures and operational cultures

${ }^{547}$ Kavanagh, 2001, pp.1-18. 
unique to their circumstances that were not necessarily compatible with each other under a single, integrated mandate. On top of these challenges to horizontal integration were the questions of information-sharing under the provisions of the Charter and Privacy Act. Material aspects aside, it is evident that identity, culture, and interests would play a significant role in shaping the marine security policy outcome as an acquired value.

\subsection{MSOC Team - Competing Visions}

\subsubsection{MSOC Construct}

The MSOC concept was designed to address known significant deficiencies in integration of critical surveillance, intelligence, and reconnaissance information from disparate government sources to provide holistic marine domain situational awareness (commonly referred to as 'fusing'). Until the government provided clear direction in the National Security Policy statement to "adopt an integrated approach to security issues across government" ${ }^{, 548}$, departments and agencies worked within their mandates unaware of the need or simply unable to share mission critical information. Having already embarked on the navy-centric MOSIC project, and with significant experience as lead department for SAR, DND was given responsibility to "head" the MSOC project.

The original intent was to model the MSOCs on the SAR Joint Rescue Coordination Centres, where a common MSOC operating picture would permit operational decision-making "to bring to bear all civilian and military resources necessary to detect, assess, and respond to a marine security threat." ${ }^{, 549}$ Staffed by personnel from the CF, CBSA, CCG, RCMP and TC, the MSOCs were originally planned to reach Full Operational Capability (FOC) by 2010. However, the complexity of

\footnotetext{
${ }^{548}$ NSP, 2004, p. vii.

${ }^{549}$ Ibid, p. 38.
} 
the task $\mathrm{k}^{550}$ became evident early on in the process as disagreements over governance models, mandates, authorities, and legalities clashed with actors' identities as a result of their position in the spectrum of national security and the cultures that these security norms engender. Although explicable through bureaucratic / organizational theories, the process of contestation goes to the heart of Canadian security identity in balancing "the needs of national security with the protection of core Canadian values" 551 and provides causal evidence of Canadian National Security Culture in policy formulation and implementation.

\subsubsection{Department of National Defence / Canadian Armed Forces}

In the spectrum of national security, DND and the CAF are at the far right of the Venn diagram in their responsibility for the armed defence of Canada and Canadian interests. Established under the National Defence Act (NDA), the Department and the CAF are separate entities under the Minister of National Defence. Under the Deputy Minister, the department is responsible for policy, resources, interdepartmental coordination and international defence relations. The CAF is commanded by the Chief of the Defence Staff (CDS) who is responsible for all conduct of military personnel and for military advice to the government of Canada. The roles and missions of the CAF are established by Crown Prerogative ${ }^{552}$, a legal authority that has the capacity to significantly shape national security policy quickly.

\footnotetext{
${ }^{550}$ See Hickey, 2011, Annex B Examples Marine Security Scenarios, pp.413-418, for Canadian examples of the complexity of various marine security scenarios.

${ }^{551}$ NSP, 2004, p. vii.

${ }^{552}$ For a substantive summary see Philippe Lagassé, "Parliamentary and judicial ambivalence toward executive prerogative powers in Canada", Canadian Public Administration, Vol 55, No.2, 2012: 157+. Academic OneFile, Web. 27 June 2015, p. 5-6.
} 
In terms of the MSOC, the established capabilities of the CAF made it the logical choice to be project lead in developing the MSOC facilities on behalf of, and in consultation with, the partner departments. Tasked with coordination of on-water responses to threats or emerging crises within the Exclusive Economic Zone and along the coastlines, the government was leveraging the Royal Canadian Navy's (RCN) expertise and experience as a principal stakeholder in the marine security domain. Already closely working with the US Navy (USN) and US Coast Guard (USCG) in producing a continental RMP, the RCN has access to critical information and available maritime platforms to meet the goals stated in the National Security Policy statement. However, the RCN's culture as an "aggressive militaristic force ... searching for a new identity by working with other government departments" ${ }^{553}$ (OGDs) created both material and ideational challenges.

In a proactive manner (aggressive being a relative term), the RCN attempted to conduct interagency maritime security patrols in September 2005 with enforcement officers from the RCMP, CCG, and TC, embarking on a navy frigate as per the first marine directive in the National Security Policy statement of increasing on-water presence. Although these security patrols were deemed to be in the national interest and in accordance with government policy, a Judge Advocate General (JAG) ${ }^{554}$ opinion

\footnotetext{
553 Allan English, Understanding Military Culture: A Canadian Perspective, Montreal: McGill-Queen's University Press, 2004, pp. 92-93.

${ }^{554}$ The JAG is a separate legal institution that acts as the legal advisor to the Governor General, the Minister of National Defence (the Minister), the Department of National Defence (DND) and the CAF in all matters relating to military law. In support of the Canadian Armed Forces and the Department of National Defence, the Office of the Judge Advocate General delivers independent, operationally focused, solution oriented legal advice and services across the full spectrum of military law, and superintends the administration of military justice. - See http://www.forces.gc.ca/en/about-org-structure/judge-advocategeneral.page
} 
indicated that such patrols did not meet the second criteria under section $273.6(2)^{555}$

(Law Enforcement Assistance) of the NDA. The opinion offered that the standing

requests from the respective Ministers were not in response to a specific matter, but were

anticipatory in nature, which

creates the perception that the $\mathrm{CF}$ will become actively engaged in routine law enforcement as opposed to remaining an available capability to assist law enforcement authorities in situations where there is a genuine need to ensure those authorities are able to effectively deal with circumstances that might otherwise overwhelm them. ${ }^{556}$

In addition, the opinion expressed doubt as to the legislative authorities for the $\mathrm{CF}$,

RCMP, or CCG to conduct such security activities outside the responsibilities of their

respective legislated mandates. ${ }^{557}$ This incident stands as an example of the legal

challenges faced by the MSOC stakeholders as the project stood-up two months later.

\subsubsection{Canadian Coast Guard / Department of Fisheries and Oceans}

The only other department with substantive marine assets is DFO. In 1995 the CCG was placed under DFO to consolidate the government civilian fleet and eventually became an internal 'special operating agency' in 2005. Under the Oceans Act and the Canada Shipping Act, the CCG is responsible for "services and programs that contribute

555 National Defence Act, Article 273.6 (2), found online http://laws-lois.justice.gc.ca/eng/acts/n-5/page137.html\#h-221, "The Governor in Council, or the Minister on the request of the Minister of Public Safety and Emergency Preparedness or any other Minister, may issue directions authorizing the Canadian Forces to provide assistance in respect of any law enforcement matter if the Governor in Council or the Minister, as the case may be, considers that

(a) the assistance is in the national interest; and

(b) the matter cannot be effectively dealt with except with the assistance of the Canadian Forces

556 Office of the Judge Advocate General, "Analysis of DFO Request For CF Assistance During Proposed Maritime Security Patrols", 1459-13-36 (D/ Law Ops 2-2), 6 September 2005, para 7, found in LCdr Paul Gravel, "The Canadian Forces and Interdepartmental Cooperation Towards Domestic Security: Tear Down These Walls!", Canadian Forces College Exercise New Horizons, 2009 found online 10 September 2015 at http://www.cfc.forces.gc.ca/259/290/295/287/gravel.pdf .

${ }^{557}$ Ibid, para 10. 
to the safety, security, and accessibility of Canada's waterways." 558 Surprisingly to many, the CCG's mandate is not to 'guard the coast', but is located on the safety end of the spectrum of national security. Although a professional, highly capable and cost effective civilian organization, the CCG is not authorized, nor equipped and trained, in the use-offorce as part of its mandate. ${ }^{559}$ The only instance where use-of-force by CCG personnel may occur is in their capacity as Fisheries Officers, where one lightly equipped Armed Boarding Team may be employed in offshore fishery enforcement on the Grand Banks. Otherwise, the CCG plays a supporting role by embarking law enforcement officers onboard CCG vessels such as in the joint CCG-RCMP Marine Security Enforcement Teams (MSET) used in the Great Lakes - St. Lawrence Seaway (GL-SLS) area.

In the post 9/11vulnerability assessment, it was recognized that effective marine security involved sufficient enforcement vessels afloat to conduct operations between two vast coastal territorial waters and the GL-SLS system. A reformed, paramilitary CCG option, as recommended by SCONSAD amongst others, was considered by the Cabinet Committee on Public Security and Anti-terrorism to have merit but was rejected on a number of grounds. ${ }^{560}$ The foremost reason was that the current system of embarking enforcement officers onboard CCG and RCN ships was pragmatic and cost-effective. To

\footnotetext{
${ }^{558}$ Canada, Canadian Coast Guard official website, "Who We Are" and "Mandate \& Organizational Values", accessed on 15 September 2015 at http://www.ccg-gcc.gc.ca/eng/CCG/Who_We_Are . The Oceans Act gives the Minister of Fisheries and Oceans responsibility for providing: aids to navigation; marine communications and traffic management services; icebreaking and ice-management services; channel maintenance; marine search and rescue; marine pollution response; and support of other government departments, boards and agencies by providing ships, aircraft and other services. The Canada Shipping Act gives the Minister powers, responsibilities and obligations concerning: aids to navigation; Sable Island; search and rescue; pollution response; and vessel traffic services.

${ }^{559}$ Fisheries and Oceans Canada / Canadian Coast Guard, Canadian Coast Guard: Maritime Security, Handout Package, 2010. See "Key Considerations" in CCG: Maritime Security Framework booklet, pp 5-7 for the $\mathrm{DFO} / \mathrm{CCG}$ explanation on their role in the national security framework.

${ }^{560}$ Information gathered during confidential interviews.
} 
transform the CCG would require complete recapitalization of the historically

underfunded unit, re-engaging personnel under new terms, retraining them in the use-offorce and, significantly, establishing a new legal mandate to authorize such a force. The costs for this increment of security, in terms of Wolfers' specifications, simply could not be justified, both materially and ideationally.

Although the CCG's role remained centred on regulatory and safety aspects of national security ${ }^{561}$, the CCG contributes significantly to the MSOC's mandate through the information it can contribute. Data from the Automated Identification System, Long Range Identification and Tracking system, marine radars, and the CCG vessel tracking management systems ${ }^{562}$ provide critical information on all known civilian vessels necessary to produce the NMP. The biggest gap in situational awareness is the plethora of pleasure craft that operate in both coastal and internal waterways, presenting significant challenges. The one unique capability that DFO/CCG brings to the MSOC is in the area of human intelligence (HUMINT). DFO and CCG personnel have a significant presence on-shore or close-to-shore, networking with locals and smaller craft every day, which provides an investigative as well as predictive capability. DFO and CCG officials explained during interviews that the lack of progress in meeting the MSOC project

\footnotetext{
${ }^{561}$ In a number of different interviews, it was evident that authorities viewed CCG/DFO as an integral part of the national security structure even though they emphasized that the CCG was a civilian safety organization. The interviewees linked the safety and information aspects of the CCG operations to secure knowledge of system integrity and vessel movements needed during times of uncertainty and crisis.

562 Data on information on vessels outside $1000 \mathrm{~km}$ from the Canadian coast from TC as well as information received from industry under the Canadian Coast Guard Marine Communications and Traffic Service (MCTS) is included in the CCG Common Operating Picture.
} 
mandate quickly was due to the lack of program authority, expressly in areas of governance and information-sharing. ${ }^{563}$

\subsubsection{Transport Canada}

At the centre of Chapter 6 in the National Security Policy statement is Transport Canada, whose Minister has lead responsibility for marine safety and security policy coordination and regulation. Responsible for the promotion of safe and secure land, sea and air transportation systems, TC has a broad mandate that encompasses $60+$ Acts of Parliament, of which over 27 apply to marine transportation. At the safety end of the spectrum of national security, TC views its role as safety and security management that identifies, prevents or reduces risks and threats before they occur. Referring specifically to security, "Transport Canada develops and enforces security regulations, and works with national and international partners to prevent and manage security risks ... by developing security regulations for ... marine security... and taking action and working with partners in the event of threats." 564

Within the MSOC, TC personnel share information obtained from the TC Situation Centre and the respective TC Regions regarding vessels on international voyages, domestic ferries, foreign vessels in Canadian waters and Canadian port facilities. TC personnel also ensure regulatory compliance and provide advice on vessel compliance with the Marine Transportation Security Act. As chair of IMSWG, TC had a vested interest in finding policy solutions among the 17 members that fit the five MSOC stakeholder requirements. During interviews carried out for this thesis, evidence of

\footnotetext{
${ }^{563}$ In confidential interviews, DFO and CCG officials stated that DoJ assessed the level of risk in information-sharing without an express legal mandate as $80-85 \%$.

${ }^{564}$ Canada, Transport Canada website, "What We Do," accessed on 15 September 2015 at https://www.tc.gc.ca/eng/aboutus-whatwedo.htm .
} 
cultural norms crept into conversations. At the safety end of the spectrum, TC, DFO and CCG officials all remarked that "the system works because the marine community in Canada is so small." ${ }^{565}$ Although the RCMP and DND officials acknowledged this as an advantage, they emphasized the need for reliance on a robust, fail-safe marine security system. The concept of security also tended to be somewhat elastic among departments, because TC includes environmental, health threats and over-fishing in Canadian waters as security threats, ${ }^{566}$ illustrating Buzan's argument for widening the concept of national security.

\subsubsection{Canada Border Services Agency}

Created in 2003, CBSA operates principally under the 2005 Canada Border Services Agency Act and the Customs Act, while also administering over 90 Acts, regulations and international agreements. The Agency is responsible for providing integrated border services that support national security and public safety priorities and facilitating the free flow of persons and goods which meet all requirements under the program legislation. As CBSA carries out key marine operations at major ports as well as conducting lengthy, complex investigations of suspected war criminals, national security cases, and organized crime groups, it is a valuable source of information and intelligence,

\footnotetext{
${ }^{565}$ Confidential interviews conducted with DND, RCMP, DFO, CCG, and TC officials in March 2015. 566 "The MSOCs provide Canadians with enhanced marine security and help detect, assess and support a response to any threat to marine security that could affect the safety, security, environment or economy of Canada. Threats could include emerging terrorist activity, trans-national crime, environmental and health threats, and over-fishing in Canadian waters by other countries." Found online on the Transport Canada website under "Operations" at https://www.tc.gc.ca/eng/marinesecurity/operations-menu-56.htm accessed on 16 September 2015.
} 
especially with its strong world-wide partnerships with law enforcement and intelligence agencies. $^{567}$

It is this linkage in the provision of intelligence from local CBSA HUMINT sources to global networks that benefits the MSOC's analysis function most and in turn provides mutually beneficial marine security information back to CBSA. Even minor pieces of information provided by partners can be important, as "each addition of information makes situational awareness go up exponentially."568 As a subordinate agency to Public Safety Canada, it is a key element at the centre of the national security spectrum through its law enforcement, intelligence and border surveillance roles. The amalgamation of the three operational cultures from CCRA, CIC, and CFIA resulted in transitional challenges as CBSA was still establishing its own integrated identity during the formative period of the MSOC project. Although eventually resolved, this evolution contributed to the challenges faced by IMSWG in resolving governance and informationsharing issues. ${ }^{569}$

\subsubsection{Royal Canadian Mounted Police}

As an agency within Public Safety Canada, the RCMP is the national police force that provides police services federally, as well as provincially in eight provinces, under The Royal Canadian Mounted Police Act. Its broad mandate is central to the spectrum of national security through "preventing and investigating crime; maintaining peace and order; enforcing laws; contributing to national security; ensuring the safety of officials,

\footnotetext{
567 See CBSA website, “About US: Our Work” accessed online 16 September 2015 at http://www.cbsaasfc.gc.ca/agency-agence/what-quoi-eng.html .

${ }_{568}$ Quote from a senior MSOC officer when explaining the value added by MSOC partners when fitting pieces of the puzzle together in both predictive analysis and during unfolding security events.

${ }^{569}$ Confidential interview.
} 
visiting dignitaries and foreign missions; and providing vital operational support services to other police and law enforcement agencies within Canada and abroad." ${ }^{, 570}$ Although the RCMP is a central agency in the national security complex, it is interesting that 'national security' is never mentioned in the RCMP Act. The RCMP's 'contribution' is in fulfilling its law enforcement and constabulary duties while selectively supporting other security stakeholders with information without prejudicing investigative integrity required by the judicial system.

The RCMP has extensive experience working bilaterally with the other MSOC stakeholders, playing a critical role as the principal agency with legal jurisdiction over domestic law enforcement and criminal investigations. Specifically, the RCMP targets organized crime and other illicit activities surrounding illegal drugs, smuggling, and people-trafficking that may make use of seaports, coastlines, waterways and marine borders as a conduit for criminal or terrorist activities. ${ }^{571}$ To overcome the CCG's lack of legal jurisdiction as peace officers, RCMP officers embark on vessels supplied by the RCN, CCG, and US Coast Guard ${ }^{572}$ providing the agency with a holistic appreciation of

\footnotetext{
${ }^{570}$ A summary of section 18 of The Royal Canadian Mounted Police Act found online 16 September 2015at the RCMP website "About the RCMP", http://www.rcmp-grc.gc.ca/about-ausujet/index-eng.htm

${ }^{571}$ Royal Canadian Mounted Police, Report on Plans and Priorities 2013-2014, Government of Canada, 26 July 2013; pp. 18-21 located online on 16 September 2015 at http://www.rcmp-grc.gc.ca/rpp/20132014/RCMP_RPP 2013 Web_eng.pdf

572 The Integrated Cross-Border Maritime Law Enforcement Operations, also known as Shiprider, is a binational initiative between the Royal Canadian Mounted Police (RCMP) and the United States Coast Guard (USCG) that authorizes Canadian and United States (US) law enforcement officers work together to enforce the law on both sides of the shared border in shared waters. More information can be found at http://www.publicsafety.gc.ca/cnt/rsrcs/pblctns/frmwrk-grmnt-ntgrtd-crss-brdr/index-eng.aspx ; Additionally, the RCMP interfaces with both CBSA and the USCG through the "Integrated Border Enforcement Teams (IBETs) - IBETs enhance border integrity and security between designated ports of entry along the U.S.-Canada border by identifying, investigating, and interdicting persons, organizations, and goods that threaten the national security of one or both countries or that are involved in organized criminal activity. The five core IBET agencies are: RCMP; the Canada Border Services Agency (CBSA); U.S. Customs and Border Protection (CBP); U.S. Immigration and Customs Enforcement (ICE); and the USCG."
} 
the marine security system that it brings to the MSOC team. Thus, the MSOCs benefit from both the operational experience and the significant intelligence network that the RCMP possesses in detecting, deterring, and defeating marine threats.

\subsection{Confluence of Factors}

The five years between 2005 and 2010 was a period of significant flux for the MSOC project, as direction from government was limited under two Prime Ministers and three successive minority parliaments ${ }^{573}$, the MSOC stakeholders grappled with mandates and governance structures, and legal opinions on information-sharing varied, causing departmental/ agency anxiety. Adding to the unfolding question of Canadian security identity and establishing the balance between individual and state rights, the Privacy Commissioner issued a comprehensive document identifying the need to reform the federal Privacy Act in 2006. Then, in 2008, the Commissioner added an addendum regarding "National Security Issues" "based on the events of the last two years"574, specifically highlighting the Arar and Air India Commissions. In this period of political uncertainty, when non-critical contentious public policy issues were being avoided by minority governments ${ }^{575}$, the ideational questions central to the reformation of the

\footnotetext{
573 This is an example of a period in time where society has maximum agency in determining policy outcomes as political elites are conscious of public opinion and sensitive to the vagaries of the political process in their contestation for power.

${ }^{574}$ Privacy Commissioner of Canada, Addendum to Government Accountability for Personal Information: Reforming the Privacy Act, April 2008, p. 10; Also see the Auditor General of Canada, 2009 Status Report, para 1.53 that explains the RCMP decision to terminate an information-sharing MOU with TC due to Ministerial directives and the O'Conner Commission Report; The Privacy Commissioner also added another Special Report to Parliament on Cyber-Surveillance on January 28, 2014, Special Report to Parliament, Checks and Controls: Reinforcing Privacy Protection and Oversight for the Canadian Intelligence Community in an Era of Cyber-Security that suggested oversight mechanisms.

${ }^{575}$ Rand Dyck, Canadian Politics: Critical Approaches, $6^{\text {th }}$ edition, Toronto: Nelson Education, 2011, pp. 460-463.
} 
national security system (mandates, governance, and information-sharing) were left unresolved.

At the operational level, the RCN established the interim MSOCs with the understanding that they would be "living laboratories" where progress would be evolutionary as policy issues were resolved. The important first step was to shift cultural paradigms by bringing all stakeholders into one facility, where institutional barriers would be eroded through collaboration, cooperation and understanding of the 'other' ${ }^{576}$ Progress was slow and iterative as each partner had a different interpretation and vision of the project and their role in it. Fundamental questions of the operational mandate identified in the National Security Policy statement were questioned on practical as well as ideational grounds. Common sense functions involved in building a common operating picture in the MSOC became complex and dysfunctional as government officials (principally with DoJ input) ${ }^{577}$ questioned legalities. As one frustrated operator said, "I can't even use the publicly available information from Lloyd's of London to place the name of a ship's captain beside the vessels name because I am told that it is a contravention of the Privacy Act because as a naval officer, the information I 'collect' cannot be shared with OGDs." 578

\footnotetext{
576 This observation was expressed in many interviews and can also be found at Tim Dunne, "Guardians of the Gateways: Maritime Security Operations Centre”, FrontLine Security, Vol.6, No.2 , Summer 2011; "Interim MSOCs facilitate collaborative information sharing environmental among the 5 federal partners through the collocation of agency / departmental personnel supported by various agency/departmental business process and information technology infrastructure." Public Works and Government Services Canada, Marine Security Operations Centres: Governance Study, September 2008.

577 As the DoJ provides legal advice to the Government and federal government departments and agencies in three distinctive roles, it became evident through the AG reports and literature review that DoJ played a central role in providing legal advice and opinions on the many facets of the MSOC question. See the DoJ website for greater detail http://justice.gc.ca/eng/abt-apd/index.html

${ }^{578}$ Confidential interview conducted March 2015. Note that his comment is based on the "consistency of use" provision in the Privacy Act that requires that information be used only for the purpose for which it was collected.
} 
Fundamental cultural differences in both structure and agency needed to be understood and overcome. Challenges in identifying paths and processes for information flow and decision-making stemmed in part from the fact that DND and CCG had hierarchical organizations, TC and the RCMP were regionally oriented and CBSA's organization was changing regularly. These structural differences were not merely organizing principles, but a reflection of the cultures that the respective department/ agency mandates inculcate. The security norms of safety institutions that create policy and ensure regulatory compliance differ significantly from the security norms of operational institutions whose responsibilities are action based. "From the missionoriented military officer's perspective, the civil servant is more concerned about consensus-building than actually getting the job done. Thus, the differences in public service and military cultures become apparent in the day-to-day interchange and liaison." 579

While the partners assigned to the MSOCs gradually built a NMP using nonclassified and uncontroversial information, the IMSWG met regularly to attempt to resolve the "complex web of responsibilities, jurisdictions and activities" of the marine security system, making some progress in meeting transactional goals ${ }^{580}$. However, as foreshadowed by SCONSAD, IMSWG was unable to resolve critical issues of governance and information-sharing as mandates, legalities, and lack of a clear vision stalled substantive progress on the MSOC project. Basic disagreement over the role of the

\footnotetext{
${ }^{579}$ Hickey, 2011, p 187; Hickey also gives a detailed account of one public servant's view that the military concept of 'command and control' gave her the impression that the military wanted to control all aspects without input from the other stakeholders, much like controlling a remote control toy aircraft or car. ${ }^{580}$ Laureen Kinney, “Canada's Marine Security”, Canadian Naval Review, Vol 4, No 4, Winter 2009. Note: Laureen Kinney was Director General of Marine Security at Transport Canada and Chairperson of IMSWG at the time of writing.
} 
MSOCs was elevated to the ADM Marine Security Committee (MSC) in April 2008, where the majority perspective was that the MSOCs were not operational centres and would not be given tasking authorities. ${ }^{581}$

In an effort to resolve disagreements over governance issues, DND engaged Public Works and Government Services Canada (PWGSC) to review and make recommendations on a governance structure for the MSOCs. The report concluded that the current ad hoc governance structure did not "adequately address core policy issues of concern to the partners, which, in turn, has led to compromised decision-making... [and] .. to a dilution of accountability." 582 The report proposed a governance structure that would fall under the "Management Authority" of Public Safety Canada as chair of a senior MSOC governance committee, with the MSOCs being accountable to the ADM MSC. Of greatest significance, the report stated that the issue of the MSOC's original mandate as operations centres, able to task and coordinate operations, may need to go back to Cabinet if a common understanding of the mandate remained unresolved. ${ }^{583}$

The security norms demonstrated over this five year period were consistent with Canadian National Security Culture. The threat of terrorism was not perceived as an existential threat to Canada, but as another possible threat to acquired values in need of state protection; in this case, to the security of the marine transportation system. When the Deputy Minister of Transport stated that "security is a journey, not a destination" 584 in

\footnotetext{
${ }^{581}$ Government Consulting Services, Marine Security Operations Centres: Governance Study, Public Works and Government Services Canada, 30 September 2008, p. 2.

${ }^{582}$ Ibid, pp. 13-14.

583 Ibid, p. 26.

584 Evidence given by Louis Ranger, Deputy Minister of Transport, Infrastructure and Communities in Proceedings of the Standing Senate Committee on National Security and Defence Issue 4 - Evidence, June
} 
testimony before SCONSAD, he was acknowledging the trade-offs required in balancing acquired values in the pursuit of security. TC chose pragmatic solutions through risk management in all transportation security policies and programs with an "overarching objective ... [of]...respect for privacy and the Charter of Rights and Freedoms. ${ }^{9585}$ In other words, state protection of the marine security system was in tension with protection of Charter and Privacy rights. TC, as IMSWG policy lead, preferred to resolve this tension through methodical application of the 'rules of the game', which contrasted with DND's cultural view as delaying the intent of the National Security Policy statement.

The 2009 Auditor General's Status Report stated "the government has fallen short on its National Security Policy vision for the new Marine Security Operations Centres (MSOCs)", in that they were not operations centres but limited analysis centres due to legal constraints over information-sharing and the lack of a single department with operational authority. ${ }^{586}$ The AG’s Status Report validated concerns raised by SCONSAD, and implied in the AG's 2004 report, about Canadian National Security Culture norms. Once the initial crisis following the 9/11 attacks had been addressed, national security became another acquired value to be weighed against other values for

19, 2006, found online on 20 Sept 2015 at http://www.parl.gc.ca/Content/SEN/Committee/391/defe/04evae.htm?Language=E\&Parl=39\&Ses=1\&comm $\mathrm{id}=76$, "Security is a journey, not a destination. " ...."We must balance security with efficiency and the rights of Canadians, starting with privacy rights."

${ }^{585}$ Ibid." Finally, respect for privacy and the Charter of Rights and Freedoms is another overarching objective in developing policies and programs for transportation security."; "Risk assessments guided our early decisions after September 11; it guided our subsequent choices in the marine sector and it is the foundation of the work now under way to consider how best to enhance security in rail and urban transit sectors. Adopting a risk management approach will always be controversial. We know that we cannot eliminate risks. Even with the best intelligence and the best analysis, we may still get it wrong in terms of deciding which areas are of highest and most immediate risk, and critics will always be able to find what they consider gaps in defences."; "The list of transportation attack scenarios is endless, and so too is the list of potential vulnerabilities. We could reduce the risk to zero but on that day, no goods or passengers would move. That is probably true also for safety. We could divert the entire budget of Transport Canada and still have no guarantee of protection from attacks."

${ }^{586}$ Auditor General of Canada, 2009 Status Report, para 1.31. 
attention and funding. The government had relegated key national security impediments to the bureaucracy to address. This in turn followed established institutional norms when dealing with security issues of forming ad hoc committees to build consensus between departmental stovepipes. ${ }^{587}$ As anticipated by SCONSAD, IMSWG was unable to develop substantive marine security policy without the direct interest of the Prime Minister.

Although the AG's report stated that DoJ was working with IMSWG to "identify potential barriers to information sharing and their possible resolution... within the MSOCs," 588 there was not much progress by 2010 . The essential problem lay in the fact that, from a policy perspective, the governance and information-sharing issues were directly linked to the legal issues pertaining to the MSOCs, which were limited and constrained by stakeholder mandates. Without a single Minister responsible and accountable for horizontal integration of the national security strategy, these marine security policy issues were incommensurable due to ideational positions based on departmental identity, institutional culture and interests.

\subsection{Resolution of Key Impediments}

The central question around which all other matters revolved in establishing the MSOCs was one of Canadian identity and the construction of the national security complex that protects that identity. The WoG concept envisioned in the National Security Policy statement that horizontally integrated the national security functions of established institutions required reassessment of foundational principles on which the security

\footnotetext{
${ }^{587}$ Para 3.77 in the AG's 2004 report specifically identified the need to address 'information 'stovepipes'... [as] these barriers could prevent the timely recognition of threats to Canada and delay its response to terrorists or other emergencies, or to make its response less effective."

${ }^{588}$ Ibid, para 1.44 .
} 
complex was based. Should the $N D A$ be amended to permit the CAF to engage directly in law enforcement activities in areas of jurisdictional overlap, or should the CCG be reconstructed from a safety organization to a paramilitary law enforcement agency? Does the perceived threat warrant changes to the Privacy Act to permit the necessary flow of information so the national security complex can protect "core Canadian values", or is the Privacy Act emblematic of the core values national security is designed to protect? What is the proper balance of rights between security rights of the individual versus security rights of the Canadian collective?

Addressing these fundamental questions of Canadian identity were avoided when the IMSWG partners determined a workable solution for the MSOC 'operations centre' mandate dilemma by reformulating the MSOC into an 'intelligence coordination centre' collocated with the CAF's Regional Joint Operations Centre (RJOC). Thus, the rationale for establishing the MSOCs by providing decision-makers with better situational awareness through data fusion and joint analysis while enhancing interagency cooperation was met, albeit in a separate room under a separate governance framework. Although this solution did not meet the 'letter of intent' in collocating decision-making powers with marine domain awareness correlation centres, it allowed the MSOCs to become marginally operational within the existing legal mandates of the partners. However, for other issues, there were no bureaucratic 'workarounds' like this as deeper issues required resolution within the polity.

\subsubsection{Mandates}

In the Westminster system of government, legislation sets out the mandates of departments and agencies, contributes to the definition of national security within the 
mandate through articulation of specific offences, and places limits on the establishment's latitude of action. By placing legitimate boundaries around national security activities, Ministers and actors can be held to account to ensure that securityoriented actions remain consistent with Canadian laws and values, and that prescribed resources are used for their intended purpose. Mandates establish departmental/agency identity, mould institutional culture and shape actor interests. As national security was not a central function and represented only one aspect in each department's mandate, anomalies in established legal frameworks under their mandates prevented marine security partners from sharing information and resolving governance issues.

The problem of WoG horizontal integration in the case of the MSOCs was legally complex and multifaceted. The legal instruments available to address deficiencies of this nature were limited to memorandums of understanding (MOUs) between actors, Orders in Council (OICs) under the Crown Prerogative, modifying legislated mandates, or introducing new stand-alone legislation. Each instrument had their pros and cons that were culturally or institutionally favoured by various stakeholders.

The National Defence Act only allows the CAF to play a supporting role in the conduct of certain national security tasks, such that a navy vessel discovering a violation of Canadian law while conducting a defence mission cannot act on its own recognizance without an appropriate law enforcement officer onboard. Significantly, the CAF has no mandate for 'national security' outside of providing 'aid of the civil power' on a case-bycase basis and its defence duties are purposely separated from its Law Enforcement 
Assistance obligations. ${ }^{589}$ The questions that first surfaced with respect to the National Security Policy statement were whether the MSOCs fell within the defence mandate and whether DND/CAF had legal authority to participate, lead, and work with OGDs through the MSOCs. Notionally the purpose of the MSOCs was to assist in the protection of Canada's coastlines, and although terrorism fell within the jurisdiction of the RCMP, defence against an armed attack on Canada was deemed by the JAG to be part of CAFs mandate. Therefore, the MSOCs fell within its mandate. The second question was more problematic as legal interpretations were contested between the JAG and DoJ legal staffs. ${ }^{590}$

DND/CAF activities are authorized under two legal instruments: the $N D A$ and/or the exercise of the Crown's Prerogative. ${ }^{591}$ Based on a Record of Decision from Cabinet approving the MSOC as identified in the National Security Policy statement, DND/CAF's position was that the Crown Prerogative provided the legal authority to lead

\footnotetext{
${ }^{589}$ One senior official explained the difference between defence and security as simply, a maritime incident involving Canada and another actor subject to the Law of Armed Conflict and associated with the Geneva and Hague Conventions is a defence matter. All other maritime incidents are security issue, and the mandate of various other government departments depending on the nature of the incident.

${ }^{590}$ Although specific legal advice and opinions are not available due to solicitor-client privilege, it is evident that the "legal and legislative" differences were the result of contestation over the best approach to overcoming legal issues. As the JAG represents DND/CAF in providing operational advice and DoJ represents the interest of the government and other federal departments, it was logical to assume these were the two institutions contesting the best way forward. This deduction was confirmed during confidential interviews. See Gravel, 2009; LCdr James Salt, "The Whole-of-Government Approach to Maritime Information Sharing- Reality or Fiction?”, Canadian Forces College Exercise New Horizons, JCSP 34, found online 10 September 2015 at http://www.cfc.forces.gc.ca/259/290/294/287/salt.pdf ; LCdr B. Henry, "The Whole of Government Approach Applied to Canadian National Security", Canadian Forces College Exercise New Horizons, JCSP 34, found online 10 September 2015 at http://www.cfc.forces.gc.ca/259/290/294/286/henry.pdf.

591 The Crown or Royal Prerogative is the residual authority of the Crown that remains from the period when the monarch's rule was almost absolute. These are generally unwritten powers based on custom and convention that theoretically reside in the Queen and her representative, the Governor General, but are in fact exercised by the Prime Minister and Cabinet through advice to the Governor General by the government. See Dyck, 2011, pp 548-551.
} 
the MSOCs. ${ }^{592}$ DoJ challenged this interpretation based on OGD domestic mandates and that the Crown Prerogative related to defence of Canada and not to domestic security. ${ }^{593}$ In this respect the basic premise of the MSOCs became problematic as DND/CAF also maintained the common data base of vessel traffic information in the RMP with information supplied by TC, DFO/CCG, and the USCG. Due to restricted mandates for information-sharing, MSOC partners only had access to the unclassified, partially populated RMP, which meant that without clear legal authorities the MSOCs would be unable to reach their full and intended potential of providing a NMP and ultimately MDA.

There were also legal concerns that, although DFO/CCG routinely contribute to the security of Canada in various ways, the vessel tracking information provided to the MSOCs may lead to risks in sharing "personal information" under the Privacy Act as there is no explicit mandate for participation in national or maritime security in the Department of Fisheries and Oceans Act. As well, the Customs Act under which CBSA operated was even more restrictive in stating that "Except as authorized under this section [107], no person shall: (a) knowingly provide, or allow to be provided, to any person any customs information." ${ }^{, 594}$ Given the absence of explicit information-sharing authority for national security purposes, CBSA was also exposed to legal risks making the goal of MSOC MDA even more difficult to achieve.

\footnotetext{
592 See Military Law, "Introduction and the Crown Prerogative”, online at http:/www.forces.gc.ca/en/about-reports-pubs-military-law-strategic-legal-paper/crown-prerogativeintroduction.page

593 The basics of the issue as explained in a confidential interview.

594 See Gravel, 2009, pp. 17-18; Canada, Customs Act, Section 107 (2), Minister of Justice, current to September 10, 2015, accessed on 22 September 2015 at http://laws-lois.justice.gc.ca/PDF/C-52.6.pdf
} 


\subsubsection{Information-sharing}

The Canadian legal framework, constructed during a time before ubiquitous interconnectivity, resulted in a legislative patchwork that was hindering MSOC operational efficiency and effectiveness in the digital age. Privacy laws, Charter considerations, third party legal constraints and incompatible legal mandates all contributed to the information-sharing enigma. The complexity of the legal landscape made it difficult for operators to determine the circumstances where information could be shared, leading to cautious interpretations on a case-by-case basis or worse, not providing information at all. ${ }^{595}$ Without clear lawful authority, each MSOC partner needed to assess whether the information they provided may attract a privacy concern and/or infringe on Charter rights.

Although the Charter does not directly mention the concept of privacy, the courts have interpreted Section 8 of the Charter as guaranteeing Canadian citizens the reasonable expectation of privacy. In 1983 the federal Privacy Act was passed, regulating how the federal government collects, uses, and discloses personal information as well as providing means for accessing such information. As introduction of the Charter had the notable effect of creating a more engaged judiciary by granting new powers ${ }^{596}$, it is evident that the approach chosen in resolving mandate and information-sharing issues was one of minimum risk to potential Charter and Privacy Act challenges to reasonable

\footnotetext{
595 See AG's 2004 and 2009 reports.

596 The Supreme Court of Canada has often been accused of judicial activism by those opposed to its rulings under the Charter. See James B Kelly, Governing with the Charter: Legislative and Judicial Activism and Framers' Intent. Vancouver: UBC Press, 2005; and Rory Leishman, Against Judicial Activism: The Decline of Freedom And Democracy in Canada, Montreal: McGill-Queen's University Press, 2006.
} 
lawful authority and expectations of privacy. ${ }^{597}$ The decision to avoid using the Crown Prerogative to solve the problems was only one example of this risk avoidance strategy. ${ }^{598}$ In the end, the ADM Marine Security Committee determined that stand-alone legislation was needed ${ }^{599}$ as opening established Acts of Parliament was complex and challenging whereas stand-alone legislation was the cleanest approach to solve the mandate and information-sharing problems.

Using the security of the Vancouver Winter Olympics as a forcing function and to avoid the uncoordinated response to marine security events experienced in the $2008 \mathrm{RV}$ Farley Mowat incident ${ }^{600}$, an interim solution that allowed the MSOCs to move forward was identified in 2010. There was frustration with those entrusted with the provision of security in the lack of progress as DoJ had yet to identify the ideal type of legislation it intended to propose. ${ }^{601}$ Contestation between using OICs or MOUs to bridge the gap resulted. OICs had the advantage of immediately limiting risk to allow operations to move ahead quickly, while MOUs provided greater risk reduction as they were more

\footnotetext{
${ }^{597}$ Charter right threshold issues revolve around the reasonable expectation of privacy within a free and democratic society a person would wish to maintain and control core personal information from the state. Information gathered by marine security agencies that might violate this expectation are photographs or videos where individuals may be identified, names aboard vessels, and, in the case of corporations, commercially sensitive information.

${ }^{598}$ For another view of the power of the Crown Prerogative see Philippe Lagassé, "Parliamentary and Judicial Ambivalence Toward Executive Prerogative Powers in Canada", Canadian Public Administration, Vol. 55, No. 2, 2012, pp. 157-180.

${ }^{599}$ See Finding 4 and Recommendation 2 in Department of Public Safety, Royal Canadian Mounted Police, "Horizontal Evaluation of the Great Lakes and St. Lawrence Seaway Marine Security Operations Centre", 10 April 2015, found online on 25 October 2015 at http://www.rcmp.gc.ca/aud-ver/reports-rapports/msoccosm-eng.htm\#fn34.

${ }^{600}$ The RV Farley Mowat incident of 2008 was used in multiple interviews to illustrate the lack of coordination between agencies due to failures in communication and information-sharing. As an example of the response to overlapping jurisdictions in marine security, TC and CCG went through the Government Operations Centre, the RCMP through their National Operations Centre and CAF through their National Defence Command Centre resulting in several different pictures and a lack of centralized decision-making. ${ }^{601}$ See Department of Public Safety, Royal Canadian Mounted Police, "Games Security and Public Safety for the Vancouver 2010 Olympic and Paralympic Games", found online on 25 October 2015 at http://www.rcmp-grc.gc.ca/aud-ver/reports-rapports/pp-gs-ps-eval-eng.htm ; Confidential interview conducted February 2014.
} 
detailed agreements negotiated between OGDs that ensured specific compliance with Canadian law but created long delays. Again, the decision by the ADM Marine Security Committee was to pursue an MOU for information-sharing while DoJ addressed a legislative way ahead. In the interim, the MSOCs had created firewalls within information systems to ensure operational risks were minimized, such as concerns with OGDs having access to military classified information and concerns with separation of security and law enforcement data for reasons of judicial due process. ${ }^{602}$

With the release of the Air India Inquiry Action Plan, the government authorized the development of legislation to address the impediments to national security information-sharing. This finally provided DoJ and the national security partners the formal authorization to determine options to best address a number of barriers to WoG information-sharing, including those of the MSOC. Although much had been discussed prior to this, the ideational questions of 'who we are' and 'how best to construct the security complex' began in earnest. Options that included a mixture of legislation and non-legislative measures were debated and refined within the bureaucracy with draft recommendations ready to be presented to government by 2012. However, resolution of WoG information-sharing for national security purposes was not significant enough to be moved forward by bureaucratic and political elites at that time. ${ }^{603}$

As is the norm with politics in liberal democracies, beyond the simple mechanics of choosing which proposed legislation takes precedent over other important pieces, timing of government announcements is critical in both shaping the discussion for

\footnotetext{
${ }^{602}$ See Gravel, 2009; RCMP, April 2015; RCMP October 2015.

${ }^{603}$ This narrative was gleaned from piecing together bits of information gathered over a number of confidential interviews.
} 
substantive debate of the issue and for political survival of the actors. This is a

particularly key consideration for Canadian Prime Ministers as security issues tend to be

divisive. The tragic deaths of military personnel due to 'terrorist acts' in October $2014^{604}$

provided the context for the government to move a number of legislative changes to the

national security apparatus forward and beyond the legacy political concerns raised by

the previously discussed commissions of inquiry and the more recent Snowden

revelations. ${ }^{605}$ In turning to the bureaucracy for ways to quickly demonstrate government

resolve, a number of changes that had been 'in the works' were pulled from the shelves

that allowed the government to introduce several pieces of security legislation

immediately. ${ }^{606}$

\footnotetext{
${ }^{604}$ A pair of CAF personnel was deliberately rammed by a car driven by an avowed domestic terrorist south of Montreal on 20 October 2014 that killed one member. Then on 22 October 2014, one soldier guarding the Ottawa War Memorial was shot and killed by another self-described terrorist who then proceeded to attack personnel in Centre Block of Parliament Hill. PM Harper labeled both incidents 'terrorist attacks' and proceeded to securitize the events as issues of national security.

${ }^{605}$ Many national security recommendations made by commissions over the years were politically divisive with little political gain for government resolution and were therefore left to wait by successive governments. The deaths in October 2014 provided the Harper Government with the pretext to move forward with an omnibus solution containing a number of controversial changes; Edward Snowden is an American computer professional who leaked classified information about global surveillance programs run by the US National Security Agency in close cooperation with Five Eyes partners (Australia, New Zealand, Canada, UK and US). These revelations precipitated heated debate on the rights of individuals to privacy from state intrusion to national security specialists who consider Snowden's actions traitorous in revealing sources of information used to protect state values; See White House, Liberty and Security in a Changing World: Report and Recommendations of The President's Review Group on Intelligence and Communications Technologies, 12 December 2013, found online 26 September 2015 at https://www.whitehouse.gov/sites/default/files/docs/2013-12-12 rg_final_report.pdf and Michael Geist, Law, Privacy, and Surveillance in Canada in the Post-Snowden Era, Ottawa: University of Ottawa Press, 2015.

${ }^{606}$ Bill C-44 was introduced shortly following the October murders and amended the Canadian Security Intelligence Service Act in two main ways. It authorized CSIS to conduct activities within and outside Canada, whether or not these activities comply with the laws of any foreign jurisdiction. Secondly, it adds in protection for "human sources" who share information with CSIS. The changes to the CSIS Act reflected recent restrictions introduced by both the Supreme Court of Canada and the Federal Court of Appeal on the ability of the government to engage in surveillance activities and limit rights under the Charter. The Bill also amended provisions in the Immigration and Refugee Protection Act, allowing the government to revoke the citizenship of dual citizens in certain circumstances. Bills C-13 and S-4 were in debate to tighten government supervision of the internet which some critics claimed the Supreme Court had already ruled were not allowed.
} 
Bill C-51, An Act to enact the Security of Canada Information Sharing Act and the Secure Air Travel Act, to amend the Criminal Code, the Canadian Security Intelligence Service Act and the Immigration and Refugee Protection Act and to make related and consequential amendments to other Acts, was an omnibus Bill that broadened the authority of government departments/agencies to share information within a new stand-alone Act. Rather than keeping the legislation simple, the government chose to package the needed information-sharing Bill with another stand-alone Act as well as amending three other pieces of legislation. By expanding the government's mandate to include the ability to disrupt terror plots by CSIS, allow the police to limit terrorist suspect movements and contain terror propaganda, expand the powers of the no-fly list, and remove the barriers to information-sharing for national security, the government sought a comprehensive reform package to enable security partners to communicate and discharge their duties at the seams of democracy. This, however, was not without its critics and detractors, pushing the limits of Canadian national security norms.

At SCONSAD hearings on Bill C-51, a wide range of witnesses expressed concern with the broad spectrum of powers that will enable government agencies to infringe on Canadians' Charter rights, such as targeting legitimate forms of activism and protest. Significantly, the government chose to ignore the oversight and review mechanisms that were central to both the Air India and Arar Commission recommendations. ${ }^{607}$ Although NSA Richard Fadden incorrectly addressed Justice

\footnotetext{
607 Proceedings of the Standing Senate Committee on National Security and Defence (SCONSAD), "National Security and Defence - The Subject Matter of Bill C-51", Issue No. 16, Forty-first Parliament Second Session, April 20/23/27, 2015. See specific testimony of Justice Major and Kent Roach, "The bill still ignores or contravenes major parts of the 2006 Arar commission recommendations, the 2010 recommendations of the Air India commission. .... This sort of broad information sharing and compilation
} 
Major's concerns about review mechanisms, indicating that PCO had evolved into "something fairly close to what Mr. Major was suggesting" ${ }^{908}$, he understood the ideational need for the information-sharing legislation in order to effect substantive change.

I think this is very necessary because, as you'll all know from having had people from various departments and agencies in front of you, all of these agencies develop their own culture, their ways of doing things, and it's not that easy to share all the time. I think, aside from anything else, the sharing of information act is meant to send a signal to the public service that, absent a prohibition, which this act does not change except for those three or four examples, we encourage you to share information for national security purposes. ${ }^{609}$

Contestation over Canadian security identity will continue within society and polity as Bill C-51 was a singular polarizing issue for the political parties engaged in the 2015 federal election ${ }^{610}$ and will undoubtedly attract Charter challenges. However, authorization for necessary information-sharing is currently in place, finally providing the institutional structure necessary to implement the ideas expressed in the National Security Policy statement and allowing the MSOCs to reach maturity.

of big data files must at least be matched by commensurate independent review as the Arar commission recommended. We also note that the new information sharing act does not include the Air India commission's recommendation for mandatory information sharing subject to enhanced oversight by the Prime Minister's National Security Advisor. We note that a Senate committee chaired by Senator Segal echoed this recommendation in 2011." (Roach)

${ }^{608}$ SCONSAD, 27-4-2015 16:139, "I think it's fair to say I have virtually no power; I have a fair bit of influence on the national security front. The other thing I do have is if I think there's a real problem, I have access to the Prime Minister and ministers. So I think Mr. Major was thinking of something with a bit more oomph in it in the sense that he wanted it to be based in statute and be given specific powers. Again, that's a matter for government and Parliament to decide, but I think both my predecessors and I have sort of evolved to something fairly close to what Mr. Major was suggesting."

${ }^{609}$ Ibid, 27-4-2015 16:134

${ }^{610}$ The Liberal party supported the Bill with the caveat that they would amend the legislation when elected. The Justin Trudeau Government is presently in power and although amendments have yet to be announced, it is not anticipated that the information-sharing Bill will see substantive changes. 


\subsubsection{Governance}

What NSA Fadden failed to realize, or chose to ignore, was that Justice Major was speaking about horizontal leadership and accountability. Although Fadden articulated a nuanced distinction between the terms 'oversight' and 'review' with respect to accountability structures ${ }^{611}$, he failed to address Major's and SCONSAD's concerns that horizontal responsibility and accountability for national security rested ultimately with the Prime Minister. Although there are some established review committees, they are insufficient to meet the needs of an integrated security complex according to Major, O’Connor, and SCONSAD. Westminster governance structures in Canada are part of Canadian identity and highly resistant to change, even in the aftermath of $9 / 11$ and the highly touted need for a WoG approach. Fadden's response to SCONSAD questions clearly indicated that change to the national security complex would continue to be evolutionary and unlikely to change in the near future.

Although the MSOC governance issues are minor in the global sense, they represent a microcosm of the difficulties in finding an acceptable horizontal framework for the national security complex as a whole. As revealed earlier, each of the MSOC partners have mandates that are broader than just national security, for which they are vertically accountable to a Minister. To compensate for the ambiguity of ownership in the National Security Policy statement, the bureaucracy relied on successive ad hoc

\footnotetext{
${ }^{611}$ Ibid, 27-4-2015 16:130, "In terms of oversight, I'd like to clarify. We use the words "oversight" and "review" interchangeably a little in this country. The word "oversight" comes from the United States governance system, which implies some ex ante authority on the part of the legislative authorities in dealing with national security matters, whereas "review" is post facto. My understanding of our system of government is that, broadly speaking, Parliament is not given ex ante authority to review the work of the executive government..... I would remind you that under our system of government, all of the agencies here represented have a minister of the Crown. Under our system, they are accountable to that minister, who is accountable to you. I find it interesting that in this debate about oversight and review, we tend to ignore the responsibility of ministers." (Fadden)
} 
committees to resolve horizontal governance issues. However, such committees are not designed or empowered to be innovative; they are transactional and limited in scope. Such a structure cannot maintain integration among so many organizations involved in such a complex endeavour. Policy debate needs to occur first at senior levels for decision-making and direction, with WGs such as IMSWG used for coordination and implementation.

The model used to develop the MSOCs was reversed. Once barriers to integration were uncovered, IMSWG became mired in unachievable policy issues and the governance question became circular through resolution by committees. At the time of writing, IMSWG is attempting to move a Memorandum to Cabinet forward that outlines options for an MSOC governance framework for a government decision. It is unclear whether this will include recommendations other than versions of the status quo identified in the 2008 Governance Study, but given Fadden's testimony only four months ago, it is unlikely to contain revolutionary options that address the lacunae in WoG horizontal accountability for national security. Without Prime Ministerial intervention or an existential imperative, Canadian National Security Culture will remain consistent with accepted, established security norms.

\subsection{Analysis and Conclusion}

The events of $9 / 11$ provided significant opportunity for Canada, the state, to increase its relative power either through balancing its national security structure with increased capabilities or through bandwagoning with the US through greater institutional integration. However, Canadian policy-makers did not follow the logic of realist doctrine, even though marine security was important to the US as national security norms dictated 
the logic of appropriateness based on domestic structures. National security in Canada is domestic-centric, where defence and foreign policy are viewed as adjuncts rather than national security policy drivers. Three significant interrelated ideational issues prevented the MSOC project from moving forward as intended: mandates, horizontal governance, and information-sharing. Each of these impediments entailed contestation over interests and changes to identity and culture. The MSOC case demonstrated the confluence of many social factors regarding the protection of acquired values and the resulting contestation of the three intervening variables that support this study's core argument.

As the Canadian national security complex evolved following the Second World War, so too did Canadian security identity. The pre-eminence of state-centric security began to give way to rights of the individual, first through the Bill of Rights and then via the Charter of Rights and Freedoms. The adoption of the Charter was a critical juncture in Canadian society-polity (the nuclear force of the state) as it empowered the judiciary to interpret the law independent of political majoritarianism, thus diminishing the powers of the government executive to invoke populist policies. Contestation over national security identity became more complex as the security rights of the individual came into direct conflict with the security rights of the state. Although Canadian National Security Culture shaped the marine security policies post $9 / 11$, the creation of the MSOCs became enmeshed in the larger ideational question of national identity - security for whom, for which values and at what cost? The specific question of information-sharing became a question of Canadian identity over security rights of individuals versus the security rights of the state involving all three branches of government. 
The whole-of-government (horizontal governance) goals of the National Security Policy statement were seen as modest, attainable and consistent with Canadian National Security Culture. However, social and legal norms with respect to security issues caused the government and bureaucracy to hesitate in moving the MSOC project forward too quickly. Given Canadian society's nominal concern about the terrorist threat, any redesign of the national security complex would be ideational in nature and need to survive political contestation in the process of identity redefinition. The answers to Wolfers' specifications of 'from what threat', 'by what means' and 'in what time period' could not be justified by taking the MSOC issues of governance, mandates, and information-sharing outside the 'rules of the game'. The perceived threat of terrorism did not justify significant changes to the identity of the security complex and its institutions. There was no need for the CAF's mandate to include law enforcement, the CCG did not need to become a paramilitary organization in order to achieve a solution for marine security, and national security concerns could be accommodated within the Privacy Act.

Since the terrorist threat was not deemed existential, the time period for resolution became indeterminate allowing time and space cultural norms to prevail. Without the pressure of an imminent threat, the material question of 'by what means' became entangled with the larger ideational question of 'for which values' at 'what cost'. In this light, the MSOC project was an issue of an increment to an acquired value rather than in the traditional paradigm of a response to a threat. The complete lack of government leadership on finding solutions to the purported existential threat from terrorism was evidence that material concerns in realist and ne-liberal assumptions were of lesser importance than social factors. Thus left to the bureaucracy, institutional identities and 
cultures clashed, such that IMSWG was not able to reach consensus over incommensurate cognitive and evaluative norms. Had the government wished to quickly achieve Marine Domain Awareness, it could have made use of the Crown Prerogative to solve the three impediments. However, the potential risks associated with Charter challenges and the unintended consequences of judicial rulings were greater than the perceived need for that specific increment of national security. ${ }^{612}$ In analyzing the intervening variables, it was evident that political, institutional, and social interests outweighed state security interests.

Developing a WoG approach to functional integration and information-sharing for national security purposes meant not only creating a governance structure for the MSOCs but one for the spectrum of national security itself. This was, in essence, the general recommendation to resolve the deficiencies observed by the AG, SCONSAD, Major and O'Conner. The traditional Westminster institutional model was proving to be inadequate for executive oversight with the convergence of domestic and international security policies into one national security policy. Prime Minister Martin's Government recognized this, but the structural measures put into place were temporal and insufficient to provide horizontal accountability in the long term as they were dependent on the government in power.

This concept of horizontal accountability in Canadian government is not without precedent as WoG national security activities have received critical senior leadership and oversight in the past. Nicknamed the 'Minister of Everything', C.D. Howe was appointed

\footnotetext{
${ }^{612}$ Unless the government takes a leadership role by 'pulling' issues to the forefront, the bureaucracy needs to 'push' issues of importance to the decision-making elite for resolution. As neither the responsible Ministers nor Deputy Ministers saw the perceived need to quickly make the MSOCs fully operational, resolution of the legal and cultural impasses became incommensurable.
} 
by Mackenzie King to ensure the success of the war effort as Minister of Munitions and Supply and later Minister of Reconstruction. However, this is not the norm. The current structure leaves national security fragmented within the Westminster 'stovepipe' model, where horizontal accountability rests solely with the Prime Minister. Government institutions have identities and cultures to ensure mandated duties are understood and followed by employees. Transcending these natural barriers requires holistic focused leadership and comprehension of the ideational issues as national security norms dictate that each institution stay within their defined rules. Without a single Ministerial-level 'champion' whose responsibility is to ensure a symbiotic relationship in horizontal security duties of multiple government departments and agencies, national security remained a fragmented concept and an ambiguous political symbol post 9/11.

Although operations-oriented partners were frustrated with the lack of progress in reaching the National Security Policy statement's stated goals, the MSOC was symbolic of the social factors in Canadian National Security Culture. The concept was sound, achievable, and met the imperatives of protecting an acquired value in a sovereign, but collaborative, way that signaled Canadian resolve to the US. Domestic security norms and structures were central in articulating the perceived threat and determining the appropriate response. In the end, domestic acquired values regarding individual security found in the Charter took precedence over the increment in state-level national security provided by the MSOCs. By using time and space, mandates were adjusted and a standalone Bill provided clear and explicit authority for partners to share information for national security purposes without redefining security institution identities. However, the quandary over MSOC governance issues is also indicative of Canadian security norms. 
Until society-polity perceives national security as a central concern, Canadian identity and structural change for horizontal accountability will remain within the cultural norms of the Westminster model resulting in state security inefficiencies.

The knock-on effect of a single policy decision established through Canadian National Security Culture demonstrated the inter-related nature of Katzenstein's causal structure. Deciding to create the Marine Security Operations Centres (causal path 1) caused a recursive reaction (causal path 5) that required cultural-institutional change. This change affected departmental identities and ultimately state identity through adoption of Bill C-51 (causal path 2). In the contestation over MSOC policy implementation, interests and policies of each stakeholder department were shaped by their existing identities (causal path 3) leading to stagnation in implementation. By reconfiguring state identity, hence departmental identity, with the passage of Bill C-51 in 2015, the environmental structure (cultural-institutional) changed to provide authorization in mandates for information-sharing, allowing for final implementation of the original policy decision. In the macro sense, the Information-sharing Act found in Bill C-51 can be seen as a recursive product of the Charter and the Privacy Act.

Importantly for the following chapter, resolution of legal and security norms in information-sharing needed to occur internally before the MSOCs could contribute internationally. The Arar Affair was symptomatic of the need for Canadian independence in security cooperation with the US, particularly in the complex maritime domain. Although MSOC partners had well established bilateral relationships with their US counterparts, the demands of a WoG integrated MSOC operation demanded prudence and pragmatism. In establishing a firm legal and ideational foundation for information- 
sharing internally, cooperation with the US and other international partners could be done in a sovereign and particularistic manner. This case study demonstrated that social factors identified in the hypothesis were instrumental in determining the MSOC policy outcome and its future worth as part of an evolving continental security complex. 


\section{Chapter: Case 3 - Not Too Close But Not Too Far: The Role of}

\section{NORAD}

\subsection{NORAD - A Unique Institution}

The North American Aerospace Defence (NORAD) Agreement is symbolic of what has been dubbed the $49^{\text {th }}$ Paradox ${ }^{613}$, where the two North American states are so similar socially and economically, but possess political and cultural imperatives that promote separate destinies. As analyst Barry Sadler observed, "Beyond these generalities, the term also implies much about Canadian perceptions of the relationship and their internal ambiguities and equivocations which stem from the fusion of independent tendencies and obligate dependencies." ${ }^{614}$ The inclusion of NORAD in the 2004 National Security Policy statement and the prospect of using this bi-national institution as a means to protect North America from marine threats are indicative of this paradox in national security norms. United States' military power cannot be too close, nor be too far away in Canadian security interests. ${ }^{615}$

As argued in earlier chapters, Canadians feel secure in North America due in large part to their communal relationship with the US and Canadian reliance on American power $^{616}$ to protect all approaches to the US Homeland, including Canada within the US

\footnotetext{
${ }^{613}$ Richard Gwyn, The 49th Paradox: Canada in North America, Toronto: McClelland and Stewart, 1985.

${ }^{614}$ Barry Sadler, "The Management of Canada-US Boundary Waters: Retrospect and Prospect," Natural Resources Journal, Spring 1986, pp. 359-376.

${ }^{615}$ This statement is supported on p. 808 in David S. McDonough, "Canada, NORAD, and the Evolution of Strategic Defence,” International Journal, Vol. 67, No.3, September 2012, pp. 797-811.

${ }^{616}$ Frank P Harvey, "Canada's Addiction to American Security: The Illusion of Choice in the War on Terrorism," The American Review of Canadian Studies, Vol 35, No. 2, Summer 2005, pp. 265-296, particularly p. 287 that speaks to NORAD.
} 
strategic second layer. ${ }^{617}$ Canadian politicians understand this, and realist analyses of Canadian security policies generally concur. The "How much is just enough?" approach to defence spending, as described by Joel Sokolsky ${ }^{618}$, is indicative of Canadian National Security Culture, and is in line with Wolfers' seven specifications and a prudent approach as argued by Philippe Lagassé and Paul Robinson in Reviving Realism in the Canadian Defence Debate. ${ }^{619}$ "Spending more on defence is not an efficient means of providing an additional degree of protection to Canadian life, property and sovereignty, nor of enhancing international stability, Canada's influence, or Canadian values." Lagassé/Robinson suggest that, given the absence of a conventional military threat, savings could be used to greater strategic effect elsewhere, including domestic security to mitigate US border concerns.

Using power as an analytical tool is useful and applicable, particularly in establishing the relationship between interests and threats to those interests. However, without considering the ideational aspects of policy decisions and the competing values and interests that are in play, realist accounts tend to provide symptomatic rather than

\footnotetext{
${ }^{617}$ See Alan Stephenson et al, Securing the Continent: Where is NORAD Today?, Toronto: Canadian International Council, 2011; Joel Sokolsky and Philippe Lagassé, "Suspenders and a Belt: Perimeter and Border Security in Canada-US Relations," Canadian Foreign Policy, Vol 12, No. 3, 2006; Douglas Bland, "Canada's national interest: alliance with the United States", Policy Options, 1 Nov 2007 found online 5 October 2015 at http://policyoptions.irpp.org/issues/ontario-2007-dalton-mcguinty/canadas-nationalinterest-alliance-with-the-united-states/

618 Joel Sokolsky, "Realism Canadian Style: National Security Policy and the Chrétien Legacy," Policy Matters, Vol 5, No. 2; Montreal: Institute for Research on Public Policy, 2004, p. 10 - Sokolsky identifies a wide gamut of security issues that require answers to 'how much'.

${ }^{619}$ Philippe Lagassé and Paul Robinson, Reviving Realism in the Canadian Defence Debate, Kingston: Centre for International Relations, Queen's University, 2008 found online at http://dspace.africaportal.org/jspui/bitstream/123456789/24426/1/Reviving\%20Realism\%20in $\% 20$ the $\% 20$ Canadian\%20Defence\%20Debate.pdf?1 -

${ }^{620}$ Lagassé and Robinson, 2008, p.111.
} 
causal explanations when analysing the post 9/11 Canada-US relationship. ${ }^{621}$ Although many assessments of Canadian security policies attribute domestic-centric factors to "inconsistent" national security policies, their conclusions become faulty when they apply a realist causal model of military-centric, international environment variables. ${ }^{622}$ Most studies fail to accept that Canada's core material interests are not threatened, and therefore there is no imperative to adopt an extra-territorial security role beyond selectively assisting the US, which most realists admit provides few material benefits ${ }^{623}$. Providing a credible military force for continental defence and robust domestic security institutions that protect the US border are the two most significant national security contributions that Canada can make towards US security interests and concerns. ${ }^{624}$ Although realists regularly categorize Canada as a middle power, they often conflate Canadian national security interests with the global national security interests of

\footnotetext{
${ }^{621}$ Boucher concludes that domestic factors in Canada may account for variations in soft-bandwagoning in Jean-Christophe Boucher, "The Cost of Bandwagoning: Canada-US Defence and Security Relations after 9/11," International Journal Vol 67, No. 4, 2012, pp. 895-914; Harvey concludes that no matter what Canada does with respect to increases in security, it will never be enough for the US and results in Canada's security dilemma in Frank Harvey, "The Homeland Security Dilemma: Imagination, Failure and the Escalating Costs of Perfecting Security," Canadian Journal of Political Science, Vol 40, No.2, 2007, pp. 283-316.

${ }^{622}$ Literature on the demise of NORAD as a result of Martin's decision not to participate in BMD as well as the rise of USNORTHCOM provides two examples that will be discussed later in the chapter. See Sokolsky, 2004; Joseph Jockel, "Saving NORAD: Should Ottawa Seize the Obama Moment?," The School of Public Policy: SPP Briefing Papers, Vol 2, Issue 3, September 2009, found online at: http://policyschool.ucalgary.ca/files/publicpolicy/Jockel\%20FINAL\%20web.pdf ; Bernard Brister, "When Perpetuity Doesn't Mean Forever: The Approaching Demise of NORAD," Options Politiques, December 2007-January 2008.

${ }^{623}$ Sokolsky, 2004, p. 37.

624 This is the essence of the 2004 National Security Policy and the 2008 Canada First Defence Strategy defence policy statement. As noted in Chapter 3, the Harper Government continues to use and refer to the 2004 National Security Policy regarding national security; Dwight Mason provides a US perspective on concerns with Canada's defence posture and its ability to protect US security interests in Dwight Mason, "The Canadian-American North American Defence Alliance in 2005," International Journal, Vol, 60, No.2, 2005, pp. 385-396.
} 
a superpower ${ }^{625}$, the US. Thus, outside domestic and continental security issues, Canada and the US often diverge on many ideologically significant international security policy issues. ${ }^{626}$ Canadian National Security Culture allows for policy decisions that are necessary to satisfy legitimate US security concerns, but not necessarily through the desired policy means of a specific US administration. Limited resources in Canada mean making choices on how to construct a national security complex that protects Canadian intrinsic and acquired values. Although Canada shares a majority of these values with the US, differences on the means to protect these values often determine security policy decisions. Perceived threats to Canadian sovereignty needed to be weighed against the perceived threat of terrorism following $9 / 11$. This was the case when considering the expansion of NORAD.

One of the fundamental errors in post- 9/11 realist analysis is not understanding the role of NORAD. ${ }^{627}$ NORAD is not only an institution, but it is also part of both Canadian and American identity. There is little evidence beyond academic conjecture that the role of NORAD was ever in jeopardy post-9/11. ${ }^{628}$ Realist pre-occupation with

\footnotetext{
625 "We must strongly emphasize that the United States will continue to view its security in global terms, and other nations will look to the United States for leadership and protection. Therefore, an important component of the twenty-first century bilateral security and defense relationship will be the extent to which Canada can make useful military contributions beyond North America." As stated in The 105th American Assembly Columbia University, Renewing the US - Canada Relationship, p. 8, found online at http://www.wilsoncenter.org/publication/105th-american-assembly-renewing-the-us-canada-relationship

${ }^{626}$ The 2003 Iraq War, the Rome Statute that created the International Criminal Court, and the Ottawa Convention that prohibited the use of landmines are a few examples during the George W Bush Administration where Canada and the US differed significantly on international security policies while within the same time frame Canada contributed to the war in Afghanistan as well as to the NATO Kosovo campaign just prior to Bush coming to power.

${ }^{627}$ Using Ørvik's Defence Against Help theory, Bratt and Barry provide symptomatic explanations in the post 9/11 period for NORAD's evolution rather than causal arguments - Duane Bratt and Donald Barry, "Defense Against Help: Explaining Canada-U.S. Security Relations." American Review of Canadian Studies, Vol 38, No1, 2008, pp. 63-89.

${ }^{628}$ Although it has been argued that Secretary of Defence Rumsfeld and USNORTHCOM's first commander, Admiral Keating, "placed the bi-national command directly in their sights", the role of
} 
power often leads to a simplistic prism where 'accumulating more power = good; missed opportunities to acquire more power $=$ bad'. Canada's decision to forego participation in Ballistic Missile Defence (BMD) did not lead to the demise of NORAD, as many predicted $^{629}$. The decision not to expand NORAD into a continental defence institution was deemed another realist opportunity lost ${ }^{630}$, but studies failed to account for opportunity costs in creating a continental defence institution. Most significantly, realist views tend to privilege Canadian self-importance in bilateral affairs while minimizing the impact of American National Security Culture that organizes the world in three security layers with only the US at its centre.

This chapter will argue that the policy decisions made after the 9/11 attack followed Canadian National Security Culture norms by quickly addressing pressing US national security concerns and then establishing time and space with respect to further security commitments. In the polity debates and decisions over acquired values, sovereignty and unity issues took precedence over increments of national security. Appalling as it was, the 9/11 attack did not constitute an act of war in the minds of Canadians. What is lost in most realist analysis during this time period is the fact that United States was already moving towards an ideational security change that was global

NORAD was never in jeopardy. The conjecture by analysts arose out of the belligerent rhetoric preferred by Rumsfeld and natural Canadian apprehensions of not being privy to the construction of the new Unified Command Plan (UCP) command, USNORTHCOM. The quote in this note is from James G Fergusson, Canada and Ballistic Missile Defence, 1954-2009: Déjà Vu All Over Again, Vancouver: UBC Press, 2010, p. 263.

629 Joseph Jockel, “Saving NORAD: Should Ottawa Seize the Obama Moment?”, The School of Public Policy: SPP Briefing Papers, Vol 2, Issue 3, September 2009, found online at: http://policyschool.ucalgary.ca/files/publicpolicy/Jockel\%20FINAL\%20web.pdf ;Bernard Brister, "When Perpetuity Doesn't Mean Forever: The Approaching Demise of NORAD", Options Politiques, December 2007-January 2008, p. 83. The possibility of assimilation is also alluded to in the 2004 Interim BPG Report. ${ }^{630}$ See Philippe Lagassé, "A Common "Bilateral” Vision: North American Defence Cooperation, 20012012", in Jonathan Paquin et al, Game Changer: The Impact of 9/11 on North American Security, Vancouver: UBC Press, 2014; Bland, Nov 2007. 
in concept and unrelated to Canada. However, 9/11 became the catalyst for immediate and more robust change. In many respects, Canada was merely a bystander that weathered the 'elephant's' post-9/11 defensive posturing through adherence to Canadian national security norms.

As the preceding chapter explained, resolving legal and security norms within Canada in the very narrow area of marine security operations has been problematic and has taken time. To do this on the scale of a new continental defence arrangement within the timeframe demanded of the Bush Administration would have put Canada at a distinct disadvantage. Thus the National Security Policy statement not only articulated Canada's national security policy to Canadians, but it was also part of the consequence management strategy of reassurance towards the US. Through NORAD's inclusion as the institution of choice for maritime warning, the duality of the NORAD identity was acknowledged domestically while ensuring that this identity was not linked to the issue of missile defence through the inclusion of BMD in the international security chapter. Beginning with the Bi-national Planning Group (BPG) and working through established military institutions, Canada employed national security norms to optimize its position within the continental security complex and maximize its sovereignty.

\subsection{The Ideational Shift with NORAD}

NORAD is unique in that it transcends the domestic/international definition by delivering domestic air security and aerospace defence to two sovereign states equally. For forty-five years it focused on delivering aerospace protection through warning and active defence against the Soviet threat. For the first 15 years, NORAD was truly a continental defence institution fulfilling all realist expectations of bandwagoning as 
portions of Canada were defended by US fighters. However, the 1971 Defence White Paper reflected Trudeau's ideational turn towards sovereignty in his "philosophy of defence" and for the first time since 1945 sovereignty became the military's primary role, changing the NORAD dynamic permanently. ${ }^{631}$ From 1971, "[t]o the extent that is feasible, [Canadians] shall endeavour to have those activities within Canada which are essential to North American defence performed by the Canadian forces." ${ }^{\text {632 }}$ Domestic air security was now a Canadian air force responsibility.

This shift in Canadian defence policy had significant cultural and legal ramifications as NORAD leaders no longer had freedom of movement of fighter aircraft within Canadian airspace. Formal agreements were developed that established the defence criteria for the transfer of US forces into Canada. ${ }^{633}$ The transition to sovereign airspace in Canada witnessed little civil-military cooperation. "The Ministry of Transport (MOT) .... was unenthusiastic about Air Defence Command's growing role in the protection of national sovereignty. ....The MOT did not believe that there was a very great need for fighter interceptors to be able to intercept and identify civilian aircraft." ${ }^{\prime 634}$ This contrasted sharply with the US, where the United States Air Force and the Federal Aviation Authority worked in concert "on a new cooperative civil-military arrangement for radar" system replacement to ring the US. ${ }^{635}$ The cultural differences between the two countries can be significant where Canadian security norms do not privilege military

\footnotetext{
${ }^{631}$ Government of Canada, Defence in the 70s: White Paper on Defence, Department of National Defence, Ottawa, 1971, p. 20; Joseph Jockel, Canada In NORAD 1957-2007: A History, Kingston: Queen's Centre for International Relations \& Defence Management Studies, 2007, pp.83-89.

${ }^{632}$ Statement by Trudeau, 3 April 1969, found in Jockel, 2007, p 83.

${ }^{633}$ CONPLAN 3310 is just such an example of predetermined movement of US air forces into Canadian air bases at specific threat levels. See https://publicintelligence.net/norad-and-northcom-operations-planssummary for an unclassified introduction to NORAD-NORTHCOM Operation Plans.

${ }^{634}$ Jockel, 2007, pp. 86-87.

${ }^{635}$ Ibid, p. 87.
} 
involvement in society to the same degree as in the US. ${ }^{636}$ Slowly outward-looking NORAD was becoming part of Canadian and American security identity as the national regions became synonymous with expanding domestic air security operations, such as counter-drug and hijacked aircraft missions. ${ }^{637}$

Following reorganization and consolidation of national air defence organizations on both sides of the border in the mid-70s to mid-80s, Canadian NORAD Region (CANR) was created in 1983 and the US authorized the establishment of "US Element NORAD” that activated Continental US NORAD Region (CONR) in $1986 .{ }^{638}$ This distinction was necessary in the evolution of domestic air sovereignty in the NORAD mandate. In Canada, the CF is restricted from interference in domestic law enforcement, except under section 273.6 of the National Defence Act (NDA), which allows for "the Canadian Forces to provide assistance in respect of any law enforcement matter". ${ }^{639}$ The Posse Comitatus Act was passed in the US to remove the US Army from civilian law enforcement and to return it to its role of defending the borders of the United States. ${ }^{640}$ Both the Posse Comitatus Act and the NDA are designed to restrict the use of military forces in domestic security, but do not preclude military involvement. Thus, when NORAD launches alert fighters through CANR for domestic missions in Canada, the

\footnotetext{
${ }^{636}$ The President of the US is the Commander in Chief of the US military and an active participant in military decision-making. Twenty-nine US presidents have had military experience with ten holding General rank prior to entering office. The US draft ensured a large portion of the American male population had military experience (until conscription was discontinued in 1973) that was infused back into society when they returned to civilian life. Each American state has some form of state military under the National Guard provision of the US Constitution.

${ }^{637}$ Jockel, 2007, p. 87 and p. 138-140.

${ }^{638}$ NORAD Office of History, A Brief History of NORAD, 31 December 2012, found online 10 October 2015 at http://www.norad.mil/portals/29/documents/history/a\%20brief\%20history\%20of\%20norad.pdf

${ }^{639}$ Government of Canada, National Defence Act ( R.S., 1985, c. N-5 )

${ }^{640}$ Craig T. Trebilcock, "The Myth of Posse Comitatus," Homeland Security, October 2000, Department of Homeland Security available at http://www.homelandsecurity.org/journal/articles/Trebilcock.htm .
} 
mission is restricted by the laws governing the supported department or agency.

American jurisprudence differs. Therefore, it was necessary that the conduct of domestic air security be separated from bi-national defence and restricted to 'national elements' of NORAD for mission execution.

\subsection{Bi-national Identity of NORAD}

Shortly after $9 / 11$, the NORAD planning staff recommended that this regional model be employed by NORAD for homeland air security "that would allow unilateral action by the US." ${ }^{\prime 41}$ The establishment of US Northern Command (NORTHCOM) by President Bush in April 2002 designated the Commander of NORTHCOM as the Commander of US Element NORAD as well as the Commander of NORAD. NORAD was more than just a bi-national agreement to the US. NORAD was part of America. It defined aerospace protection of American acquired values.

Consolidation of the bi-national identity of NORAD occurred when Canada confirmed the Commander of NORTHCOM as being dual-hatted as the Commander of NORAD. It was a significant symbol that the US identified both the Commander and Headquarters as NORAD-NORTHCOM and identified NORAD, the bi-national command, as the sole provider for aerospace defence and security of the US homeland. ${ }^{642}$ To illustrate this further, the 9/11 Commission Report spoke only of NORAD failures in anticipating the threat and made no recommendation to replace the bi-national command

\footnotetext{
${ }^{641}$ Jockel, 2007, pp. 177-178.

${ }^{642}$ US Northern Command official website, Air Forces Northern, accessed on 10 October 2015 at http://www.northcom.mil/Newsroom/FactSheets/ArticleView/tabid/3999/Article/564002/air-forcesnorthern.aspx ; Also see Andrea Charron and James Fergusson, NORAD in Perpetuity? Challenges and Opportunities for Canada, Winnipeg: Centre for Defence and Security Studies, 31 March 2014 found online 10 October 2015 at https://umanitoba.ca/centres/cdss/media/0 NORAD in_Perpetuity final report_March_2014.pdf . For academic disclosure, this dissertation author was an academic member of this report.
} 
with an American only air force command. As in Canada ${ }^{643}$, NORAD is part of American security identity. ${ }^{644}$

To understand the importance of NORAD in practical terms, it is necessary to deconstruct and identify the three elements that constitute NORAD: the essence, the institution, and the 'service delivery'. Unquestionably, both nations seek security and sovereignty within their territory. For the proponents of NORAD, the means by which this is best achieved is through access to senior defence / security officials and influence in policy formulation and decision-making regarding the defence of North America. This is the essence and the reason for the judicious decision in both countries to pursue the NORAD-NORTHCOM concept. For Canada, NORAD militates against unilateral American action on the continent and provides senior government officials with an additional avenue for strategic discourse with their US counterparts. ${ }^{645}$ For the US, NORAD provides the self-assurance that their northern border is well protected.

\footnotetext{
${ }^{643}$ With the consolidation of functional commands into 1 Canadian Air Division in 1997, the CAF no longer had an independent command and control organization capable of conducting fighter operations with the demise of Fighter Group. Canadian NORAD Region effectively became the only means for command and control of fighter operations within Canada. Although theoretically, there exists the possibility of Canadian only operations, the personnel and equipment are in actuality double-hatted NORAD assets. NORAD has been synonymous with air defence and air security in Canada since the stand-up of Air Command in 1975.

${ }^{644}$ Commander NORAD-NORTHCOM General Renuart's testimony to SCONSAD in May 2010 is evidence of NORAD's Geertzian symbolism in American security identity, "Finally, as one small indicator of the importance of NORAD in the United States, I would like to mention that, just a few days ago on April 28, 2010, I had honour of presiding over the a ribbon-cutting for the new NORAD corridor and its permanent exhibit site in the halls of the Pentagon. The exhibit showcases the development, operations and success of the enduring NORAD relationship that has protected Canada and the United States for nearly 52 years." - Proceedings of the Standing Senate Committee on National Security and Defence (SCONSAD), "Issue 4 - Evidence - Meeting of May 3, 2010", found online on 17 October 2010 at http://www.parl.gc.ca/Content/SEN/Committee/403/defe/04evae.htm?comm id=76\&Language $=$ E $\&$ Parl $=40 \&$ Ses $=3$

${ }^{645}$ For a reasoned explanation of this phenomenon using Ørvik's 'Defence Against Help' theory as a strategy see Duane Bratt and Donald Barry, "Defense Against Help: Explaining Canada-U.S. Security Relations." American Review of Canadian Studies, Vol 38, No1, 2008, pp. 63-89; See Philippe Lagassé, "Nils Ørvik's "Defence Against Help": The Descriptive Appeal of a Prescriptive Strategy", International Journal, Vol 65, No.2, 2010, pp. 463-74 for a similar account through a realist prism.
} 
However, more importantly for the US, NORAD embodies the virtues of American

hegemony that demonstrates to the world that sovereignty and security can co-exist - not too close, but not too far away. ${ }^{646}$

The 'institution' called NORAD is a bi-national command and control structure that is unique in the world, as well as in time and space, since the likelihood of its reconstitution, should it ever disappear, is questionable. Along with "symbolic embodiment of the partnership and friendship of "two great nations"" ${ }^{647}$, it provides the conduit for transnational action in an efficient, effective, transparent, and timely manner, and fosters enduring relationships built on trust and confidence, as well as providing Canada access to privileged information and advanced technology. The cultural aspects of this bi-national institution cannot be understated, as the foundational security norms transcend NORAD into all supporting and supported government departments and agencies of both countries. Internal contestation of political, legal, and ideological norms and acquired values regarding the evolution of NORAD are part of the process that shapes interests and policy choices.

Finally, the evolution of NORAD over the past 50 years demonstrates that, beyond the principal role of air defence, the 'service delivery' of mission sets ebbs and flows with advances in technology and threat postures. Missile defence is one area of

\footnotetext{
${ }^{646}$ With the signing of the NORAD Agreement, the US was able to ensure the ensuing air battle with the Soviets would take place as far away from Canadian and US population centres as possible. In realist terms, US defence strategy has always favoured forward perimeter security that protects its territory and, over time, this perimeter has become deeper and higher with the introduction of BMD. However, virtually all US government politicians and security officials make certain to point out the uniqueness of NORAD "as the world's only bi-national command," to underscore the fact that hegemony does not mean loss of sovereignty. - Statement of Admiral William E. Gortney, United States Navy, Commander United States Northern Command and North American Aerospace Defense Command before the Senate Armed Services Committee, March 12, 2015.

${ }^{647}$ D. Fraser Holman, NORAD: In the New Millennium, Toronto: Irwin Publishing Ltd, 2000, p. 96.
} 
transcended operational responsibilities while homeland security missions are in

ascendance. With greater global responsibilities in the provision of international security, the US has had to view national security as a comprehensive network of inter-related commands and capabilities. This has resulted in continual organizational and structural changes within the US security complex with resultant changes to NORAD. ${ }^{648}$ Given political will, there is an array of defence and security capabilities that can be accomplished in a bi-national fashion without changing the face of NORAD. To many, the tangible benefit of the NORAD defence cooperation is in the burden sharing, in both direct and indirect costs, that clearly favours Canada. ${ }^{649}$ However, 'service delivery' involves more than material considerations; it involves protection of competing acquired values and the associated costs for the increment in national security attained. ${ }^{650}$

\subsection{September 11, 2001 - A Critical Juncture}

The 9/11 attack on the US by a relatively small group of terrorists demonstrated the limitations of a formidable military in confronting the asymmetric tactics employed by transnational terrorist groups. As the 9/11 Commission Report concluded, NORAD reacted as it was trained to do, but it, and the security system in place, was ill-prepared for a threat that to all intents and purposes simply materialized. Although 9/11 was the catalyst, the structural reforms for homeland defence and security that quickly followed had been under construction for nearly a decade in the US. The increasing number of

\footnotetext{
${ }^{648}$ See NORAD Office of History, A Brief History of NORAD, 31 December 2012, for a brief summary of the many structural changes within the US military that have had direct impact on NORAD. The movement of USSPACECOM and some NORAD responsibilities to USSTRATCOM will be addressed later in the dissertation.

${ }^{649}$ Ibid.

650 'Service delivery' is a variable that depends on contestation of acquired values and national interests. The question of BMD is an example of the contestation of competing ideologies and values towards the provision of security. This will be discussed in greater detail later.
} 
terrorist acts against US targets and the rise in intercontinental capabilities of 'rogue states' to deliver Weapons of Mass Destruction (WMD) caused great concern to US leaders over the vulnerability of the US homeland to attack. ${ }^{651}$

The US Congress approved the Missile Defense Act in 1991 to address the emerging threat of 'rogue state' missile capabilities, followed by the National Missile Defense Act of 1999 that authorized deployment of a National Missile Defense system. ${ }^{652}$ Michel Fortmann and David Haglund identified nine official commission reports on homeland defense and reported that "No fewer than a dozen bills pertaining to various aspects of homeland security were on the congressional agenda in the months preceding the attacks of September 2001." ${ }^{653}$ Significantly, the Hart-Rudman Commission, The United States Commission on National Security / $21^{\text {st }}$ Century, recommended the formation of a National Homeland Security Agency ${ }^{654}$ in January 2001, seven months before the 9/11 attack. Thus the US was in a position to move quickly on the most formative federal government restructure in its history. As the 1990's ended and the new century began, many of the post 9/11 security issues had already been examined, particularly the US concern with potential terrorist attacks on home soil.

\footnotetext{
${ }^{651}$ Michel Fortmann and David Haglund, "Canada and the Issue of Homeland Security: Does the 'Kingston Dispensation' Still Hold?” Canadian Military Journal, Spring 2002, pp. 17-22.

${ }^{652}$ National Defense Authorization Act for Fiscal Years 1992 and 1993 (Engrossed Amendment as Agreed to by Senate) Part B-Strategic Defense Initiative SEC. 211. MISSILE DEFENSE ACT OF 1991; Public Law 106-38, $106^{\text {th }}$ Congress, National Missile Defense Act of 1999, July 22, 1999, found online at https://www.congress.gov/106/plaws/publ38/PLAW-106publ38.pdf .

${ }^{653}$ Fortmann and Haglund, 2002, p. 20.

${ }^{654}$ Gary Hart and Warren Rudman, The United States Commission on National Security / $21^{\text {st }}$ Century, 31 January 2001, found online at http://www.au.af.mil/au/awc/awcgate/nssg/ ; For a concise overview of all 3 commission reports from 1999-2001 see Elinor C. Sloan, Security and Defence in the Terrorist Era: Canada and the United States Homeland, 2nd ed. Montréal: McGill-Queen's University Press, 2010, pp. 58-60.
} 
With this weight of analysis behind the Bush Administration, US Secretary of Defense Donald Rumsfeld was prepared to write "a confidential letter to his Canadian counterpart, Minister of National Defence Art Eggleton, recommending that the two countries expand NORAD's mandate to include an integrated defence of North America on land and at sea" ${ }^{655}$ at the end of October, 2001. Eggleton quietly declined in a return letter, explaining that Canada was not prepared to expand NORAD into a full bi-national military command. One year later the US announced the establishment of a new Unified Combatant Command, US Northern Command (NORTHCOM). To most Canadian analysts, this development was of deep concern and was caused "[b]ecause of Canada's unwillingness to immediately work towards expanding NORAD.”656

As much as some may wish, Canada does not factor into the American decisionmaking process in such a significant way. In an article explaining the rationale for structural change, the Chairman of the Joint Chiefs of Staff (CJCS) Richard Meyers wrote,

In the 56 years since the first UCP [Unified Command Plan], our combatant command structure has been expanded geographically and empowered legally, The Goldwater-Nichols Act of 1986 strengthened the role of our combatant commands, and with UCP 2002, the last remaining unassigned regions of the world - Russia, the Caspian Sea, Antarctica, and the countries of North America were finally placed within our combatant commanders' areas of responsibility (AOR). Now, the entire globe is encompassed within the AORs of our five regional commands. ${ }^{657}$

\footnotetext{
${ }^{655}$ Lagassé, 2007, p194; Fergusson, 2010, Act 5.

${ }^{656}$ Ibid, p. 197;

${ }^{657}$ Richard B. Myers, "Shift to a Global Perspective," in Paul Bolt et al, eds., American Defense Policy, Eighth Edition, Baltimore: The Johns Hopkins University Press, 2005, p. 392. The five Regional Combatant Commands are US European Command, US Pacific Command, US Central Command, US Northern Command and US Southern Command. The sixth, US Africa Command, stood up in 2007. The three Functional Combatant Commands are US Special Operations Command, US Strategic Command, and US Transportation Command.
} 
The restructuring of the UCP was global in nature and included reassessment and reassignment of some US force capabilities to the functional combatant commands, especially the merger of US Space Command into US Strategic Command. "The president's decision to join USSPACECOM and USSTRATCOM to form a new US Strategic Command was a major step in fulfilling the vision for a new strategic triad." 658

To believe that Canada would have had much say in the way that the US would structure an 'expanded NORAD' is pure fantasy. ${ }^{659}$ Unlike in Canada, the 9/11 attack had an enormous impact on the American psyche, shattering the psychological myth of invulnerability ${ }^{660}$ When the UCP was first created in 1947 , there was never one commander for the North American AOR because of concerns that too much military power should never accrue to one individual other than the President. ${ }^{661}$ The US was now bringing the UCP into the $21^{\text {st }}$ century by ensuring all regions of the globe were assigned and NORTHCOM was specifically created to defend the homeland. Any institution that had responsibility for the North American AOR would have to abide by the legal, constitutional, and political norms under the UCP ${ }^{662}$ Therefore an 'expanded

\footnotetext{
${ }^{658}$ Ibid, p. 393.

${ }^{659}$ For a similar assessment see Bernard Brister, The Same Yet Different: Continuity and Change in the Canada-United States Post-9/11 Security Relationship. Kingston: Canadian Defence Academy Press, 2012. ${ }^{660}$ See David C. Hendrickson, "toward Universal Empire: The Dangerous Quest for Absolute Security”, in Paul Bolt et al, eds., American Defense Policy, Eighth Edition, Baltimore: The Johns Hopkins University Press, 2005, pp. 40-45.

${ }^{661}$ Prior to USNORTHCOM's establishment, four different combatant commanders (Joint Forces Command, Pacific Command, Southern Command, and NORAD Command) coordinated separate responsibilities for defence of the US.

${ }^{662}$ NORTHCOM was created to rectify a security vulnerability. The $9 / 11$ attack drew attention to the fact that the American military was not organized to best support homeland defence and protect itself from emerging terrorist groups such as al Qaeda. Although Canada and several other countries fall within its AOR, the geographic assignment only gives the commander the responsibility for regional defence planning, security cooperation, and military coordination with regional allies. NORTHCOM's mission is to provide homeland defence and civil support. On 14 October 2015 the NORTHCOM official website stated the NORTHCOM Mission: "USNORTHCOM partners to conduct Homeland Defense and Civil Support operations within the assigned area of responsibility to defend, protect, and secure the United States and its
} 
NORAD' would have had to be an adjunct institution in order to meet US legal norms;

otherwise, Canadian legal norms would have had to adjust to fit into the UCP

construct. ${ }^{663}$ At the time, there were senior officials on both sides of the border who

argued forcefully against such a bi-national approach ${ }^{664}$, primarily on sovereignty

grounds. There were also those who questioned the costs to Canadian independence for

the increment of security that this new acquired value would provide. ${ }^{665}$

What realists have failed to explain is why a terrorist threat would precipitate the need for bi-national military structure when military capabilities have limited utility in domestic operations. If there was no perceived need for a bi-national continental defence command at the height of the Cold War, what additional protection does bi-national military involvement provide from a nebulous terrorist threat? As explicated in the previous chapter, legal restrictions limit any domestic CAF military response to terrorism to assistance to law enforcement. ${ }^{666}$ As this precludes direct US military intervention in Canadian domestic affairs, the only rationale for a bi-national military command would have been for Canada to accrue more national power by bandwagoning with the US.

interests." Integrating Canadian institutions that would be needed to support NORAD with NORTHCOM's 60+ partner departments and agencies would have been prohibitively problematic. ${ }^{663}$ It is unclear how an expanded NORAD could also fulfill the UCP requirements the US was intent on completing. "In reality, joining USNORTHCOM was always out of the question, unlike transforming NORAD, which seemed possible in late 2001 and early 2002." - Jockel, 2007, p. 179; For an American perspective on the impact and transformation see Richard H. Kohn, "Using the Military at Home: Yesterday, Today, and Tomorrow”, in Paul Bolt et al, eds., American Defense Policy, Eighth Edition, Baltimore: The Johns Hopkins University Press, 2005, pp. 441-456.

${ }^{664}$ Fergusson, 2009, pp. 218-221 and 230-231; Dwight Mason, "The Canadian-American North-American Defence Alliance in 2005", International Journal, Vol 60, No. 2, 2005, pp. 385-396.

${ }^{665}$ See Jonathan Paquin, "Canadian Foreign and Security Policy: Reaching a Balance between Autonomy and North American Harmony in the Twenty-First Century," Canadian Foreign Policy, Vol 15, No.2, 2009, pp 99-108 who argues that Canada needs to balance its foreign policy with the US through greater Atlanticism while cautiously increasing bilateral security perimeter cooperation to preserve its political autonomy to the greatest extent possible.

${ }^{666}$ See Chris Madsen, "Military Responses and Capabilities in Canada's Domestic Context Post 9/11," Journal of Military and Strategic Studies, Vol 13, Issue 3, Spring 2011, pp. 14-17, for a succinct explanation. 
Increased bi-national coordination ${ }^{667}$ is not significant enough to warrant an 'enhanced NORAD' to address the perceived threat from terrorism and such goals can be achieved by other means, particularly in light of the sovereignty challenges surrounding information-sharing.

The Chrétien Government's decision to forego the invitation for an 'expanded NORAD' was prudent and in line with Canadian National Security Culture. The ramifications for sovereignty of merging defence institutions were significant and completely unexplored at the time. The perceived threat of terrorism in Canadian government official minds did not warrant such a drastic response and acceptance, even in principle, would have had immense political costs given concerns over Canadian sovereignty and anti-Bush sentiment in Canadian society. ${ }^{668}$ National security priorities in Canada were rightly focused on strengthening domestic security institutions since maintaining the flow of trade (the life-blood of the Canadian economy) while assuring the US that their northern border was secure were both critical to post 9/11 Canadian national interests. ${ }^{669}$ Defence issues could wait.

\subsection{Constructing A Security Complex}

Following the stand-up of NORTHCOM in October 2002, Canada and the US formed the Bi-National Planning Group (BPG) in December 2002 to study 'the merits of

\footnotetext{
${ }^{667}$ Lagassé, 2014, p. 196. Other than suggesting that the US would use its superior power to force its way into Canadian sovereign territory to address security concerns, the only rationale used to argue for an expanded NORAD, outside accruing more power for Canada, is to "provide the greatest degree of coordination". As this dissertation will argue, the required coordination was achieved bilaterally through cultural use of time and space to establish the Tri-Command roles and the proper bilateral military agreements that facilitate coordination while preserving sovereignty.

${ }^{668}$ NHillmer, and Granatstein, 2007, p. 311-318; Goldenberg, 2006, p. 256-285.

${ }^{669}$ See Stéfanie von Hlatky and Jessica N. Trisko, "Sharing the Burden of the Border: Layered Security CoOperation and the Canada-US Frontier", Canadian Journal of Political Science, Vol 45, No.1, 2012 , pp. 63-88.
} 
broadening the bi-national defence arrangements ${ }^{670}$ and to address the military response to terrorism, natural disasters or other major emergencies in Canada or the United States. Given the building disenchantment between Canadians and Americans at that time over the invasion of Iraq and the earlier F-16 'friendly fire' incident that killed four Canadian soldiers in Afghanistan, both countries had national factions that were becoming polarized towards unilateralism. ${ }^{671}$ Thus, it was politically prudent to establish the BPG for both countries to openly discuss continental defence and pragmatic for Canada to be part of the process of constituting NORTHCOM, albeit peripherally through NORTHCOM's developing relationship with NORAD.

Turbulent is not too strong a word to describe the CANUS national security relationship between 2001 and $2005 .{ }^{672}$ Canada participated in the invasion of Afghanistan, but publicly rejected a role in the Iraq War and strengthened the US's northern border through domestic security initiatives, but rejected bi-national continental defence. Part of this was a result of the Bush Administration's belligerent, unilateralist rhetoric, but successive Liberal governments 'straddled the fence' on critical national

\footnotetext{
${ }^{670}$ Bi-National Planning Group, The Final Report on Canada and the United States (CANUS) Enhanced Military Cooperation, March 13, 2006, Peterson Air Force Base, Colorado; According to Dwight Mason, the formation of the BPG was agreed to at a meeting of the Permanent Joint Board on Defence, see Dwight Mason, "The Canadian-American North American Defence Alliance in 2005," International Journal, Vol, 60, No.2, 2005, pp. 385-396.

${ }^{671}$ Ferguson, 2009, pp. 20-221; According to a public opinion poll in November 2002, 67\% of Canadians believed the US was 'starting to act like a bully with the rest of the world', Norma Greenaway, 'Most Canadians Think U.S. Acts Like a "Bully to World"', Ottawa Citizen, 28 December 2002; the "supposed' friendly fire incident involved an American fighter pilot who disregarded the established Rules of Engagement by declaring he was acting in self-defence. Although he only received a reprimand, all fighter pilots know that he was flying at a safe altitude above small-arms fire when he noted the flashes on the ground and needed to descend into the threat zone in order to declare 'self-defence'.

${ }^{672}$ See Stephen Azzi and Norman Hillmer, "Intolerant allies: Canada and the George W. Bush administration, 2001-2005, Carleton University, 2015 unpublished work, for a succinct overview of the complex bilateral national security situation; See Wikileaks diplomatic messages from the US Embassy in Ottawa to Admiral Keating, Commander NORAD, Commander NORTHCOM - Subject: SCENE-

SETTER FOR VISIT TO CANADA, 12-14 DEC 2004, 8 December, 2004, found online 15 October 2015 at http://wikileaks.org/plusd/cables/04OTTAWA3303 a.html for a summary of the US concerns with the state of the CANUS security relationship.
} 
security issues, with "their eye more on public opinion than on the national interest."673 Through it all, the BPG members worked closely with each other to analyse and identify areas of common security interests. It is clear from the $214^{\text {th }}$ meeting of the Permanent Joint Board on Defence (PJBD) in October 2004 that the BPG was considered by the US to be the bridge for the "historic opportunity to transform NORAD." ${ }^{674}$ However, this PJBD meeting also identified bi-national information-sharing as problematic and "recognized the need for enhanced bi-national maritime defense cooperation." 675 Although politically turbulent, the future continental security complex was being professionally constructed through these fora.

In August 2003, Canada signed an Amendment to the NORAD Agreement to sanction NORAD's participation in providing information in regard to its air-breathing and missile warning function (Integrated Attack Warning and Attack Assessment ITW/AA) to NORTHCOM for its Ballistic Missile Defence (BMD) mission. Most saw this as a precursor to Canada joining the BMD system. At the $214^{\text {th }} \mathrm{PJBD}$, the US Chairman Jack David "said the US is open to Canadian participation, but ..... is not 'pushing on this; the US would press ahead to meet necessary deadlines regardless of Canadian participation." ${ }^{676}$ In response, the Department of Foreign Affairs member indicated that the 2004 Fall parliamentary non-binding vote looked favourable, but that "the political environment for the minority government...was 'complex and difficult'."677

\footnotetext{
${ }^{673}$ Ibid, p. 23.

${ }^{674}$ See Wikileaks diplomatic messages from the US Embassy in Ottawa to Washington - Subject: $214 \mathrm{TH}$ MEETING OF THE PERMANENT JOINT BOARD ON DEFENSE, OCTOBER 20-21, 2004 found online 15 October 2015 at http://wikileaks.org/plusd/cables/04OTTAWA3048_a.html ${ }^{675}$ Ibid.

${ }^{676}$ Ibid.

${ }^{677}$ Ibid.
} 
As indicated in US Chairman David's remarks, the US did not need Canada's participation in BMD to protect the US homeland, as BMD was already being integrated into the larger US global security complex. The strategic reorganization of the UCP precipitated by $9 / 11$ was a continuation of the Revolution in Military Affairs ${ }^{678}$ (RMA) begun in the late 1990s and the drive towards Network Centric Warfare that "focuses on the combat power that can be generated from the effective linking or networking of the warfighting enterprise."679 A monumental strategic shift was taking place within the US national security complex. Regional Combatant Commands were networked with USSTRATCOM ${ }^{680}$ and decision-making with respect to strategic threats, such as nuclear weapons, became an integrated American-only process. Given the strategic complexity of missile defence, it is questionable whether Canada's participation would have led to any significant operational influence regarding BMD. ${ }^{681}$ Participation by Canada was a

${ }^{678}$ See Elinor Sloan, The Revolution in Military Affairs: Implications for Canada and NATO. Montreal: McGill-Queen's University Press, 2002.

${ }^{679}$ David S. Alberts, John J. Garstka, and Frederick P. Stein, NETWORK CENTRIC WARFARE: Developing and Leveraging Information Superiority, 2nd Edition (Revised), DoD C4ISR Cooperative Research Program, August 1999, found online on 15 October 2015 at http://dodccrp.org/files/Alberts_NCW.pdf , p.87 - Network Centric Warfare can be traced to Admiral William Owens' concept of 'system of systems' where technological advances had allowed evolution of a system of intelligence sensors, command and control systems, and precision weapons that enabled enhanced situational awareness, rapid target assessment, and distributed weapon assignment. ${ }^{680}$ See Charron and Fergusson, 2014, pp. 30-34, for an analysis of the NORAD-NORTHCOM / STRATCOM relationship to BMD; Also David McDonough, "BMD and US Strategic Doctrine: Canadian Strategic Interests in the Debate on Missile Defence", Journal of Military and Strategic Studies, Vol. 9, Issue 3, Spring 2006/07.

${ }^{681}$ The US was in the process of restructuring its management of threats posed by air and cruise missile (ACM), short and medium range ballistic missiles (S/MRBM) and intercontinental ballistic missiles (ICBMs). Significantly all three categories of missiles were integrated into a single concept - Integrated Air and Missile Defence (IAMD). In July 2008, STRATCOM was given overall coordination authority for this initiative. STRATCOM and initially determined that NORAD's concept for homeland ACM defence was acceptable for expansion into S/MRBM. However, STRATCOM's goal of providing a single, comprehensive command and control construct for command decision-making meant moving towards compartmentalization of sensitive, US only information. Although Canada has long been a trusted ally, the policy implications of becoming more deeply involved in the STRATCOM mission would likely have caused greater consternation with Canadian society than the simple question of BMD. To understand the complexity of the global, active layered IAMD program see Statement by Lieutenant General David 1. Mann, USA Commanding General, U.S. Army Space and Missile Defense Command/ Army Forces 
question of moral judgment by Canadian decision-makers in resolving competing

acquired values that had shaped contesting arguments about national interests.

Delving into Prime Minister Martin’s decision in February 2005 that Canada

would not take part in BMD is beyond the scope of this paper. ${ }^{682}$ However, the political

costs associated with this increment of national security were too high for the government

at the time and were still assessed as too high for the Harper Government 10 years

later. ${ }^{683}$ Contestation of acquired values within Canadian society will make it difficult for

any government to make the realist case for joining BMD, although paradoxically

Canada is a signatory to the North Atlantic Treaty Organization (NATO) Integrated Air

and Missile Defence System (NATINAMDS) ${ }^{684}$ that includes a BMD component.

Whether Martin's 'moral judgment' ${ }^{685}$ was based on ideational opposition expressed by

Strategic Command and Joint Functional Component Command for Integrated Missile Defense before the Committee on Armed Services Strategic Forces Subcommittee United States Senate, Second Session, 113 th Congress, April 2, 2014 found online 16 October 2015 at http://www.armed-

services.senate.gov/imo/media/doc/Mann_04-02-14.pdf.

${ }^{682}$ See Lagassé, 2014, pp. 199-204; Azzi and Hillmer, 2015; Fergusson, 2009,

${ }^{683}$ Despite moving the political debate forward with the SCONSAD report, Dan Lang et al, Canada and Ballistic Missile Defence: Responding to the Evolving Threat, Standing Senate Committee on National Security and Defence, 2014, the Harper Government has been reluctant to raise the BMD issue publicly although it has been quietly discussed internally - confidential interview. Also see, Charron and Fergusson, 2014, pp. 30-31; Philippe Lagassé, "The Harper Government and the Politics of Continental Defence", speaking notes from University of Ottawa, November 2007, “The Conservatives dropped their support for BMD. At this time, missile defence is off the negotiating table... While most Conservatives likely support BMD,... the Harper Government has decided that BMD is not worth fighting for, or worth spending capital on."

684 "The system known as the NATO Integrated Air and Missile Defence System (NATINAMDS) detects, tracks, identifies and monitors airborne objects (for instance aircraft, helicopters, unmanned aerial vehicles and ballistic missiles), and - if necessary - intercepts them using surface-based or airborne weapons systems." At the Lisbon summit in 2010, Allied leaders agreed to develop a BMD capability and at the Chicago Summit in w2012, Allied leaders declared at the Alliance achieved interim NATO BMD capability. North Atlantic Treaty Organization, NATO INTEGRATED AIR AND MISSILE DEFENCE, 01 Sep. 2015, found online on 14 October at http://www.nato.int/cps/en/natohq/topics_8206.htm ${ }^{685}$ This issue is reminiscent of the nuclear weapons quandary that Diefenbaker, Pearson and Trudeau found when trying to balance support to US strategic security polices with Canadian society's ideational opposition to nuclear weapons. See Jockel, 2007, pp. 49-66; Matthew Trudge, "A Canadian Approach: Canada's Cold War Grand Strategy, 1945 to 1989," Journal of Military and Strategic Studies, Vol 14, No. $3 \& 4,2012$, found online at http://jmss.journalhosting.ucalgary.ca/jmss/index.php/jmss/issue/view/64. 
Canadian society through his caucus ${ }^{686}$ or political self-interest in retaining power ${ }^{687}$, the fact remains that rejection of NORAD's 'service delivery' of this increment of national security has not critically endangered the essence or institution of NORAD. ${ }^{688}$

Most analysts link the creation of Canada Command directly with the formation of NORTHCOM. ${ }^{689}$ However, the causation is less straight forward and more a result of Canada's own RMA process and the appointment of General Rick Hillier as Chief of the Defence Staff (CDS) in February 2005. Up to this point, there is no evidence that Canadian officials were contemplating a 'counter-balancing' institution; otherwise one would have expected the establishment of Canada Command to have been announced in the 2004 National Security Policy statement or the 2005 International Policy Statement. ${ }^{690}$ In fact, the 2004 BPG Interim Report identifies the Deputy Chief of the

${ }^{686}$ Azzi and Hillmer, 2015, pp 18-22.

${ }^{687}$ David Rudd, "Muddling through on Missile Defence: The Politics of Indecision", Vol. 26, Institute for Research on Public Policy, 2005, pp. 30-34. Although Rudd equates the BMD crisis with the conscription crisis, it is more synonymous with the nuclear debate in Canada as argued in the note above; Wikileaks Paul Cellucci, diplomatic message , 24 February 2005, www.wikileaks.org/plusd/cables/05OTTAWA572 a.html .

${ }^{688}$ Successive NORAD-NORTHCOM commanders have sought ways to increase NORAD's value as the "cornerstone of the Canada-US defence relationship". General Jacoby initiated the NORAD Strategic Review as part of his 'NORAD NEXT' concept meant to be an enduring process to ensure NORAD can adapt to meet emerging strategic and operational challenges. His NORAD motto, "Forever Relevant, Ever Evolving". The NORAD Strategic Review Terms of Reference were approved by the CDS and CJCS in June 2013 and the progress of the review was a topic of discussion at the $233^{\text {rd }}$ meeting of the PJBD in November 2014. - Confidential interview.

${ }^{689}$ Lagassé, 2014, p 202; Fergusson, pp 262-263- "With no Canadian equivalent to NORTHCOM, there existed no formal institutional mechanism save NORAD for defence cooperation." - this is an incorrect statement as reflected in the accompanying note as DCDS was the Canadian equivalent until its domestic duties were transferred with establishment of Canada Command. This is reflected in both the 2004 Interim and 2006 Final BPG Reports.

${ }^{690}$ Although Canada Command was not mentioned specifically in the IPS, page 22 contains a statement that may indicate this change was forthcoming - "we will renew our commitment to continental defence, including through enhancing our domestic capabilities and establishing a single national command structure.." - Government of Canada, Canada's International Policy Statement: Defence (IPS-D), 2005, p. 22. It would make sense that General Hillier would have had a hand in shaping this statement as the IPS was released two months after he formally took command of the $\mathrm{CF}$, but he would have been consulted prior to February once he was selected by the government. Comments made at the NORAD Agreement renewal negotiations support the premise that it was General Hillier who precipitated the structural change as Canada Command's creation had not been anticipated. "The creation of Canada Command (CanCom) 
Defence Staff (DCDS) as being the equivalent of the Commander NORTHCOM for missions of homeland defence and military aid to civil authorities. ${ }^{691}$

As part of the Canadian RMA process begun in 1998, analysis of the evolution of the CF command and control process resulted in the Mason Crabbe Report delivered in January 2001. Among its recommendations was the separation of strategic and operational-level headquarters for command of operations. Thus, seven months before 9/11, the CF was moving towards a more joint operational structure. With the announcement of the creation of NORTHCOM, it was logical in 2002 that

The favored course of action is the creation of a new, distinct Canadian Joint Headquarters (CJHQ) focused solely on force employment, which would report to the DCDS and allow the division of the current joint staff into its two logical strategic- and operational-level components. This new Joint Headquarters could also serve as a link to US Northern Command (NORTHCOM) Headquarters and likely also incorporate the Canadian NORAD Region, currently in North Bay. ${ }^{692}$

The DCDS Group had already begun restructuring and created the Joint Task Force regional concept when General Hillier took Command of the Canadian Forces (CF). Hillier's recent operational experience in Afghanistan in 2004 had confirmed his belief that the CF needed a more robust and more operationally focused command structure and four months later he began CF Transformation. ${ }^{693}$ His Transformation team essentially divided the domestic operational duties previously performed by the DCDS

would bring dedicated staff to Ottawa to address these issues. He [Rear Admiral Robertson] added that the existence of CanCom had not been anticipated in the Cabinet mandate for NORAD negotiations." Wikileaks diplomatic messages from the US Embassy in Ottawa to Washington, SUBJECT: CANADA: NORAD AGREEMENT NEGOTIATIONS, ROUND I, 2005 October 24, para 7, found online on 16 October at http://wikileaks.org/plusd/cables/05OTTAWA3179 a.html

${ }^{691}$ Bi-National Planning Group, Interim Report on Canada and the United States (CANUS) Enhanced Military Cooperation, 13 October 2004.

${ }^{692}$ G.L. Garnett, "The Evolution of the Canadian Approach to Joint and Combined Operations at the Strategic and Operational Level," Canadian Military Journal, Winter 2002 - 2003, p. 8.

${ }^{693}$ See Daniel Gosselin and Craig Stone, From Minister Hellyer to General Hillier: Understanding the Fundamental Differences between the Unification of the Canadian Forces and its present Transformation," Canadian Military Journal, Winter 2005 - 2006, pp. 5-15; Michael Jeffery, "Inside Canadian Forces Transformation," Canadian Military Journal, Vol. 10, No. 2, 2010, pp. 9-18. 
Group between the Strategic Joint Staff at National Defence Headquarters (NDHQ) and a more robust Canada Command. This is reflected in the 2006 BPG Final Report that explains, "Canada Command and the U.S. Northern Command are not symmetrical. For instance, Canada Command is organized regionally, whereas U.S. Northern Command is organized with functional components and Joint Task Forces." ${ }^{694}$ The creation of Canada Command was not organizationally transformative with respect to interaction with NORTHCOM, and the efficacy of the restructure was questionable. A Report on the Validation of the Transformed Canadian Forces Command Structure ${ }^{695}$ "on the new command structure, prepared for the Chief of Defence Staff (CDS) by three former senior officers, criticized the redundancy in the new structure, but suggested that now was not the time to make significant changes to the present transformed command headquarters. ${ }^{\circ 96}$

The establishment of Canada Command was the result of an ideational shift in organizational structure caused by the new CDS rather than changes in response to the international system. ${ }^{697}$ Had a different officer been selected as CDS, it is very likely that NORTHCOM would have been dealing with the DCDS Group as per the 2004 BPG Interim Report. The subsequent reversion to the Canadian Joint Operations Command (CJOC) in October 2012, "ostensibly the re-creation of the old Canadian Deputy Chief of

\footnotetext{
${ }^{694}$ Bi-National Planning Group, Final Report on Canada and the United States (CANUS) Enhanced Military Cooperation, 13 March 2006, p. 1.

${ }^{695}$ R.R. Crabbe, L.G. Mason, and F.R. Sutherland, “A Report on the Validation of the Transformed Canadian Forces Command Structure,” 31 January 2007.

${ }^{696}$ Report of the Standing Senate Committee on National Security and Defence, Four Generals and an Admiral: The View from the Top, Second Session Thirty-ninth Parliament 2008, p. 13, found online on 17 October at http://www.parl.gc.ca/Content/SEN/Committee/392/defe/rep/rep11aug08-e.pdf .

${ }^{697}$ Jockel, 2007, p. 180. Jockel's assessment of the causal factors in the establishment of Canada Command is accurate and supports this study's analysis.
} 
the Defence Staff (DCDS) structure, ${ }^{, 698}$ is testimony to this constructivist analysis of how social factors shape different aspects of national security policy. Nevertheless, the creation of Canada Command provided a much clearer delineation of military responsibilities ${ }^{699}$ for the clarification of roles and responsibilities between Canada Command, NORAD, and NORTHCOM, which both BPG reports said were necessary.

\subsubsection{Tri-Command Study}

When comparing the organizational relationship of the DCDS to Canada Command, the reporting structures are practically identical in respect of the domestic air domain. ${ }^{700}$ However, the new US Combatant Command structure and the inclusion of Maritime Warning in the 2006 NORAD Agreement renewal brought new dynamics to the bilateral/ bi-national equation. With NORAD, Canada Command, and NORTHCOM now sharing the task of defending North America, it was necessary to examine all recent changes and assess the way ahead. In July 2006, the CDS and the CJCS signed the

${ }^{698}$ Charron and Fergusson, 2014, p. 25; Also Allan English, “Outside CF Transformation Looking In", Canadian Military Journal, Vol. 11, No. 2, Spring 2011, validates this constructivist approach in the scepticism he voices of this ideational shift.

${ }^{699}$ Canada Command's mandate, reflective of USNORTHCOM's, placed Canada and continental North America under a single theatre of operations for the Canadian Forces, offering a single point of contact for the spectrum of defence and security partners. For the first time, military support to civilian authorities for domestic operations was to be deliberately planned and coordinated through established operational commands thereby increasing each nation's ability to protect its citizens by being prepared to meet all national needs across the entire security spectrum, from safety to security to defence.

${ }^{700}$ Command and control linkage comparison of briefing decks given by the DCDS in September 2005 and the Commander of Canada Command 2009. In both cases the Commander of 1 Canadian Air Division generates the air forces on behalf of the Commander of Air Command, was operationally responsible for air defence to the Commander NORAD, and was the Joint Forces Air Component Commander responsible to the designated Joint Forces Commander (ie DCDS or Commander Canada Command for domestic Joint operations) - see Chief of the Air Staff, Canadian Aerospace Doctrine B-GA-400-000/FP-000, December 2010 found online at http://www.rcaf-arc.forces.gc.ca/assets/AIRFORCE_Internet/docs/en/cf-aerospacewarfare-centre/b-ga-400-000-fp-000.pdfAchapter_6_command and_control ; Also see K.L. Woiden, "Domestic Operations in Canada: The Relevance and Applicability of Mission Command", Canadian Forces College AMSP 10, 2007 found online http://www.cfc.forces.gc.ca/259/260/270/woiden.pdf. 
Canada-United States Basic Defence Document ${ }^{701}$ (BDD) that directed the commanders of the three commands to 'initiate a study to investigate the future roles, missions, and relationships for their Commands. ${ }^{, 702}$ The $B D D$ also directed the development of two bilateral plans, the Canada-US Combined Defence Plan (CDP) and the Canada-US Civil Assistance Plan $(\mathrm{CAP})^{703}$, as well as revision of one bi-national plan, NORAD Concept Plan (CONPLAN) $3310 . .^{704}$

With the Final BPG Report ${ }^{705}$ as the starting point, the "the overall goal of the Tri-Command Study was to increase North American defence and security, while respecting national sovereignty." 706 The study was tightly controlled through Terms of Reference issued jointly by the CDS / CJCS that provided study objectives, scope, methodology, and evaluation criteria for determining possible courses of action (COA). A Senior Steering Group (SSG), comprised of executive level officers and civilians from the two militaries and Foreign Affairs/ US State departments, provided oversight to the Working Group efforts. This military to military study was told to focus initially on

\footnotetext{
701 The Canada-US Basic Defence Document designates the Commander Canada Command (now CJOC) and Commander USNORTHCOM as planning agents responsible for the production of the Combined Defence Plan in synchronization with NORAD and established bilateral plans.

${ }^{702}$ Canada, Department of National Defence (Tri-Command Report), Framework for Enhanced Military Cooperation among North American Aerospace Defense Command, United States Northern Command, and Canada Command, June 2009, found online at: http://www.canadacom.forces.gc.ca/docs/pdf/BGFramework-eng.pdf

${ }^{703}$ See Sloan, 2010, pp 119-120 for a succinct overview of the CDP and CAP.

${ }^{704} \mathrm{Ibid}$, paragraph 12 .

${ }^{705}$ The BPG Reports had a heavy bi-national flavour, no doubt influenced in the rarefied atmosphere of the NORAD environment that was passé by the time it was published. Of the four future concepts listed on pages 35-41 in the final report, only concept 1 (Three Commands - Complementary Missions) was relatively acceptable. Whether the BPG was an information-sharing mission or an appeasement exercise, the knowledge gained through analysing the bi-national options certainly impacted the COAs contemplated and shaped the continued development of a bilateral vice a bi-national relationship. See Brister, 2012, Chapter 6.

${ }^{706}$ Canada Command Backgrounder found online at http://www.canadacom.forces.gc.ca/par-par/canuscaneu/frm-frm-eng.asp . Another good synopsis of the Tri-Command study can be found online at http://nationalstrategy.com/Portals/0/documents/Summer\%202010\%20NSFR/George\%20Gaines\%20\%20Summer\%202010\%20NSFR.pdf
} 
operational level working relationships of a bilateral nature, with a view to identifying possible bi-national COAs for future consideration. The Vancouver 2010 Olympic Games was to be used as the benchmark event for determining the NORAD/Canada Command relationship in supporting the games ${ }^{707}$, as well as a forcing function in the Tri-Command study. According to those interviewed, the CDS/CJCS directed that "no harm come to NORAD' when considering relationships and COAs. ${ }^{708}$

The Terms of Reference were written to focus primarily on military-centric issues. However, two important evaluation criteria bounded the analysis: maintenance of national sovereignty and political acceptability in the form of public and political opinion. ${ }^{709}$ The $222^{\text {nd }}$ Meeting of the PJBD was briefed that the study had produced "sixteen "quick hits"" action items in the first phase of the study "that could be put into effect within the current policy framework over the winter of 2008-09."710 Recommendations regarding potential areas for extending bi-nationalism were beyond the authority of the military commanders and were passed to respective defence/foreign affairs policy divisions for further consideration. In all, the Tri-Command Study resulted in three keystone documents, The Framework for Enhanced Military Cooperation (September 2009), Tri-Command Vision (March 2010), and Tri-Command Strategy

\footnotetext{
${ }^{707}$ Historically, and by authority of the NORAD Agreement, NORAD worked directly with Other Government departments and interagencies in Canada. This arrangement had caused some coordination issues during security of previous special events. Canada Command argued that it should be responsible for all military support for National Special Security Events in Canada as NORTHCOM was in the US where NORAD was a supporting command.

${ }^{708}$ Confidential interviews.

${ }^{709}$ Confidential Interviews.

${ }^{710}$ Wikileaks diplomatic message from the US Embassy in Ottawa to Washington - Subject: USCANADA PERMANENT JOINT BOARD ON DEFENSE (PJBD), December 2, 2008 found online 15 October 2015 at https://wikileaks.org/plusd/cables/08OTTAWA1508_a.html .
} 
(December 2010) ${ }^{711}$, and spawned the Tri-Command Cooperative Initiatives that now includes two more agreements signed in December 2012 at the $230^{\text {th }}$ PJBD. ${ }^{712}$

The Framework for Enhanced Military Cooperation was the initial product of the study and provides a clear understanding of how central the NORAD mission continues to be in its own right and how integral NORAD is to the overall effectiveness of the other two national commands. The Framework also states that both nations "desire to retain unilateral response options to air threats... [that will] require careful coordination of efforts during planning and execution" $" 713$ between NORAD and the national commands. This unilateral response clause acknowledges that there are missions where sovereignty issues are paramount and NORAD must operate accordingly, such as during National Special Security Events, where differences in national legislation and responsibilities for

\footnotetext{
${ }^{711}$ Department of National Defence, The Canada-U.S. Defence Relationship Backgrounder, 4 December 2014, found online on 16 October 2015 at http://www.forces.gc.ca/en/news/article.page?doc=the-canada-us-defence-relationship/hob7hd8s

"The Tri-Command Framework, signed by the Commanders in September 2009, described how the three Commands - CJOC, NORAD and the USNORTHCOM - will operate and interact, highlighted fundamental relationships, and underscored command responsibilities concerning mutual support and cooperation. The Framework led to the identification of sixteen specific action items, most of which have since been completed, aimed at improving cooperation, efficiency and interoperability among the three Commands. The Tri-Command Vision, signed in March 2010, provided a strategic view on how the three Commands should cooperate and collaborate to achieve their missions and identified five strategic goals. Those goals are to: strengthen the collective ability to detect, deter, defend against, and defeat threats to our nations; improve unity of effort and with respective mission partners; develop a culture of continuous collaboration and cooperation in planning, execution, training, information management, and innovation; enhance intelligence and information sharing and fusion to support mission accomplishment; and to strengthen the collective ability to provide appropriate, timely and effective support to civil authorities, when requested. The third keystone document is the Tri-Command Strategy. Signed in December 2010, the strategy outlines a series of shared tasks designed to strengthen working relationships with defence and security partners, including such things as: improving the ability to share classified information; completing the review of the Civil Assistance Plan; sharing best practices/lessons learned; and improving shared situational awareness in the five domains in which the military operates (land, sea, air, space, cyber)."

712 Ibid. "The Commander of CJOC, Lieutenant-General Stuart Beare, and the Commander of NORAD and USNORTHCOM, General Charles H. Jacoby, Jr. signed two documents - the Tri Command Framework for Arctic Cooperation and the Tri Command Training and Exercise Statement of Intent - during the 230th meeting of the Canada-U.S. Permanent Joint Board on Defense, in Colorado Springs, Colorado, in December 2012."

713 Tri-Command Report, Framework, 2009, paragraph 9.
} 
security operations require tailored mission planning and execution. ${ }^{714}$ This was the case with NORAD's contribution to the security effort for the Vancouver Olympics. ${ }^{715}$

Concurrent with the study, Canada Command and NORTHCOM had signed the bilateral CAP in February 2008 that quickly proved effective, with Canada Command providing support for Hurricane Hanna/Tropical Storm Gustav relief in 2008 and NORTHCOM reciprocating with support to the Vancouver Olympics. ${ }^{716}$ The CDP is not a product but a planning framework for enhanced defence cooperation between Canada and the US. ${ }^{717}$ As an iterative process, the three commands are constantly seeking ways and means to ensure close collaboration in jointly defending North America from external attack, and the aim of the CDP was to adapt and update previous defence plans into the new construct. Thus the CDP could not be formalized until the construction of the post 9/11 North American security complex had matured with defined roles and missions through the Tri-Command Study.

\footnotetext{
${ }^{714}$ National Command Authorities differ between Canada and the US, where the authority to destroy a civilian aircraft in Canada is ultimately held by the Prime Minister and select Ministerial authorities, while the US has delegated that authority to the Commander NORTHCOM. See Jockel, 2007, pp.169-170; Madsen, 2011, p. 6; "Backstrom described challenges to synchronization emanating from various causes, to include sovereignty issues, political realities, and incongruous command authorities among partners with complementary missions, despite differing organizational structures." - Wikileaks, December 2, 2008, paragraph 9.

715 Overall security for V2010 was the responsibility of the Royal Canadian Mounted Police (RCMP) who led a multi-organizational Integrated Security Unit, with the Canadian Forces (CF) supplying unique military capabilities in support of RCMP operations. Canada COM led the CF effort as Operation (OP) Podium, providing land, sea, and air support while NORAD was a supporting command ensuring airspace security both inside and outside the Olympic Airspace Control Area. Due to the congested airspace of the Vancouver area, NORAD was integrated into the interagency Air Security Operations Centre to ensure close coordination and control of all aircraft inside the Olympic Airspace, while outside, NORAD performed its normal duties on both sides of the border. See Canadian Forces Air Warfare Centre, "Canadian Special Security Events: An Improved Framework for Royal Canadian Air Force Command and Control”, Air Force Journal, Vol 12, Issue 2, Spring 2013, pp. 8-16; Alan Stephenson, Securing the Continent: Where is NORAD Today?. Toronto: Canadian International Council, 2011.

${ }^{716}$ See DND/CAF Backgrounder December 2014; Statement of General Victor E. Renuart, Jr. USAF, United States Navy, Commander United States Northern Command and North American Aerospace Defense Command before the Senate Armed Services Committee, 11 March, 2010.

${ }^{717}$ See DND/CAF Backgrounder December 2014.
} 
Rejection of Rumsfeld's hasty offer of a bi-national military command allowed time and space for both countries to determine national priorities first. The transition to NORTHCOM was not as straightforward and unproblematic as national leaders may have imagined. ${ }^{718}$ The US experienced comparable issues with domestic informationsharing, as the previous chapter identified in Canada. In fact, as expressed in the Framework, the challenges with sharing classified information is "a cumbersome and time consuming process" ${ }^{\mathrm{719}}$ and has been a long-standing problem with all militaries working bilaterally with the US. ${ }^{720}$ Attempting to create an 'expanded NORAD' in the aftermath of 9/11 would have been impossible unless significant convergence of security norms in both countries occurred. The subsequent loss of sovereignty and independent security action required of a bi-national continental defence structure simply could not be justified given the perceived threat of terrorism by Canadians.

In the end, however, the aim of Rumsfeld's proposal "of an integrated defence of North America" is being realized, albeit in a more bilateral fashion. The Framework for Enhanced Military Cooperation agreement essentially established a NATO-like structure, where each nation provides for its own national security until an established threat level

\footnotetext{
718 In meetings January 20 with NorthCom Deputy Commander and U.S. NORAD Vice Commander, "Lt. General Inge reiterated the points he made to PCO's Gauvin, saying the U.S. would like to explore ways to improve NORAD and expand its functions, but we needed to see what was possible in the short term and find ways to amend and add functions when we were ready. Responding to a question about NorthCom, the General said that the Command had a platter-ful of issues before it, including force protection, working with DHS to define roles and relationships, and coordinating JTF actions in a variety of areas." Wikileaks diplomatic messages from the US Embassy in Ottawa to Washington - Subject: Canada: Cabinet to Review Mandate to Negotiate/Conclude 2006 NORAD Agreement in Early February, 2005 February 2, online 16 October 2015 at http://wikileaks.org/plusd/cables/05OTTAWA315_a.html 1 .

719 Tri-Command Report, Framework, 2009, paragraph 14.

${ }^{720}$ Wikileaks, February 2, 2005 - "The most difficult area, Gauvin said, was with regard to intelligence sharing. For example, Canadians needed to know immediately what the threat was when asked to board a ship. Often the intelligence was marked NOFORN or not releasable, and it would take days to obtain clearance to release or share. Gauvin said that Canada has a different culture in classifying documents." Marking a document "CAN Eyes Only" was very difficult, so just about everything was made releasable to U.S. whereas the U.S. tended to default to NOFORN classification."
} 
triggers a 'change in operational control' (CHOP). In peacetime, the Commanders Canada Command and NORTHCOM command national land and sea forces while the Commander NORAD commands air forces. "USNORTHCOM and Canada COM are national commands reporting to their governments through the Secretary of Defense (SecDef) and CDS respectively, while NORAD is a bi-national command reporting to both governments through the SecDef and CDS." ${ }^{, 721}$ The lines of command and control are clearly delineated nationally. In this manner, sovereignty and independence are ensured for both countries. In times of tension and war, it is logical that the CDP would have provisions to CHOP national forces to a regional UCP Commander. ${ }^{722}$ Thus, the incrementalism that realists disparage is actually the process of constructing a North American security complex that is predicated on Canadian National Security Culture. ${ }^{723}$

\subsubsection{Maritime NORAD}

Concerns with maritime security, and the possibility of 'rogue states' or transnational terrorist organizations attacking the US, were emerging in the late 1990s. ${ }^{724}$ The vulnerabilities of the maritime system were well known. Criminal elements had historically been exploiting weaknesses for illegal gain. However, the 9/11 attack demonstrated that a small group of purposive actors could inflict considerable damage on a powerful nation by attacking at the seams of a liberal democracy using modern

\footnotetext{
721 Tri-Command Report, Framework, 2009, Executive Summary.

${ }^{722}$ Although the CDP is classified and the specifics are not releasable, it is logical to assume parallel provisions as those in CONPLAN 3310 that provide additional forces to the Commander NORAD as the threat escalates. Similarly in NATO, the Commander USEUCOM is double-hatted as the NATO Supreme Allied Commander (SACEUR) and acquires predetermined national forces as threats to the alliance dictate. ${ }^{723}$ Lagassé, 2014; Jockel, 2009.

724 Report of the National Defense Panel, Transforming Defense: National Security in the 21st Century, December 1997 found online 19 October 2015 at http://www.ists.dartmouth.edu/docs/trf defl.pdf ; Sam Tangredi, The Future Security Environment, 2001-2025”, in Paul Bolt et al, eds., American Defense Policy, Eighth Edition, Baltimore: The Johns Hopkins University Press, 2005, p. 55;Hart and Rudman, 2001, p. 16.
} 
technology to advantage. Extrapolating the possible terrorist scenarios, it was evident that water-borne WMDs could be easily transported and delivered to coastal and inland population centres. Critical infrastructure, crucial to commerce and defence, was exposed to very large water-borne improvised explosive devices that could have a crippling effect if detonated in US Navy harbours, near major ports or beside one of 68 nuclear power plants along navigable waterways. ${ }^{725}$

The genesis of the NORAD Maritime Warning mission can be traced back to the list of options presented to Rumsfeld to consider in the aftermath of $9 / 11 .^{726}$ The concept to expand NORAD to include land and sea was reactive and ill-defined. It was wise for the Chrétien Government to pass on the initial offer and wait to determine the best way forward. Many analysts agree that the 'maritime NORAD' envisioned by Canada did not coincide with the direction the US had in mind for a 'maritime NORAD' ${ }^{727}$ Whereas Canada saw this in an institutional sense, the "dominant U.S. 'Maritime NORAD' vision ....focuses on adapting NORAD air defence tactics to maritime tasks to allow the U.S. agencies to detect, track, identify, and, when necessary, interdict shipping well before that shipping arrives in their ports." ${ }^{.728}$

This 'dominant US vision' model stemmed from the very successful US Joint Interagency Task Force (South) (JIATF-S) concept used to combat organized crime cartels from illicit trafficking of drugs and humans into the US, described by Munsing

\footnotetext{
${ }^{725}$ Michael O'Hanlon, "Protecting the American Homeland," The Brookings Review, Vol 20, No.3, 2002, p. 13-16.

${ }^{726}$ Lagassé, 2014, p. 194.

${ }^{727}$ See Eric Lerhe, “Will We See A Maritime NORAD?", Journal of Military and Strategic Studies, Vol 8, Issue 4, Summer 2006; R. B. Watts, Implementing Maritime Domain Awareness, Thesis paper at Naval Postgraduate School, Monterey, California, March 2006, found online on 20 October 2015 at https://www.hsdl.org/?view\&did=461642

${ }^{728}$ Lehre, 2006, p. 1.
} 
and Lamb as "The Gold Standard for Interagency Operations". ${ }^{729}$ However, unlike a binational command, JIATF-S is a unilateral US initiative that incorporates international partners under the command and control of the Combatant Commander of US Southern Command. Although an exceptional institution, its success stems from the specificity of its mission and the Presidential/National Security Decision Directives that empowered military leadership of the interagency organization. ${ }^{730}$ The Canadian equivalent of a Decision Directive is an Order in Council (OIC) under the Crown Prerogative which the Canadian government chose to reject in solving the MSOC governance issue. Canadian National Security Culture does not embrace military leadership in civil-military institutions ${ }^{731}$ and successive Canadian governments have become less prone to making use of OICs to provide contestable political solutions.

Two important factors lost in the analysis of the American offer of an 'enhanced NORAD' are the egocentricity of the US military and the emergence of the nascent Department of Homeland Security (DHS). ${ }^{732}$ First, Secretary of Defense Rumsfeld represented the interests of the US military and there are no indications that he had consulted widely outside of military advisors regarding the vision of his premature and

\footnotetext{
${ }^{729}$ Evan Munsing, and Christopher J. Lamb, Joint Interagency Task Force-South: The Best Known, Least Understood Interagency Success, Washington, D.C: National Defense University Press, June 2011, p. 30.

${ }^{730}$ Ibid. "In 1986, President Reagan took a major step toward institutionalizing DOD support for the war on drugs. National Security Decision Directive 221 declared narcotrafficking a national security threat and authorized the Secretary of Defense to take measures that would "enable U.S. military forces to support counternarcotics efforts more actively." - p. 9; and President Clinton signed the Presidential Decision Directive 14 in 1993 that led to the merging of US military and civilian agencies responsible for drug interdiction operations in to three interagency task forces. These forces eventually became 'Joint' with the inclusion of representatives from other participating nations. - pp. 16-30.

${ }^{731}$ See Allan English, Understanding Military Culture: A Canadian Perspective, Montreal: McGill-Queen's University Press, 2004, pp 123-124.

${ }^{732}$ In securing the homeland, DHS brings together 22 Federal departments and agencies. As in Canada, there are specific DHS organizations, such as the USCG, the Federal Emergency Management Agency, Citizen and Immigration Services, and the US Customs and Border Protection, which contribute along with the FBI and other Federal institutions towards maritime security. Each provides intelligence/information input towards creating the maritime Common Operating Picture.
} 
hasty proposal for a bi-national continental military command. It is clear from the comments of Admiral Vern Clark, Chief of Naval Operations (CNO), that to the US Navy (USN), maritime NORAD' was predicated on separation of homeland defence from homeland security. In his view, the USN and USCG under Title $10^{733}$ would be central to a global 'NORAD-like' network where the 'key to success' would be through exploiting the two arenas that lack sovereignty, space and the high seas. ${ }^{734}$ With global partners, the USN would detect, track, identify, and interdict shipping using the freedom of sovereignty to provide information for unilateral action on the high seas.

The use of the term NORAD in this context referred only to the operational concept in military defence. The American military thinks and acts in global terms. The responsibilities of each service transcend regionalism and their "distinct roles produce distinct cultures."735 Unlike the newly created regional Combatant Commander, Commander NORTHCOM, in the USN's global defence capacity, it could ignore the necessary whole-of-government (WoG) integration required for effective maritime domain awareness (MDA) of North America. Canada did not significantly factor into this

\footnotetext{
${ }^{733}$ Under Title 10 of the U.S. legal code, the USCG operates under the Department of Defence and is considered the 'fifth' service in the military organization. Under Title 14, the USCG is a multi-dimensional security organization within the Department of Homeland Security, with substantial constabulary authority. ${ }^{734}$ The insert article "A Maritime NORAD?" provides a clear vision of the US global, integrated military approach to maritime security that uses the operational concept of NORAD but envisions the creation of a global "virtual maritime traffic centre." "The Coast Guard and the Navy also will require agreements to delineate responsibilities for the two. Adm. Clark suggests that the Coast Guard may be placed in charge of coastal operations while the Navy handles more distant efforts, but even so there are some aspects of more distant operations that can be handled only by the Coast Guard. These include situational awareness specifics such as knowing the contents of a container in an overseas port." See Robert K. Ackerman, "Pace of Change Accelerates For U.S. Navy", Signal Magazine, December 2004, found online 16 October at http://www.afcea.org/content/?q=pace-change-accelerates-us-navy

${ }^{735}$ English, 2004, p. 9.
} 
"maritime NORAD" 736 , and likely not in Rumsfeld's idea of an "enhanced NORAD" either.

Secondly, discussion of 'maritime NORAD' under Admiral T.J. Keating, Commander NORAD-NORTHCOM 2004-07, began to reflect the realities of the internal processes undertaken by the US after 9/11. Although Canadian analysts and military officers viewed 'maritime NORAD' as the "logical next step"737, as a Combatant Commander in charge of Homeland Defense, Keating had a larger area of responsibility that did not lend itself to a bi-national agreement for maritime operations. As Keating stated before Congress, "a maritime NORAD is a nice concept, but we think it would be unnecessarily restrictive." ${ }^{, 738}$ The NORAD construct implied command authority, not cooperation. Not only were Canadian departments struggling internally with maritime security issues, so too were American institutions. As Robert Watts observed, "many of the agencies that operate under the DHS umbrella that are potential users/contributors to MDA would have a difficult time operating under a military command structure that is

\footnotetext{
${ }^{736}$ Joseph Jockel and Joel Sokolsky, "Continental Defence: 'Like farmers whose lands have a common concession line"', in David McDonough, ed, Canada's National Security in the Post-9/11 World: Strategy, Interests, and Threats, Toronto: Toronto University Press, 2012, p. 128.

${ }^{737}$ Philippe Lagassé, “A Maritime NORAD?” SITREP, Royal Canadian Military Institute, Vol. 64, No. 5, November- December 2004, p. 10, found online on 20 July 2015 at http://www.rcmi.org/getmedia/7157568f-c8ae-44f4-955f-d9f4929c3d5e/04-5-Sitrep.aspx ; In a statement before SCONSAD 2003, the Chief of Maritime Staff, Vice Admiral Ron Buck, said, "In January, the Canada-U.S. Bi-national Planning Group completed their mission analysis session in Colorado and will soon embark on the production of bi-national plans to improve our ability to work in the domestic binational context. I am pleased to report that Rear-Admiral James Fraser, currently in Command of Maritime Forces Pacific, has been appointed as Liaison between the Planning Group and Northern Command. Subordinate to the Canada-U.S. Bi-national Planning Group is a Maritime Plans and Surveillance Working Group that will concentrate on bi-national maritime security and surveillance. This group will collaborate with groups like the IMSWG and the NORAD Maritime Surveillance Working Group to create military plans that deal with the unique lens of bi-national military cooperation when federal governments agree to include the military in resolving future challenges."

${ }^{738}$ Statement found in Lehre, 2006, p 10, with quote taken from U.S. DOD, "U.S. Senator John W. Warner (R. VA) holds hearing on military strategy and operational requirements for combat commanders,"

Political Transcript Wire, Lanham, 15 Mar. 2005. p. 3,4.
} 
completely foreign, in addition to a host of legal issues that could arise from such an arrangement."739

The legal and security norms that delineate law enforcement from military action in Canada were similarly causing WoG integration issues in the US. At the $214^{\text {th }}$ PJBD in October 2004, the newly appointed DHS representative expressed a divergent view of the 'maritime NORAD' concept that mirrored the discussions at IMSWG.

In the lively discussion of options for enhanced maritime security cooperation, Department of Homeland Security (DHS) representative Mr. Matthew Broderick argued that much work would be needed for Washington to agree, by Fall 2005, to give to NORAD responsibility for maritime defense threat warning and control, similar to its role in aerospace defense. While NORAD had demonstrated an unprecedented level of U.S. collaboration with a foreign government, he said, it remained unclear that this type of fusion necessarily was "desirable" in the maritime domain. Moreover, in his view an incoming vessel that posed a threat was more "homeland security" than "defense."

Defence and security institutions on both sides of the border were straining to find a more integrated way forward within their own legal and security norms. ${ }^{741}$ Resolving the significant bi-national impediments required by the Rumsfeld proposal would have been nearly impossible without the abrogation of national norms by both countries.

The US had enacted the USA PATRIOT Act to overcome the information-sharing issues with which Canada was struggling. The stronger role that the US military held in the American civil-military relationship allowed hemispheric Combatant Commanders greater leadership roles in overcoming problems of WoG integration through Presidential

\footnotetext{
${ }^{739}$ Watts, 2006, pp. 44-45. Watts presents a succinct explanation of the challenges of using the JIATF-S and NORAD models for Maritime Domain Awareness, pp 41-49.

${ }^{740}$ Wikileaks, $214^{\text {th }}$ PJBD, October 2004;

${ }^{741}$ Charron and James Fergusson, 'Left of Bang': NORAD's Maritime Warning Mission and North American Domain Awareness, Winnipeg: Centre for Defence and Security Studies, 08 October 2015, p 16, found online 15 January 2016 at http://umanitoba.ca/centres/cdss/media/0_NORAD_Maritime_Warning_Mission_Final_Report_8_Oct_201 $\underline{5 . p d f}$. For academic disclosure, this dissertation author was an academic member of this report.
} 
and National Security Decision Directives. Elites in the Canadian government were not willing to make use of the Crown Prerogative to overcome national security norms, as Canadian society was thought not likely ready to accept the loss of acquired values for the increments of security proposed. ${ }^{742}$ Nor was the government ready to make the structural changes to the CCG and Canadian navy to bring them in operational alignment with the US ${ }^{743}$, such that the Commander of NORAD would have ready vessels at his disposal to control. Ultimately, legal and security norms made a 'maritime NORAD' not commensurate with Canadian independence and sovereignty. In addition, the US was moving unilaterally on a different path that made a 'maritime NORAD' inconsistent with its domestic and global security interests.

\subsubsection{Evolution of NORAD's Maritime Warning Mission}

Although there was much uncertainty about the exact form that NORAD would play in the protection of Canadian acquired values in 2004, it was significant that the National Security Policy statement identified the BPG and NORAD as the vehicles to improving marine security cooperation. ${ }^{744}$ One year later, the International Policy Statement on Defence expressed the effort for "Enhanced North American Defence Cooperation" in more bilateral than bi-national terms as examining a number of "security

\footnotetext{
${ }^{742}$ A number of factors kept the Crown Prerogative option in check. Firstly, both society and elites viewed the 9/11 attack as a criminal act rather than an existential threat in need of drastic protective measures. Secondly, as detailed in Chapter 5, the use of the Crown Prerogative to overcome issues of informationsharing, mandate changes, and governance would have certainly precipitated Charter challenges. Thirdly, society's agency in determining policy outcomes was greatly increased due to the minority government positions.

${ }^{743}$ See previous two chapters regarding challenges with structural changes and information sharing. Unlike the USCG, the CCG has no 'blue water' (open ocean) capability. The safety and regulatory role of the CCG limits its operations to 'brown water' (navigable rivers and estuaries) and 'green water' (coastal waters, ports and harbours). With no paramilitary operational capability or mandate for use-of-force, the CCG cannot be compared to the USCG.

${ }^{744}$ Government of Canada, Securing an Open Society: Canada's National Security Policy, (NSP), April 2004, p. 36.
} 
and defence areas in which our two countries could work more closely together." ${ }^{, 75}$ This emphasis on bilateralism was confirmed during negotiations for the NORAD Agreement renewal six months later. ${ }^{746}$

With input from $\mathrm{IMSWG}^{747}$, the BPG, and American sources ${ }^{748}$, Canadian officials understood that maritime domain awareness covered the full spectrum of national security and was not simply the purview of defence, the last sector of the Venn diagram identified in the National Security Policy statement. The Martin Government realized the American-centricity of security norms in the US and the implications to Canada, particularly with respect to the National Security Presidential Directive NSPD41/ HSPD- $13^{749}$ that ordered the development of a national security strategy for maritime security by the Department of Defense (DoD) and DHS. By limiting the bi-national

\footnotetext{
${ }^{745} I P S-D, 2005$, p. 22.

${ }^{746}$ Wikileaks, 2005 October 24, para 6 - "Bi-nationally, Chapin proposed that NORAD be expanded to include maritime surveillance and warning, and the Aagreement [sic] should be of no fixed term. Additionally, the BPG planning function should be maintained. Bilaterally, he noted, the United States and Canada should: discuss how to enhance maritime defense, explore how to develop bilateral military-tomilitary support for civil authorities, and explore training opportunities to test and evaluate existing plans for defense of the continent." and Para 14 - "In presenting its text, the Canadian delegation pointed out issues of particular importance. References to information sharing were included to send an "important signal" and stress the need for information exchange. On maritime warning, it was important to develop a complete maritime picture at NORAD. Responses to maritime threats would be through bilateral channels." ${ }^{747}$ See the previous two chapters. The 2004 Auditor General's Report indicates the leadership void and intra-departmental problems that existed when the IPS was being staffed. Most analysts focus on the BPG and do not relate the fundamental interdepartmental disagreements on MDA identified at IMSWG. Bilateral feedback was occurring amongst CANUS security partners on the development of the DHS approach to MDA prior to the HSPD 13.

${ }^{748}$ The US was being very clear in the direction it was heading with respect to maritime security and how it intended to conduct operations in its national interests. In meetings on 20 January 2005, Canadian security officials met with NorthCom Deputy Commander and U.S. NORAD Vice Commander, Lieutenant General Joseph Inge. "On the question of expanding security cooperation to the maritime domain, Inge urged a thoughtful approach given that domain awareness was considerably larger than the operations domain. It would be important first to identify what we want to accomplish, he said, and then decided how and where to manage it. There was room in the operational domain for U.S.-only operations and Canada-only operations." Wikileaks, 2005 February 2.

${ }^{749}$ Issued on December 21, 2004, the National Security Presidential Directive NSPD-41 was also called the Homeland Security Presidential Directive HSPD-13 in recognition that maritime security policy was essentially a domestic security process vice a military defence issue. Contents were found online on 20 October 2015 at https://fas.org/irp/offdocs/nspd/nspd41.pdf
} 
aspects of maritime security to surveillance, information-sharing and assessment in the International Policy Statement on Defence, ${ }^{750}$ the Canadian government began laying the policy foundation for the addition of a limited maritime role to the NORAD Agreement in 2006.

The US government was well aware of the complexity of the maritime environment in achieving MDA and the domestic security norms that needed alignment before this acquired value could be achieved. The increment of security was important enough for the President to use his powers to facilitate the necessary structural changes through such policy vehicles as the USA PATRIOT Act and NSPD-41. This did not occur in Canada and, while negotiations on the renewal of the NORAD Agreement were ongoing, the US issued The National Strategy for Maritime Security in September $2005 .^{751}$ This national strategy was aimed "to better integrate and synchronize" the American web of relationships through "eight supporting plans to address the specific threats and challenges of the maritime environment."752 This emphasis on "activities on a global scale" presaged the use of the entire American security network to form the foundation for the US global maritime security complex, much in the same way that the integrated support network for missile defence had gone.

This was confirmed in the supporting plan, National Plan to Achieve Domain Awareness, issued one month later, as well as in the Navy Maritime Domain Awareness Concept issued in May 2007. Both define Maritime Domain Awareness (MDA) as "the

\footnotetext{
${ }^{750}$ IPS-D, 2005, p. 22

${ }^{751}$ United States, The National Strategy for Maritime Security, Washington, DC: White House, September 2005, found online 22 October 2015 at https:/www.hsdl.org/?collection\&id=4\#Maritime

${ }^{752}$ Ibid, p. ii. The supporting plans include: National Plan to Achieve Domain Awareness; Global Maritime Intelligence, Integration Plan; Interim Maritime Operational Threat Response Plan; International Outreach and Coordination Strategy; Maritime Infrastructure Recovery Plan; Maritime Transportation System Security Plan; Maritime Commerce Security Plan; and the Domestic Outreach Plan.
} 
effective understanding of anything associated with the global maritime environment that could impact the security, safety, economy, or environment of the United States." ${ }^{.753}$ As Admiral Keating had earlier observed, 'maritime NORAD' was too restrictive to the security interests of the US. This may have been true regarding direct operational aspects; however, the National Plan to Achieve Domain Awareness also provided a segue for the expansion of NORAD as a security partner in the defence of North America. As stated in the National Plan,

The purpose of MDA is to facilitate timely, accurate decision-making. MDA does not direct actions, but enables them to be done more quickly and with precision. MDA is achieved by (1) collecting, analyzing and disseminating data, information and intelligence to decision makers, and (2) applying functional and operational knowledge in the context of known and potential threats. ${ }^{754}$

This was a role that both nations could embrace in a bi-national fashion because it provided for centralized analysis and decentralized execution through national commands, allowing each state to use the MDA information to suit its own purposes.

Thus the 2006 renewal of the NORAD Agreement included a new maritime warning (MW) mission that

consists of processing, assessing, and disseminating intelligence and information related to the respective maritime areas and internal waterways of, and the maritime approaches to, the United States and Canada, and warning of maritime threats to, or attacks against North America utilizing mutual support arrangements with other commands and agencies, to enable identification, validation, and response by national commands and agencies responsible for maritime defense and security. Through these tasks NORAD shall develop a comprehensive shared understanding of maritime activities to better identify potential maritime threats to

\footnotetext{
${ }^{753}$ United States, National Plan to Achieve Domain Awareness, Washington, DC: White House, October 2005, p. 1, found online at https://www.hsdl.org/?collection\&id=4\#Maritime

754 Ibid. p. 7.
} 
North American security. Maritime surveillance and control shall continue to be exercised by national commands and, as appropriate, coordinated bilaterally. ${ }^{755}$

In adding MW, the renewal not only enhanced the service delivery of NORAD, but the mission expansion reinforced its institutional value and, along with declaring the agreement valid 'in perpetuity" 756 , reinforced NORAD as part of the security identity of both nations.

\subsection{NORAD's Maritime Warning Mission}

\subsubsection{A Square Peg in a Round Hole?}

NORAD's maritime warning mission essentially has three components, two of which were part of the stated purpose of MDA in the US National Plan to Achieve Domain Awareness. The first, 'processing, assessing, and disseminating intelligence', gathers the disparate pieces of information and provides professional analysis to decisionmakers. The second tasks the command to 'develop a comprehensive shared understanding of maritime activities to better identify potential maritime threats to North American security through actively engaging and understanding the complexity of the maritime domain from a North American perspective. It is significant that the word 'security' was chosen to reflect the multi-dimensional homeland mission instead of the word defence. Finally, NORAD is to provide 'warning of maritime threats to, or attacks against North America' to allow national decision-makers to act. ${ }^{757}$ In this manner, the centralized analysis provides advice to facilitate decentralized execution. Depending on

\footnotetext{
${ }^{755}$ Agreement between the Government of the United States of America and the Government of Canada on the North American Aerospace Defense Command, 28 April 2006, Article 1, paragraph 2c, found online on 16 May 2014 at http://www.state.gov/documents/organization/69727.pdf.

756 Jockel, 2007, pp. 182-183.

${ }^{757}$ Charron and Fergusson, 2015, p. 15.
} 
the specificity of the situation, responses could be conducted either unilaterally or bilaterally.

However, many obstacles lay before NORAD in implementing the MW mission in 2006. First, the exact nature of the military roles and responsibilities of NORAD were in question given the creation of NORTHCOM and Canada Command. Secondly, NORAD lacked the WoG background, maritime networks, and subject matter expertise to fulfill the MW mission. Finally, the complexity of the mission covered the spectrum of national security from safety to defence and the maritime environment demanded NORAD's integration with partners long dominated by civilian agencies and departments that knew one another. NORAD was immediately seen as an outsider with limited added value by the maritime community. In 2006, NORAD had the MW mission but lacked the tools to accomplish it. NORTHCOM had just stood-up, Canada Command was being established, and both IMSWG and DHS were deep in policy development. North American maritime security was in a state of transition on the path to continental security reconstruction.

Most analysts assume a perfect world when focusing on a single policy issue and fail to take into account the surrounding limitations and constraints. This was the case with NORAD's ability to pursue the MW mission. Priorities needed to be established. Both NORTHCOM and Canada Command were preoccupied with transformation issues which led to personnel-power shortages to conceptualize and deal with the issue ${ }^{758}$. This

\footnotetext{
${ }^{758}$ In his statement to the Senate Armed Services Committee, Commander NORAD-NORTHCOM stated, "We have also moved forward in the development of a shared bi-national common operating picture of the maritime domain. We continue to be challenged in a constrained environment to match the Canadian manpower commitment to this important mission area." - Statement of General Victor E. Renuart, Jr. before the Senate Armed Services Committee, 11 March, 2010.
} 
meant that the MW mission could not move ahead until the Tri-Command Study resolved the first impediment and determined the way ahead. As a result, MW remained in relative stasis until the study was complete in December 2010 and appropriate staff posted in. The social construction of the institutional framework needed to be accomplished before the details of the MW mission could be addressed and this took five years.

Adapting from an aerospace-centric military institution with limited exposure to civilian sectors was challenging. The initial concept of an operational 'maritime NORAD' had passed ${ }^{759}$, but the organizational culture was embedded within NORAD personnel who were unprepared for the slower, more intricate nature of maritime security. Both the US and Canadian navies were opposed to the new MW mission ${ }^{760}$ that they viewed as unnecessarily duplicating their role while the close-knit civilian maritime world viewed this development with skepticism. "For most of the maritime sector, especially the civilian agencies, NORAD was a 'black hole' - few agencies had any idea what NORAD really did or did not do. This was compounded by the relative vagueness, and perceived irrelevance of the NORAD MW mission."761 To all, NORAD was viewed as being at the end of the intelligence food chain with no value to add value to the process. Maritime warning demanded a decentralized approach to achieving MDA in developing a Common Operating Picture (COP) across multiple agencies in the maritime environment and sensitivity to partner identities. To overcome the second impediment, NORAD had to first educate itself on a distinctly different environment from aerospace

\footnotetext{
759 The concept of 'maritime NORAD' may have been overtaken by events, but successive Commanders NORAD-NORTHCOM continued to view their role in more proactive terms than simply MW. In confidential interviews, this came up more than once. "Commander NORAD xxxxx would liked to have recreated JIATF-S around North America."

760 Jockel, 2007, p. 182.

${ }^{761}$ Charron and Fergusson, 2015, p. 15.
} 
where civilian agencies focused on regulatory, safety, and security issues within domestic jurisdictions. $^{762}$

As explained in the MSOC case study, Canadian civilian maritime partners were not only doubtful of NORAD's involvement but apprehensive of any direct military involvement outside prescribed supporting functions. Although American society embraces a larger US military leadership role at the seams of national security, US domestic agencies also had concerns with NORAD's involvement in homeland security.

These perceptions made NORAD's engagement in the MW world that much more difficult because of deeper cultural/organizational perceptions stemming from the once, usually exclusive maritime defence versus security environments that were fused after $9 / 11$; no longer are external threats the sole domain of the military and internal threats the sole domain of civilian organizations. ${ }^{763}$

To overcome this third impediment, NORAD embraced the military principle of 'leading from behind'. With the authority of the NORAD Agreement in hand and the resources of the Commander NORAD-NORTHCOM ${ }^{764}$, NORAD began the slow process of socially constructing the MW mission, beginning with education and awareness becoming 'norm entrepreneurs' in the process. ${ }^{765}$

\footnotetext{
${ }^{762}$ In confidential interviews with Canadian civilian maritime stakeholders, many mentioned NORAD's role in bringing the North American maritime stakeholders together to educate and facilitate. "There is a role for NORAD in ensuring we keep moving forward and in breaking down cultural barriers. NORADNORTHCOM made a concerted effort to understand other government departments. We're not there yet and still making steps." - Confidential interview..

${ }^{763}$ Ibid, p. 15.

${ }^{764}$ As a function of NORTHCOM's Defense Support of Civil Authorities (DSCA), there are over 60 other government departments/agencies represented in NORTHCOM. Although technically separate entities, the Commander of NORTHCOM has the authority of a Combatant Commander which brings with it substantial power and influence, particularly with respect to issues directly related to defense of the USA. Therefore, when the Commander of NORAD requests the support of the Commander of NORTHCOM to bring US homeland security stakeholders together to discuss NORAD's maritime warning mission, a meeting with all actors will likely take place. This was the 'leading from behind' principle adopted in creating the CANUS Maritime Stakeholders' Conference.

${ }^{765}$ Finnemore and Sikkink, 1998, pp. 896-901.
} 
In 2010, the Commander NORAD-NORTHCOM took the opportunity to invite all Canadian and American maritime security actors to the NORAD and USNORTHCOM CANUS Maritime Stakeholders' Conference. This first ever meeting was attended by 255 Canadian and American personnel, representing 55 US and 22 Canadian commands, departments, and agencies. ${ }^{766}$ The conference objectives of information and intelligence sharing were broad, but the main goal was to break down cultural barriers and begin the process of synchronizing the disparate organizations pursuing maritime domain awareness in North America. The conference acted as a forcing function, particularly in Canada ${ }^{767}$, where IMSWG members came away with a greater understanding of larger picture and their place in relation to their US counterparts. Today, IMSWG co-hosts the annual conference along with the National Maritime Intelligence-Information Office (NMIO) and NORAD as the synchronization instrument for MDA of North America. ${ }^{768}$

Accepting NORAD as a new maritime security actor was facilitated in 2009 with the M/V Ocean Lady incident and again in 2010 with the M/V Sun Sea voyage. NORAD had begun testing its maritime warning system through exercises in late 2008; however, the lack of intelligence/information sharing among all organizations had resulted in the M/V Ocean Lady 'materializing' off the coast of British Colombia with 76 Tamil asylum

\footnotetext{
${ }^{766}$ See Thomas J. Doscher, "NORAD, USNORTHCOM Maritime Stakeholders Conference provides clarity for new mission", NORAD and USNORTHCOM Public Affairs, March 31, 2010 found online on 20 October, 2015 at http://www.northcom.mil/Newsroom/tabid/3104/Article/563806/norad-usnorthcommaritime-stakeholders-conference-provides-clarity-for-new-miss.aspx ; NORAD and USNORTHCOM CANUS Maritime Stakeholders' Conference "Quick Look” Report March 20 through April 1, 2010.

${ }^{767}$ During confidential interviews, a number of individuals from four different departments commented on NORAD's achievement of bringing reluctant stakeholders together.

768 " $5^{\text {th }}$ Annual Canada and U.S. (CANUS) Maritime Stakeholders Conference (MSC) - NMIO co-hosted the annual CANUS MSC with the North American Aerospace Command (NORAD) and Canada's Interdepartmental Marine Security Working Group (IMSWG) in June 2014.” See Department of the Navy, National Maritime Intelligence-Integration Office Annual Report: 2014, 31 December 2014, p. v and 1.
} 
seekers aboard. At the time, there was fear that some of the individuals could be members of the Tamil Tiger terrorist group. Incorporating the lessons learned from this incident, NORAD issued its first maritime warning when the M/V Sun Sea was at sea, allowing the MDA community to track its progress towards North America and the Canadian navy to interdict the ship as it entered Canadian waters. Successful intelligence/information sharing allowed NORAD to issue a warning to the two governments and bi-national mission partners that provided time to address this potential threat. Following this proof of concept, the MW mission adapted its procedures with the creation of a maritime advisory message to enable the two governments greater time to plan and perhaps use other means to stop a vessel of interest, such as the M/V Sun Sea, from ever leaving port. ${ }^{769}$

Many of the maritime security initiatives in Canada were mirror approaches acquired from developments in the US maritime community. In 2006, the final US Maritime Operational Threat Response (MOTR) Plan was developed and approved. In Canada, a similar plan, the Maritime Event Response Protocol (MERP), was incorporated into the Federal Emergency Response Plan (FERP) in 2009 as a means for the federal government to coordinate the response to a maritime event and assign the appropriate lead-department given the specificity of the incident. First used with the M/V Ocean Lady and later with M/V Sun Sea, the utility of a coordinated North American approach became apparent and the NORAD Stakeholders Conference became the catalyst for renewed effort by IMSWG members to overcome institutional barriers. ${ }^{770}$ In 2012, the MERP became a stand-alone document and the bilateral MERP/MOTR Strategic Protocol

\footnotetext{
${ }^{769}$ See Charron and Fergusson, 2015, for a fuller account, p. 17.

${ }^{770}$ Comments made by several Canadian departments during confidential interviews.
} 
was signed to "provide an agreed upon process for enhanced information exchange,

supporting timely and effective responses to significant maritime threats and events" $" 771$ in

North America.

From 2009 on, NORAD slowly built its capacity to receive, analyse, and react to maritime intelligence/information through the NORAD J-32 Division.

NORAD J-32 stands at the "end" of the North American MDA/RMP/COP "food chain'. However, there is no significant time differential being a COP user at MARLANT or at NORAD. NORAD J-32 formally receives the North American Maritime COP from USNORTHCOM per se, which in turn receives it from USFFC/NAVNorth, which has combined the U.S. COP and the Canadian COP (after applying filters) into a single North American one. ${ }^{772}$

In Canada, as the information and intelligence is gathered and assembled at various locations, the unclassified maritime domain awareness (MDA) package is combined with the military's classified recognized maritime picture (RMP) to produce a regional combined operating picture (COP) that the MSOC feeds into USFFC/NAVNorth. NORAD J-32 is not a formal intelligence centre, but an analytical one that relies on information-sharing. Being a bi-national command, NORAD J-32 has the ability to 'reach back' domestically to obtain or qualify relevant intelligence/information that may be nationally sensitive or restricted ${ }^{773}$, facilitating time-sensitive decision-making.

\footnotetext{
${ }^{771}$ Canada, Maritime Event Response Protocol/Maritime Operational Threat Response: Strategic Protocol, 2012, p. 1. Interestingly, the protocol links this initiative to the Beyond the Border: A Shared Vision for Perimeter Security and Economic Competitiveness declaration and the bi-national statements; however, the two references to bi-nationalism reflect NORAD's role in defence and organizing committees. The cultural effect of NORAD's leadership imbues other actors with a common North American identity.

${ }^{772}$ Charron and Fergusson, 2015, p 36. MARLANT is Canadian Force Maritime Atlantic, USFFC/NAVNorth is US First Fleet Command/ Navy service element to USNORTHCOM.

${ }^{773}$ Ibid, p.42.
} 
As General Renuart stated to the Canadian Senate Committee in 2010, "I think information-sharing is at the crux of everything our two nations do together."774 He then outlined the difficulties on the US side that were similar to the questions of informationsharing being experienced domestically by IMSWG and the MSOC partners. The sovereignty concerns of the US were analogous to those being debated in Canada, although the acquired values being contested domestically were nation specific. Although improving through stand-alone, interdepartmental and bilateral information-sharing agreements, information/ intelligence sharing issues continue to be a challenge with the Commander NORAD-NORTHCOM today. ${ }^{775}$ A desire for perfect knowledge is to be expected of all military commanders, but it is ultimately society-polity that will determine the extent to which the increment of security is worth the loss of privacy in its own liberal democracy. ${ }^{776}$

The collection of domestic maritime information and production of intelligence is primarily the responsibility of civilian regulatory, security, and law enforcement agencies. The process of reconstructing the national security norms to conform to contemporary transnational threats was an iterative, ideational process that could not be rushed if it was to be sustainable. With the MSOCs declaring Full Operational Capability

\footnotetext{
${ }^{774}$ SCONSAD, 2010, p. 4:38, Renuart testimony, "about information-sharing, I think information-sharing is at the crux of everything our two nations do together. I have some technical frustration because I cannot always put my Canadian and U.S. team mates on the same computer system. Our U.S. SIPRNet - Secret Internet Protocol Router Network - has a releasable version. We are working technically to put the right software on that so the planning tools we need every day are available. Having said that, we, the U.S., have some unique challenges as to who is on that from our civilian side as well, and we are working through the interesting discussion, from the civilian side, of including our closest military partners routinely on that." 775 Confidential interview.

${ }^{776}$ Examples of this contestation are the debates in Canadian society-polity over Bill C-51 and the lack of Congressional approval for parts of the USA Patriot Act that expired on 1 June 2015 that resulted in the USA Freedom Act on 2 June 2015 that amended and restored the expired parts.
} 
in December 2014 and the passage of Bill C-51 $1^{777}$ that aligns Canadian departmental mandates with increased ability to share security relevant information, the major hurdles in providing NORAD with a complete Canadian COP for MDA have been surmounted. It remains to be seen, however, whether the penchant to apply national 'filters' provides adequate protection to sovereignty and acquired privacy values or becomes another impediment to effective decision-making in NORAD's Maritime Warning mission.

\subsubsection{Acquired Value of NORAD's Maritime Warning Mission}

Although many have questioned the added value of NORAD's role in MDA and the MW mission, NORAD has contributed significantly to national and bi-national maritime security through presence and position. As a national symbol of both countries, NORAD is a 'trusted brand' that commands respect as a result of its aerospace defence legacy. The fact of NORAD's presence in the National Security Policy statement was indicative of its value as a national security institution to the government of Canada. This belief allowed NORAD to use its unique position and perspective to facilitate bi-national, interdepartmental cooperation that might not otherwise have occurred without NORAD's non-partisan leadership. Significantly, the maritime security community's view of NORAD as an 'outsider' enabled NORAD to break down cultural barriers through education and exercises as it was seen to be less threatening to the established actors. ${ }^{778}$

The existing national processes for maritime security are embedded within complex, interdepartmental bureaucratic structures for legitimate reasons, as described in the previous chapter. Through NORAD, both Canadian and American stakeholders were

\footnotetext{
777 The newly elected Liberal government of Justin Trudeau supported the passage of Bill C-51 with caveats. It is expected that the less controversial portions of the omnibus bill that pertain to the MSOCs will not be changed in any substantive way to preclude the transmission of a more complete COP from Canada.

${ }^{778}$ Charron and Fergusson, 2015, pp. 41-44; Confidential interviews.
} 
provided a unique North American perspective where they could assess how their specific mandates, responsibilities, jurisdictions, and cultures fit into the larger security picture. Comprehensive maritime domain awareness was in every actor's interest, but according to many of those interviewed it took intermestic socialization through NORAD's leadership to align MDA evaluative and cognitive norms. Although there were many other principal actors involved, NORAD's legitimacy facilitated national and binational consolidation of important enablers, such as developing a common MDA lexicon, creating common standards for evaluating information, and breaking down information-sharing barriers due to significant terminological differences. "As a function of these initiatives, NORAD has served as an important catalyst in deepening interdepartmental and bilateral maritime cooperation among the multi-faceted primary agencies. .779

NORAD's primary value stems from its place of authority within the national command structure of two nations, where it is responsible and accountable for defined defence and security missions in both. Whereas other maritime security actors reside within well-defined national mandates, NORAD provides a unique North American perspective to MDA and MW. It leverages its twinned position with NORTHCOM to obtain a global MDA COP with a focus on the implications to North America. With direct access to each country's National Command Authorities, the Commander of NORAD has the ability to quickly pass information and resolve uncertainties that may affect decision-making between Canada and the US. Although other stakeholders bear responsibility for acting on identified threats, NORAD provides a measure of redundancy

${ }^{779}$ Ibid, p. 43; Confidential interviews. 
in assuring potential threats do not slip through the cracks because of myopic

bureaucratic or national perspectives. ${ }^{780}$

Whether intended or not, the incorporation of a maritime component into the NORAD mandate has positioned the institution for greater roles and responsibilities in the future. Although Canada formally rejected an 'enhanced NORAD' that would provide bi-national continental defence, the construction of the NORAD MW mission has expanded NORAD's capability suite to include the second dimension of the air-land-sea battle space. The Tri-Command defence arrangement has a NATO-like skeletal structure, where the Regional Combatant Commander can quickly transform into the Regional Alliance Commander, with NORAD providing the air and sea domain awareness. In evolving the Tri-Command defence relationship as protection for acquired values rather than being engulfed by the Rumsfeld proposal for defence against a perceived threat, Canada has maintained its independence, maximized its sovereignty and positioned itself to take the next step of a continental defence institution on its own terms should it ever choose such an arrangement. NORAD has been institutionally and culturally central in this process as a symbol that both nations embrace.

\subsection{Conclusion and Analysis}

Wolfers 'specifications' refer not only to the concept of national security as a policy objective but also to the means for its pursuit. ${ }^{781}$ In considering Rumsfeld's proposal for an 'enhanced NORAD', Prime Minister Chrétien chose to use time and space to Canada's advantage, since Canada's perception of the terrorist threat did not

\footnotetext{
${ }^{780}$ Ibid, pp 41-44; Confidential interviews.

${ }^{781}$ David Baldwin, "The Concept of Security", Review of International Studies, Vol 23, No.1, 1997, p 6.
} 
warrant the potential costs to sovereignty and independence. ${ }^{782}$ Canada's core material interests were not threatened by transnational terrorism. The Rumsfeld remedy, however, represented the only direct threat to Canada's national sovereignty and independence, gradual assimilation into the US. As the inclusion of NORAD in the National Security Policy statement demonstrated, Canada's communitarian identity supported collective security. However, society-polity expects a pragmatic security policy solution with clear 'rules of the game' to ensure that change in North American security was in Canada's national interest to pursue. ${ }^{783}$ The threat of terrorism was better addressed through intelligence and law enforcement than with increased military power. In other words, Canada chose to protect established acquired values over embracing a reflexive US security response to a nebulous threat.

As part of both national security identities, it was in Canada's interest to use the symbol of NORAD to reinforce Canada's commitment to North American security. Although the initial concept of NORAD's role in maritime security was vague, its inclusion as an element of Canada's national security was consistent with Canadian National Security Culture in keeping US military power not too close, but not too far

\footnotetext{
782 The Rumsfeld proposal failed the seven specification questions: 1. 'Security for whom?'- favoured the US; 2. Security for which values?- intrinsic values were not threatened so continental defence favoured 'fortress US' values; 3 and 4. 'How much security and at what cost?- Canada would have received marginal increments of 'national security' at the expense of independence and sovereignty in defence policy formulation; 5. From what threats?- this is the critical question, as increased military power does not contribute greatly to preventing terrorist acts in Canada and is mainly used extra-territorially. This is a highly contested concept in Canada and contradicts Canadian National Security Culture.; 6. 'By what means?' - Alignment with US national security norms is contrary to Canadian National Security Culture; and 7. In what time period? - as argued in this chapter, the time period was too short as Canadian National Security Culture favours the use of time and space to determine the best course of action for national interests.

${ }^{783}$ A recent example of analysis of this pragmatic security norm is found in Paquin, 2009, p 105 - "By signing a treaty on a security perimeter that establishes the "rules of the game" and by explicitly opposing the extension of the perimeter to other considerations, Canada should be able to control the continental integration."
} 
away. The US military complex was in the midst of ideational and structural transformation due to the RMA begun in the late 90s. Prime Minister Chrétien was prudent to decline Rumsfeld's offer, as Canada was just a bit player in the larger US global security complex, where the cost of membership would have been substantial without the privileged benefits accorded to 'American-only' institutions. ${ }^{784}$

The Cold War realist paradigm of Canada 'bandwagoning' with the US through NORAD began to shift with the ideational turn of the Trudeau Government. Canada became responsible for its own domestic air security and any US military build-up in Canada during 'times of tension and war' would follow established cognitive security norms. This change increased the need for diplomacy and transactional administration, causing NORAD's institutional actors to become sensitized to the distinctive cognitive and evaluative security norms of each state. As time progressed, articulation of NORAD's role domestically resulted in it becoming a constitutive norm embedded in each nation's security identity. Realist focus on 'revitalizing' NORAD's role through binational continental defences ${ }^{785}$ fails to understand the willingness of both countries to work together bilaterally to defend intrinsic values while collaboratively ensuring the protection of each nation's acquired values.

\footnotetext{
${ }^{784}$ As a matter of security practice, the US military compartmentalizes areas of national security such that only a privileged few actors see the complete security picture. Alliance partners gain certain privileged information based on the size and relevance of their specific contributions and a 'need to know'. Additionally, a bi-national military command would be seen by allies and adversaries alike as Canada being a military appendage of the US. This would have not only meant a loss of sovereignty and independence but would have increased the likelihood of Canada being made a surrogate target by enemies of the US, thus increasing Canada's insecurity vice decreasing it.

${ }^{785}$ See Jockel, 2009; Fergusson, 2010; Lagassé, 2014; Canada, Standing Committee on National Security and Defence, Canada and Ballistic Missile Defence: Responding to the Evolving Threat, Ottawa: Senate of Canada, June 2014, p. v.
} 
The question of Canada's participation in BMD was consciously segregated from institutional NORAD by the Martin Government in the National Security Policy statement, although the expectations were that it would be embedded as an element of the ITW/AA. The ideational contestation over the increment of security gained by BMD lost out to the associated costs in terms of Canadian acquired values and political interests. BMD was an instrumental 'service delivery' value that Canadian society-polity determined did not adhere to Canadian acquired values and was therefore rejected. Undoubtedly disappointed, the US "put no pressure" on Canada and accepted the decision. As the 'service delivery' elements ebbed and flowed over more than 50 years, the three elements of NORAD (essence, institution, service delivery) survived and remained solid ${ }^{786}$ because NORAD is part of both countries' identities.

Although an 'enhanced NORAD' was rejected, time and space allowed for the development of the other two domains of continental defence (land and sea) to develop along sovereign lines. The US would have transformed their global UCP to include a North American Combatant Commander regardless of Rumsfeld's proposal for an 'enhanced NORAD'. In considering the significant ideational changes occurring concurrently in the global US security complex (UCP, DHS, and global BMD), it is clear that Canada was a minor actor in the larger American equation. In methodically approaching the evolving changes to continental security through the Canada-United States Basic Defence Document, both nations maximized their ability for independent military action and sovereign decision-making via one bi-national and two national commands. The Tri-Command Study formed the foundation for continental defence roles

\footnotetext{
${ }^{786}$ See J. T Jockel and J. J. Sokolsky, "NORAD does not need saving," International Journal, Vol 70, No.2, 2015, pp. 188-195.
} 
and responsibilities, where land and sea forces remained under national command, and strengthened continental defence and security through the attendant CDP, CAP, and CONPLAN 3310 plans. Although material factors precipitated change, social factors were causal mechanisms in determining the final policy outcomes of the restructure of the North American security complex, supporting the core argument of this study.

Addressing the terrorist threat required the social reconstruction of defence and security institutions into a more integrated system that respected the dominant security norms of each while seeking ways and means for collaboration. Although the BPG did exceptional work, it was analysing 'enhanced security cooperation' through a militarydefence prism, and therefore their conclusions with respect to expansion into the maritime domain and bi-national information sharing failed to take domestic security norms into account. This became apparent in the evolution from the 'maritime NORAD' concept into the maritime warning mission as the reality of the complex nature of the maritime environment unfolded. The potential for NORAD operational control of vessels disappeared before the 2006 NORAD Agreement renewal, although achieving maritime domain awareness (MDA) was thought realistic. NORAD was given the maritime warning mission as a demonstration of the bi-national resolve to securing the continent.

However, the embedded cognitive and evaluative maritime security norms proved to be substantial impediments in achieving MDA. Information-sharing was not clear-cut in either country due to legalities, jurisdictions, mandates, and protection of sources, particularly with respect to intelligence information and individual privacy rights. As achieving MDA was critical to maritime warning (MW) mission success and required multi-dimensional and multi-departmental input, it was imperative for NORAD to assist 
in the alignment of maritime information-sharing security norms. By using its formidable presence and substantial position as a bi-national security institution, NORAD became a 'norm entrepreneur'. Quietly 'leading from behind', NORAD brought maritime security stakeholders together, enabling social reconstruction of cultural environments and actor identities that would make continental MDA achievable. With the recent legislation to allow greater security related information-sharing in Canada and advances in the bilateral structure providing MDA, NORAD MW has delivered an increment of national security that meets Wolfers' specifications.

In privileging state-level, military factors, realist analysts could not account for the complexity of marine domain awareness or the significant WoG restructuring that achieving this capability entailed. Too much emphasis on the BPG and not enough on the critical role that domestic actors (IMSWG and DHS) played nationally precluded realist understanding of the causal mechanisms behind policy decisions on the role of NORAD. Realist accounts tended to provide symptomatic rather than causal explanations. It is true that "improving their homeland security and working to strengthen ties and information sharing .... dominated continental security discussions ... [as] the defence relationship was a lower priority in both countries" ${ }^{\$ 787}$ immediately after $9 / 11$. It could not have been any other way. However, improvements to the Canadian domestic security complex provided greater assurances to the US than any slight increment in military power that Canada could offer. What realist accounts failed to present were the specific reasons behind the need for bi-national continental defence against a terrorist threat, other than as simply an increase in overall national power for Canada.

${ }^{787}$ Lagassé, 2014, p. 197. 
The case of NORAD's role in Canadian national security post 9/11 demonstrated significant social factors that shaped the initial policy decisions and were causal to final policy outcomes. Canadian National Security Culture prevented impromptu acceptance of North American military integration, but sanctioned the use of an established bi-national institution to pursue further communitarian, pragmatic security solutions based on mutual respect of national sovereignty. Time and space allowed the construction of a new North American security complex to evolve around a common security identity, NORAD. Contestation of the three intervening variables was evident during the Tri-Command study and the subsequent resolution of the MW mission with other maritime stakeholders. In the end, NORAD became a classic example of norm entrepreneurs for a common continental approach to maritime security.

It is beyond the scope of this dissertation to provide the full extent of the national and bilateral American effort in constructing the maritime security complex. However, it was evident during interviews that, while American cognitive norms provided the ideational framework for the North American maritime security complex, Canadian evaluative norms were used in developing an independent, sovereign policy that fit within the overarching construct. In applying Canadian national security norms, Canada pursued policies for state sponsored protection of acquired values that were ideational. The identification of Canada's national interests in the evolving North American security complex involved identity, culture, and institutional norms. The role of NORAD in this process was indicative of how Canadian National Security Culture shapes the social construction of national security policy in Canada. 


\section{Chapter: Conclusion}

\subsection{National Security in Canada Post 9/11}

The attack on New York City on 11 September 2001 (9/11) had a profound effect on the United States that reverberated around the world. It was this immediate catalyst for change to the North American security complex that provided a unique opportunity for observational study and analysis of Canada's perception of national security. In applying scientific methodology, this research paper has exposed how social factors shaped different aspects of Canadian national security policies following the events of 9/11. In conceiving Canada in relational terms and investigating the domestic sources of security policy, this study has demonstrated the degree to which the identity of actors and state-level security preferences are constructed by the state-society-polity relationship. The concept of Canadian National Security Culture broadens the traditional view of what constitutes national security by investigating it from the cultural perspective of the society which provides the resources to the state in exchange for state sponsored security - a central, though often overlooked, factor in liberal democracies. Culture comprises beliefs about the way the world is and ideas about the way the world ought to be; therefore, it is a logical place to locate norms and values central to national security. It was evident from the literature review that materialist theories were limited in explanatory power, given their exogenously attributed properties were insufficient to determine the ideational factors that shaped the post $9 / 11$ national security outcomes. Sociological approaches were also limited as they failed to investigate behavior below state level actions and elite decision-makers. Although strategic culture held promise, it was too narrow in its definition of national security, limiting its analysis to a posteriori 
state behaviour rather than to a priori social factors that shaped and determined the paths available for resolution of national security policy issues. Political culture literature contained the necessary elements for analysis, but lacked the specificity to address the research question. This necessitated conception of a novel approach that required several theoretical paradigmatic changes to the concept of state-level causal factors and the prism from which state sponsored protection (threat perception) was determined. In turn, this study developed a theory of Canadian National Security Culture to operationalize the hypothesis for testing through the use of case studies and process-tracing.

\subsection{Changing the Paradigm - The Theoretical Framework}

To prepare the theoretical framework, a number of factors were clarified from first principles. Most theoretical explanations of national security posit a priori deterministic perception of threats to the state. This is problematic as threats can be politically temporal and span a wide spectrum from persistent, transient, occasional, possible, to unpredictable, each with its own specificity to legitimacy and political contestation. In order to change this paradigm, this study chose to approach state sponsored protection from Wolfers' subjective sense, as the absence of fear that values will be attacked. Defining security as an acquired value in competition with other acquired values allowed measureable analysis of the contestation over values involved in state sponsored protection.

State level explanans failed to identify what really matters, how identities and norms influence the ways in which Canadian actors defined national security in the first place. In deconstructing Buzan's four components of the state within the international relations paradigm, this study determined that the state-level society-polity nexus was an 
integral part of the state and could legitimately be used as the referent object. The integral nature of the society-polity relationship as a state-level causal force made sense from a constructivist perspective as the identities of domestic actors are constructed by state-society relations and the polity represented the mutually constructed organizing principles that shape decision-making by actors in liberal democracies. Thus, investigation into the norms, values, interests, and identities in the state-level societypolity nexus would theoretically provide causal explanations to the research question.

To explicate a theory of Canadian National Security Culture, four criteria were established to ensure methodological legitimacy. First, I defined the functional role of national security culture as defining the range of acceptable possible alternatives from which groups or individuals may, other circumstances permitting, choose a course of action. Second, preference formation is grounded in national security as an acquired value and determined in contestation with other acquired values. Third, the sociological context is located in the integral nature of the society-polity nexus where national security norms, values, beliefs, and interests are located and contested. Finally, bridging sociological and rational choice models provides the connection for interaction between the normative level and the level of preference formation through political contestation and eventual 'moral judgment' by decision-makers.

This theoretical framework proved to be effective and discerning by reorienting the prism through which state sponsored protection was considered and analysed. For example, the evidence clearly showed that the contestation over information-sharing within the polity was a debate over value trade-offs between individual and state rights that were intrinsically tied to Canadian identity. In the security discourse analysed, the 
perception of terrorism was never identified as an existential threat. This kept the question of information-sharing within the 'rules of the game' for contestation over competing acquired values. As with all social inquiry, this study was challenged with establishing boundary limits and specificity in measuring the social variables. This being said, the results achieved by this research were within acceptable tolerances and met all scientific standards. ${ }^{788}$

Establishing a theory of national security culture based on a political culture model opened the opportunity for the use of established political culture literature from political science, sociology, and history to establish Canadian National Security Culture through pluralistic consolidation of security norms and values over time. This was important as social factors in society-polity are not static, as norms, values and beliefs are constantly being contested from both external events and internal contradictions, and therefore require the temporal analysis of qualified scholars. ${ }^{789}$ Although this theory of Canadian National Security Culture is generalizable and captured critical aspects of agency in post $9 / 11$ security policy formulation and outcomes, analysis of the specificity involved in 'moral judgment' by decision-makers requires application of theories from other disciplines related to psychology.

\subsection{Hypothesis Testing}

This research required a two stage approach to investigating how social factors shaped different aspects of Canadian national security policy post 9/11. First, it was

\footnotetext{
${ }^{788}$ This study is empirically-based, verifiable within social science standards, non-normative, transmissible, generalizable, explicatory, predictive, and provisional.

789 This was the essence of the debate between Lipset (Continental Divide) and Grabb/Curtis (Regions Apart) where Lipset argued that the temporal power structure of the British elite in Canada negated the commonality of Canadian and American societies that Grabb/Curtis placed in contemporary majoritarian terms.
} 
necessary to establish that sui generis preferences $^{790}$ towards national security existed in the form of a Canadian National Security Culture and then determine the general nature of these predispositions for further analysis. Secondly, three case studies provided the vehicles to investigate how the three intervening social variables impacted final post $9 / 11$ national security policy outcomes and the degree to which these policies were consistent with contemporary Canadian National Security Culture.

This study found that a distinct national security culture exists in Canada that emerged from the deep roots of Canadian historical experiences and foundational cultures that has varied over time. Due to Canada's geostrategic location, the evolution of its national security culture has revolved around the one existential threat to Canada's sovereignty and independence, the United States. This has resulted in a Grotian worldview that has privileged lessons learned in dealing with insecurities generated by the American hegemon. Although the threat of physical annexation has dissipated and a deep sense of amity exists, the threat of inadvertent assimilation through loss of acquired values is the source of much Canadian insecurity. In contrast to materialist approaches, this makes national security contestation a domestic intersubjective political debate over competing acquired values, particularly when there is no direct clear and present danger to Canada.

The Canadian National Security Culture hypothesis was successful in capturing the role of agency in establishing and determining national security policies. It was shown to encapsulate the purpose and means for state sponsored protection of acquired values and the establishment of general limits and constraints placed on decision-makers.

\footnotetext{
${ }^{790}$ Emile Durkheim established that 'social facts' could be objectively measured and quantified such that beliefs, predispositions, and traditions of a social group could be collectively determined.
} 
Canadian National Security Culture provides the lens from which the articulation of danger is refracted, explaining the subjective understanding of an objective threat, and becomes the foundation for political contestation of norms, values, and interests that take place in society and the polity in determination of an appropriate response. ${ }^{791}$ With no imminent threat to Canada, most decisions on national security enter the realm of preventative (insurance-like) policies that protect Canada through indirect means of domestic security readiness and stabilization of international society. Policies of this type become matters of choice rather than issues of compellence making them more susceptible to contestation over acquired values and resource extraction.

The second stage analysis was based on the real obligations Canada had towards providing continental security to both itself and the United States following the terrorist attack on New York City. In positing that direct security threats to the United States also become potential national security threats to Canada, this study investigated this significant variable in policy determination rather than accepting quid pro quo American threat securitization. Findings demonstrated the way in which the definition of threats manifests itself was dependent on the nature of the threat, American insecurities, and the 'moral judgments' made by decision-makers. In determining post 9/11 security policies, the evaluative standards (norms and values) located in Canadian National Security Culture limited and constrained decision-makers, accounting for Canada's participation in the invasion of Afghanistan, but not Iraq, as well as the expansion of the NORAD mandate, but not bi-national continental defence, both of which confound realist explanations.

\footnotetext{
${ }^{791}$ Kirchner and Sperling, 2010.
} 
Investigation into the policy outcomes of the three interrelated cases using identity, cultural-institutional structure, and interests as intervening variables clearly showed how domestic structures and agency affected final policy outcomes through contestation of social factors embedded in Canadian society and polity. Making use of Katzenstein's five cultural causal mechanisms provided identifiable criteria for measurement and application to the case studies. This study predicted the recursivity of the introduction of the Charter of Rights and Freedoms on security policies on Katzenstein's macro-scale, and this was borne out in the contestation over informationsharing. However, what was surprising and became evident through analysis was the recursiveness of the entire causal structure on a domestic micro-scale during this critical juncture in the reconstruction of the North American security complex.

The knock-on effect of a single policy decision established through Canadian National Security Culture demonstrated the inter-related nature of the structure. Deciding to create the Marine Security Operations Centre (MSOC) (causal path 1) caused a recursive reaction (causal path 5) that required cultural-institutional change. This environmental change affected departmental identities and ultimately state identity (causal path 2). In the contestation over MSOC policy implementation, the interests and policies of each stakeholder department were shaped by their existing identities (causal path 3) leading to stagnation in implementation. By reconfiguring state identity, hence departmental identity, with the passage of Bill C-51 in 2015, the environmental (culturalinstitutional) structure changed to provide authorization in mandates for informationsharing allowing for final implementation of the original policy decision. The significance of this discovery highlighted the intersubjective domestic social factors that 
are causal to Canadian national security policy outcomes and neglected in other theories, supporting the hypothesis of this study.

\subsection{Canadian National Security Culture}

Historical events, geographic location, and political-cultural traditions affect the prism through which a collective society views the world and determines what acquired values are in need of state sponsored protection. In essence, Canadian society sees the solution to international security problems through the prism of their historical experiences in the territorial confines of a relatively peaceful, secure environment. Canadian National Security Culture is part of an overlapping mosaic of norms and values that comprise Canadian culture. It has evolved through amicable resolution of wide ranging issues with its powerful neighbour that involved state protection of Canadian values. The security norms and values that have emerged are part of Canadian identity, are endogenous, and have been embedded in domestic institutions.

Five sets of norms and values nested in Canadian identity form the foundation of Canadian National Security Culture, setting the evaluative and cognitive standards used in forming preferences and shaping interests to security related issues. National sovereignty, particularism, communitarianism, respect for authority, and pragmatism are the basic elements of 'evolving national ideologies of collective purpose and distinctiveness' that form contemporary Canadian National Security Culture. Mutual accommodation, the willingness to compromise in order to settle a dispute or move an agenda forward, is part of Canadian identity and encompasses all five sets of norms. The most important manifestation of its pragmatic security norm is found in Canada's risk management of its relationship with the US, the only true existential threat to Canada as 
an independent, sovereign state. The particularism of Canadian security norms provides latitude for compromise such that, even when circumstances do not seem promising, the impact of this flexibility improves the chances for non-violent conflict resolution. Collective rather than unilateral action, broadening the inclusive order that starts at home and extends abroad, containing rather than defeating what cannot be accommodated at a particular time, are all seminal aspects of Canadian National Security Culture.

Canadian society as a whole and elites within the polity share a well-established set of fundamental beliefs and values that are instrumental in shaping national security institutions and policies. These include a deep-seated belief regarding the appropriateness and utility of the use of force as an act of last resort, a fundamental belief in ameliorating insecurities by establishing rules based order through multilateral institutions, a particularistic approach to conflict resolution that seeks common ground, and a desire to be a reliable, team player (ally) while maintaining the sovereign right for protection of Canadian acquired values. Canada intentionally separates endogenous national security from exogenous international security, as the latter is a matter of choice for Canada whereas the former is a matter of survival as an independent state.

However, the separation of domestic and international policy is never clear-cut, particularly with respect to the Canada-United States interdependent relationship. There is a symbiotic relationship between domestic and bilateral issues that involves complex sovereignty. ${ }^{792}$ Canadian society conceives national security in terms of state protection of acquired values that are in need of protection primarily from a hegemonic neighbour and secondarily from an inconsistent, dynamic international environment. This makes the

\footnotetext{
792 See Pauly and Reus-Smit, 2012.
} 
US Canada's principal international concern, leading to international policies that will vary between continentalist and internationalist approaches depending on the specificity of policy issues in question. Canada has choice due to its geopolitical position and secure relationship with the US.

\subsection{National Security is the Home Game}

Contemporary Canadian National Security Culture was exposed by the events of 9/11 and was eventually expressed through the 2004 National Security Policy statement. Behavioral evidence demonstrated that Canadian National Security Culture was instrumental in shaping post $9 / 11$ policies for crisis and consequence management. The security policies that Canada instituted were not indicative of an existential threat, but of protective measures for a persistent, low level threat such as criminality in the economic and societal sectors. Canada could have maximized material gains assumed in realism by 'bandwagoning' with the US on many security issues, such as Iraq and BMD, but domestic security norms and values intervened. When the US closed the border, trade would have quickly been facilitated had neoliberal material assumptions prevailed, but Canadian National Security Culture was clearly evident in the intermestic overlap of domestic and international security norms during the negotiations and implementation of the Smart Border Declaration and associated 30-point Action Plan.

Analyses of the events leading up to the issuance of the National Security Policy statement provide clarity and precision to contemporary aspects of Canadian National Security Culture. First, the only existential threat to Canada remained assimilation into the United States, causing continued focus on the protection of acquired values that was domestic-centric and sectorally wide. Second, identity issues and maintenance of 
sovereignty were central concerns in all major post 9/11 policy decisions analysed. Third, accommodating pragmatic, negotiated settlement of disputes was preferable to ideological intransigence, particularly with respect to issues of border jurisdiction. Fourth, risk management and the use of time and space worked to advantage both militarily and ideationally, providing avenues for alternative solutions. Lastly, negotiation and establishment of rules based authority provided the greatest protection from arbitrary decision-making by the US. These security norms encouraged Canadian officials to employ a risk management strategy that quickly addressed legitimate American insecurities while working out long-term solutions that maximized Canadian national security concerns, thus supporting the hypothesis of this paper.

Social factors were instrumental in the formulation and decision to release the National Security Policy statement. Canada could have simply emulated the US and released a National Security Strategy document based on defence and foreign policy to placate American concerns, but it chose instead to express its identity and long-held belief that national security was endogenous. Canadian public servants proposed and developed the policy statement based on embedded societal security norms and values. 'Peace, Order, and Good Government', foundational to Canadian identity, was one of many examples of Canadian values embedded in the five sets of Canadian National Security Culture norms and values that were responsible for shaping the statement. The National Security Policy statement may never have been released had it not been in the political interest of the new Martin Government's identity to distinguish itself to the Canadian polity as a government that understood Canadian National Security Culture. 
The National Security Policy statement was designed to be the central expression of a new integrated way of looking at national security. In fact, it was a prescient systems approach to national security where modern networking and integration act as force multipliers, much as the Revolution in Military Affairs (RMA) did for military effectiveness. It included articulation of the spectrum of security embedded in Canadian National Security Culture that places state sponsored protection to acquired values between the individual's responsibilities for personal security and the state's responsibility to promote and defend international society. The division of the second section into six chapters recognized that national security was indeed domestic-centric in covering a wide spectrum of security to acquired values, discreetly acknowledging the delineation of domestic 'national security' from external 'international security' that had been historically evident in security norms in government organization and policy articulation.

The goal of the National Security Policy statement was to create a seamless security continuum through time and space (domestically, continentally, and internationally) that operated intermestically, vertically (municipally, provincially, and federally), horizontally, and inter-sectorally. In order to accomplish this, a division of labour and responsibilities needed to be fostered by the creation of an effective Canadian security community (policy, operations, and stakeholders), a cross-government security culture, effective machinery, incentives, and a sense of urgency communicated from the very top of government. In other words, this seismic change in the environmental structure (cultural-institutional) significantly impacted identities, interests, and policy options, as became more evident in the other case studies. Although the government 
made structural changes to facilitate this new whole-of-government (WoG) approach, implementation proved 'a bridge too far' due to a lack of leadership and systemic political and cultural factors.

\subsection{Contestation of Security Identity in the Digital Age}

Case analysis of the MSOCs provided further evidence of how Canadian security norms and values shape national security policy. As the causal pathways explicated earlier showed, identity recalibration was required for the digital age. This contestation of constitutive security norms and values in Canadian identity regarding Charter rights was occurring elsewhere within the intelligence and constabulary communities, but the MSOC study provided insight and substantiation from a traditional military security prism. The whole-of-government goals of the National Security Policy statement that established the MSOCs were apparently modest and attainable. However, security related social and legal norms caused the government and bureaucracy to hesitate in moving the project forward as quickly as planned. Since the threat of terrorism was not deemed acute, the redesign of the national security complex became more ideational than material in nature and needed to survive political contestation in the process of identity redefinition. Thus, without the compellence of an existential threat, the time period for resolution became indeterminate allowing time and space for cultural norms to prevail.

Three significant interrelated ideational issues prevented the MSOC project from moving forward as intended: departmental mandates, horizontal governance, and information-sharing concerns. Each of these entailed changes to identity, culture and institutions throughout the Canadian security complex. Exacerbating the specificity of the MSOC problem were the larger ideational issues that involved resolution of the 
uncertainties surrounding privacy concerns created by the Charter of Rights and Freedoms to Canadian identity as well as the ideational shift required of the new WoG approach. This confluence of social factors caused the MSOC policy implementation to stagnate until the larger issues of individual versus traditional state security rights were resolved and solutions for making horizontal government work were found. Had the threat been acute and/or had there been leadership to resolve contestation over departmental security norms and values, a solution to the MSOC impasse would have undoubtedly been found. Risk strategies and preferences would have been different in dealing with an existential threat, but without that urgency actors stuck to established departmental norms and values.

Although organization theories can account for the stagnation, they fail to understand the inability of departments to cooperate without important changes to their identities. This can only occur through changes to their mandates, the constitutive norms that provide the legal authorization to pursue specific activities. Three of the MSOC stakeholders were prohibited from engaging in the necessary security activities to varying degrees due to restrictive mandates. Although there were options available to resolve the issues quickly, they conflicted with Canadian national security norms that stipulate the solution remain within normal rules and cognitive standards of behaviour. This was one of the first hurdles that needed resolution in the effort towards horizontal integration in the WoG approach that successive governments failed to address.

The second significant barrier to the entire project and the WoG approach entailed the issue of information-sharing. The Arar Affair had highlighted the horrible consequences of mishandling of government information, giving the legal issue of 
sharing information for state security purposes a moral imperative. Thus, stakeholder departments were unwilling to take short-cuts to improve security awareness without concrete changes to cognitive standards, meaning the resolution of Charter issues involving privacy concerns. Society demanded a balance in state-individual security rights and the polity was engaged in contestation over acquired values in how to achieve this. The Charter had empowered the judiciary to interpret the law to such a degree that it impacted how the government chose to resolve the issue. Prior to the Charter, majoritarianism prevailed; however, with the Charter in place, all three branches of government became engaged in issues of identity resolution. It is this society-polity variable that was one of the causal mechanisms in shaping the final resolution of the MSOC policy and the reason why using society-polity as a referent object is crucial to understanding national security policy outcomes.

Without a single Minister responsible and accountable for the horizontal integration of the national security strategy identified in the National Security Policy statement, these marine security policy issues were incommensurable due to ideational positions based on departmental identity, institutional culture, and interests. Although Bill C-51 introduced the necessary changes to mandates and provided specifications for information-sharing, the issue of governance continues to be problematic. The social construction of the polity makes it difficult to make the necessary changes for horizontal integration of government departments and agencies due to competing norms and values. A WoG approach will be limited unless identity and cultural barriers to horizontal accountability are found. The MSOC case provides an insight into the challenges of 
socially reconstructing the Canadian security complex to meet the security needs of Canada in the digital age.

\subsection{Construction of a North American Security Complex}

The inclusion of NORAD in the 2004 National Security Policy statement was indicative of its value as a national security symbol and institution to the government of Canada. The prospect of using this bi-national institution as a means to protect North America from marine threats demonstrates the paradox in Canadian national security norms where United States' military power cannot be too close, but not too far away in Canadian security interests. Through NORAD's inclusion as the institution of choice for maritime warning, the duality of the NORAD identity was domestically acknowledged by Canada. The events immediately following the 9/11 attack had all the hallmarks of neorealist power shifts within the international system; however, the subsequent reaction of Canada to the American security response can only adequately be explained from a sociological perspective.

In rejecting Rumsfeld's proposal for an 'enhanced NORAD', Prime Minister Chrétien chose to use time and space to Canada's advantage since Canada's perception of the terrorist threat did not warrant the potential costs to sovereignty and independence that an expansion of NORAD would entail. As evident in the MSOC case study, resolving legal and security norms within Canada on the very narrow marine security area were challenging and complex. To accomplish this on the scale of a new continental defence arrangement within the timeframe demanded of the Bush Administration would have put Canada at a distinct disadvantage. 
At the time, a monumental strategic shift was taking place within the US national security complex on a global scale, particularly with the creation of US Northern Command under the Unified Command Plan (UCP). Canada was a minor consideration in this ideational security transformation and would have held little power and influence within Rumsfeld's framework. There were few advantages for Canada in further integration of its military with the US. An 'expanded NORAD' would have had to have been an adjunct institution in order to meet US legal norms; otherwise, Canadian acquired values would have had to adjust to fit into the UCP legal construct. In the deliberations within the Canadian polity over national interests and values, sovereignty and unity issues took precedence over this increment of national security.

Following Katzenstein's causal paths, evidence showed that social factors were instrumental in establishing the final policy outcome on the role of NORAD in post 9/11 national security. The initial rejection of Rumsfeld's 'enhanced NORAD' was due to identity (sovereignty and independence) interests and concerns (causal path 3). This policy decision caused NORAD and the Department of National Defence to reassess the cultural-institutional norms and values in light of US changes to the American security complex (causal path 5). To resolve the identity crisis that resulted, the two militaries initiated the Tri-Command Study (causal path 2) that led to the construction of a new North American security regime on a more bilateral basis than the proposed 'enhanced NORAD' (causal path 4). Armed with renewed contingent properties (identity, interest, and capabilities) and a mandate from both governments via the 2006 NORAD Agreement renewal, NORAD began the next recursive cycle of this sociological process to resolve the Maritime Warning mission mandate with other stakeholders (causal path 1). 
Many obstacles lay before NORAD in its effort to implement the Maritime Warning mission in 2006. First, the exact nature of the military roles and responsibilities of NORAD (identity) were in question, given the creation of NORTHCOM and Canada Command. This precipitated the Tri-command Study that was foundational to the construction of a new North American security complex. Secondly, the complexity of the Maritime Warning mission covered the spectrum of national security from safety to defence, and the unfamiliar maritime environment demanded NORAD integrate with partners long dominated by civilian agencies and departments that knew one another. To overcome these obstacles, NORAD adapted its cultural norms and values through a slow socialization of all stakeholders, becoming 'norm entrepreneurs' in the process, and demonstrating how changes in identity and culture affected interests and policies of all concerned.

NORAD contributed significantly to national and bi-national maritime security through presence and position. As a national symbol of both countries, NORAD was a 'trusted brand' that commanded respect as a result of its aerospace defence legacy. This bi-national identity allowed NORAD to use its unique position and perspective to facilitate bilateral, interdepartmental cooperation that might not otherwise have occurred without NORAD's non-partisan leadership. Comprehensive Maritime Domain Awareness was in every actor's interest, but it took holistic socialization of the Maritime Domain Awareness challenge through NORAD to align community-wide evaluative and cognitive norms.

Addressing the threat of terrorism required the social reconstruction of Canadian and American defence and security institutions into a more integrated system that 
respected the dominant security norms of each while seeking ways and means for collaboration. In applying Canadian national security norms, Canada pursued policies for state sponsored protection of acquired values that were ideational. The identification of Canada's national interests in the evolving North American security complex involved identity, culture, and institutional norms. Determining and redefining the role of NORAD in this transformative process demonstrated the social factors involved in shaping national security policy in Canada and supports the hypothesis of this paper. NORAD was too important a symbol to be merely swept aside through materialist considerations and was therefore provided a meaningful Tri-Command role in the reconstructed North American security complex. In adapting to its new Maritime Warning mission, NORAD needed to first refine its new Tri-Command identity and then navigate the social construction of a new continental Maritime Domain Awareness regime that encompassed interrelated contestation of identities, cultures, norms, values and interests.

Attempting to create an 'expanded NORAD' in the aftermath of $9 / 11$ would have been impossible unless significant convergence of security norms in both countries occurred. It is evident that the subsequent loss of sovereignty and independent security action required of a bi-national continental defence structure could not be justified given the negligible perceived threat of terrorism by Canadians. In the end, however, the aim of the Rumsfeld's proposal "of an integrated defence of North America" is being realized, albeit in a more bilateral fashion. In rejecting continental 'enhanced NORAD', the sociological constitutive processes led to a new North American Tri-command security 
complex - with similarity to the military structure of NATO. ${ }^{793}$ In the process, an integrated civil-military Maritime Domain Awareness regime was socially constructed via NORAD. It will likely prove to be robust in meeting the national security needs of both countries due to attention provided to the social factors embedded in agency and structure.

\subsection{Summary and Implications}

The events of 9/11 provided significant opportunity for Canada, the state, to increase its relative power either through balancing its national security structure with increased capabilities or through bandwagoning with the US through greater institutional integration. However, Canadian policy-makers did not follow the logic of realist doctrine, as national security norms dictated the logic of appropriateness based on domestic structures. This paper hypothesized that:

Canadian national security policy decisions post 9/11 resulted from policy choices that were limited and constrained by domestic institutional structures and a Canadian National Security Culture that views security broadly and endogenously as a value to be weighed against other competing values. Although initial policy decisions were shaped by domestic security norms found in Canadian National Security Culture, variation in final security policy outcomes was determined in large measure by the interrelated contestation of the intervening variables, identity, cultural-institutional, and interests. Stated simply, state protection of acquired values embodied in Canadian National Security Culture (IV) shaped the post 9/11 national security policy decisions while the interaction of the three social variables (IntV) determined the final policy outcomes (DV).

\footnotetext{
${ }^{793}$ In NATO, the American UCP Commander of US European Command (EUCOM) is double-hatted as the Supreme Allied Commander - Europe (SACEUR) in NATO. Alliance countries provide limited standing forces to SACEUR for routine matters such as 'air defence' and 'air policing'. This is similar in nature to the Commander NORTHCOM who is double-hatted as Commander NORAD with standing forces for 'air defence' and domestic 'air security'. Assuming the NORTHCOM-CJOC Common Defence Plan includes contingencies for continental military defence, the only key difference is in a government to government agreement to formalize the command and control arrangements under one continental allied commander.
} 
This paper demonstrated that the Canadian National Security Culture hypothesis captured the role of agency in establishing and determining national security policies. It explained the purpose and means for state sponsored protection and provided the general limitations and constraints that shaped decision-making. Canadian National Security Culture provided the foundation for analysis of the political contestation of norms, values, and interests that took place in society and the polity during national security policy formulation. However, as evident in the three case studies, the three intervening social factors (identity, cultural-institutional structure, and interests) were instrumental in constitutively shaping and at times causal in determining final national security policy outcomes.

Thus the answer to the research question, "how does Canada view national security in the post 9/11 world?" is that Canada views national security as a continuum with its focus on the protection of Canadian society and its acquired values. National security is domestic-centric where the roots of a comprehensive security system begin at home with a strong national security system. This provides the foundation from which foreign and defence policies emerge, allowing Canada to engage in extraterritorial security. A well-developed Canadian National Security Culture limits and constrains the rational choices available to decision-makers in determining national security policies.

The implications of this research are fivefold: First, this research has provided evidence that social factors shape different aspects of national security policy and include causal mechanisms that determine national security policy outcomes. Second, this dissertation developed a theoretical framework of national security as an acquired value, unique to each state. Analysis of state behavior needs to take into account the social 
factors found in the national security culture of that state which can only be determined using the society-polity nexus as the referent object. Third, Canada's concept of national security is domestic-centric, with international security being an extension of these ideational underpinnings and viewed as a matter of choice. This differs from the traditional prism of defence and foreign policy assumed by many international relations theories. Misunderstanding this basic fact leads to misapplication of theoretical models and ultimately to misinterpretation of Canadian national security policies. Fourth, Canadian national security practitioners will be better equipped to provide consistent and coordinated policy advice and options, given a more nuanced understanding of the social factors involved in Canadian national security policy outcomes. Finally, this research increases the capacity for predictability of Canadian national security behavior, particularly when combined with other theoretical perspectives as research specificity warrants.

This study demonstrated that social factors were instrumental in shaping security policy outcomes. Culture is not an exogenous feature of the state, nor can culture be given attribution by simply analysing state behaviour. To truly understand the foundations of state behaviour, endogenous sources need to be understood and accounted for in research designs. Although national security culture has been studied, it has been under-researched, particularly at the state-society-polity interface where social factors meet rational-choice decision-makers. To overcome this deficiency, the next logical step would be to conduct additional case studies, using the theoretical framework developed in this dissertation, that focus on the society-polity nexus to increase the data base and refine national security culture theory criteria. This will provide an avenue for the 
standardization of content when employing comparative methods to different national security cultures. As case studies accumulate, scholars should increasingly look towards working in a comparative framework with a view to eventually compare similar and dissimilar states. With respect to the study of Canadian national security, the results of this research should be incorporated within other theoretical paradigms to assist in analysing material factors dependent on the research question. Complex neo-realism introduced the idea of using societal and polity factors to answer realist questions and neo-classical realism has provided the theoretical tools to do so. This research establishes the means for incorporating social variables into other frameworks that can provide greater meaning to material analysis of policy decisions. 
Appendix
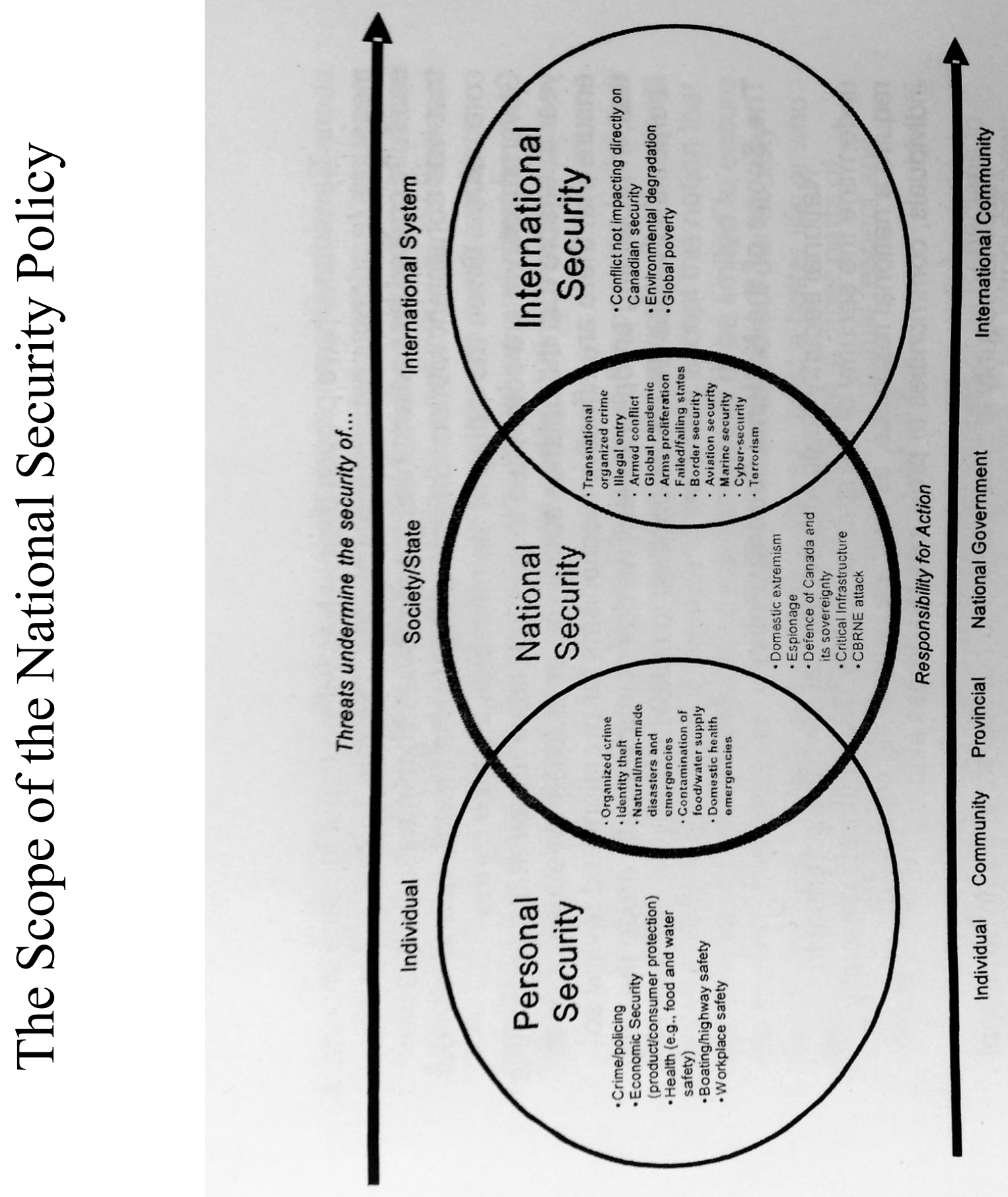


\section{Bibliography}

The 105th American Assembly Columbia University, Renewing the US - Canada Relationship, found online at http://www.wilsoncenter.org/publication/105th-americanassembly-renewing-the-us-canada-relationship .

Ackerman, Robert K. "Pace of Change Accelerates For U.S. Navy", Signal Magazine, December 2004, found online 16 October at http://www.afcea.org/content/?q=pacechange-accelerates-us-navy .

Adams, Paul C. "The September 11 attacks as viewed from Quebec: the small-nation code in geopolitical discourse”, Political Geography, Vol 23, 2004, pp. 765-795.

Adler, Emmanuel. "Seizing the Middle Ground: Constructivism in World Politics", European Journal of International Relations, Vol 3 No. 3, 1997, pp 319-363.

. "Constructivism and Internationals Relations" in Carlsnaes, Walter, et al, ed. Handbook of International Relations, London: Sage Publications, 2002.

Aikens, Greg. "Network-Centric Operations and Interdepartmental Marine Security", Canadian Naval Review, Vol 1, No. 3, Fall 2005.

Albert, Mathias. "From Defending Borders towards Managing Geographical Risks? Security in a Globalized World”, Geopolitics, Vol 5, No.1, 2000, pp. 57-80.

Alberts, David S., John J. Garstka, and Frederick P. Stein, NETWORK CENTRIC WARFARE: Developing and Leveraging Information Superiority, 2nd Edition (Revised), DoD C4ISR Cooperative Research Program, August 1999, found online on 15 October 2015 at http://dodccrp.org/files/Alberts_NCW.pdf .

Allison, Graham T., Essence of Decision: Explaining the Cuban Missile Crisis. Boston: Little, Brown and Company, 1971.

Almond, Gabriel A., and Sidney Verba. The Civic Culture: Political Attitudes and Democracy in Five Nations, an Analytic Study. Boston: Little, Brown, 1965.

Angus Reid. "Attack on Parliament Hill: terrorism or mental illness? Canadian public opinion is divided", November 25, 2014, online at http://angusreid.org/homegrownterrorism-radicalization-canada-overblown-serious-threat/\#II

Auditor General of Canada, "Chapter 3: National Security in Canada - The 2001 Antiterrorism Initiative", Report of the Auditor General Of Canada to the House of Commons - March 2004, Ottawa: Public Works and Government Services Canada, 2004. 
. "Chapter 1-National Security: Intelligence and Information Sharing", 2009

March Status Report of the Auditor General of Canada to the House of Commons, online at www.oag-bvg.gc.ca.

Australia. Strong and Secure: A Strategy for Australia's National Security, Australian Government, 2013.

Avis, Peter. "Surveillance and Canadian Maritime Domestic Security", Canadian Military Journal, Department of National Defence, Spring 2003, found online at http://www.journal.forces.gc.ca/vo4/no1/policy-police-eng.asp .

Axworthy, Tom. "New Bottles for Old Wine: Implementing the International Policy Statement", in Andrew F Cooper and Dane Rowlands, Canada among Nations, 2005: Splitting Images, McGill-Queens University Press, 2005.

Azzi, Stephen. Reconcilable Differences: A History of Canada-US Relations, Don Mills, Ontario: Oxford University Press, 2015.

and Norman Hillmer, "Intolerant allies: Canada and the George W. Bush administration, 2001-2005, Carleton University, 2015 unpublished work.

Bakvis, Herman and Luc Juillet, The Horizontal Challenge: Line Departments, Central Agencies and Leadership, Canada School of Public Service, 2004 accessed online http://publications.gc.ca/Collection/SC103-1-2004E.pdf, 18 August 2015.

Baldwin, David. "The Concept of Security", Review of International Studies, Vol 23, No.1, 1997.

. "Power and International Relation", in Carlsnaes, Walter, et al, ed. Handbook of International Relations, London: Sage Publications, 2002.

Balzacq, Thierry. Securitization Theory: How Security Problems Emerge and Dissolve, New York: Routledge, 2010.

Barry, Donald. "Managing Canada-US Relations in the Post 9/11 Era: Do We Need a Big Idea?", in Duane Bratt and Christopher John Kukucha, Readings in Canadian Foreign Policy: Classic Debates and New Ideas, Toronto: Oxford University Press, 2007.

Beahen, William. "Evolution of Use of Force by Police in the Canadian Context", prepared for Commission for Public Complaints Against the RCMP, June 16, 2008.

Beck, Ulrich. "World Risk Society and Foundations of Transnational Politics," in Louis W. Pauly and Edgar Grande, eds, Complex Sovereignty: Reconstituting Political Authority in the Twenty-First Century, Toronto: University of Toronto Press, 2005. 
Bell, Colleen. "Biopolitical Governance in Canada's National Security Policy", Security Dialogue, 2006, Vol 37, No.2, pp. 147-165.

Bender, Jonathon and Hammond, Thomas, "Rethinking Allison's Models", American Political Science Review, Vol 86 No. 2, June 1992, pp.301-322.

Bendor, Jonathon. Bounded Rationality and Politics, Berkeley: University of California Press, 2010.

Berdahl, Loleen and Tracey Raney. "Being Canadian in the World: Mapping the Contours of National Identity and Public Opinion on International Issues in Canada." International Journal Vol 65, No.4, 2010, pp. 995-1010.

Berger, Thomas U. "Norms, Identity, and National Security in Germany and Japan," in Peter J Katzenstein, The Culture of National Security: Norms and Identity in World Politics, New York: Colombia University Press, 1996.

Bland, Douglas L. and Sean M. Maloney. Campaigns for International Security: Canada's Defence Policy at the Turn of the Century, Montreal: McGill-Queen's University Press, 2004.

Bland, Douglas L. Canada without Armed Forces?, Montreal: McGill-Queen's University Press, 2004.

. "Canada's national interest: alliance with the United States", Policy Options, 1 Nov 2007 found online 5 October 2015 at http://policyoptions.irpp.org/issues/ontario2007-dalton-mcguinty/canadas-national-interest-alliance-with-the-united-states/

Blatchford, Christie. "Tepid Speech, Tepid Nation: Chretien's Yawner Illustrates How Soft the Country Has Grown”, National Post, September 29, 2001.

Bloomfield, Alan and Kim R Nossal, "Towards an Explicative Understanding of Strategic Culture: The Cases of Australia and Canada", Contemporary Security Policy, Vol.28, No.2, August 2007, pp.286-307.

Bolton, M. Kent. U.S. Foreign Policy and International Politics: George W. Bush, 9/11, and the Global-Terrorist Hydra, New Jersey: Pearson Prentice Hall, 2005.

Booth, Ken. "Security and Emancipation", Review of International Studies, Vol 17, 1991, pp. 313-26.

Booth, Kenneth and Wheeler, Nicholas, Security Dilemma: Fear, Cooperation, and Trust In World Politics, New York: Palgrave MacMillan, 2008.

Bothwell, Robert. "The Canadian Isolationist Tradition," International Journal, Vol 54, No.1, 1999, pp. 76-87. 
Boucher, Jean-Christophe. "The Cost of Bandwagoning: Canada-US Defence and Security Relations after 9/11”, International Journal Vol 67, No. 4, 2012, pp. 895-914.

Bourne, Mike. Understanding Security, Hampshire: Palgrave Macmillan, 2014.

Boyd, Robert, and Peter J. Richerson. "Norms and Bounded Rationality", pp. 281-296 in Bounded Rationality?", pp. 343-359, in Selten, Reinhard and Gerd Gigerenzer. Bounded Rationality: The Adaptive Toolbox, Cambridge, Mass: MIT Press, 2001.

Bratt, Duane and Christopher John Kukucha, Readings in Canadian Foreign Policy: Classic Debates and New Ideas, Toronto: Oxford University Press, 2007.

Bratt, Duane and Donald Barry, "Defense Against Help: Explaining Canada-U.S. Security Relations." American Review of Canadian Studies, Vol 38, No.1, 2008, pp. 6389.

Breton, Raymond. "From ethnic to civic nationalism: English Canada and Quebec", Ethnic and Racial Studies, Vol 11 No. 1, 1988, 85-102.

Brister, Bernard. "When Perpetuity Doesn't Mean Forever: The Approaching Demise of NORAD”, Options Politiques, December 2007-January 2008.

. The Same Yet Different: Continuity and Change in the Canada-United States

Post-9/11 Security Relationship. Kingston: Canadian Defence Academy Press, 2012.

Brodie, Bernard. "Strategy as a Science”, World Politics, Vol 1, 1949, pp. 467-88.

Brown, Robert Craig. Canada's National Policy, 1883-1900: A Study in CanadianAmerican Relations, Princeton, NJ: Princeton University Press, 1964.

Bucholtz, Mary and Kira Hall, "Identity and interaction: a sociocultural linguistic approach", Discourse Analysis, Vol 7, No.4-5, pp 585-614.

Bull, Hedley. The Anarchical Society: A Study of Order in World Politics, $3^{\text {rd }}$ ed. Columbia: Columbia University Press, 2002.

Burchill, Scott et al. Theories of International Relations, New York: Palgrave Macmillan, 2005.

Burke, Kathleen. Old World, New World, New York: Atlantic Monthly Press, 2007.

Buzan, Barry. People, States \& Fear: The National Security Problem in International Relations, London: Harvester Wheatsheaf, 1983.

. "Peace, Power, and Security: Contending Concepts in the Study of International Relations", Journal of Peace Research, Vol 21, No. 2, 1984. 
People, States \& Fear: An Agenda for International Security Studies in the

Post-Cold War Era, Second Edition, Colchester, UK: ECPR Press, 2009.

. "The English School: An Underexploited Resource in IR." Review of

International Studies, Vol 27, No.3, 2001, pp. 471-88.

Buzan, Barry and Ole Waever. "Slippery? Contradictory? Sociologically Untenable? The Copenhagen School Replies", Review of International Studies, Vol 23, no 2, 1997, pp. 241-250.

Buzan, Barry, Ole Wæver, and Jaap de Wilde. Security: A New Framework for Analysis, Boulder CO: Lynne Rienner Publishers, 1998.

Buzan, Barry and Lene Hansen. The Evolution of International Security Studies, Cambridge, UK: Cambridge University Press, 2009.

Canada. Legislative Acts. Bill C-36-Canadian 'Anti-terrorism Act.

. Bill C-51 - An Act to enact the Security of Canada Information Sharing Act and the Secure Air Travel Act, to amend the Criminal Code, the Canadian Security Intelligence Service Act and the Immigration and Refugee Protection Act and to make related and consequential amendments to other Acts, 18 June 2015.

. Canada Border Services Agency Act

- Canadian Security Intelligence Service Act

. Criminal Code of Canada

. Constitution Act, 1982 - Canadian Charter of Rights and Freedoms.

. Customs Act

. Department of Public Safety and Emergency Preparedness Act.

. Marine Transportation Security Act.

- National Defence Act of Canada

. Oceans Act and the Canada Shipping Act,

. Personal Information Protection, Security Provision and Electronic

Documents Act

. Privacy Act

. Royal Canadian Mounted Police Act.

Canada. Standing Senate Committee on National Security and Defence, "Canadian Security and Military Preparedness", First Session Thirty-Seventh Parliament, February 2002, found online at

http://www.parl.gc.ca/sencommitteebusiness/CommitteeReports.aspx?parl=39\&ses=1\&L anguage $=\mathrm{E} \&$ comm $\mathrm{id}=1076$.

. Standing Senate Committee on National Security and Defence, "Canada's

Coastlines: The Longest Under-Defended Borders in the World", Vol 1, Thirty-Seventh 
Parliament - Second Session, October 2003 found online at http://www.parl.gc.ca/Content/SEN/Committee/372/defe/rep/rep17voll-e.htm .

. Proceedings of the Standing Senate Committee on National Security and Defence Issue 4, "Evidence, June 19, 2006" on the topic of 'the national security policy of Canada', found online 20 Sept 2015 at http://www.parl.gc.ca/Content/SEN/Committee/391/defe/04evae.htm? Language $=E \&$ Parl $=39 \&$ Ses $=1 \&$ comm $\mathrm{id}=76$.

. Report of the Standing Senate Committee on National Security and Defence, Four Generals and an Admiral: The View from the Top, Second Session Thirty-ninth Parliament 2008, found online on 17 October at http://www.parl.gc.ca/Content/SEN/Committee/392/defe/rep/rep1 laug08-e.pdf .

Proceedings of the Standing Senate Committee on National Security and Defence, "Issue 4 - Evidence - Meeting of May 3, 2010", on the topic on 'Canada's role in NORAD', found online on 17 October 2010 at http://www.parl.gc.ca/Content/SEN/Committee/403/defe/04evae.htm?comm id $=76 \&$ Language $=E \&$ Parl $=40 \& S e s=3$

Standing Committee on National Security and Defence, Canada and Ballistic Missile Defence: Responding to the Evolving Threat, Ottawa: Senate of Canada, June 2014.

. Proceedings of the Standing Senate Committee on National Security and Defence, "National Security and Defence - The Subject Matter of Bill C-51", Issue No. 16, Forty-first Parliament - Second Session, April 20/23/27, 2015 found online at http://www.parl.gc.ca/Content/SEN/Committee/412/secd/16cve.htm? Language $=E \& P a r l=41 \& S e s=2 \&$ comm $\_$id $=76$, and Issue No. 18, May 25/26/28, 2015 found online at http://www.parl.gc.ca/Content/SEN/Committee/412/secd/18cve.htm?Language $=\mathrm{E} \& \mathrm{Parl}=41 \&$ Ses $=2 \&$ comm $\mathrm{id}=76$

. Standing Senate Committee on National Security and Defence, "Evidence on the subject of Bill C-51 - An Act to enact the Security of Canada Information Sharing Act and the Secure Air Travel Act, to amend the Criminal Code, the Canadian Security Intelligence Service Act and the Immigration and Refugee Protection Act and to make related and consequential amendments to other Acts", Forty-first Parliament - Second Session, 27April 2015 found online 12 Sep 15 at http://www.parl.gc.ca/content/sen/committee/412/SECD/52069-e.HTM .

Canada. Truth and Reconciliation Commission of Canada, Honouring the truth, reconciling for the future: Summary of the final report of the Truth and Reconciliation Commission of Canada, 2015, found online on 3 November, 2015at http://www.trc.ca/websites/trcinstitution/File/2015/Honouring the Truth_Reconciling fo r the Future July 23 2015.pdf. 
Carlsnaes, Walter, et al, ed. Handbook of International Relations, London: Sage Publications, 2002.

Caudle, Sharon. "National Security Strategies: Security from What, for Whom and by What Means", Journal of Homeland Security and Emergency Management, Vol 6, No.1 Art 22, 2009.

Charron, Andrea and James Fergusson. NORAD in Perpetuity? Challenges and Opportunities for Canada, Winnipeg: Centre for Defence and Security Studies, 31 March 2014 found online 10 October 2015 at https://umanitoba.ca/centres/cdss/media/0 NORAD in Perpetuity final report March 2014.pdf.

. 'Left of Bang': NORAD's Maritime Warning Mission and North American Domain Awareness, Winnipeg: Centre for Defence and Security Studies, 08 October 2015 , found online at http://umanitoba.ca/centres/cdss/media/0_NORAD_Maritime_Warning_Mission_Final Report_8_Oct_2015.pdf.

Checkel, Jeffrey T. 'The Constructivist Turn in International Relations Theory', World Politics, 50, No.2, 1998.

Chretien, Jean. Reflections by, "Staying Out of Iraq", in Jack Cunningham and Ramesh Chandra Thakur, Australia, Canada, and Iraq: Perspectives on an Invasion, Toronto: Dundurn Press, 2015.

Essay found online at http://arts.lgontario.ca/lestweforget/essays/jean-chretien/

Christensen, Tom and Per Lægreid, "The Whole-of-Government Approach to Public Sector Reform." Public Administration Review, Vol. 67, No.6, 2007, pp. 1059-66.

Cooper, Andrew F. and Dane Rowlands, "A State of Disconnects", Canada among Nations, 2005: Splitting Images, Montreal: McGill-Queens University Press, 2005.

Cooper, D.A. "Canada's Silhouette is Distinct in the Shadow of the Empire: Canada's National Security Policy reflects distinct National Interests", Canadian Forces College, June 2006.

Cortell, Andrew P. and James W. Davis, Jr, "Understanding the Domestic Impact of International Norms: A Research Agenda" International Studies Review, Vol. 2, No. 1, Spring 2000, pp. 65-87.

Cox, Robert W. "Social Forces, States and World Orders: Beyond International Relations Theory," Millennium - Journal of International Studies, Vol 10, Issue 2, 1981, pp. 126155. 
. "A Canadian Dilemma: The United States Or the World." International Journal, Vol 60 No.3, 2005, pp. 667-84

Crabbe, R.R., L.G. Mason, and F.R. Sutherland, "A Report on the Validation of the Transformed Canadian Forces Command Structure," 31 January 2007.

Croci, Osvaldo. "Facing up to regional security challenges", in Kirchner, Emil and Sperling, James, eds, National Security Cultures: Patterns of Global Governance, New York: Routledge, 2010.

Cunningham, Jack and Ramesh Chandra Thakur, Australia, Canada, and Iraq: Perspectives on an Invasion, Toronto: Dundurn Press, 2015.

Cutler, A. Claire. "The 'Grotian Tradition' in International Relations", Review of International Studies, Vol. 17, No. 1, January, 1991, pp. 41-65.

Dahl, Robert A. “The Concept of Power”, Behavioral Science, Vol 2, 1957.

d'Aquino, Thomas. "Security and Prosperity in the Canada-United States Relationship: Two Sides of the Same Coin", Canadian Defence \& Foreign Affairs Institute, March 2011.

Denholm Crosby, Ann. Dilemmas in Defence Decision-making: Constructing Canada's Role in NORAD, 1958-96 Research, New York: St. Martin's Press, 1998.

Department of Fisheries and Oceans. Canadian Coast Guard: Maritime Security, DFO Canada / Canadian Coast Guard, Handout Package, 2010.

. Canadian Coast Guard official website, "Who We Are" and "Mandate \& Organizational Values", accessed on 15 September 2015 at http://www.ccggcc.gc.ca/eng/CCG/Who_We_Are.

Department of Foreign Affairs. Trade and Development. "Draft - Not for Circulation" Working Titles, Access to Information Request A-2005-00275 previously released, 04 May 2015. Draft working titles included were Building Canada's Global Advantage, Meeting the Challenges of Globalization, Making a Difference in the World, and finally Canada's Agenda for Global Engagement which was the closest draft to the final International Policy Statement produced, A Role of Pride and Influence in the World.

Department of Justice official website online at http://justice.gc.ca/eng/abtapd/index.html 
Department of National Defence. Bi-National Planning Group, Interim Report on Canada and the United States (CANUS) Enhanced Military Cooperation, 13 October 2004.

. "Maritime Security Operations Centre - Scope Statement," June 2005.

. Office of the Judge Advocate General, "Analysis of DFO Request For CF

Assistance During Proposed Maritime Security Patrols", 1459-13-36 (D/ Law Ops 2-2), 6 September 2005, in LCdr Paul Gravel, "The Canadian Forces and Interdepartmental Cooperation Towards Domestic Security: Tear Down These Walls!", Canadian Forces College Exercise New Horizons, 2009 found online 10 September 2015 at http://www.cfc.forces.gc.ca/259/290/295/287/gravel.pdf .

. Office of the Judge Advocate General website online at http://www.forces.gc.ca/en/about-org-structure/judge-advocate-general.page

. Bi-National Planning Group, The Final Report on Canada and the United States (CANUS) Enhanced Military Cooperation, 13 March 2006.

. Canada Command Backgrounder found online at http://www.canadacom.forces.gc.ca/par-par/canus-caneu/frm-frm-eng.asp .

. Marine Security Operations Centres: Concept of Operations for Initial Operational Capability (IOC), Ottawa: Chief of Maritime Staff, 2008.

. Framework for Enhanced Military Cooperation among North American Aerospace Defense Command, United States Northern Command, and Canada Command, June 2009, (Tri-Command Report), found online at: http://www.canadacom.forces.gc.ca/docs/pdf/BG-Framework-eng.pdf

Chief of the Air Staff, Canadian Aerospace Doctrine B-GA-400-000/FP-000, December 2010 found online at http://www.rcafarc.forces.gc.ca/assets/AIRFORCE_Internet/docs/en/cf-aerospace-warfare-centre/b-ga400-000-fp-000.pdf\#chapter_6 command and control.

. Canadian Forces Air Warfare Centre, "Canadian Special Security Events: An Improved Framework for Royal Canadian Air Force Command and Control", Air Force Journal, Vol 12, Issue 2, Spring 2013, pp. 8-16.

. The Canada-U.S. Defence Relationship Backgrounder, 4 December 2014, found online on 16 October 2015 at http://www.forces.gc.ca/en/news/article.page?doc=the-canada-u-s-defencerelationship/hob7hd8s

Department of Public Safety. Public Safety Canada website online at http://www.publicsafety.gc.ca/cnt/bt/index-eng.aspx on 26 July 2015 
. CBSA website, "About US: Our Work" accessed online 16 September 2015 at http://www.cbsa-asfc.gc.ca/agency-agence/what-quoi-eng.html

. Royal Canadian Mounted Police, "Games Security and Public Safety for the Vancouver 2010 Olympic and Paralympic Games", October 2012, found online on 25 October 2015 at http://www.rcmp-grc.gc.ca/aud-ver/reports-rapports/pp-gs-ps-evaleng.htm

. Royal Canadian Mounted Police, Report on Plans and Priorities 2013-2014, Government of Canada, 26 July 2013; pp. 18-21 located online on 16 September 2015 at http://www.rcmp-grc.gc.ca/rpp/2013-2014/RCMP_RPP_2013_Web eng.pdf

. Royal Canadian Mounted Police, "Horizontal Evaluation of the Great Lakes and St. Lawrence Seaway Marine Security Operations Centre", 10 April 2015, found online on 25 October 2015 at http://www.rcmp.gc.ca/aud-ver/reports-rapports/msoccosm-eng.htm\#fn34

Department of Transport. Transport Canada website, "What We Do", accessed on 15 September 2015 at https://www.tc.gc.ca/eng/aboutus-whatwedo.htm .

. Transport Canada website, "Operations," accessed on 16 September 2015 at https://www.tc.gc.ca/eng/marinesecurity/operations-menu-56.htm.

Deudney, Daniel and John Ikenberry, "The Nature and Sources of Liberal International Order”, Review of International Studies, April 1999, Vol 25, Issue 2, pp.179-196.

Dewitt, David B., and John J. Kirton, Canada as a Principal Power: A Study in Foreign Policy and International Relations, Toronto: Wiley, 1983.

Dewitt David B. and John Kirton, "Three Theoretical Perspectives", in Duane Bratt and Christopher John Kukucha, Readings in Canadian Foreign Policy: Classic Debates and New Ideas, Toronto: Oxford University Press, 2007.

Dewitt and Leyton-Brown et al, Canada's Internationals Security Policy, Toronto: Prentice Hall Canada Inc., 1995.

Dewitt, David B. and Jeffrey P. Plante. "National Defence Vs. Foreign Affairs: Culture Clash in Canada's International Security Policy?" International Journal, Vol 59, No.3, 2004, pp. 579-95.

Doran, Charles F., "Thoughts on a Different Tomorrow," Annals of the American Academy of Political and Social Science, Vol 538, No.1, 1995, pp. 9-15.

"Was 9/11 a Watershed?," in Paquin, P. and James, P. et al, Game Changer:

The Impact of 9/11 on North American Security, Vancouver: UBC Press, 2014. 
Doscher, Thomas J. "NORAD, USNORTHCOM Maritime Stakeholders Conference provides clarity for new mission", NORAD and USNORTHCOM Public Affairs, March 31, 2010 found online on 20 October, 2015 at http://www.northcom.mil/Newsroom/tabid/3104/Article/563806/norad-usnorthcommaritime-stakeholders-conference-provides-clarity-for-new-miss.aspx .

Duffield, John S., World Power Forsaken: Political Culture, International Institutions, and German Security Policy After Unification, Stanford: Stanford University Press, 1998. . "Political Culture and State Behavior: Why Germany Confounds Neorealism," International Organization, vol. 53, 1999.

Dunn, Frederick S. 'The Present Course of International Relations Research', World Politics, Vol 2, 1949, p. 94.

Dunne, Tim, et al, International Relations Theories: Discipline and Diversity, Oxford: Oxford University Press, 2007.

Dunne, Tim. "Guardians of the Gateways: Maritime Security Operations Centre", FrontLine Security, Vol.6, No.2, Summer 2011.

Dyck, Rand. Canadian Politics: Critical Approaches, $6^{\text {th }}$ edition, Toronto: Nelson Education, 2011.

Eden, Lorraine and Maureen Appel Molot, "Canada's National Policies: Reflections on 125 Years", Canadian Public Policy, Vol 19, No.3, 1993, pp. 232-251.

Eikenberry. Karl W. "Thoughts on Unconventional Threats and Terrorism", Working Group on Foreign Policy and Grand Strategy, Hoover Institution, Stanford University, 2014, online at www.hoover.org/taskforces/foreign-policy .

Elkins, David J. "A Cause in Search of its Effect, Or what does Political Culture Explain?" Comparative Politics Vol 11, No.2, 1979, pp. 127-45.

English, Allan. Understanding Military Culture: A Canadian Perspective, Montreal: McGill-Queen's University Press, 2004, pp 123-124.

. “Outside CF Transformation Looking In”, Canadian Military Journal, Vol. 11, No. 2, Spring 2011.

Farrell, Theo, "Constructivist Security Studies: Portrait of a Research Program", International Studies Review, Vol 4, no.1, 2002, pp. 49-72.

Fergusson, James G. Canada and Ballistic Missile Defence, 1954-2009: Déjà Vu All Over Again, Vancouver: UBC Press, 2010. 
Finnemore, Martha and Kathryn Sikkink, "International Norm Dynamics and Political Change", International Organization, Vol 52, No. 4, pp. 887-917.

Fitzsimmons, Scott, Allan Craigie, and Marc André Bodet. "Canadian Public Opinion about the Military: Assessing the Influences on Attitudes Toward Defence Spending and Participation in Overseas Combat Operations," Canadian Journal of Political Science, Vol 47, No.3, 2014, pp. 503-518.

Fortmann, Michel and David Haglund, "Canada and the Issue of Homeland Security: Does the 'Kingston Dispensation' Still Hold?,' Canadian Military Journal, Spring 2002, pp. 17-22.

Fraser, Graham. "Liberal Continuities: Jean Chretien's Foreign Policy, 1993 - 2003”, in David Carment et al, Canada among Nations 2004: Setting Priorities Straight, Montréal: McGill-Queens University Press, 2005.

Funk, Nathan. "Applying Canadian Principles to Peace and Conflict Resolution in the Middle East" in Bessma Momani and Paul Heinbecker, Canada and the Middle East: In Theory and Practice, Waterloo: Wilfred Laurier University Press, 2007.

Garnett, G.L. "The Evolution of the Canadian Approach to Joint and Combined Operations at the Strategic and Operational Level", Canadian Military Journal, Winter $2002-2003$.

Geertz, Clifford. The Interpretation of Cultures, New York: Basic Books, 1973.

Geist, Michael. Law, Privacy, and Surveillance in Canada in the Post-Snowden Era, Ottawa: University of Ottawa Press, 2015.

Gellner, Ernest. Nations and Nationalism, Ithaca, NY: Cornell University Press, 1983.

Glenn, John. "Realism versus Strategic Culture: Competition and Collaboration?," International Studies Review, Vol 11, 2009, pp. 523-551.

Godefroy, Andrew B. Canada's International Policy Statement Five Years Later, Calgary: Canadian Defence \& Foreign Affairs Institute, 2010.

Goldenberg, Eddie. The Way it Works: Inside Ottawa, Toronto: McClelland \& Stewart, 2006.

Gollom, Mark. "Ottawa attack: Was Michael Zehaf-Bibeau's attack a terrorist act: Mulcair calls Ottawa gunman's attack a 'criminal act"', CBC News, 30 Oct 2014 online at http://www.cbc.ca/news/canada/ottawa-attack-was-michael-zehaf-bibeau-s-attack-aterrorist-act-1.2818329. 
Gosselin, Daniel and Craig Stone, "From Minister Hellyer to General Hillier: Understanding the Fundamental Differences between the Unification of the Canadian Forces and its present Transformation", Canadian Military Journal, Winter 2005 - 2006, pp. 5-15.

Gourevitch, Peter. "The Second Image Reversed", International Organization 32, No. 4, Autumn, 1978, pp. 881-912.

Government of Canada. Defence in the 70s: White Paper on Defence, Department of National Defence, Ottawa, 1971.

. Challenge and Commitment: A Defence Policy for Canada, Department of National Defence, Ottawa, 1987.

1994. 1994 White Paper on Defence, Department of National Defence, Ottawa,

. Securing an Open Society: Canada's National Security Policy, April 2004.

. Securing an Open Society: One Year Later, Progress Report on the Implementation of Canada's National Security Policy, April 2005.

. Canada's International Policy Statement: A Role of Pride and Influence in the World, 2005.

. Canada First Defence Strategy, Department of National Defence, Ottawa, 2008.

. Agreement between the Government of Canada and the Government of the United States of American on the North American Aerospace Defence Command, 28 April 2006.

. Privy Council Office, The Role and Structure of the Privy Council Office, November 2008, archived 2010, accessed online 12 Sep 15 at http://www.pcobcp.gc.ca/index.asp?lang=eng\&page $=$ information $\& s u b=$ publications \&doc $=$ aarchives $/$ role /role2008-eng.htm .

. National Strategy for Maritime Domain Awareness (draft), January 2010.

. Maritime Event Response Protocol/Maritime Operational Threat Response: Strategic Protocol, 2012.

. Action Plan: The Government of Canada Response to the Commission of Inquiry into the Investigation of the Bombing of Air India Flight 182, 2010, accessed online 30 August 2015 at http://www.publicsafety.gc.ca/cnt/rsrcs/pblctns/rspnscmmssn/rspns-cmmssn-eng.pdf. 
Government Consulting Services, Marine Security Operations Centres: Governance Study, Public Works and Government Services Canada, 30 September 2008.

Grabb, Edward G. and James E. Curtis. Regions Apart: The Four Societies of Canada and the United States, New York: Oxford University Press, 2005.

Grabb, Edward, James Curtis, and Douglas Baer. "Defining moments and recurring myths: Comparing Canadians and Americans after the American Revolution," The Canadian Review of Sociology and Anthropology, Vol 37, No. 4, Nov 2000, pp. 373-419.

Granatstein, J. L. Who Killed the Canadian Military?, 1st ed, Toronto: Harper Flamingo Canada, 2004.

. Whose War is it?: How Canada can Survive in the Post 9/11 World, 1st Canadian ed., Toronto: HarperCollins, 2007.

Gravel, Paul. "The Canadian Forces and Interdepartmental Cooperation Towards Domestic Security: Tear Down These Walls!", Canadian Forces College Exercise New Horizons, 2009 found online 10 September 2015.

Graybill, Andrew. Policing the Great Plains: Rangers, Mounties, and the North American Frontier, 1875-1910, Lincoln: University of Nebraska Press.

Greenaway, Norma. 'Most Canadians Think U.S. Acts Like a "Bully to World", Ottawa Citizen, 28 December 2002.

Greenfeld, Liah. "Varieties of Nationalism", in Bernard E. Brown, ed., Comparative Politics: Notes and Readings, Belmont, CA: Wadsworth, 2006.

Gwyn, Richard. The 49th Paradox: Canada in North America, Toronto: McClelland and Stewart, 1985.

. Nation Maker - Sir John A. Macdonald: His Life, Our Times, Volume Two, Toronto: Random House Canada, 2011.

Haglund, David G. "North American Cooperation in an Era of Homeland Security," Orbis, Vol 47, No.4, 2003, pp.675-691.

."'Let's Call the Whole Thing Off'? Security Culture as Strategic Culture", Contemporary Security Policy, Vol 32, no. 3, 2011, pp. 494-516.

Haglund, David G. and Tudor Onea. "Sympathy for the Devil: Myths of neoclassical Realism in Canadian Foreign Policy," Canadian Foreign Policy, Vol 14, Issue 2, 2008, pp. 53-66. 
Haglund, David G. and Stéphane Roussel. "It's a Long Road from Fort Greely to Chicoutimi: Sovereignty and the Issue of Missile Defense", Comparative Strategy, Vol 27, No. 4, July 2008, pp. 361-375.

Hale, Geoffrey. So Near Yet so Far: The Public and Hidden Worlds of Canada-US Relations, Vancouver: UBC Press, 2012.

Harper, Tim. "Canadians back Chrétien on war, poll finds", Toronto Star. 22 March 2003 found online on 05 October 2015 at http://www.ekospolitics.com/articles/torstar-2403-2003c.html.

Hart, Gary and Warren Rudman, The United States Commission on National Security / $21^{\text {st }}$ Century, 31 January 2001, found online at http://www.au.af.mil/au/awc/awcgate/nssg/.

Harvey, Frank P. "Canada's Addiction to American Security: The Illusion of Choice in the War on Terrorism", The American Review of Canadian Studies, Vol 35, No. 2 , Summer 2005, pp 265-296.

."The Homeland Security Dilemma: Imagination, Failure and the Escalating Costs of Perfecting Security", Canadian Journal of Political Science, Vol 40, No.2, 2007, pp. 283-316.

. The Homeland Security Dilemma: Fear, Failure and the Future of American Insecurity, New York: London: Routledge, 2008.

Hassan-Yari, Houchang. “A Diminishing Middle Power: Canada's National Security and Peacekeeping" in Conny Steenman-Marcusse and Aritha van Herk, eds, Building Liberty: Canada and World Peace, 1945-2005, Gröningen, Netherlands: Barkhuis Publishing, 2005.

Heinbecker, Paul. Getting Back in the Game: A Foreign Policy Playbookfor Canada, Toronto: Key Porter, 2010.

Henrich, Joseph. "Group Report: What is the Role of Culture in Bounded Rationality?", pp. 343-359, in Selten, Reinhard and Gerd Gigerenzer. Bounded Rationality: The Adaptive Toolbox, Cambridge, Mass: MIT Press, 2001.

Henderson, Ailsa. "Regional Political Cultures in Canada," Canadian Journal of Political Science, Vol 37, No.3, 2004, pp. 595-615.

Hendrickson, David C. "toward Universal Empire: The Dangerous Quest for Absolute Security", in Paul Bolt et al, eds., American Defense Policy, Eighth Edition, Baltimore: The Johns Hopkins University Press, 2005, pp. 40-45. 
Henry, B. "The Whole of Government Approach Applied to Canadian National Security", Canadian Forces College Master of Defence Studies Research Project, JCSP 34, pp. 51-56 found online at http://www.cfc.forces.gc.ca/303/171/171eng.html?action=author .

Herz, John. Political Realism and Political Idealism, Chicago: University of Chicago Press, 1951.

Hickey, Laurence. The Canadian Navy and Domestic Maritime Enforcement, Halifax: Centre for Foreign Policy Studies, Dalhousie University, 2011.

Higley, John, and Heinrich Best. Democratic Elitism: New Theoretical and Comparative Perspectives, 1st ed., Vol. 111, Boston: Brill, 2010.

Hillmer, Norman. "The Secret Life of Canadian Foreign Policy", Policy Options, Vol. 26, Montreal: Institute for Research on Public Policy, 2005.

- "National Independence and the National Interest: O.D. Skelton's Department of External Affairs in the 1920's", in Greg Donaghy and Michael Carroll, eds., In the National Interest: Canadian Foreign Policy and the Department of Foreign Affairs and International Trade, 1909-2009, Calgary: University of Calgary Press, 2011.

. O.D. Skelton: A Portrait of Canadian Ambition, Toronto: University of Toronto Press, 2015

. "NATO: When Canada Really Mattered", The Canadian Encyclopedia, Historica Canada, 04/03/15 found online on 03 November 2015 at http://www.thecanadianencyclopedia.com/en/article/nato-when-canada-really-matteredfeature.

Hillmer, Norman, Fen Hampson, and David Carment. "Smart Power in Canadian Foreign Policy", in Canada among nations 2004: setting priorities straight, Montreal: McGillQueen's University Press, 2005, pp. 3-17.

Hillmer, Norman, and J. L. Granatstein. For Better Or For Worse: Canada and the United States into the Twenty-First Century, Toronto: Thomson/Nelson, 2007.

. Empire to Umpire: Canada and the World into the 21st Century, 2nd ed., Toronto: Thomson Nelson, 2008.

Hitch, Charles J. "National Security Policy as a Field for Economics Research," World Politics, Vol 12, 1960, pp. 434-52.

Hobbes, Thomas. Leviathan, Oxford: Oxford University Press, 1996. 
Hof, Ted. "The Promise of Constructivism in International Relations Theory", International Security, Vol 23, No. 1, 1998, pp. 171-200.

Hoffman, Stanley. "International Relations: The Long Road to Theory," World Politics, 11, No, 3, 1959.

. "An American Social Science: International Relations.” Daedalus: Proceedings

of the American Academy of Ares and Sciences, Vol 106, Summer 1977, pp. 41-49.

Holloway, Steven Kendall. Canadian Foreign Policy: Defining the National Interest, Peterborough: Broadview Press, 2006.

Holman, D. Fraser. NORAD: In the New Millennium, Toronto: Irwin Publishing Ltd, 2000.

Horowitz, Gad . "Conservatism, Liberalism, and Socialism in Canada: An Interpretation", The Canadian Journal of Economics and Political Science, Vol. 32, No. 2, 1966. pp. 143-171.

. "Notes on 'Conservatism, Liberalism and Socialism in Canada", Canadian

Journal of Political Science, Vol. 11, No. 2, 1978, pp. 383-399.

Howard, Michael and Peter Paret, ed., Carl von Clausewitz: On War, Princeton:

Princeton University Press, 1984.

Ignatieff, Michael. Peace, Order and Good Government: A Foreign Policy Agenda for Canada, O.D. Skelton Memorial Lecture, 2004, accessed 09 November 2015 online at http://www.international.gc.ca/odskelton/ignatieff.aspx?lang=eng .

James, William. Pragmatism: A New Name for some Old Ways of Thinking : Popular Lectures on Philosophy, 1st ed., New York: Longmans, Green, 1925.

Jarvis, Darryl S.L. "Risk, Globalisation and the State: A Critical Appraisal of Ulrich Beck and the World Risk Society Thesis," Global Society, Special Edition, Vol 21, No.1, 2007.

Jeffery, Michael. "Inside Canadian Forces Transformation," Canadian Military Journal, Vol. 10, No. 2, 2010, pp. 9-18.

Jervis, Robert. Perception and Misperception in International Politics, Princeton, N.J: Princeton University Press, 1976. 
Jockel, Joseph, Canada In NORAD 1957-2007: A History, McGill-Queen's University Press, 2007.

. "Saving NORAD: Should Ottawa Seize the Obama Moment?", The School of Public Policy: SPP Briefing Papers, Vol 2, Issue 3, September 2009, found online at: http://policyschool.ucalgary.ca/files/publicpolicy/Jockel\%20FINAL\%20web.pdf.

Jockel, Joseph and Joel Sokolsky, "Continental Defence: 'Like farmers whose lands have a common concession line"”, in David McDonough, ed., Canada's National Security in the Post-9/11 World: Strategy, Interests, and Threats, Toronto: Toronto University Press, 2012. pp. 188-195.

"NORAD does not need saving", International Journal, Vol 70, No.2, 2015,

Johnston, Alastair Iain. "Thinking about Strategic Culture", International Security, Vol. 19, No. 4, 1995, pp. 32-64.

. "Strategic cultures revisited: reply to Colin Gray," Review of International Studies, Vol 25, 1999, pp. 519-523.

Katzenstein, Peter J. "September 11 in Comparative Perspective: The Antiterrorism Campaigns of Germany and Japan," Dialog-IO, Spring 2002 found online at http://www.pkatzenstein.org/resources/view/1

. Cultural Norms and National Security: Police and Military in Postwar Japan, Ithaca, N.Y: Cornell University Press, 1996 a. . ed., The Culture of National Security: Norms and Identity in World Politics, New York: Colombia University Press, 1996 b.

Katzenstein, Peter, Robert Koehane, and Stephen Krasner, "International Organization and the Study of World Politics", International Organization, Vol 54, No. 4, pp. 645-686.

Kavanagh, D. "Departmentalism and Joined-Up Government." Parliamentary Affairs, Vol 54, No.1, 2001, pp. 1-18.

Kean, Thomas H and Lee Hamilton, and National Commission on Terrorist Attacks upon the United States, The 9/11 Commission Report: Final Report of the National Commission on Terrorist Attacks upon the United States, Official government ed. Washington, DC: National Commission on Terrorist Attacks upon the United States, 2004.

Keating, Tom. Canada and World Order: The Multilateralist Tradition in Canadian Foreign Policy, Toronto: McClelland and Stewart Inc., 1993. 
Keeble, Edna, "Defining Canadian Security: Continuities and Discontinuities," American Review of Canadian Studies, Vol 35. No.1, 2005, pp. 1-22.

Kellock, Roy and Robert Taschereau. Royal Commission to Investigate the Facts Relating to and the Circumstances Surrounding the Communication by Public Officials and Other Persons in Position of Trust of Secrets and Confidential Information to Agents of a Foreign Power, 27 June 1946 found online at http://publications.gc.ca/site/eng/472640/publication.html .

Kelly, James B. Governing with the Charter: Legislative and Judicial Activism and Framers' Intent, Vancouver: UBC Press, 2005.

Keohane, Robert, After Hegemony: Cooperation and Discord in the World Political Economy, Princeton: Princeton University Press, 2005

Keohane, Robert and Joseph Nye Jr. "Introduction: The Complex Politics of CanadianAmerican Interdependence", International Organization, Vol 28, No 4, Autumn 1974, p 596. . Power and Interdependence, $4^{\text {th }}$ ed, Toronto: Longman, 2012.

Kersey, Timothy. Constrained Elitism and Contemporary Democratic Theory, Vol. 4, New York, NY: Routledge, 2016.

Kier, Elizabeth. "Culture and French Military Doctrine Before World War II," in Peter J Katzenstein, The Culture of National Security: Norms and Identity in World Politics, New York: Colombia University Press, 1996.

Kinney, Laureen. "Canada's Marine Security”, Canadian Naval Review, Vol 4, No 4, Winter 2009, pp. 15-19.

Kirchner, Emil and James Sperling eds, National Security Cultures, New York: Routledge, 2010.

Kissinger, Henry. White House Years, Boston: Little Brown, 1979.

Kohn, Richard H. "Using the Military at Home: Yesterday, Today, and Tomorrow", in Paul Bolt et al, eds., American Defense Policy, Eighth Edition, Baltimore: The Johns Hopkins University Press, 2005, pp. 441-456.

Kratochwil Friedrich V. and John G. Ruggie, "International Organization: A State of the Art on an Art of the State," International Organization, Vol 40, No. 4, Autumn 1986, pp. 753-776.

Kymlicka, Will. "Being Canadian", Government and Opposition, Vol 38, No. 3, 2003, pp. 357-385. 
Lagassé, Philippe. “A Maritime NORAD?” SITREP, Royal Canadian Military Institute, Vol. 64, No. 5, November- December 2004, found online on 20 July 2015 at http://www.rcmi.org/getmedia/7157568f-c8ae-44f4-955f-d9f4929c3d5e/04-5-Sitrep.aspx

. "The Harper Government and the Politics of Continental Defence", speaking notes from University of Ottawa, November 2007.

."Nils Ørvik's "Defence Against Help": The Descriptive Appeal of a Prescriptive Strategy", International Journal, Vol 65, No.2, 2010, pp. 463-74.

. "Parliamentary and Judicial Ambivalence Toward Executive Prerogative Powers in Canada", Canadian Public Administration, Vol. 55, No.2, 2012, pp. 157-180.

. "A Common "Bilateral" Vision: North American Defence Cooperation, 20012012", in Jonathan Paquin et al, Game Changer: The Impact of 9/11 on North American Security, Vancouver: UBC Press, 2014.

Lagassé, Philippe and Paul Robinson, Reviving Realism in the Canadian Defence Debate, Kingston: Centre for International Relations, Queen's University, 2008 found online at http://dspace.africaportal.org/jspui/bitstream/123456789/24426/1/Reviving\%20Realism\% 20in\%20the \%20Canadian\%20Defence\%20Debate.pdf?1 .

Lane, Ruth. "Political Culture: Residual Category Or General Theory?" Comparative Political Studies, Vol 25, No.3, 1992, pp. 362-87.

Lang, Dan et al, Canada and Ballistic Missile Defence: Responding to the Evolving Threat, Standing Senate Committee on National Security and Defence, 2014.

Laswell, H and A. Kaplan. Power and Society: A Framework for Political Inquiry, New Haven: Yale University Press, 1950.

Layton, Peter. "Making a Canadian National Security Strategy," On Track, Vol 20, No 1, Conference of Defence Associations and CDA Institute, Summer 2015, pp. 37-40.

Legros, Jeffrey. "Which Norms Matter? Revisiting the "Failure" of Internationalism", International Organization, Vol 51, No. 1, 1997, pp. 31-63.

Leishman, Rory. Against Judicial Activism: The Decline of Freedom And Democracy in Canada, Montreal: McGill-Queen's University Press, 2006.

Lennox, Patrick. "From Golden Straitjacket to Kevlar Vest: Canada's Transformation to a Security State." Canadian Journal of Political Science, Vol 40, No.4, 2007, pp. 1017-38.

Lerhe, Eric. "Will We See A Maritime NORAD?," Journal of Military and Strategic Studies, Vol 8, Issue 4, Summer 2006. 
Lipset, Seymour Martin. Continental Divide: The Values and Institutions of the United States and Canada, New York: Routledge, 1990.

. "The Values of Canadians and Americans: A Reply", Social Forces, Vol 69, No. 1, September 1990, pp. 267-272.

. "Defining Moments and Recurring Myths: A Reply", Canadian Review of

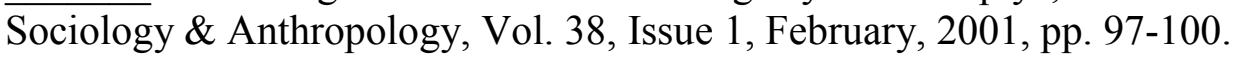

Lipson, Michael et al, "Divided Discipline?", International Journal, Vol 62, No.3, 2007, pp. 327-343.

Mabee, Bryan, The Globalization of Security: State Power, Security Provision and Legitimacy, New York: Palgrave MacMillan, 2009.

MacCharles, Tonda. "Air India inquiry head baffled by Ottawa's response", Toronto Star newspaper, published 07 December 2010 found online at

http://www.thestar.com/news/canada/2010/12/07/air_india_inquiry_head_baffled_by_ott awas response.html.

Macdonald, William A. "A new role for Canada and the U.S. in a world of persistent Menace", Globe and Mail, July 31, 2015.

Macnamara, Don. "Canada's National and International Security Interests", p 45-46, in David McDonough, ed., Canada's National Security in the Post-9/11 World: Strategy, Interests, and Threats, Toronto: Toronto University Press, 2012.

Macnamara, Don and Ann Ftiz-Gerald. "A National Security Framework for Canada", IRPP Policy Matters, Vol 3, No. 10, October 2002.

Madar, Daniel R., Canadian International Relations, Toronto: Prentice Hall Allyn and Bacon Canada, 2000.

Madsen, Chris. "Military Responses and Capabilities in Canada's Domestic Context Post 9/11”, Journal of Military and Strategic Studies, Vol 13, Issue 3, Spring 2011, pp. 14-17.

Major, John C. Commission of Inquiry into the Investigation of the Bombing of Air India Flight 182, 1 May 2006, accessed online 30 August 2015 at http://epe.lac-

bac.gc.ca/100/206/301/pco-bcp/commissions/air india/2010-07-

23/www.majorcomm.ca/en/reports/finalreport/default.htm .

. Commission of Inquiry into the Investigation of the Bombing of Air India Flight 182, "Remarks by Commissioner John C. Major, June 17, 2010", accessed online 30 August 2015 at http://epe.lac-bac.gc.ca/100/206/301/pco- 
bcp/commissions/air_india/2010-07-

23/www.majorcomm.ca/en/reports/finalreport/default.htm .

Maloney, Sean M., "Are We Really Just: Peacekeepers? The Perception Versus the Reality of Canadian Military Involvement in the Iraq War", IRPP Working Paper Series No. 2003-02.

Mandel, Robert. The Changing Face of National Security: A Conceptual Analysis, London: Greenwood Press, 1989.

Manheim, J., R. Rich, L. Willnat, and C. Brians, 2007. Empirical Political Analysis: Research Methods in Political Science. 6th ed., New York: Pearson Longman, 2007, Chapter 5.

March, James G. and Olsen, Johan P., "The New Institutionalism: Organizational Factors in Political Life", The American Political Science Review, 1984, Vol 78, p. 734-49.

Marsh, David, Theory and Methods In Political Science: Third Edition, New York: Palgrave Macmillan.

Maslow, A.H. “A Theory of Human Motivation.” Psychological Review, Vol 50, 1943.

Mason, Dwight. "The Canadian-American North-American Defence Alliance in 2005", International Journal, Vol 60, No. 2, 2005, pp. 385-396.

Massie, Justin. "Regional Strategic Subcultures: Canadians and the use of Force in Afghanistan and Iraq." Canadian Foreign Policy Journal, Vol 14, No.2, 2008, pp. 19-48.

. "Making Sense of Canada's "Irrational" International Security Policy: A Tale of Three Strategic Cultures," International Journal, Vol. 64, No. 3, 2009, pp. 625-645.

. "Towards Greater Opportunism: Balancing and Bandwagoning in CanadianAmerican Relations," in Paquin, P. and James, P. et al, Game Changer: The Impact of 9/11 on North American Security, Vancouver: UBC Press, 2014.

McDonald D.C. et al. Freedom and Security under the Law: Second Report of the Canada Commission of Inquiry Concerning Certain Activities of the Royal Canadian Mounted Police, Ottawa: Supply and Services Canada, 1981.

McDonough, David S. "BMD and US Strategic Doctrine: Canadian Strategic Interests in the Debate on Missile Defence", Journal of Military and Strategic Studies, Vol. 9, Issue 3, Spring 2006/07. . ed., Canada's National Security in the Post-9/11 World: Strategy, Interests, and Threats, Toronto: Toronto University Press, 2012. 
. "Canada, NORAD, and the Evolution of Strategic Defence", International

Journal, Vol. 67, No.3, September 2012, pp. 797-811.

McGuire, Sara. "'Securing' the Homeland? A Comparison of Canadian and American Homeland Security Policy in the Post-9/11 Period", McMaster University, 2013, doctoral thesis found at http://digitalcommons.mcmaster.ca/opendissertations .

McLachlin, Beverley. "The Judiciary's Distinctive Role in our Constitutional Democracy", Verbatim: Policy Options, September 2003.

McRae, Rob. "International Reviews in Perspective", in David Carment et al, Canada among Nations 2004: Setting Priorities Straight, Montréal: McGill-Queens University Press, 2005, pp 56-61.

McSweeney, Bill. "Identity and Security: Buzan and the Copenhagen School", Review of International Studies, Vol 22, no 1, 1996, pp. 81-93.

. "Durkehim and the Copenhagen school: A Response to Buzan and Waever", Review of International Studies, Vol 24, no 1, 1998, pp. 137-140.

. Security, Identity, and Interests: A Sociology of International Relations, Cambridge: Cambridge University Press, 1999.

Mearsheimer, John J. The Tragedy of Great Power Politics, New York: Norton, 2001.

Michaud, Nelson. "Setting the Canadian Foreign Policy Agenda, 1984-2009: Prime Ministers as Actors", in Greg Donaghy and Michael Carroll, eds., In the National Interest: Canadian Foreign Policy and the Department of Foreign Affairs and International Trade, 1909-2009, Calgary: University of Calgary Press, 2011, pp. 194196.

Milner, Helen V. "Rationalizing Politics: The Emerging Synthesis of International, American, and Comparative Politics." International Organization, Vol52, No.4, 1998, pp. $759-86$.

. Interests, Institutions, and Information: Domestic Politics and International Relations, Princeton: Princeton University Press, 2010.

Moens, Alexander and Gabler Nachum. What Congress Thinks of Canada, Studies in Canada-US Relations, Fraser Institute, 2011.

Molot, Maureen Appel. "Where Do We, or Should We, or Can we Sit? A review of Canadian Foreign Policy Literature," in Duane Bratt and Christopher John Kukucha, Readings in Canadian Foreign Policy: Classic Debates and New Ideas, Toronto: Oxford University Press, 2007. 
Monahan. Patrick J. Constitutional Law, Third Edition, Toronto: Irwin Law Inc., 2006.

Moravcsik, Andrew. "World Power Forsaken: Political Culture, International Institutions, and German Security Policy After Unification John S. Duffield Stanford: Stanford University Press, 1998, Pp. Xvi, 385," Canadian Journal of Political Science, Vol 32, No.2, 1999, pp. 402-404.

Morgenthau, Hans. Scientific Man vs Power Politics, Chicago: University of Chicago Press, 1946.

. Politics Among Nations: The Struggle for Power and Peace, $5^{\text {th }}$ ed. New York:

Alfred A. Knopf, 1973.

Munsing, Evan and Christopher J. Lamb. Joint Interagency Task Force-South: The Best Known, Least Understood Interagency Success, Washington, D.C: National Defense University Press, June 2011.

Mustapha, Jennifer. "Threat Construction in the Bush Administration's Post-9/11 Foreign Policy: (Critical) Security Implications for Southeast Asia." The Pacific Review, Vol24, No.4, 2011, pp. 487-504.

Myers, Richard B. "Shift to a Global Perspective", in Paul Bolt et al, eds., American Defense Policy, Eighth Edition, Baltimore: The Johns Hopkins University Press, 2005.

Neocleous, Mark. "From Social to National Security: On the Fabrication of Economic Order," Security Dialogue, Vol 37, No.3, 2006, pp. 363-84.

Nolin, Pierre Claude. "Accommodation as a Canadian Tradition", Canadian Parliamentary Review, Vol 31, No. 2, 2008.

NORAD-NORTHCOM, CANUS Maritime Stakeholders' Conference "Quick Look" Report, March 20 through April 1, 2010.

. An unclassified introduction to Operation Plans Summary found online on 10 October 2015 at https://publicintelligence.net/norad-and-northcom-operations-planssummary.

NORAD Office of History, A Brief History of NORAD, 31 December 2012, found online 10 October 2015 at

http://www.norad.mil/portals/29/documents/history/a\%20brief\%20history\%20of\%20nora d.pdf

North Atlantic Treaty Organization, NATO Integrated Air and Missile Defence, 01 Sep. 2015, found online on 14 October at http://www.nato.int/cps/en/natohq/topics 8206 .htm 
O'Connor, Dennis R. A New Review Mechanism for the RCMP's National Security Activities - Commission of Inquiry into the Actions of Canadian Officials in Relation to Maher Arar, Ottawa: Public Works and Government Services Canada, 2006.

O'Hanlon, Michael. "Protecting the American Homeland." The Brookings Review, Vol 20, No.3, 2002, pp. 13-16.

Ormerod, R. "The History and Ideas of Pragmatism", The Journal of the Operational Research Society Vol 57, No.8, 2006, pp. 892-909.

Paquin, Jonathan. "Canadian Foreign and Security Policy: Reaching a Balance between Autonomy and North American Harmony in the Twenty-First Century." Canadian Foreign Policy, Vol 15, No.2, 2009, p. 99.

Parsons, Talcott \& Edward A. Shils. eds., Towards a General Theory of Action, Cambridge:Harvard University Press, 1951.

Pauly, Louis W. and Edgar Grande, eds. Complex Sovereignty: Reconstituting Political Authority in the Twenty-First Century, Toronto: University of Toronto Press, 2005.

and Christian Reus-Smit. "Negotiating Anglo-America: Australia, Canada, and the United States", in Peter Katzenstein, ed, Anglo-America and its Discontents:

Civilizational identities beyond West and East, New York: Routledge, 2012, pp. 127-151.

Perry, David. "The Growing Gap Between Defence Ends and Means: The Disconnect between the Canada First Defence Strategy and the Current Defence Budget", Vimy Paper 19, Conference of Defence Associations Institute, June 2014.

. "Defence Budget 2015: The Promise of Long-term Funding, but Short-term Deficits Remain" in The Dispatch, Volume XIII, Issue II, Calgary: Canadian Global Affairs Institute, 2015.

Peters, Guy B. "Managing Horizontal Government: The Politics of Co-Ordination", Public Administration, Vol 76, No.2, 1998, pp. 295-311.

Price, Richard and Christian Reus-Smit, 'Dangerous Liasons? Critical International Theory and Constructivism', European Journal of International Relations, Vol. 4, No. 3, pp. 259-294.

Prince, Michael and James Rice, "Governing through Shifting Social-Policy Regimes: Brian Mulroney and Canada's Welfare State", in Raymond B Blake, Transforming the Nation: Canada and Brian Mulroney, Montreal: McGill-Queen's University Press, 2007, pp 166-168. 
Privacy Commissioner of Canada, Addendum to Government Accountability for Personal Information: Reforming the Privacy Act, April 2008.

Public Works and Government Services Canada, Marine Security Operations Centres: Governance Study, September 2008.

Putnam, Making Democracy Work: Civic Traditions in Modern Italy, Princeton: Princeton University Press, 1993.

Pye, Lucian W., Sidney Verba, and Social Science Research Council. Committee on Comparative Politics. Political Culture and Political Development. 5 Vol. Princeton, N.J: Princeton University Press, 1965

Rae, Bob. Lessons to be Learned Report, Government of Canada, The report of the Honourable Bob Rae, Independent Advisor to the Minister of Public Safety, on outstanding questions with respect to the bombing of Air India Flight 182, accessed online at http://www.publicsafety.gc.ca/cnt/rsrcs/pblctns/lssns-lrnd/index-eng.aspx\#toc10 on $02 \mathrm{Sep} 2015$.

Rempel, Roy. Dreamland: How Canada's Pretend Foreign Policy Has Undermined Sovereignty, Montreal: McGill-Queen's University Press, 2006.

Resnick, Philip. The European Roots of Canadian Identity, Peterborough, Ontario: Broadview Press, 2005.

Reus-Smit, Christian. "Constructivism", in Birchell et al, Theories of International Relations, $3^{\text {rd }}$ edition, New York: Palgrave MacMillan, 2005.

Rioux, Jean-Sébastien . "Two Solitudes: Quebecers' Attitudes Regarding Canadian Security and Defence Policy", Canadian Defence and Foreign Affairs Institute, Research Paper Series, 23 February 2005.

Ross, Douglas A and Hira Anil. "Canada, a Land of Deep Ambivalence: Understanding the Divergent Response to US Primacy After 9/11", Canadian-American Public Policy, no. 68 , December, 2006, pp. 1-65.

Roussel, Stéphane, The North American Democratic Peace: Absence of War and Security Institution-Building in Canada-US Relations, 1867-1958, Montreal: McGill-Queen's University Press, 2004.

Roussel, Stéphane and Charles-Philippe David. "Middle Power Blues": Canadian Policy and International Security after the Cold War', American Review of Canadian Studies, Vol 28, No. 1, 1998, pp. $131-156$. 
Roussel, Stéphane et Robichaud, Chantal. «L'État postmoderne par excellence ? Internationalisme et promotion de l'identité internationale du Canada », Études internationales, Vol. 35, No. 1, 2004, pp. 149-170.

Rudd, David. "Muddling through on Missile Defence: The Politics of Indecision", Vol. 26, Institute for Research on Public Policy, 2005, pp. 30-34.

Ruggie, J.G., "What makes the world hang together", International Organization, Volume 52, Issue 04, Autumn 1998, pp 855-885.

Russell, Peter H., Rainer Knopff, and F. L. Morton. Federalism and the Charter: Leading Constitutional Decisions, 5th ed., Vol. 155, Ottawa: Carleton University Press, 1989.

Sadler, Barry. "The Management of Canada-US Boundary Waters: Retrospect and Prospect”, Natural Resources Journal, Spring 1986, pp. 359-376.

Salt, James. "The Whole-of-Government Approach to Maritime Information SharingReality or Fiction?", Canadian Forces College Exercise New Horizons, JCSP 34, found online 10 September 2015 at http://www.cfc.forces.gc.ca/259/290/294/287/salt.pdf.

Sands, Christopher. "Fading Power or Rising Power: 11 September and Lessons from the Section 110 Experience", in Duane Bratt and Christopher John Kukucha, Readings in Canadian Foreign Policy: Classic Debates and New Ideas, Toronto: Oxford University Press, 2007.

Savoie, Donald J. Governing from the Centre: The Concentration of Power in Canadian Politics. Toronto: University of Toronto Press, 2003.

Schmidt, Brian C. The Political Discourse of Anarchy: A Disciplinary History of International Relations, Albany, NY: SUNY Press, 1998.

. "Competing Realist Conceptions of Power", Millennium: Journal of

International Studies, Vol. 33, No 3, 2005, pp. 523-549.

Schmidt, Brian C. and Thomas Juneau, "Neo-classical realism and power" in A. Toje and B Kunz eds., Neoclassical Realism in European Politics: Bringing Power Back In, New York: Manchester University Press, 2012.

Schmitz, Gerald and James Lee, "Split Images and Serial Affairs: Reviews, Reorganizations, and Parliamentary Roles", in Andrew F Cooper and Dane Rowlands, Canada among Nations, 2005: Split Images, McGill-Queens University Press, 2006.

Shadwick, Martin. "The Chrétien Legacy” Canadian Military Journal, Winter 2003 2004, accessed online on 16 September 2015 at http://www.journal.forces.gc.ca/vo4/no4/doc/comment-eng.pdf . 
Shaw, Martin. "There is no such Thing as Society: Beyond Individualism and Statism in International Security Studies." Review of International Studies, Vol 19, No.2, 1993, pp. 159-75.

Shepsle, Kenneth, "Rational Choice Institutionalism”, presentation Harvard University, January 2005 http://scholar.harvard.edu/kshepsle/files/rational_choice_institutionalism_4.5.05.pdf

Simpson, Jeffrey. "Timing is Everything for PM's New York Trip," The Globe and Mail, Friday, September 28, 2001, A.7.

Sloan, Elinor C. The Revolution in Military Affairs: Implications for Canada and NATO. Montreal: McGill-Queen's University Press, 2002.

- Security and Defence in the Terrorist Era: Canada and the United States

Homeland, 2nd ed. Montréal: McGill-Queen's University Press, 2010.

Smith, Steve. "Mature Anarchy, Strong States and Security", Arms Control, Vo1 12, No $2,1991$.

Snider, Don M. "The National Security Strategy: Documenting Strategic Vision", Strategic Studies Institute, US Army War College, March 1995.

Sokolsky, Joel J. “Canada, Getting It Right This Time: The 1994 Defence White Paper”, May 31, 1995, paper presented at the U.S. Army War College Sixth Annual Strategy Conference April 26-28, 1995 accessed online at http://www.dtic.mil/doctrine/doctrine/research/canada.pdf, 30 August 2015.

. "Realism Canadian Style: National Security Policy and the Chrétien Legacy", Policy Matters, Vol 5, No. 2, Montreal: Institute for Research on Public Policy, 2004.

Sokolsky, Joel and Philippe Lagassé, "Suspenders and a Belt: Perimeter and Border Security in Canada-US Relations”, Canadian Foreign Policy, Vol 12, No 3, 2006.

Sproule-Jones, Mark. Restoration of the Great Lakes: Promises, Practices, and Performances, East Lansing: Michigan State University Press, 2002.

Stairs, Denis. "The Making of Hard Choices in Canadian Foreign Policy", in Canada among nations 2004: setting priorities straight, Montreal: McGill-Queen's University Press, 2005.

Steele, Sam. Forty Years in Canada: Reminiscences of the Great North-West with some accounts of His Service in South Africa, Toronto: Prospero Books, 2000. 
Stein, Janice Gross. "Threat Perception in International Relations", in Leonie Huddy, David O. Sears, and Jack S. Levy, eds., The Oxford Handbook of Political Psychology, 2nd ed., Oxford: Oxford University Press, 2013.

Stephenson, Alan. "Shades of Gray: Gradual Escalation and Coercive Diplomacy", Chairman Joint Chiefs of Staff Strategy Essay Competition 2002, Washington, DC: National Defense University Press, 2002, pp. 1-20.

. Securing the Continent: Where is NORAD Today?, Toronto: Canadian International Council, 2011. . "Canadian Nationalism / Nationalisme Québécois", unpublished paper, November, 2011.

Studin, Irvin. The Strategic Constitution: Understanding Canadian Power in the World, Vancouver: UBC Press, 2014.

Sucharov, Mira. "Security Ethics and the Modern Military: The Case of the Israel Defense Forces." Armed Forces \& Society, Vol 31, No .2, 2005, pp. 169-99.

. "Values, Identity, and Israel Advocacy," Foreign Policy Analysis, Vol 7, No.4, 2011, pp. 361-380.

Sun Tzu, Art of War, translated by Ralph Sawyer, Oxford: Westview Press, 1994.

Supreme Court of Canada, Justice Le Dain $R v$ Crown Zellerbach Canada Ltd [1988] 1 S.C.R. 401.

Talliaferro, J, "State Building for Future Wars: Neoclassical Realism and the ResourceExtractive State”, Security Studies, Vol 15, No 3, pp. 464-495.

Tangredi, Sam. "The Future Security Environment, 2001-2025”, in Paul Bolt et al, eds., American Defense Policy, Eighth Edition, Baltimore: The Johns Hopkins University Press, 2005.

Taylor, Charles. "Conditions of an Unforced Consensus on Human Rights", in J. R. Bauer and D. Bell eds., The East Asian Challenge for Human Rights, New York: Cambridge University Press, 1999, p. 124 found in Daniel Bell, "Communitarianism", The Stanford Encyclopedia of Philosophy, Fall 2013 Edition, Edward Zalta, ed., found online at http://plato.stanford.edu/archives/fall2013/entries/communitarianism/ .

Thelen, Kathleen. "Historical Institutionalism in Comparative Politics", Annual Review of Political Science, Vol 2, 1999, pp. 369-404.

Thompson, John Herd, and Stephen J. Randall. Canada and the United States: Ambivalent Allies. 4th ed. Athens: University of Georgia Press, 2008, pp. 267-270. 
Tickner, J. Ann. "Re-visioning Security", in Ken Booth and Steve Smith (eds.), International Relations Theory Today, Oxford: Oxford Press, 1995, pp. 175-97.

Tilly, Charles. Big Structures, Large Processes, Huge Comparisons, New York: Russell Sage Foundation, 1984.

Tomlin, Brian W., Fen Osler Hampson, and Norman Hillmer. Canada's International Policies: Agendas, Alternatives and Politics. Toronto: Oxford University Press, 2008.

Trebilcock, Craig T. "The Myth of Posse Comitatus," Homeland Security, October 2000, available at http://www.homelandsecurity.org/journal/articles/Trebilcock.htm .

Tremblay, Éric and Bill Bentley, "Canada's Strategic Culture: Grand Strategy and the Utility of Force”, Canadian Military Journal, Vol. 15, No.3 Summer 2015.

Trudge, Matthew. "A Canadian Approach: Canada's Cold War Grand Strategy, 1945 to 1989", Journal of Military and Strategic Studies, Vol 14, No. 3 \& 4, 2012, found online at http://jmss.journalhosting.ucalgary.ca/jmss/index.php/jmss/issue/view/64.

Truman, Tom. "A Scale for Measuring a Tory Streak in Canada and the United States," Canadian Journal of Political Science, Vol 10, No. 3, 1977, pp 597-614.

Twomey, Christopher. "Lacunae in the Study of Culture in International Security," Contemporary Security Policy, Vol.29, No.2, August 2008, pp.338-357.

Ullman, Richard. "Redefining Security," International Security, Vol 8, No. 1, Summer 1983, pp. 129-153.

United Kingdom. Her Majesty's Government, A Strong Britain in an Age of Uncertainty: The National Security Strategy, October 2010.

United States Congress. Public Law 106-38, $106^{\text {th }}$ Congress, National Missile Defense Act of 1999, July 22, 1999, found online at https://www.congress.gov/106/plaws/publ38/PLAW-106publ38.pdf.

. National Defense Authorization Act for Fiscal Years 1992 and 1993

(Engrossed Amendment as Agreed to by Senate) Part B-Strategic Defense Initiative SEC. 211. MISSILE DEFENSE ACT OF 1991.

United States Congress. Senate Armed Services Committee. Statement of General Victor E. Renuart, Jr. USAF, United States Navy, Commander United States Northern Command and North American Aerospace Defense Command before the Senate Armed Services Committee, 11 March, 2010. 
. Statement by Lieutenant General David 1. Mann, USA Commanding General, U.S. Army Space and Missile Defense Command/ Army Forces Strategic Command and Joint Functional Component Command for Integrated Missile Defense before the Committee on Armed Services Strategic Forces Subcommittee United States Senate, Second Session, 113th Congress, April 2, 2014 found online 16 October 2015 at http://www.armed-services.senate.gov/imo/media/doc/Mann_04-02-14.pdf.

. Statement of Admiral William E. Gortney, United States Navy, Commander United States Northern Command and North American Aerospace Defense Command before the Senate Armed Services Committee, March 12, 2015.

US Department of the Army, Army Field Manual FM-3 Military Operations, Headquarters, Fort Leavenworth, Texas: Department of the Army, February 2008.

US Department of Defense. "U.S. Senator John w. Warner (R. VA) holds hearing on military strategy and operational requirements for combat commanders," Political Transcript Wire, Lanham, 15 Mar. 2005.

. Report of the National Defense Panel, Transforming Defense: National Security in the 21st Century, December 1997 found online 19 October 2015 at http://www.ists.dartmouth.edu/docs/trf def1.pdf .

. 2008 National Defense Strategy, Washington, DC, June 2008.

US Department of the Navy, National Maritime Intelligence-Integration Office Annual Report: 2014, 31 December 2014.

US Department of State. Fact sheet, "US-Canada Smart Border/30 Point Plan Update", December 6, 2002, online at http://2001-2009.state.gov/p/wha/rls/fs/18128.htm .

US Northern Command. Air Forces Northern official website, accessed on 10 October 2015 at

http://www.northcom.mil/Newsroom/FactSheets/ArticleView/tabid/3999/Article/564002/ air-forces-northern.aspx .

Vaughan, Frederick. The Canadian Federalist Experiment: From Defiant Monarchy to Reluctant Republic, Montreal: McGill-Queen's University Press, 2003

von Hlatky, Stéfanie. The Great Asymmetry: American Allies in Times of War, Oxford: Oxford University Press, 2013.

von Hlatky, Stéfanie and Jessica N. Trisko. "Sharing the Burden of the Border: Layered Security Co-Operation and the Canada-US Frontier", Canadian Journal of Political Science, Vol 45, No.1, 2012, pp. 63-88. 
Vucetic, Srdjan. The Anglosphere A Genealogy of a Racialized Identity in International Relations, Stanford: Stanford University Press, 2011.

and Brendon O'Connor. "Another Mars-Venus Divide? Why Australia Said 'Yes' and Canada Said 'Non' to Involvement in the 2003 Iraq War." Australian Journal of International Affairs Vol 64, No.5, 2010, pp. 526-48.

Walt Stephen M., "The Renaissance of Security Studies," International Studies Quarterly 35, no. 2, June 1991, pp. 211-239.

. Taming American Power: The Global Response to US Primacy, New York:

W. W. Norton, 2005.

Waltz, Kennth N. Theory of International Politics, New York: Random House, 1979.

. "The Origins of War in Neorealist Theory", in The Origin and Prevention of

Major Wars, eds. Robert I Robert and Theodore K. Rabb, Cambridge: Cambridge

University Press, 1989.

Watts, R. B. Implementing Maritime Domain Awareness, Thesis paper at Naval Postgraduate School, Monterey, California, March 2006, found online on 20 October 2015 at https://www.hsdl.org/?view\&did=461642 .

Weeks, Stanley. "The Department of Homeland Security: Will It Address The Threat?," Continental Security and Canada-US Relations, Halifax: Dalhousie University, 2003.

Weingast, B. "Rational-Choice Institutionalism" in Political Science: The State of the Discipline, eds. I. Katznelson and H. Milner, New York: W.W. Norton. 2002, pp. 660692.

Weinrib, Lorraine. "Trudeau and the Canadian Charter of Rights and Freedoms: A Question of Constitutional Maturation", pp. 258-282, in Andrew Cohen and J.L. Granatstein, eds., Trudeau's Shadow: The Life and Legacy of Pierre Elliott Trudeau, Toronto: Random House of Canada, 1998.

Wells, Paul. “Word Politics”, MacLean's, Vol 127, No. 45, 17 November 2014.

Welsh, Jennifer M. At Home in the World: Canada's Global Vision for the 21st Century, Toronto: HarperCollins, 2004.

."Reality and Canadian Foreign Policy", in Andrew F Cooper and Dane Rowlands, Canada among Nations, 2005: Split Images, McGill-Queens University Press, 2006.

Wendt, Alexander. "Anarchy is What States Make of it: The Social Construction of Power Politics", International Organization, Vol 46, No.2, 1992. 
Press, 1999.

Social Theory of International Politics, Cambridge: Cambridge University

Whitaker, Reg. "Arar: The Affair, the Inquiry, the Aftermath", Institute For Research on Public Policy, Vol 9, no. 1, 28 May 2008, online at http://irpp.org/researchstudies/policy-matters-vo19-no1/.

Whitaker, Reg and Stuart Farson. "Public Inquiries in Canada: Making Espionage, Organizational Culture, Wrongdoing and Mass Murder More Transparent", in Mark Phythian and Anthony Stuart Farson, Commissions of Inquiry and National Security: Comparative Approaches, Santa Barbara, California: Praeger, 2011.

White House. National Security Strategy of the United States, September 2002. National Security Presidential Directive NSPD-4, issued on December 21, 2004 was also called the Homeland Security Presidential Directive HSPD-13 found online on 20 October 2015 at https://fas.org/irp/offdocs/nspd/nspd41.pdf .

. The National Strategy for Maritime Security, Washington, DC: White House, September 2005, found online 22 October 2015 at https://www.hsdl.org/?collection\&id=4\#Maritime

. United States, National Plan to Achieve Domain Awareness, Washington, DC: White House, October 2005, found online at https://www.hsdl.org/?collection\&id=4\#Maritime . National Security Strategy of the United States, May 2010. . Liberty and Security in a Changing World: Report and Recommendations of The President's Review Group on Intelligence and Communications Technologies, 12 December 2013, found online 26 September 2015 at https://www.whitehouse.gov/sites/default/files/docs/2013-12-12 rg final report.pdf

White, Hugh. "Why Australia Invaded Iraq: A Study in Alliance Management”, in Jack Cunningham and Ramesh Chandra Thakur, Australia, Canada, and Iraq: Perspectives on an Invasion, Toronto: Dundurn Press, 2015.

Whittaker, Alan G., Shannon A Brown, Frederick C. Smith, and Elizabeth McKune. The National Security Policy Process: The National Security Council and Interagency System, Washington, D.C.: National Defense University, U.S. Department of Defense, August, 2011.

Wikileaks. Diplomatic messages from the US Embassy in Ottawa to Admiral Keating, Commander NORAD, Commander NORTHCOM - Subject: SCENE-SETTER FOR 
VISIT TO CANADA, 12-14 DEC 2004, 8 December, 2004, found online 15 October 2015 at http://wikileaks.org/plusd/cables/04OTTAWA3303 a.html

. Diplomatic messages from the US Embassy in Ottawa to Washington Subject: 214TH MEETING OF THE PERMANENT JOINT BOARD ON DEFENSE, OCTOBER 20-21, 2004 found online 15 October 2015 at http://wikileaks.org/plusd/cables/04OTTAWA3048_a.html

. Diplomatic messages from the US Embassy in Ottawa to Washington, SUBJECT: CANADA: NORAD AGREEMENT NEGOTIATIONS, ROUND I, 2005 October 24, found online on 16 October at http://wikileaks.org/plusd/cables/05OTTAWA3179 a.html

. Paul Cellucci, diplomatic message, 24 February 2005, found online 15 October 2015www.wikileaks.org/plusd/cables/05OTTAWA572_a.html .

. Diplomatic message from the US Embassy in Ottawa to Washington Subject: US-CANADA PERMANENT JOINT BOARD ON DEFENSE (PJBD), December 2, 2008 found online 15 October 2015 at https://wikileaks.org/plusd/cables/08OTTAWA1508 a.html .

- Diplomatic messages from the US Embassy in Ottawa to Washington Subject: Canada: Cabinet to Review Mandate to Negotiate/Conclude 2006 NORAD Agreement in Early February, 2005 February 2, online 16 October 2015 at http://wikileaks.org/plusd/cables/05OTTAWA315_a.html 1 .

Williams, Michael C. "Modernity, Identity and Security: A Comment on the 'Copenhagen Controversy', Review of International Studies, Vol 24, No 3, 1998, pp. 435-439.

. "Words, Images, Enemies: Securitization and International Politics", International Studies Quarterly, Vol 47, 2003, pp.511-531.

. Culture and Security: Symbolic Power and the Politics of International Security, New York: Routledge, 2007.

- "The continuing evolution of securitization theory", in Thierry Balzacq, Securitization Theory: How Security Problems Emerge and Dissolve, New York: Routledge, 2010.

Wilson, Richard W. "The Many Voices of Political Culture: Assessing Different Approaches." World Politics [H.W. Wilson - SSA] Vol 52, No.2, 2000, p. 246.

Wiseman, Nelson. In Search of Canadian Political Culture, Vancouver: UBC Press, 2007. 
Wispinski, Jennifer. "The USA PATRIOT Act and Canada's Anti-terrorism Act: Key Differences in Legislative Approach", Library of Parliament PRB 05-83E, 31 March 2006.

Woiden, K.L. "Domestic Operations in Canada: The Relevance and Applicability of Mission Command", Canadian Forces College AMSP 10, 2007 found online http://www.cfc.forces.gc.ca/259/260/270/woiden.pdf .

Wolfers, Arnold. "National Security' as an Ambiguous Symbol”, Political Science Quarterly, Vol 67, No. 4, December 1952, pp. 481-502.

Discord and Collaboration: Essays on International Politics, Baltimore: The John Hopkins Press, 1962. 